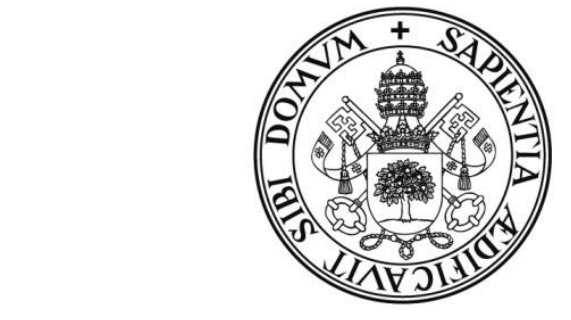

Universidad deValladolid

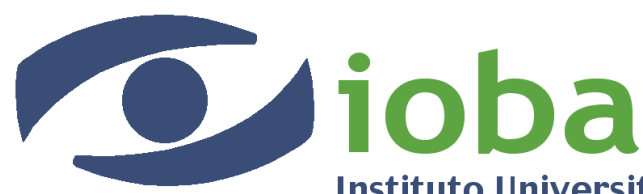

Instituto Universitario de Oftalmobiología Aplicada

UNIVERSIDAD DE VALLADOLID

INSTITUTO DE OFTALMOBIOLOGÍA APLICADA (IOBA)

\title{
ESTUDIO DE LA VARIACIÓN DEL GROSOR DE LA CÓRNEA POR CAPAS EN LA FACOEMULSIFICACIÓN DE LA CATARATA MEDIANTE TOMOGRAFÍA DE COHERENCIA ÓPTICA DE DOMINIO ESPECTRAL
}

Presentada por MARÍA CALABUIG GOENA para optar al grado de Doctora por la Universidad de Valladolid

Dirigida por:

Dr. Miguel J. Maldonado López

Dr. Alberto López Miguel 



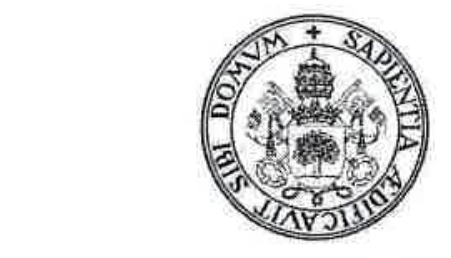

\section{Universidad deValladolid}

\section{AUTORIZACIÓN DEL DIRECTOR DE TESIS}

Impreso 2T

(Art. 2.1. c de la Normativa para la presentación y defensa de la Tesis Doctoral en la UVa)

D. Miguel José Maldonado López con D.N.I. n 25149971-T profesor del departamento de Cirugía, Oftalmología, Otorrinolaringología y Fisioterapia,

Centro: Facultad de Medicina.

Correo electrónico: maldonado@ioba.med.uva.es.

como Director de la Tesis Doctoral titulada ESTUDIO DE LA VARIACIÓN DEL GROSOR DE LA CÓRNEA POR CAPAS EN LA FACOEMULSIFICACIÓN DE LA CATARATA MEDIANTE TOMOGRAFÍA DE COHERENCIA ÓPTICA DE DOMINIO ESPECTRAL, presentada por Dña. María Calabuig Goena, alumna del programa de Doctorado en Ciencias de la Visión impartido por el Instituto de Oftalmobiología Aplicada, autoriza la presentación de la misma, considerando que es APTA para su defensa

Valladolid, 29 de Septiembre de 2015.

El Director de la Tesis,

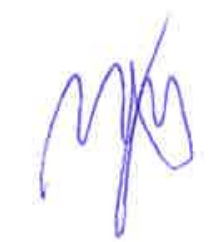

Fdo.: Miguel J Maldonado López 


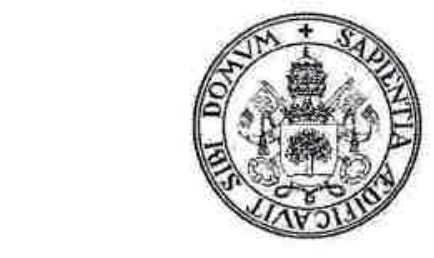

\section{Universidad deValladolid}

\section{AUTORIZACIÓN DEL DIRECTOR DE TESIS}

Impreso 2T

(Art. 2.1. c de la Normativa para la presentación y defensa de la Tesis Doctoral en la UVa)

D. Alberto López Miguel con D.N.I. n 71121957-T profesor del departamento de Cirugía, Oftalmología, Otorrinolaringología y Fisioterapia,

Centro: Facultad de Medicina.

Correo electrónico: alopezm@ioba.med.uva.es.

como Director de la Tesis Doctoral titulada ESTUDIO DE LA VARIACIÓN DEL GROSOR DE LA CÓRNEA POR CAPAS EN LA FACOEMULSIFICACIÓN DE LA CATARATA MEDIANTE TOMOGRAFÍA DE COHERENCIA ÓPTICA DE DOMINIO ESPECTRAL, presentada por Dña. María Calabuig Goena, alumna del programa de Doctorado en Ciencias de la Visión impartido por el Instituto de Oftalmobiología Aplicada, autoriza la presentación de la misma, considerando que es APTA para su defensa

Valladolid, 29 de Septiembre de 2015.

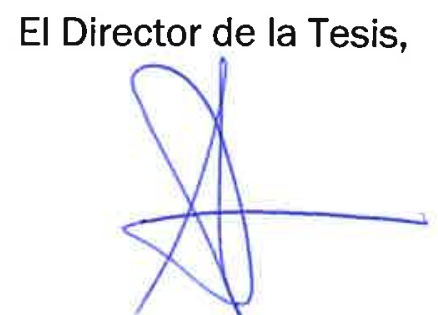

Fdo.: Alberto López Miguel

SRA. PRESIDENTA DE LA COMISIÓN DE DOCTORADO 


\section{DIVULGACIÓN CIENTÍFICA}

\section{Artículos científicos}

La presente tesis doctoral ha dado lugar a las siguientes publicaciones en revistas científicas especializadas:

- Early changes in corneal sublayer thickness after cataract surgery: a pilot study.

María Calabuig-Goena, Alberto López-Miguel, Victoria Marqués-Fernández, María Begoña Coco-Martín, Darío Iglesias-Cortiñas, Miguel J. Maldonado.

Curr Eye Res. 2015 Mar 24:1-7. Factor impacto: 1.639

El siguiente manuscrito se encuentra bajo revisión en la revista Eye and Contact Lens:

- Consistency of corneal sublayer thickness measurements using Fourierdomain optical coherence tomography after phacoemulsification.

Alberto López-Miguel, María Calabuig-Goena, Victoria Marqués Fernández, Itziar Fernández, Jorge L. Alió, Miguel J. Maldonado. 


\section{Comunicaciones en congresos científicos}

La presente tesis doctoral ha dado lugar a las siguientes comunicaciones:

- Early changes in corneal sublayer thickness alter cataract surgery.

Miguel J. Maldonado-López, A. López-Miguel, M. Calabuig-Goena, V. Marqués-Fernández, B. Coco-Martín, D. Iglesias-Cortiñas.

American Academy of Ophthalmology Annual Meeting. November 16-19, 2013. Nueva Orleans. EEUU

- Cambios en el grosor corneal epitelial tras cirugía de catarata. Miguel J. Maldonado-López, A. López-Miguel, M. Calabuig-Goena, V. MarquésFernández, B. Coco-Martín, D. Iglesias-Cortiñas.

90 Congreso de la Sociedad Española de Oftalmología. Octubre 2014. Bilbao. 
AGRADECIMIENTOS 

En primer lugar quería expresar mi más sincero agradecimiento al Dr. Miguel Maldonado, a quien conozco desde mi época universitaria en la Universidad de Navarra. En cuanto supe que actualmente desarrollaba su actividad profesional en Valladolid, tuve la certeza de que estar cerca suyo me iba a ayudar a dar el salto de calidad a nivel profesional y personal que supone adentrarse en el mundo de la tesis doctoral. Agradezco su nivel de exigencia y su búsqueda de la excelencia porque para mi supone un referente en la precisión y en el trabajo bien hecho.

Quiero agradecer de corazón al Dr. Alberto López sus desvelos y su paciencia a la hora de codirigir esta tesis doctoral. La ilusión y la empatía, así como el apoyo y la dedicación que me ha transmitido a lo largo de este tiempo, han sido el motor para continuar y no desfallecer en los momentos en los que el trabajo parecía que no daba sus frutos. Su calidad como profesional también está reflejado en su alo nivel de exigencia.

También quería agradecer a Itziar Fernández, cuya ayuda ha sido fundamental a la hora de realizar el análisis estadístico.

Todas y cada una de las personas que componen el servicio de Oftalmología del Hospital Universitario Río Hortega de Valladolid, los que están y los que ya no están con nosotros, han sido de una ayuda inestimable y han sufrido conmigo en algunos momentos mis desvelos en la elaboración de esta tesis doctoral. Han sido los que me han visto nacer y empezar a crecer como oftalmóloga, y espero que sigan siendo testigos de una manera $u$ otra de mi futuro profesional. Mención especial a mis compañeros residentes, las que fueron mis maestras y los que se han ido incorporando, en especial a Victoria Marqués, cuya ayuda fue fundamental. 
A mis padres. Si hoy soy lo que soy es gracias a vosotros. Me habéis dado todo, os habéis dado a mí, me habéis educado en el amor y en unos valores fundamentales de los que hoy puedo hacer gala. Sois un pilar fundamental en mi vida, un ejemplo y un modelo a seguir para mí. Gracias por todo, por ser vosotros y por quereros y quererme tanto. Gracias papá por animarme tanto a hacer la tesis, gracias mamá por aguantarme al teléfono día tras día.

A mis hermanos Álvaro, Jaime, Ana, Íñigo, Enrique, Gabriel y José. Me siento muy orgullosa de ser vuestra hermana mayor. Espero que este trabajo os sirva de inspiración a alguno para complicaros un poco más la vida después de acabar la universidad. Pero sobre todo espero que sepáis que podéis contar conmigo siempre.

A mi familia política, por vuestro apoyo.

A mis amigas, también sois parte importante en este proyecto aunque no os deis cuenta.

Mi agradecimiento más profundo a Gabriel, mi marido, porque sabes sacar lo mejor de mí y tienes una paciencia infinita conmigo, porque sabes ver en mí en lo que yo no veo, porque has participado activamente en la elaboración de mi tesis y por estar a mi lado incondicionalmente cada día. Sin ti todo esto no habría sido posible. 
ÍNDICE, ABREVIATURAS, TABLAS Y FIGURAS 



\section{INDICE GENERAL}

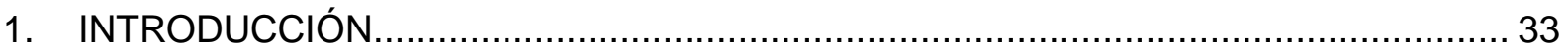

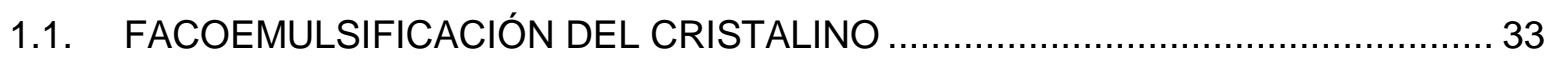

1.1.1. EVOLUCIÓN DE LA CIRUGÍA DE CATARATA .......................................... 33

1.1.2. LA CIRUGÍA DE CATARATAS EN LA ACTUALIDAD ................................... 36

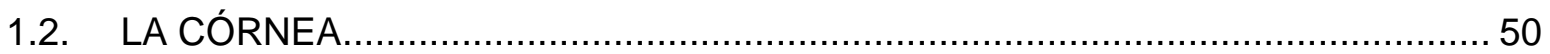

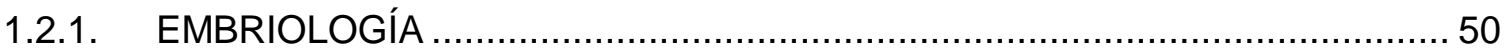

1.2.2. RECUERDO ANATÓMICO Y FUNCIONAL ................................................... 52

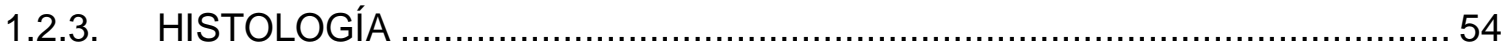

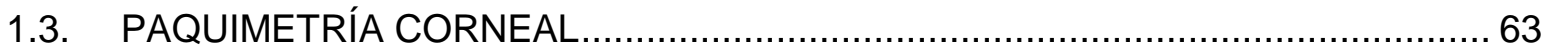

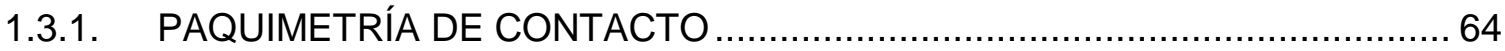

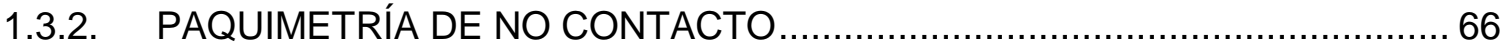

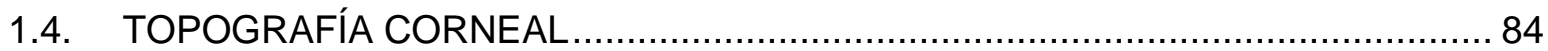

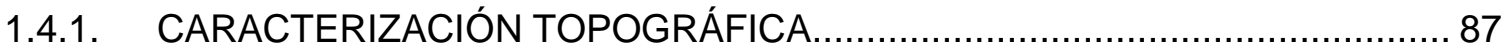

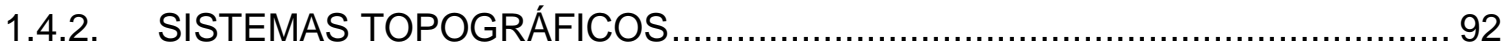

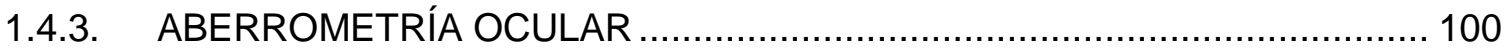

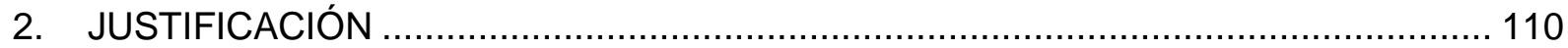

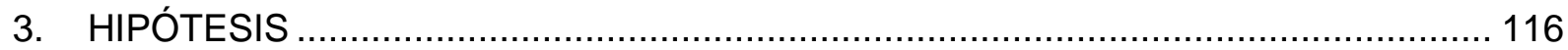

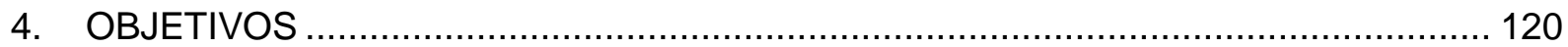

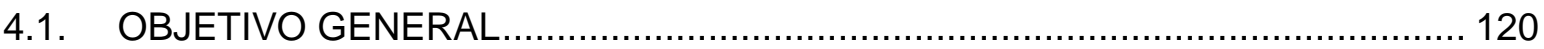

4.2. OBJETIVOS ESPECíFICOS …............................................................... 120

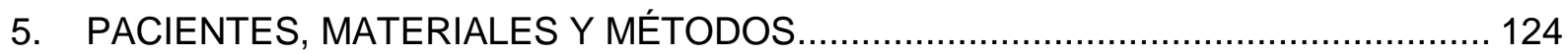

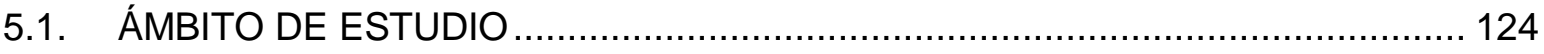

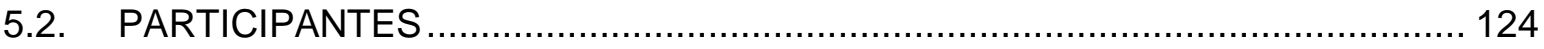

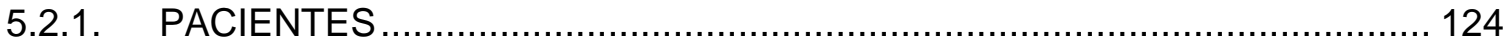

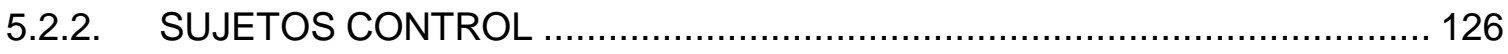

5.3. TÉCNICA QUIRÚRGICA DE LA CIRUGÍA DE CATARATA ............................. 127

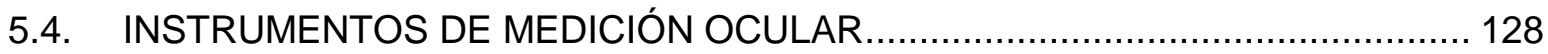

5.4.1. TOMOGRAFÍA DE COHERENCIA ÓPTICA ............................................. 128

5.4.2. TOPOGRAFÍA Y ABERROMETRÍA CORNEAL ......................................... 133

5.5. DISEÑO DE LOS ESTUDIOS............................................................ 136

5.5.1. DISEÑO DEL ESTUDIO PILOTO DEL ANÁLISIS DEL ESPESOR CORNEAL POR CAPAS EN PACIENTES OPERADOS DE CATARATA 
5.5.2. DISEÑO DEL ESTUDIO DE FIABILIDAD DE MEDIDA: REPETIBILIDAD INTRAOBSERVADOR Y REPRODUCIBILIDAD INTEROBSERVADOR DE LAS MEDIDAS DE ESPESOR CORNEAL POR CAPAS CON CIRRUS HD-OCT

5.2.3. DISEÑO DEL ESTUDIO CLÍNICO: DETERMINACIÓN DE LOS CAMBIOS ABERROMÉTRICOS Y EN EL GROSOR POR CAPAS DE LA CÓRNEA TRAS CIRUGÍA DE CATARATA CON FACOEMULSIFICACIÓN

5.6. ANÁLISIS ESTADÍSTICO.

5.6.1. ESTUDIO PILOTO DEL ANÁLISIS DEL ESPESOR CORNEAL POR CAPAS

EN PACIENTES OPERADOS DE CATARATA.

5.6.2. ESTUDIO DE FIABILIDAD DE MEDIDA: REPETIBILIDAD

INTRAOBSERVADOR Y REPRODUCIBILIDAD INTEROBSERVADOR DE LAS

MEDIDAS DE ESPESOR CORNEAL POR CAPAS CON CIRRUS HD-OCT.

5.6.3. DISEÑO DEL ESTUDIO CLÍNICO: DETERMINACIÓN DE LOS CAMBIOS ABERROMÉTRICOS Y EN EL GROSOR POR CAPAS DE LA CÓRNEA TRAS CIRUGÍA DE CATARATA CON FACOEMULSIFICACIÓN

6. RESULTADOS

6.1. ESTUDIO PILOTO DEL ANÁLISIS DEL ESPESOR CORNEAL POR CAPAS EN

PACIENTES OPERADOS DE CATARATA. 154

6.2. ESTUDIO DE FIABILIDAD DE MEDIDA: REPETIBILIDAD INTRAOBSERVADOR Y REPRODUCIBILIDAD INTEROBSERVADOR DE LAS MEDIDAS DE ESPESOR CORNEAL POR CAPAS CON CIRRUS HD-OCT. 158

6.2.1. REPETIBILIDAD INTRAOBSERVADOR ............................................... 159

6.2.2. REPRODUCIBILIDAD INTEROBSERVADOR ……................................. 160

6.3. ESTUDIO CLÍNICO: DETERMINACIÓN DE LOS CAMBIOS ABERROMÉTRICOS Y EN EL GROSOR POR CAPAS DE LA CÓRNEA TRAS CIRUGÍA DE CATARATA CON FACOEMULSIFICACIÓN.

6.3.1. CAMBIOS ABERROMÉTRICOS Y EN LOS GROSORES CORNEALES..... 174

6.3.2. ANÁLISIS POST-HOC DE ASOCIACIÓN ENTRE LOS CAMBIOS ABERROMÉTRICOS Y EN LOS GROSORES CORNEALES .................................. 210

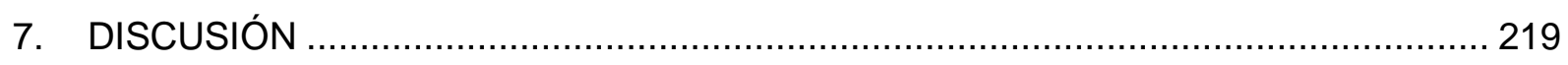

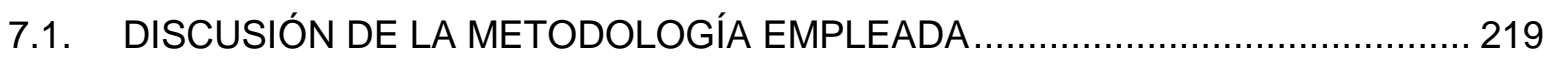

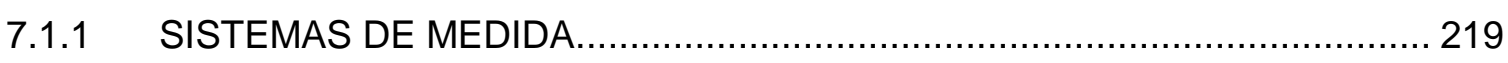

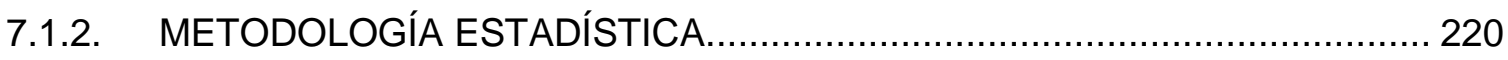

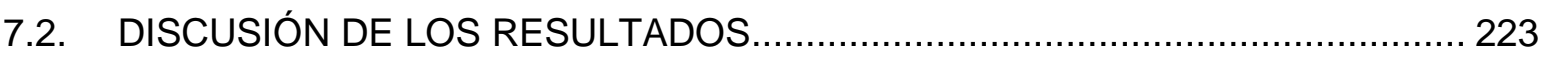

7.2.1. ESTUDIO PILOTO DEL ANÁLISIS DEL ESPESOR CORNEAL POR CAPAS

EN PACIENTES OPERADOS DE CATARATA...................................................... 224

7.2.2. ESTUDIO DE FIABILIDAD DE MEDIDA: REPETIBILIDAD INTRAOBSERVADOR Y REPRODUCIBILIDAD INTEROBSERVADOR DE LAS MEDIDAS DE ESPESOR CORNEAL POR CAPAS CON CIRRUS HD-OCT 229 
7.2.3. ESTUDIO CLÍNICO: DETERMINACIÓN DE LOS CAMBIOS

ABERROMÉTRICOS Y EN EL GROSOR POR CAPAS DE LA CÓRNEA TRAS

CIRUGÍA DE CATARATA CON FACOEMULSIFICACIÓN.

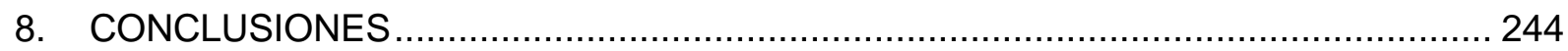

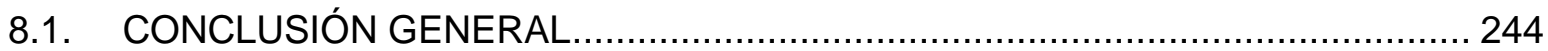

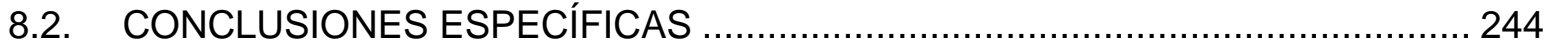

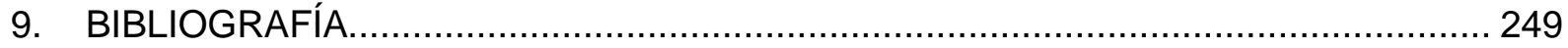

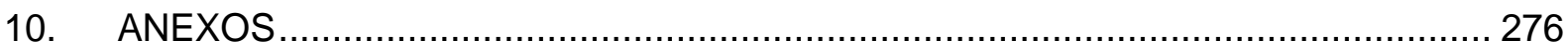

10.1. INFORME DE APROBACIÓN DEL ESTUDIO POR PARTE DEL COMITÉ ÉTICO DE INVESTIGACIÓN CLÍNICA DEL HOSPITAL UNIVERSITARIO DEL RÍO HORTEGA

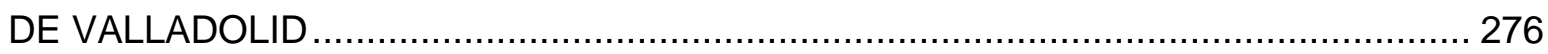

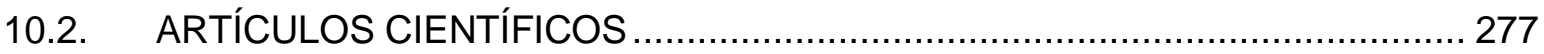





\section{ABREVIATURAS}

- LOCS: Lens Opacities Classification System

- LIO: Lente intraocular

- BMU: Biomicroscopía Ultrasónica

- mm: Milímetro

- $\mu \mathrm{m}$ : Micra

- D: Dioptría

- OCT: Optical Coherence Tomography (Tomografía de Coherencia Óptica)

- TD-OCT: Time Domain (Dominio Tiempo) OCT

- SD-OCT: Spectral Domain (Dominio Espectral) OCT

- FD-OCT: Fourier Domain (Dominio Fourier) OCT

- HD-OCT: High Definition (Alta Definición) OCT

- EDI-OCT: Enhanced Depth Imaging (Imágenes de Profundidad Mejorada) OCT

- SS-OCT: Swept-Source (Fuente con Barrido) OCT

- RMS: Root Mean Square (Valor Cuadrático Medio)

- ANOVA: Analysis of Variance (Análisis de Varianza)

- $\mathrm{DE}_{\mathrm{i}}$ : Desviación Estándar intrasujeto

- IC: Intervalo de Confianza

- CCl: Coeficiente de Correlación Intraclase

- $\mathrm{CV}_{\mathrm{i}}$ : Coeficiente de Variación intrasujeto

- DE: Desviación Estándar

- LC: Límite de Concordancia 



\section{ÍNDICE DE TABLAS}

- Tabla 1: Características distintivas de dispositivos de Tomografía de Coherencia Óptica comercializados.

- Tabla 2: Características distintivas de dispositivos de Tomografía de Coherencia Óptica comercializados exclusivos de segmento anterior.

- Tabla 3: Estadísticos descriptivos para el espesor epitelial, en las tres zonas de medida en los tres periodos de tiempo.

- Tabla 4: Estadísticos descriptivos para el espesor corneal total no epitelial, en las tres zonas de medida en los tres periodos de tiempo.

- Tabla 5: Estadísticos descriptivos para el espesor corneal total, en las tres zonas de medida en los tres periodos de tiempo.

- Tabla 6: Repetibilidad Intraobservador para la medida del espesor corneal por capas.

- Tabla 7: Reproducibilidad Interobservador para el análisis de espesor corneal por capas.

- Tabla 8: Limites de concordancia al $95 \%$ superior e inferior correspondientes a la reproducibilidad interobservador.

- Tabla 9: Diferencias de las medias marginales de la agudeza visual (logMAR) para los efectos estadísticamente significativos, en este caso el tiempo y la interacción tiempo y grupo.

- Tabla 10: Diferencias de las medias marginales del espesor corneal total en el área paracentral más próxima a la incisión para los efectos estadísticamente significativos, en este caso el tiempo y la interacción tiempo y grupo. 
- Tabla 11: Diferencias de las medias marginales del espesor corneal total no epitelial en el área paracentral más próxima a la incisión para los efectos estadísticamente significativos, en este caso el tiempo y la interacción tiempo y grupo.

- Tabla 12: Diferencias de las medias marginales del espesor corneal total en el área paracentral más alejada de la incisión para los efectos estadísticamente significativos, en este caso el tiempo y la interacción tiempo y grupo.

- Tabla 13: Diferencias de las medias marginales del espesor corneal total no epitelial en el área paracentral más alejada de la incisión para los efectos estadísticamente significativos, en este caso el tiempo y la interacción tiempo y grupo.

- Tabla 14: Diferencias de las medias marginales del espesor corneal total en el área central para los efectos estadísticamente significativos, en este caso el tiempo y la interacción tiempo y grupo.

- Tabla 15: Diferencias de las medias marginales del espesor corneal total no epitelial en el área central para los efectos estadísticamente significativos, en este caso el tiempo y la interacción tiempo y grupo.

- Tabla 16: Diferencias de las medias marginales de la excentricidad corneal para los efectos estadísticamente significativos, en este caso el tiempo, grupo e interacción tiempo y grupo.

- Tabla 17: Diferencias de las medias marginales del coma secundario horizontal para los efectos estadísticamente significativos, en este caso el tiempo y grupo. 
- Tabla 18: Diferencias de las medias marginales de la aberración esférica primaria corneal para los efectos estadísticamente significativos, en este caso el tiempo y grupo.

- Tabla 19: Diferencias de las medias marginales del "spherical like" para los efectos estadísticamente significativos, en este caso el tiempo y grupo.

- Tabla 20: Diferencias de las medias marginales de las aberraciones de alto orden corneales anteriores totales para los efectos estadísticamente significativos, en este caso el tiempo, grupo e interacción grupo y tiempo. 



\section{ÍNDICE DE FIGURAS}

- Figura 1: Clasificación LOCS III (Lens Opacities Classification System).

- Figura 2: Arquitectura de la incisión corneal en 1, 2 o 3 planos.

- Figura 3: Técnica de "facoemulsificación in situ en cuatro cuadrantes" descrita por Shepherd.

- Figura 4: Formación de las vesículas ópticas a partir de evaginaciones del cerebro anterior.

- Figura 5: Corte histológico corneal.

- Figura 6: Paquimetría ultrasónica adaptada a lámpara de hendidura.

- Figura 7: BMU de segmento anterior.

- Figura 8: Paquímetro óptico Haag Streit acoplado a lámpara de hendidura Haag Streit 900.

- Figura 9: Orientación relativa del scan axial (A-scan), scan transversal (Tscan), longitudinal (B-scan) y corte transversal (C-scan).

- Figura 10: Interferómetro de Michelson aplicado a OCT.

- Figura 11: Comparación de la misma imagen con distintos tipos de OCT.

- Figura 12: Dispositivo Cirrus HD-OCT de dominio espectral.

- Figura 13: Ejemplo de medida del espesor corneal central mediante el módulo "Anterior Segment HD 5 line raster" de Cirrus HD-OCT.

- Figura 14: Valores paquimétricos proporcionados por el sistema Pentacam (Oculus).

- Figura 15: El dispositivo Gailei (Ziemer) utiliza simultáneamente una doble cámara Scheimpflug y discos de Plácido. 
- Figura 16: Imagen del primer queratoscopio con luz incorporada descrito por el Dr. Klein en 1957.

- Figura 17: Mapa topográfico aportado por el dispositivo Oculus Pentacam.

- Figura 18: Diferencia entre mapa de escala relativa o autoescala (A) y absoluta (B).

- Figura 19: Diferencia entre topografía regular e irregular por alteración película lagrimal.

- Figura 20: Queratógrafo CTK 922.

- Figura 21: Imagen de la cámara de Scheimpflug del topógrafo Pentacam HR.

- Figura 22: Superficie corneal anterior y posterior, queratometría y paquimetría proporcionadas por el dispositivo Orbscan II.

- Figura 23: Fotografía de Scheimpflug y mapa paquímetrico obtenidos con el sistema Sirius.

- Figura 24: Efecto de los defectos refractivos en el frente de onda.

- Figura 25: Representación de las aberraciones de frente de onda para la superficie corneal anterior, interna (córnea posterior y cristalino) y ocular en un paciente joven (superior) y un paciente anciano (inferior).

- Figura 26: Mapa del error de frente de onda completo resultante de la suma de las aberraciones individuales.

- Figura 27: Descomposición en los Polinomios de Zernike hasta el 5ํㅜ일.

- Figura 28: Imagen obtenida al realizar OCT de segmento anterior en la modalidad "Anterior Segment HD 5 line raster" de Cirrus HD-OCT.

- Figura 29: Espesor corneal total central medido manualmente con el sistema Cirrus HD-OCT. 
- Figura 30: Grosor del espesor epitelial corneal medido manualmente con el sistema Cirrus HD-OCT.

- Figura 31: Grosor del espesor corneal total no epitelial medido manualmente con el sistema Cirrus HD-OCT.

- Figura 32: Datos queratométricos proporcionados por CTK-922.

- Figura 33: Análisis de los coeficientes de Zernike en el queratógrafo CTK-922.

- Figura 34: Medida del espesor corneal a nivel central y ambos lados paracentrales.

- Figura 35: Representación esquemática de la localización de los hemimeridianos de $180^{\circ}$ (área paracentral más próxima a la incisión principal) y 0oㅡ (área paracentral más próxima a la paracentesis de ayuda) en ojo derecho y ojo izquierdo.

- Figura 36: Gráfico tipo Bland \& Altman mostrando la distribución de las diferencias de las medias de la medida del espesor epitelial corneal en el grupo de pacientes operados entre el observador 1 y el observador 2.

- Figura 37: Gráfico tipo Bland \& Altman mostrando la distribución de las diferencias de las medias de la medida del espesor epitelial corneal en el grupo de pacientes no operados entre el observador 1 y el observador 2.

- Figura 38: Gráfico de análisis de regresión tipo Bland \& Altman entre los dos observadores en la medida del espesor corneal total no epitelial en el grupo de pacientes operados.

- Figura 39: Gráfico de análisis de regresión tipo Bland \& Altman entre los dos observadores en la medida del espesor corneal total no epitelial en el grupo de pacientes no operados. 
- Figura 40: Distribución de los residuos sobre la diferencia de las medias de los dos observadores en la medida del espesor corneal total no epitelial en el grupo de pacientes operados.

- Figura 41: Distribución de los residuos sobre la diferencia de las medias de los dos observadores en la medida del espesor corneal total no epitelial en el grupo de pacientes no operados.

- Figura 42: Gráfico tipo Bland \& Altman mostrando la distribución de las diferencias de las medias de la medida del espesor corneal total en el grupo de pacientes operados entre el observador 1 y el observador 2 .

- Figura 43: Gráfico tipo Bland \& Altman mostrando la distribución de las diferencias de las medias de la medida del espesor corneal total en el grupo de pacientes no operados entre el observador 1 y el observador 2

- Figura 44: Distribución de las diferencias en la medida del espesor corneal total en pacientes operados entre el observador 1 y el observador 2 .

- Figura 45: Distribución de las diferencias en la medida del espesor corneal total en pacientes no operados entre el observador 1 y el observador 2 .

- Figura 46: Evolución en el tiempo del componente esférico de la refracción para los grupos de casos y controles.

- Figura 47: Evolución en el tiempo del componente cilíndrico de la refracción para los grupos de casos y controles.

- Figura 48: Evolución en el tiempo de la agudeza visual para los grupos de casos y controles.

- Figura 49: Evolución en el tiempo del espesor corneal total en el área más cercana a la incisión (hemi-meridiano 180) para los grupos de casos y controles. 
- Figura 50: Evolución en el tiempo del espesor epitelial corneal en el área más cercana a la incisión (hemi-meridiano 180ํ) para los grupos de casos y controles.

- Figura 51: Evolución en el tiempo del espesor corneal total no epitelial en el área más cercana a la incisión (hemi-meridiano 180) para los grupos de casos y controles.

- Figura 52: Evolución en el tiempo del espesor corneal total en el área más alejada de la incisión (hemi-meridiano $0^{\circ}$ ) para los grupos de casos y controles.

- Figura 53: Evolución en el tiempo del espesor epitelial corneal en el área más alejada de la incisión (hemi-meridiano $0^{\circ}$ ) para los grupos de casos y controles.

- Figura 54: Evolución en el tiempo del espesor corneal total no epitelial en el área más alejada de la incisión (hemi-meridiano $0^{\circ}$ ) para los grupos de casos y controles.

- Figura 55: Evolución en el tiempo del espesor corneal total en el área central para los grupos de casos y controles.

- Figura 56: Evolución en el tiempo del espesor epitelial corneal en el área central para los grupos de casos y controles.

- Figura 57: Evolución en el tiempo del espesor corneal total no epitelial en el área central para los grupos de casos y controles.

- Figura 58: Evolución en el tiempo de los valores queratométricos en el meridiano de menor potencia.

- Figura 59: Evolución en el tiempo de los valores queratométricos en el meridiano de mayor potencia. 
- Figura 60: Evolución en el tiempo del astigmatismo corneal para los grupos de casos y controles.

- Figura 61: Evolución en el tiempo de la excentricidad corneal para los grupos de casos y controles.

- Figura 62: Evolución en el tiempo del valor de $Z_{3}{ }^{1}$ corneal anterior para los grupos de casos y controles.

- Figura 63: Evolución en el tiempo del valor de $Z_{3}^{-1}$ corneal anterior para los grupos de casos y controles.

- Figura 64: Evolución en el tiempo del valor de $Z_{5}{ }^{1}$ corneal anterior para los grupos de casos y controles.

- Figura 65: Evolución en el tiempo del valor de $Z_{5}^{-1}$ corneal anterior para los grupos de casos y controles.

- Figura 66: Evolución en el tiempo del valor de "coma-like" corneal anterior para los grupos de casos y controles.

- Figura 67: Evolución en el tiempo del valor de la aberración esférica primaria corneal anterior para los grupos de casos y controles.

- Figura 68: Evolución en el tiempo del valor de la aberración esférica secundaria corneal anterior para los grupos de casos y controles.

- Figura 69: Evolución en el tiempo del valor de "spherical-like" corneal anterior para los grupos de casos y controles.

- Figura 70: Evolución en el tiempo de las aberraciones de alto orden corneales anteriores totales para los grupos de casos y controles.

- Figura 71: Asociación entre las variaciones encontradas en el espesor corneal total no epitelial en el hemi-meridiano de $180^{\circ}$ y las aberraciones de alto orden 
corneales anteriores totales en el periodo comprendido entre el preoperatorio y una semana postcirugía.

- Figura 72: Asociación entre las variaciones encontradas en el espesor corneal total no epitelial en el hemi-meridiano de $0^{\circ}$ y las aberraciones de alto orden corneales anteriores totales en el periodo comprendido entre el preoperatorio y un mes postcirugía.

- Figura 73: Asociación entre las variaciones encontradas en el espesor corneal total no epitelial en el ápex corneal y las aberraciones de alto orden corneales anteriores totales en el periodo comprendido entre el preoperatorio y un mes postcirugía. 

INTRODUCCIÓN 



\section{INTRODUCCIÓN}

\subsection{FACOEMULSIFICACIÓN DEL CRISTALINO}

\subsubsection{EVOLUCIÓN DE LA CIRUGÍA DE CATARATA}

Hoy en día, la catarata asociada a la edad es la causa más frecuente de discapacidad visual reversible en adultos ancianos (Meuleners y cols., 2013). Se estima que se realizan a nivel mundial entre 8 y 10 millones de cirugías al año, a los que se debería añadir otros 10 millones de pacientes que tienen catarata pero no son operados por diversas causas (Taylor, 2000). El cristalino es un cuerpo transparente y avascular que realiza un papel fundamental junto a la córnea como es focalizar la luz incidente en los elementos sensoriales de la retina. Para ello es necesaria la transparencia del cristalino y el mantenimiento de un índice de refracción mayor que el de los líquidos circundantes. Con la edad, el cristalino va ganando peso y grosor y perdiendo capacidad de acomodación. Se van formando nuevas capas de fibras corticales concéntricas y se producen cambios químicos en las proteínas del cristalino lo que deriva en cambios refractivos y aberrométricos, pérdida de transparencia, pigmentación progresiva y dispersión de la luz. Los principales tipos de catarata, según la localización de la opacidad, son nuclear, cortical y subcapsular (Rosenfeld, 2007). 


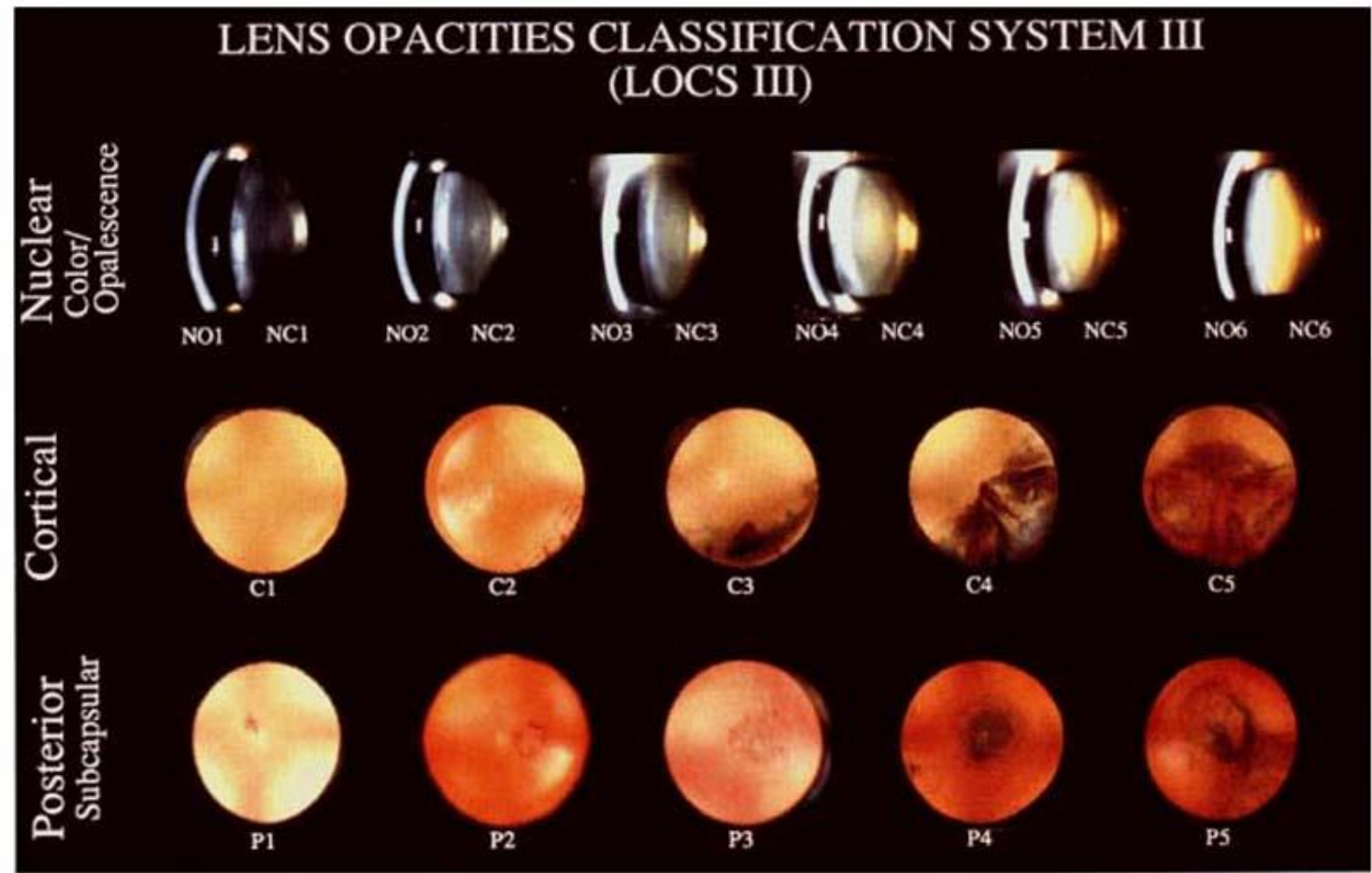

Figura 1: Clasificación LOCS III (Lens Opacities Classification System) (Chaylack y cols., 1993).

La primera cirugía de la que se tiene constancia escrita data alrededor del nacimiento de Jesucristo, aunque se sabe que se realizaban estas cirugías por lo menos 800 años antes, (Ashwin y cols., 2009) si bien ya en el código de Hammurabi, conjunto de leyes de la antigua Mesopotamia, se hace referencia a la cirugía ocular.

El procedimiento, denominado "coaching" o reclinación, consistía en la dislocación del cristalino a cámara posterior empujándolo con una aguja que se introducía por delante del iris (Ashwin y cols., 2009). De este modo, se conseguía una visión más clara. Esta técnica fue descrita por Celso en el año 25 d.C. aproximadamente y se ha estado utilizando de manera generalizada hasta el siglo XVIII, pero hoy en día aún sigue vigente en áreas de África y Asia (Asuquo y cols., 2014). 
En el año 1722 el francés Charles Saint Yves describió la técnica intracapsular, ya que extrajo un cristalino luxado accidentalmente a cámara anterior durante una reclinación (Lozano, 2001). En 1748 el cirujano francés Jacques Daviel describió la cirugía extracapsular, en la que se realizaba una incisión a nivel limbar inferior que era ampliada mediante tijeras $180^{\circ}$, se realizaba una capsulotomía anterior y mediante presión digital se extraía el cristalino y se lavaban los restos capsulares (Duke-Elder, 1969). En el siglo XIX el oftalmólogo alemán Albrecht von Graefe diseñó un cuchillete que permitía una mejor fisiología de la cicatriz corneal. A diferencia del queratomo y las tijeras, este cuchillete bien afilado y con una buena técnica de incisión (se perforaba primero a las 9, luego a las 3 y se unían ambas incisiones con un barrido superior hacia el limbo), permitía obtener buena aposición de los bordes que resultaban en una mejor cicatrización en este momento en que no existía la sutura corneal. Sin embargo, tanto las endoftalmitis como la efusión uveal estaban a la orden del día dada la inestabilidad de la incisión.

A principios del siglo $\mathrm{XX}$ la técnica más común era la intracapsular, que evitaba la catarata secundaria y facilitaba la extracción de la catarata, siendo uno de sus principales promotores el doctor Ignacio Barraquer. Éste diseñó una ventosa y un aparato de vacío para la extracción completa del cristalino. Otro cirujano español, el doctor Joaquín Barraquer, describió en los años 50 la zonulolisis enzimática, para evitar los riesgos derivados de la tracción del núcleo durante la extracción de la catarata (Barraquer, 1958).

Durante un tiempo coexistieron ambas técnicas con distinta indicación cada una; la cirugía extracapsular estaba más aceptada en pacientes jóvenes, en los que la cápsula posterior está más adherida a la hialoides anterior. Hoy en día, sin 
embargo, está plenamente aceptada la indicación de cirugía extracapsular frente a intracapsular en casos de cataratas muy avanzadas.

En cualquier caso, los pacientes operados de cataratas hasta ese momento quedaban afáquicos. En el contexto histórico de la II Guerra Mundial, el inglés Harold Ridley constató que las partículas de plexiglás a nivel intraocular que presentaban algunos pilotos accidentados, no generaban reacción a cuerpo extraño (Moore y cols., 2010). Ridley diseñó un modelo de lente de polimetilmetacrilato (PMMA) que imitaba al cristalino, y en 1949 realizó la primera cirugía de catarata con implante de lente intraocular (LIO). En un primer momento la LIO se colocaba entre la cápsula posterior y el iris, y las complicaciones postquirúrgicas hicieron que se abandonara parcialmente el implante de LIO hasta que se introdujeron mejoras en la misma (Moore y cols., 2010).

Otro de los grandes hitos en la cirugía de catarata fue el desarrollo de la facoemulsificación por el doctor Charles Kelman, que en 1967 publicó su primer trabajo. Esta nueva técnica permitía la realización de la cirugía del cristalino a través de incisiones mucho menores que las utilizadas en la técnica extracapsular (Pandey y cols., 2004).

\subsubsection{LA CIRUGÍA DE CATARATAS EN LA ACTUALIDAD}

Toda esta evolución ha sentado las bases para la cirugía moderna, en la que no sólo las técnicas se han perfeccionado sino que hasta se ha minimizado la estancia del paciente en el hospital, de modo que se clasifica como cirugía mayor, puesto que penetra una cavidad corporal y se implanta una prótesis -la lente 
intraocular-, y ambulatoria. Además, hoy en día podemos entender la cirugía de catarata como una cirugía refractiva, dada la cada vez mayor demanda social de eliminar o disminuir la dependencia del uso de gafas para una buena visión tanto en visión lejana como próxima (Fernández-Vega y cols., 2001).

La técnica habitual de facoemulsificación requiere de dispositivos especializados denominados facoemulsificadores. En los aparatos de facoemulsificación se genera una energía electromagnética que es conducida hasta la pieza de mano, donde se transforma en energía ultrasónica de alta frecuencia. Por último esta energía se transmite a la punta del facoemulsificador produciéndose un movimiento longitudinal de energía mecánica. De este modo la energía mecánica permite la emulsificación del cristalino al mismo tiempo que un sistema de irrigación sustituye el material emulsificado por solución salina, manteniendo la cámara anterior durante la intervención, y enfriando la punta del faco para evitar las temidas quemaduras de la incisión corneal.

Los mecanismos de destrucción del núcleo son los llamados efecto taladro, que es puramente mecánico y se basa en el choque de la punta del faco con el cristalino, y el efecto cavitación, que se debe al rápido movimiento de un sólido en un líquido. Tras cada oscilación de la punta del faco, se crea una baja presión o vacío que favorece la formación de microburbujas. Cuando la punta del faco se mueve hacia delante se crea una alta presión que hace explosionar las burbujas, así como una altísima temperatura y una onda de choque (Ollero y cols., 2008).

Las plataformas de facoemulsificación utilizan o bien una bomba peristáltica de flujo, que requiere oclusión en la punta del faco para generar vacío y empujar 
líquido y material del cristalino, o bien bomba de Venturi, que genera vacío por creación de presión negativa en un vaso.

El protocolo quirúrgico convencional de la cirugía de catarata hoy en día consta de los siguientes puntos:

\subsubsection{Anestesia:}

I. Bloqueo retrobulbar. Se inyecta anestésico entre el tercio externo y dos tercios internos del párpado inferior. Con el ojo en posición neutra, se introduce una aguja paralela al suelo de la órbita y a la altura del ecuador, la dirección de la aguja cambia dirigiéndose hacia el cono orbitario. Esta técnica ha perdido seguidores dadas sus severas complicaciones, tales como perforación del globo, daño en el nervio óptico o estrabismo restrictivo (Celiker y cols., 2014).

II. Anestesia subtenoniana. Requiere incisión conjuntival y se inyecta anestésico más allá del ecuador por debajo de la cápsula de Tenon. Es igual de efectiva que la retrobulbar en cuanto a resultados analgésicos, sin embargo la acinesia no está garantizada y tampoco está exenta de complicaciones (Lai y cols., 2005).

III. Anestesia peribulbar. Es aquella en la que se produce difusión de anestésico local inyectado desde el cuadrante temporal inferior al resto de la órbita. 
IV. Anestesia tópica. Hoy en día es la más utilizada. Se aplica anestésico local de forma tópica y se puede añadir inyección intracamerular de lidocaína durante el procedimiento. Es la que menos riesgos implica, pero obviamente el ojo puede moverse y complicar la cirugía, y los pacientes pueden referir mayor dolor que con la anestesia inyectada (Dole y cols., 2014).

\subsubsection{Incisiones:}

I. Paracentesis de servicio. Se realiza habitualmente entre $60-90^{\circ}$ a la izquierda y/o derecha de la incisión principal. No todos los cirujanos la realizan. Es menor a $1 \mathrm{~mm}$. Se utiliza para introducir el manipulador.

II. Incisión principal. La incisión principal puede ser corneal o limbar. La tendencia es la realización de una incisión cada vez menor, partiendo de los tamaños iniciales de 5,5-6.0 $\mathrm{mm}$ que requerían sutura a las actuales microincisiones de $1,5 \mathrm{~mm}$ o menores. Para lograr una incisión estanca, ésta requiere una arquitectura tunelizada, de unos $2 \mathrm{~mm}$ de largo. Para la realización de estas cirugías se utilizan cuchilletes de acero ó diamante, con una forma trapezoidal habitualmente. El túnel corneal se puede realizar en uno, dos ó tres planos, lo que va a favorecer el autosellado de la herida. Las incisiones corneales temporales o nasales producen 
menos astigmatismo que las superiores, además de ser más accesibles (Barequet y cols., 2004).

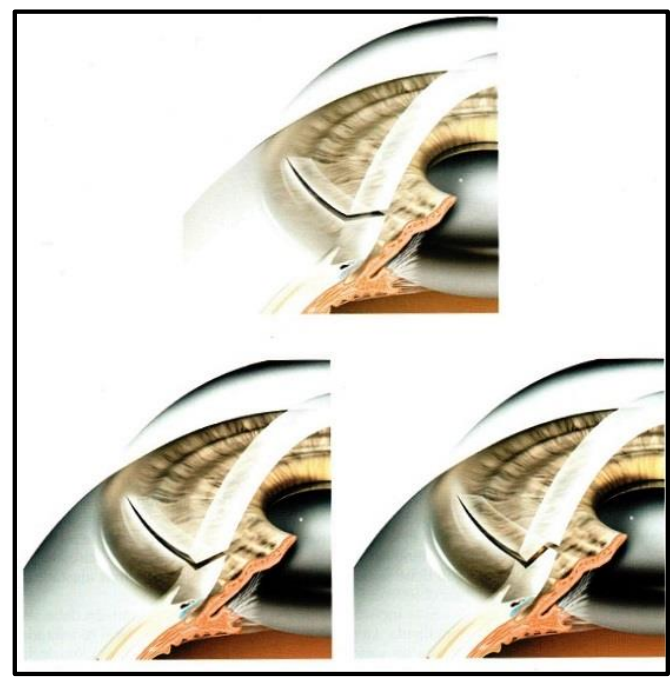

Figura 2: Arquitectura de la incisión corneal en 1, 2 o 3 planos. (Fernández-Vega y cols., 2001).

Otra técnica menos común hoy en día para la realización de microincisiones es la utilización de láser femtosegundo, que es capaz de crear espacios virtuales en forma de incisiones que posteriormente se abren con otro instrumento quirúrgico como pueda ser un gancho de Sinskey (Alió y cols., 2014). Estas incisiones se realizan en tres planos y se ha probado su estabilidad y su mínima alteración a nivel tisular (Sugar, 2002).

\subsubsection{Viscoelásticos:}

Las sustancias viscoelásticas (en inglés ophthalmic viscosurgical devices OVDs), se utilizan para mantener espacio en la cámara anterior y además proteger tejidos intraoculares durante la cirugía; en el caso de la 
cirugía de catarata son fundamentales en la protección del endotelio corneal (Shiba y Tsuneoka, 2014).

Los viscoelásticos, que vienen presentados en dispositivos precargados, están divididos en varios grupos según la clasificación de Arshinoff (Arshinoff y Jafari, 2005). Por un lado encontramos los cohesivos de alta, media y muy baja viscosidad, con cadenas largas y enlaces fuertes, que son capaces de mantener buenos espacios dentro del ojo y son fáciles de retirar. Entre los de alta viscosidad encontramos el Healon® y el Biolon®. Por otro lado tenemos los viscoelásticos dispersivos, de menor viscosidad y menor peso molecular, con cadenas cortas que presentan mayor adherencia y capacidad de protección del endotelio (Maar y cols., 2001; Rainer y cols., 2000), resultando más difíciles de eliminar. Estos se dividen a su vez en alta viscosidad (DisCoVisc $\AA)$, media (Viscoat®) y muy baja (HPMP®). Por último, el grupo de los pseudodispersivos que incluye al Healon5®.

El hialuronato sódico asociado al condroitín sulfato pertenece al grupo de los dispersivos, que por sus cargas negativas se adhiere fuertemente al endotelio (cargado positivamente) actuando como una barrera de protección durante la acción de los ultrasonidos (Kiss y cols., 2003). Es capaz de proteger al endotelio corneal durante el tiempo de aplicación de ultrasonidos, mantener y crear espacios intraoculares durante la cirugía, así como proteger el endotelio en el momento de la introducción de la LIO (Barrio y cols., 2006).

\subsubsection{4. $\quad$ Capsulorrexis:}


La capsulorrexis fue descrita en 1985 de manera simultánea por distintos oftalmólogos (Gimbel, Neuhann y Shimizu) que luego unificaron criterios y describieron de manera conjunta la técnica en 1990 (Gimbel y Neuhann, 1990). Esta técnica nació fruto de la necesidad de crear una capsulotomía sin solución de continuidad que evitara desgarros de la cápsula anterior hasta el ecuador y su extensión al saco capsular, provocando inestabilidad de la LIO y complicaciones quirúrgicas. Esta técnica se describe como circular, continua y central. Se realiza con cistitomo o con pinza.

El tamaño ideal de la capsulorrexis es de 5.0-5,5 mm de diámetro, aunque la magnitud va a estar limitada por el tamaño de la pupila y por la inserción central de las fibras de la zónula. El hecho de que la rexis esté centrada evita el descentramiento de la lente además de la opacificación capsular (Lorente y Mendicute, 2008).

\subsubsection{Hidrodisección e hidrodelaminación del cristalino:}

Con las maniobras de hidrodisección e hidrodelaminación lo que se pretende es la liberación del núcleo del córtex cristaliniano de manera que el núcleo rota y se mueve fácilmente y de forma segura, ya que se disminuye la tracción sobre las fibras zonulares. La técnica fue descrita en los años 80 por Faust (1984). Consiste en insertar una cánula de 27 gauges de punta roma y plana bajo el borde de la rexis y el líquido se inyecta bajo la cápsula anterior.

La hidrodelaminación consiste en la separación del núcleo y epinúcleo, de modo que se divide la catarata nuclear, que requerirá ultrasonidos, de la catarata epinuclear, que requerirá aspirado para su eliminación. La misma 
cánula utilizada para la hidrodisección se introduce en el cristalino y se inyecta suero.

\subsubsection{Facoemulsificación:}

Para facilitar la manipulación del cristalino y su posterior facoemulsificación es necesaria su fragmentación. Con la fragmentación del núcleo se ahorra en energía y se reducen los daños colaterales derivados de un uso excesivo de la misma. Inicialmente esta fragmentación se realizaba fuera de la cápsula, en el plano del iris o en cámara anterior. Normalmente se utiliza una punta de facoemulsificación de Kelman y se siguen los siguientes pasos: esculpido de los surcos, fractura del cristalino y extracción de los fragmentos.

Es difícil determinar valores universales de flujo, vacío y potencia de facoemulsificación, puesto que estos van a depender de los equipos, de las puntas utilizadas y de las necesidades del cirujano. En cualquier caso son valores que hay que modificar según el momento de la cirugía en el que nos encontremos.

Uno de los sistemas de energía torsional existentes en el mercado es el denominado Ozilß (Alcon, EEUU). La energía torsional se basa en movimientos oscilatorios de lado a lado de la punta a 32.000 ciclos por segundo. Esto lo distingue del ultrasonido tradicional, caracterizado por movimiento longitudinal de la punta. Esta técnica va a favorecer la oclusión de la punta, dado que hay una menor repulsión de los fragmentos, lo que va a permitir trabajar con unos menores parámetros de aspiración y vacío, y por 
consiguiente se liberará menor cantidad de energía (Fahkry y El Shazly, 2011).

Algunas de las técnicas descritas de facoemulsificación son las siguientes:

I. "Chip and flip". Esta técnica habitualmente se utiliza en cataratas blandas. Consiste en emulsificar la parte central de la catarata en planos superficiales hasta conseguir la llamada cazoleta, que mantiene un rodete de tejido a nivel periférico. Posteriormente se aspira el epinúcleo.

II. "Divide y vencerás". Técnica introducida por Gimbel, consiste en realizar surcos perpendiculares con el terminal de faco, en forma de cruz, y con una longitud y profundidad aptas para la fractura del núcleo del cristalino en cuadrantes. En la técnica descrita por Gimbel (1991), se fractura el núcleo inmediatamente después de realizar el primer surco. Otra variante de Gimbel se basa en la realización de una cazoleta y su posterior fragmentación. La técnica de los cuatro cuadrantes como tal fue descrita por Shepherd (2003). Esta técnica se denomina "fractura in situ de cuatro cuadrantes". Ambas requieren la ayuda de un manipulador en la mano no dominante para realizar la fractura.

III. "Crack and flip". Aprovecha la ventaja de conservación del epinúcleo del "chip and flip" con la de la fractura en el "divide y 
vencerás", en la que se ahorra tiempo de ultrasonidos. Se basa en una meticulosa hidrodisección e hidrodelaminación.

IV. "Faco-chop". Se basa en la disposición radial de las fibras del cristalino.En esta técnica no se realizan surcos para fracturar el núcleo, lo que conlleva un ahorro de ultrasonidos que no se van a utilizar hasta la emulsificación. Fue descrita por Nahagara y presentada en 1993 en el congreso de la Sociedad Americana de Cirugía Refractiva y Cataratas en Seattle (Can y cols., 2004). La técnica consiste en introducir el terminal del faco en el centro del cristalino con vacíos altos y luego con ayuda del "chopper" (que tiene un borde cortante), se corta el cristalino en dirección a la punta del faco, separando el cristalino en dos mitades con fuerzas opuestas entre chopper y terminal del faco. Esta técnica, indicada en cataratas duras, permite un ahorro de tiempo y de ultrasonidos, si bien requiere una curva de aprendizaje para realizar un buen rasgado que permita separar bien los fragmentos y luxarlos.

V. "Stop and chop". Koch modificó la técnica de Nahagara y describió el "stop and chop" (1994), técnica en la que se realiza un surco central y se divide el núcleo en dos mitades. Posteriormente se realiza "chop" en cada heminúcleo. Puesto que el "stop and chop" es una técnica híbrida, entre el esculpido y el "faco-chop", Chang (1999) estableció el término "non-stop faco-chop" para referirse al "faco- chop" puro. 
VI. "Snap and split". Descrita por Fukasaku, se utiliza un "snapper", más corto que el "chopper", y no busca la periferia del núcleo sino que se trabaja a nivel central.

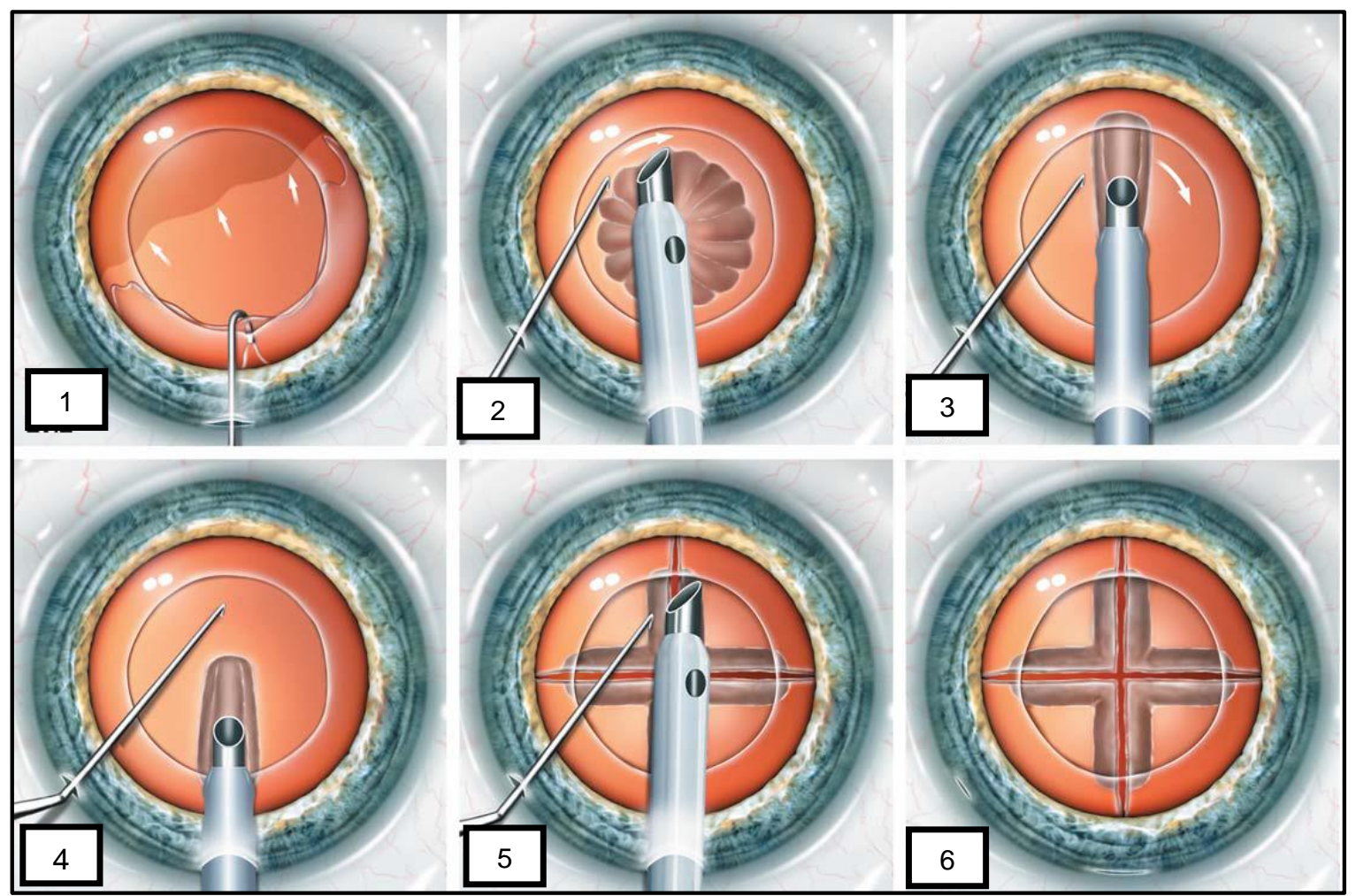

Figura 3: Técnica de "facoemulsificación in situ en cuatro cuadrantes" descrita por

Shepherd. 1. Hidrodisección. 2. Eliminación del córtex superficial. 3. Inicio del primer surco. 4. Finalización del primer surco. Tras rotar $180^{\circ}$ se completa el tallado del primer surco. 5. Tras tallar los dos surcos se practican las sucesivas roturas hasta obtener cuatro cuadrantes. 6 . El cristalino está dividido en cuatro cuadrantes y dispuesto a ser facoemulsificado (Mendicute, Lorente, 2008).

\subsubsection{Irrigación/aspiración del córtex:}


En este paso se eliminan los restos corticales. Se recomienda su completa eliminación porque los restos de córtex que permanezcan en el ojo pueden hidratarse y ocupar el eje visual, además pueden desencadenar procesos inflamatorios durante el postoperatorio inmediato y respuestas de tipo facoanafiláctico a largo plazo.

Las bombas de aspiración pueden ser de tipo peristáltico o Venturi según las características de la plataforma de facoemulsificación, y se realiza mediante un terminal de irrigación-aspiración de sistema bimanual o de sistema coaxial, como en nuestras cirugías. Por un mismo terminal sale la irrigación y presenta un pequeño orificio que tras ser ocluído favorece la aspiración de las masas mediante vacío.

\subsubsection{Implante de la lente intraocular (LIO):}

Tras el aspirado de los restos corticales, el saco capsular y la cámara anterior se rellenan con viscoelástico y se dispone la LIO dentro del mismo. En caso de necesidad por complicaciones quirúrgicas o disposición anatómica de distinta consideración, las LIOs pueden ser colocadas en sulcus, entre la cápsula anterior y el iris, o en cámara anterior. Tras el implante de la LIO se aspira el viscoelástico residual.

En nuestro medio, las LIOs utilizadas son las plegables, capaces de ser introducidas por pequeñas incisiones, mientras que en países menos desarrollados persiste el uso de lentes rígidas que requieren una incisión corneal de por lo menos $5.0 \mathrm{~mm}$, mayor que el tamaño de la óptica de la LIO. Hoy en día las LIOs plegables pueden estar presentadas en dispositivos 
inyectores precargados. Otras tendencias en LIO son el diseño de bordes angulados, la incorporación de filtros para luz ultravioleta y/o azul y la adopción de formas asféricas para reducir las aberraciones esféricas postoperatorias (Morcillo y Durán, 2008).

En la práctica clínica diaria las LIOs más utilizadas son las monofocales. La composición de las LIOs va a determinar su índice de refracción, su contenido en agua, propiedades de superficie y resistencia mecánica, entre otros aspectos. Las LIOs constan de óptica, central y circular, y hápticos, que sirven de anclaje a la óptica. Según su composición distinguimos:

I. Lentes de polímeros de acrilato-metacrilato.

A. Lentes rígidas de polimetilmetacrilato (PMMA):

Ridley fue el primero en implantar una LIO de PMMA en 1949 (Moore y cols., 2010), y desde entonces se continúan utilizando. Actualmente se utilizan más en países subdesarrollados, dado su menor coste y mayor incidencia de cirugía extracapsular. En nuestro medio se utilizan en cirugías complicadas o con mal soporte para lente, colocándose en cámara anterior. Las que se implantan en el saco tienen muy buenos resultados visuales, aunque con mayor frecuencia asocian opacificación de la cápsula posterior (Oner y cols., 2000). Se cree que la causa no es tanto el material de la lente como su diseño (Nishi y cols., 2004). 
B. Lentes plegables:

- Lentes acrílicas hidrofóbicas, con un menos de un $1 \%$ de contenido en agua. Pueden ser de tres piezas o monobloque $\mathrm{y}$ tienen un desplegado lento y controlado.

- Lentes acrílicas hidrofílicas, también llamadas lentes de hidrogel, tiene más de un $18 \%$ de contenido en agua.

II. Lentes de elastómeros de silicona. La silicona fue el material con el que se realizó la primera lente plegable en 1984. Es un material hidrofóbico. Las lentes pueden ser monobloque o de tres piezas. Actualmente son el material que se utiliza en algunas lentes tóricas para corregir el astigmatismo preoperatorio (Doors y cols., 2012).

\subsubsection{Cierre de la incisión:}

La incisión principal puede cerrarse con hidratación o sutura en casos de cirugía complicada o mal estado de la córnea que impida su hidratación. Aunque las incisiones actuales se dice que son autosellables, es recomendable el cierre de las mismas mediante solución salina balanceada. Ésta, mediante una cánula plana o una aguja de 30G (Nithyanandarajah y cols., 2014), se infiltra en el espesor estromal en las paredes laterales de la incisión hasta que se observa blanqueamiento y se comprueba la estanqueidad. Otras técnicas describen la creación de un bolsillo supraincisional que al hidratarse favorece el sellado del labio superior de la 
incisión mientras que la propia presión intraocular cierra el labio inferior (Wong, 2003).

\subsection{LA CÓRNEA}

\subsubsection{EMBRIOLOGÍA}

Alrededor del día 22 de gestación, aparecen dos surcos poco profundos a cada lado del cerebro anterior. Con el cierre del tubo neural el día 25, los surcos van a producir evaginaciones del cerebro anterior, denominadas vesículas o primordios ópticos. Las células de la cresta neural (neuroectodermo) migran para rodear la vesícula, y el día 28 la vesícula induce la formación de la placoda cristalina (Langman y Sadler, 2006).

Al final de la quinta semana, el primordio ocular está rodeado de células mesenquimales y el ectodermo está formado por dos capas de células epiteliales que descansan sobre una fina membrana basal. Esta doble capa de ectodermo forma por tanto la placoda del cristalino y va a dar lugar al epitelio corneal y conjuntival y a la epidermis palpebral (Sutphin, 2007). 


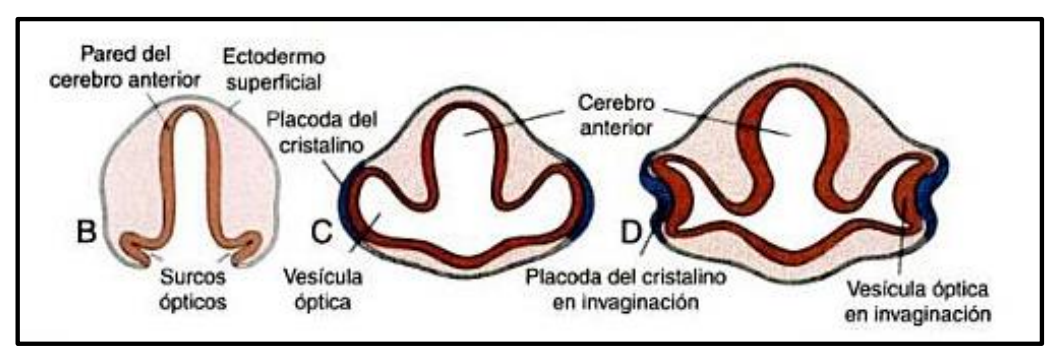

Figura 4: Formación de las vesículas ópticas a partir de evaginaciones del cerebro anterior (Sadler y Langman, 2006).

La separación entre la vesícula (placoda) del cristalino y el ectodermo superficial marca el desarrollo de la córnea, puesto que se induce en la capa basal de células epiteliales la secreción de fibrillas de colágeno y glucosaminglucanos que van a constituir el estroma primario. Las células mesenquimales migran hasta la superficie posterior del estroma primario, dando origen al endotelio corneal. Esta migración celular es la primera de las tres oleadas sucesivas de invasión celular. La segunda oleada de células mesenquimales, que tiene lugar en la 6ª semana, avanza en dos direcciones dando lugar al iris y a la membrana pupilar primaria. Ya en la 7ํㅡ semana de gestación se produce la tercera oleada hacia el estroma corneal. Estas células se van a diferenciar en queratocitos que secretan fibrillas de colágeno tipo I y forman la matriz del estroma secundario o maduro (Civis, 2007a).

La membrana de Descemet se origina durante el tercer mes de gestación como una membrana basal discontinua, y la membrana de Bowman se forma a final del cuarto mes como una zona acelular del estroma anterior.

El diámetro corneal mide $2 \mathrm{~mm}$ a las 12 semanas de gestación, $4.5 \mathrm{~mm}$ a las 17 semanas y $9.3 \mathrm{~mm}$ a las 35 semanas (Civis, 2007a). Del mismo modo, el grosor corneal va aumentado, alcanzando valores de $576 \pm 26$ micas (Uva y cols., 2012) a 
$616 \pm 61$ micras (Rushood y cols., 2012) en recién nacidos según series, encontrando mayor espesor corneal en prematuros (599 \pm 36 micras) (Uva y cols., 2012), aunque a los tres meses se iguala a los recién nacidos a término.

El mayor crecimiento ocular tiene lugar durante el primer año de vida, y la córnea que va a tener un poder dióptrico de 52 dioptrías (D) al nacimiento pasa a las $46 \mathrm{D}$ a los 6 meses, alcanzando el poder adulto de entre 42 y $44 \mathrm{D}$ a los 12 años (Simon, 2007).

\subsubsection{RECUERDO ANATÓMICO Y FUNCIONAL}

La córnea es un tejido con una alta diferenciación para permitir la refracción y la transmisión de la luz, dos de sus funciones más importantes junto con la protección del contenido intraocular. Su forma consiste en una lente cóncavoconvexa con una cara anterior, en contacto íntimo con la película lagrimal precorneal, y otra cara posterior, bañada por el humor acuoso. Estas relaciones permiten a la córnea carecer de vascularización, pues estos líquidos son los máximos responsables de mantener sus requerimientos fisiológicos. La glucosa difunde desde el humor acuoso y el oxígeno difunde a través de la película lagrimal. Además, la córnea periférica recibe oxigenación a partir de la circulación limbar.

La córnea posee una de las mayores densidades de terminaciones nerviosas del cuerpo, lo que le proporciona una muy alta sensibilidad. La densidad de terminaciones nerviosas corneales es entre 300 y 400 veces mayor que en la piel (Müller y cols., 2002). Las terminaciones sensoriales provienen de los nervios ciliares 
largos que proceden de la rama oftálmica del trigémino. Estos nervios contribuyen al anillo nervioso perilimbar. Las fibras nerviosas penetran en la córnea de forma radial a nivel del estroma profundo periférico, formando un plexo subepitelial. Estos nervios pierden su mielina nada más penetrar en la córnea, atraviesan el estroma, perforan la membrana de Bowman y se localizan a nivel subepitelial.

Otra de las cualidades corneales es que es uno de los pocos tejidos avasculares del organismo. Sin embargo, factores derivados de la sangre son fundamentales en el metabolismo y reparación corneal. La arteria ciliar anterior, derivada de la oftálmica, forma una arcada vascular mediante anastomosis con ramas de la arteria facial, derivada de la carótida externa. De este modo, las arterias carótida interna y externa contribuyen al aporte vascular corneal.

La córnea tiene un diámetro horizontal de 11-12 mm y vertical de 9-11 mm y tiene un índice de refracción de 1.376. El espesor corneal a nivel central ronda los $0.5 \mathrm{~mm}$. Como ejemplo, Doughty y Zaman (2000) describieron en su estudio una media del espesor corneal central de $535 \pm 0.031$ micras. A nivel periférico, se produce un engrosamiento que además es mayor en la periferia nasal respecto a la temporal. Jonuscheit y cols. (2015) describen está asimetría mediante Scheimpflug (Pentacam), encontrando valores de $672 \pm 44 \mu \mathrm{m}$ a $4 \mathrm{~mm}$ temporales del centro corneal y $731 \pm 45 \mu \mathrm{m}$ a $4 \mathrm{~mm}$ nasal. A mayor distancia del ápex corneal, mayor asimetría (59 $\pm 22 \mu \mathrm{m})$. La curvatura de la superficie corneal no es constante, siendo mayor a nivel central y menor a nivel periférico. En los $3 \mathrm{~mm}$ centrales, donde la córnea es más esférica, los radios corneales miden entre 7.5 y $8.0 \mathrm{~mm}$. El poder refractivo de la córnea puede variar de 40 a 44 D, constituyendo cerca de dos tercios del poder refractivo total del ojo (Krachmer, 2011). 


\subsubsection{HISTOLOGÍA}

La córnea está formada por tres capas celulares y dos interfases. De externa a interna encontramos el epitelio, membrana de Bowman, estroma, membrana de Descemet y endotelio, aunque recientemente se ha descrito adicionalmente la capa de Dua entre el estroma y la membrana de Descemet (Dua y cols., 2013). En la córnea encontramos células epiteliales, queratocitos y células endoteliales. La integridad y función corneal se consigue gracias a la interacción y disposición de los distintos componentes, garantizando su transparencia y fuerza. La película lagrimal, íntimamente unida a la córnea, se incluye en este apartado.

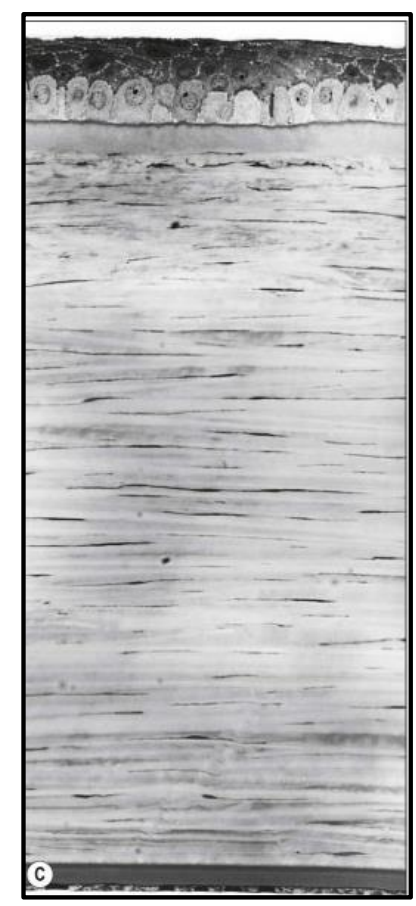

Figura 5: Corte histológico corneal (Krachmer, 2011). 


\subsubsection{Película lagrimal:}

La película lagrimal tiene un volumen de 6-9 $\mu \mathrm{L}$, y está compuesta por agua en un $98 \%$. Su pH normal varía entre 6.5 y 7.6 , y la osmolaridad entre 290-310 mOsm.

La película lagrimal tiene como funciones proporcionar una superficie óptica lisa en la interfase aire-ojo eliminando las irregularidades corneales, actuar como medio para la eliminación de material de desecho, proteger la superficie ocular y aportar al epitelio corneal oxígeno y factores de crecimiento y otros compuestos. Además, la película lagrimal contiene gran cantidad de agentes antimicrobianos, lubrica la interfase entre córnea y párpados y evita la desecación de la superficie ocular (Civis, 2007b).

Históricamente, la película lagrimal, que tiene un espesor de unas $7 \mu \mathrm{m}$ se ha dividido en tres capas, lipídica, acuosa y mucosa, sin embargo hoy en día se tiende a considerar la película como un medio continuo en el que el componente lipídico tiene una disposición más anterior (Krachmer, 2011).

La capa lipídica, que es la más anterior, es muy fina $(0.1 \mu \mathrm{m})$ y está compuesta por lípidos hidrofóbicos e hidrofílicos en estado líquido. Los lípidos hidrofílicos (fosflípidos) están en contacto con la superficie acuosa y los hidrofóbicos (triglicéridos, ésteres de esterol, ésteres de cera, hidrocarbonos) con la interfaz aérea (Masmali y cols., 2014). Estos lípidos están secretados principalmente por las glándulas de Meibomio, localizadas en el tarso palpebral, y por las glándulas de Zeiss, localizadas en el borde palpebral. Las funciones de la capa lipídica son retrasar la evaporación, contribuir a las 
propiedades ópticas de la película lagrimal, mantener una barrera hidrófoba que evita el rebosamiento de las lágrimas al aumentar la tensión superficial y prevenir la lesión de la piel del borde palpebral por las lágrimas (Benítez del Castillo y cols., 2004).

El componente acuoso de la lágrima es secretado por las glándulas lagrimales principal (secreción refleja) y accesorias de Wolfring y Krause (secreción basal), así como por los epitelios corneal y conjuntival. Constituye el componente principal de la lágrima en cuanto a volumen y su espesor es de unas $6 \mu \mathrm{m}$. Está formada por electrolitos, agua y proteínas. Sus principales funciones son aportar oxígeno al epitelio corneal, mantener constante la concentración de electrolitos en el epitelio corneal, proporcionar defensa antimicrobiana (la lágrima contiene inmunoglobulina $\lg A$, lisozima, lactoferrina, fosfolipasa, lipocalina, defensinas, interferón, citokinas, factores de crecimiento), reducir las irregularidades de la superficie corneal anterior, eliminar los deshechos mediante lavado y modular la función de las células epiteliales corneales y conjuntivales (Civis, 2007b).

El componente mucoso tiende a ubicarse más internamente. Constituye un gel que está compuesto por el glicocálix de las microvellosidades de las células epiteliales superficiales de la córnea y por el mucus secretado desde las células caliciformes. El mucus incluye lipoproteínas, glicoproteínas y proteínas, siendo la mucina el principal componente glicoproteico. La mucina soluble y los lípidos meibomianos en la capa acuosa le confieren mayor estabilidad a la película lagrimal disminuyendo la tensión superficial y favoreciendo su distribución sobre la superficie ocular durante el parpadeo (Benítez del Castillo y cols., 2004). El 
componente mucoso tiene como otras funciones la adherencia de la película lagrimal al epitelio corneal, la barrera contra la invasión bacteriana y de células inflamatorias y la lubricación palpebral.

\subsubsection{Epitelio corneal:}

Es un epitelio escamoso estratificado no queratinizado compuesto aproximadamente por cinco capas de células y tiene un grosor aproximado de 50-60 $\mu \mathrm{m}$. Las células que componen el epitelio son células superficiales, alares y basales columnares, las cuales se adhieren a la membrana basal mediante hemidesmosomas y tonofilamentos. La membrana basal del epitelio mide unos $75 \mathrm{~nm}$ y en ella se distingue una lámina lúcida y una lámina densa. Una compleja red de colágeno tipo VII y placas de anclaje de colágeno tipo VI conectan la lámina densa con las fibras de colágeno de la membrana de Bowman (Benítez del Castillo y cols., 2004).

Las células basales, de aspecto poligonal, se originan de las células amplificadoras transitorias del limbo esclerocorneal que migran centrípetamente, tienen actividad mitótica y son responsables de la regeneración y renovación del epitelio (Huang y Tseng, 1991). Las células alares constituyen la segunda capa celular y son producto de la mitosis de las células basales. Presentan interdigitaciones entre sus paredes laterales y uniones intercelulares mediante desmosomas. Las células apicales son las más superficiales. Son anchas y aplanadas y la capa más superficial presenta micovellosidades y micropliegues que expresan un glicocálix que favorece la 
adherencia a la capa mucinosa de la película lagrimal. En sus paredes laterales abundan los desmosomas y uniones tipo "gap", lo que va a proporcionar impermeabilidad en la capa más externa del epitelio. La falta de queratina en el epitelio lo hace susceptible de desecación y traumatismos (Benítez del Castillo y cols., 2004).

El epitelio corneal se renueva constantemente a partir de la actividad mitótica de la capa basal y la exfoliación de las células apicales que se descaman hacia la lágrima, estimándose un recambio total cada 7-14 días (Krachmer, 2011). El epitelio corneal posee una rápida respuesta frente a soluciones de continuidad, con rápido desplazamiento de las células adyacentes al defecto hasta cubrirlo en pocas horas (Benítez del Castillo y cols., 2004).

No existen células de Langerhans ni melanocitos en el epitelio corneal central. Este hecho asociado a la ausencia de vasos sanguíneos, proporciona a la córnea un privilegio inmunológico sumamente importante para el éxito de los trasplantes corneales. El metabolismo de las células epiteliales de la córnea requiere de glucosa, aminoácidos y vitaminas, que proceden del humor acuoso, y de oxígeno, que se obtiene por difusión desde la película lagrimal. Con los párpados cerrados, al ser menor la presión parcial de oxígeno en la lágrima, la difusión desde los vasos conjuntivales es el principal aporte de oxígeno (Benítez del Castillo y cols., 2004).

\subsubsection{Membrana de Bowman:}


La membrana de Bowman se localiza por debajo de la membrana basal del epitelio y está formada por una capa resistente de fibras de colágeno tipo I y III de pequeño diámetro $(20-30 \mathrm{~nm})$ dispuestas de manera aleatoria en comparación con el estroma, cuyas fibras se orientan de manera paralela (Komai y Ushiki, 1991). Es por tanto una región modificada del estroma anterior. Su función no está claramente definida, pero se cree que sirve de protección del estroma ante traumatismos y ofrece una barrera frente a la invasión de microorganismos y células tumorales. Del mismo modo la membrana de Bowman contribuye a la transparencia corneal y a la inervación epitelial en caso de trauma, patología o intervención quirúrgica (Germundsson y cols., 2013). A diferencia de la membrana de Descemet, no se restaura después de una lesión sino que es sustituida por tejido cicatricial. Existe discrepancia a cerca del espesor total de esta membrana, con valores entre 8 y $19 \mu \mathrm{m}$ según el tipo de medida (in vivo o ex vivo), el método de preparación del tejido y la técnica de medición (Lagali y cols., 2009).

\subsubsection{Estroma:}

El estroma tiene un espesor central de entre 500-540 $\mu \mathrm{m}$ siendo mayor en la periferia donde puede alcanzar las $700 \mu \mathrm{m}$. Constituye por tanto el $90 \%$ del grosor corneal total. El estroma está constituido por fibras de colágeno, matriz extracelular, células y agua.

Las fibras de colágeno forman láminas de orientación oblicua en el tercio anterior del estroma y láminas paralelas en los dos tercios posteriores. 
Las fibras de colágeno se extienden por todo el diámetro corneal y se enrollan circunferencialmente alrededor del limbo. La disposición uniforme y la continua producción y degradación de las fibras de colágeno son fundamentales para la transparencia corneal. Los tipos de colágeno del estroma son en su mayoría tipo I, y en menor cantidad tipo III, V y VI, mientras que las fibrillas de anclaje al epitelio son tipo VII. El colágeno constituye más del 70\% del peso en seco de la córnea. Las fibras tienen un diámetro de 22.5$35.0 \mathrm{~nm}$ y están dispuestas a distancia de $640 \AA$ (Civis, 2007a; Krachmer, 2011).

La sustancia fundamental del estroma está compuesta por proteoglicanos que se distribuyen entre las fibras de colágeno. Los proteoglicanos se componen de cadenas de glucosaminglucanos y proteínas que van a modular la génesis del colágeno. El ácido hialurónico es el único glucosaminglucano que no está presente en forma de proteoglucano, y es el queratán sulfato el glucosaminglucano más abundante del estroma, constituyendo el $65 \%$ del total. En menor cantidad encontramos condroitín sulfato y dermatán sulfato (Funderburgh, 2000). Los glucosaminglicanos son muy polares y por tanto van a ser responsables de la tumefacción del estroma, puesto que son capaces de absorber y retener grandes cantidades de agua. Aunque la hidratación corneal depende fundamentalmente de la bomba endotelial, también se va a ver influenciada por la barrera epitelial, evaporación de la superficie, presión intraocular y la presión de tumefacción estromal (Krachmer, 2011). En cuanto a proteínas, el estroma contiene lumicán, keratocán, mimecán, decorina y biglicán. 
Los queratocitos son el principal componente celular del estroma, con un recambio celular cada 2 ó 3 días. Con una morfología fusiforme, estas células se dispersan entre las lamelas del estroma y poseen uniones intercelulares tipo uniones "gap" entre sus prolongaciones. Hay aproximadamente 2.4 millones de queratocitos en la córnea, y constituyen un 3-5\% del volumen estromal. La densidad celular a nivel anterior es mayor que en estroma posterior, al igual que ocurre con los proteoglicanos. Los queratocitos son células ricas en mitocondrias y otros orgánulos debido a su alta actividad de síntesis de colágeno y matriz extracelular. En condiciones de agresión corneal son fundamentales en su reparación, reponiendo las estructuras dañadas (Arffa y Grayson, 1998).

\subsubsection{Membrana de Descemet:}

Es una membrana basal verdadera, y su grosor aumenta con la edad, partiendo de $3 \mu \mathrm{m}$ en el recién nacido y llegando a medir entre 8 y $10 \mu \mathrm{m}$ en ancianos (Coster, 2002). Está compuesta por una zona estriada anterior, formada durante el periodo embrionario, una zona no estriada posterior, que es depositada por el endotelio corneal durante toda la vida y es más homogénea. En la membrana de Descemet encontramos colágeno tipo IV y VII así como laminina y fibronectina, aunque se han descrito hasta 5 tipos de colágeno en ella. La membrana está fuertemente adherida al estroma posterior y refleja cualquier cambio en la forma del estroma gracias a la capacidad de elasticidad y deformidad que le proporciona la alta densidad de colágeno. En la parte periférica, pueden aparecer engrosamientos localizados 
de la membrana de Descemet, denominados cuerpos de Hassall-Henle, que contienen restos celulares y otros depósitos de naturaleza desconocida relacionados con el envejecimiento del ojo. A diferencia de la capa de Bowman, la membrana de Descemet se desprende del estroma con facilidad y es capaz de regenerarse con rapidez tras una lesión cuando hay un desprendimiento localizado (Marcon y cols., 2002).

\subsubsection{Endotelio:}

El endotelio corneal está formado por una monocapa de células hexagonales originarias de la cresta neural que cubre la superficie posterior de la membrana de Descemet. En la periferia las células se vuelven más irregulares en tamaño y forma. La densidad celular en adultos jóvenes de 3500 células $/ \mathrm{mm}^{2}$. Las células endoteliales no se regeneran in vivo, pero son capaces de dividirse en medios de cultivo. La pérdida de células endoteliales resulta en el alargamiento y extensión de las células vecinas para cubrir el defecto (Sutphin, 2007). A medida que crece el tamaño celular disminuye su función.

Las células endoteliales tienen núcleos grandes y abundantes orgánulos, destacando las mitocondrias, lo que implica una alta actividad metabólica. Estas células se interdigitan y poseen muchas uniones intercelulares formando una barrera al flujo de iones y agua del humor acuoso, sin embargo van a permitir el paso de pequeñas moléculas y electrolitos entre ellas (Krachmer, 2011). El endotelio es una barrera débil 
pero la difusión a través del mismo es igual a la función de bomba endotelial, lo que permite una hidratación corneal constante de un $78 \%$.

Ante la pérdida de células endoteliales se produce una entrada de agua en el estroma alterando la estructura de las fibras de colágeno y produciendo opacidad corneal, y si el edema llega a localizarse debajo del epitelio aparecerán microbullas y microquistes. Se produce un edema irreversible con población celular endotelial menor de 500 células $/ \mathrm{mm}^{2}$. En el endotelio corneal encontramos sistemas de transporte iónico (transporte activo de bicarbonato y de $\mathrm{Na}^{+}$y $\mathrm{K}^{+}$) que catalizan el paso de iones hacia el humor acuoso, creando un gradiente osmótico que favorece el paso de agua de estroma a humor acuoso. Esto define la segunda función endotelial que es la actuar como bomba, manteniendo a la córnea parcialmente deshidratada (Civis, 2007a). La baja temperatura inhibe el metabolismo endotelial produciendo edema corneal que se restaura a la temperatura fisiológica.

\subsection{PAQUIMETRÍA CORNEAL}

Entendemos por paquimetría a la medida del espesor corneal en cualquiera de sus localizaciones. La paquimetría se ve alterada por patología a nivel endotelial, estromal y epitelial, por tanto es necesario conocerla a la hora del diagnóstico y seguimiento de alteraciones corneales como ectasias o edema corneal primario o secundario a cirugía. También se utiliza en pacientes con hipertensión ocular y glaucoma puesto que el espesor corneal afecta a la medida de la presión intraocular, 
y es fundamental a la hora de seleccionar pacientes para cirugía refractiva y para el seguimiento postoperatorio de los mismos (López-Miguel y cols., 2012).

Las técnicas disponibles para medir el espesor corneal pueden requerir o no el contacto corneal, lo que va a servir para la clasificación de los métodos de paquimetría.

\subsubsection{PAQUIMETRÍA DE CONTACTO}

\subsubsection{Paquimetría Ultrasónica:}

Se considera el patrón oro ("gold standard") para la estimación del grosor corneal central y es la técnica más utilizada clásicamente, puesto que se considera un método fiable y válido (Ishibazawa y cols., 2011). El paquímetro ultrasónico emite una onda de $20 \mathrm{MHz}$ y esta onda atraviesa la córnea, se refleja en la interfase endotelio-humor acuoso y vuelve al terminal del paquímetro. Esta reflexión de la onda se digitaliza y se genera una medida paquimétrica. Dicha medida es solo relativamente exacta, ya que el lugar exacto de la reflexión ultrasónica en la parte posterior de la córnea se desconoce.

El método de obtención de la medida supone una de sus principales desventajas puesto que la sonda requiere contacto con la córnea, lo que implica la instilación previa de colirio anestésico en el paciente con el consecuente malestar ocular, y además el contacto aumenta el riesgo de infección y de daño epitelial. El paquímetro ofrece un valor promedio de las 
medidas realizadas, y la exactitud de esta medida va a depender de la perpendicularidad con la que la sonda se coloca en la córnea, mientras que la reproducibilidad dependerá en gran medida de la colocación correcta de la sonda en el centro corneal (Kawana y cols., 2004).

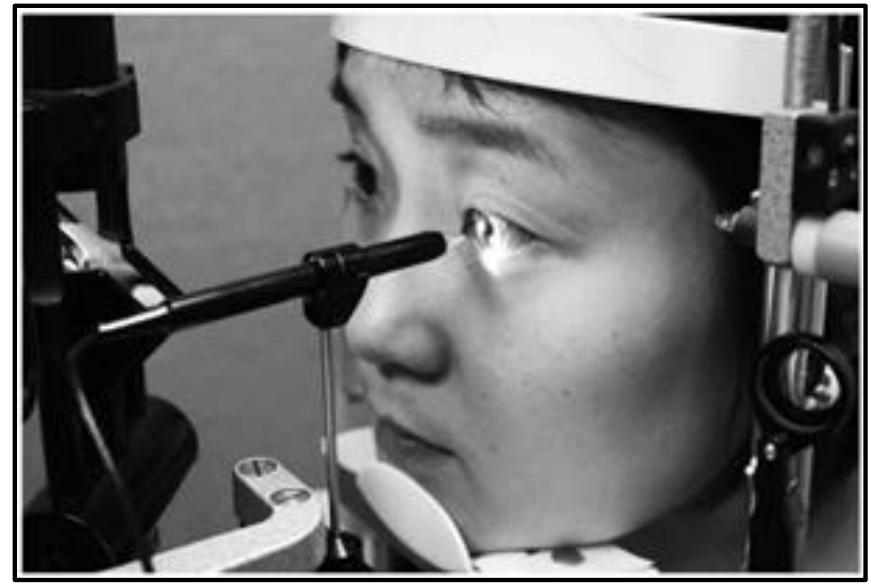

Figura 6: Paquimetría ultrasónica adaptada a lámpara de hendidura (Hong y cols., 2012).

\subsubsection{Biomicroscopía Ultrasónica:}

La biomicroscopía ultrasónica (BMU) es una ecografía de segmento anterior de alta resolución. Los ultrasonidos se emiten a $50 \mathrm{MHz}$ lo que va a proporcionar gran detalle de estructuras de segmento anterior como córnea, cámara anterior, iris, cristalino, cuerpo ciliar y espacios retrolentales y retroiridianos. La sonda realiza un movimiento lineal oscilatorio que posibilita la emisión de multitud de ultrasonidos que posteriormente se digitalizan y dan lugar a una imagen de alta resolución. La BMU es una 
técnica de inmersión por lo que requiere un medio, que puede ser acuoso o gel, entre el transductor y la superficie ocular. El paciente debe permanecer en decúbito supino, lo que nuevamente puede generar molestias en el paciente (Rio-Cristobal y Martin, 2014).

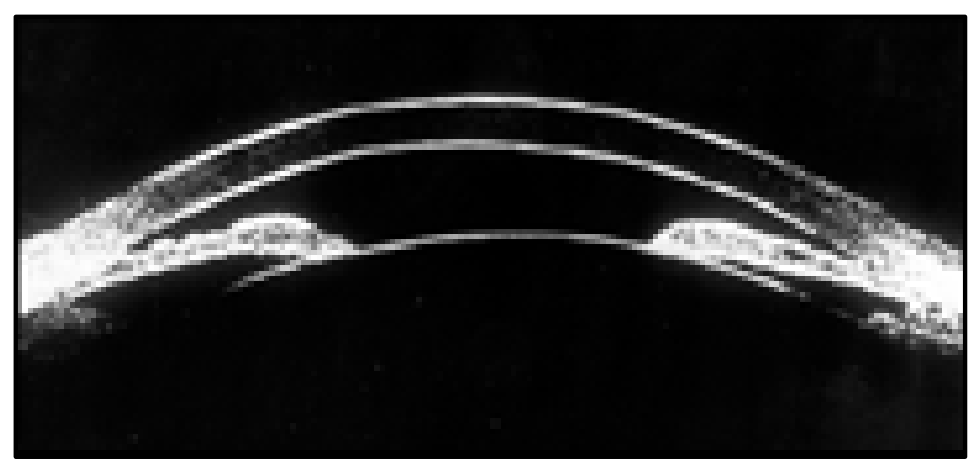

Figura 7: BMU de segmento anterior (Breingan y cols, 1999).

\subsubsection{PAQUIMETRÍA DE NO CONTACTO}

\subsubsection{Paquimetría Óptica:}

La paquimetría óptica se utiliza para conocer la profundidad de cámara anterior o el grosor corneal, lo que resulta muy útil en el estudio y diagnóstico del glaucoma. El paquímetro de Haag-Streit (Haag-Streit, Bern, Suiza) es uno de los más utilizados en la práctica clínica diaria ya que puede ser adaptado a la lámpara de hendidura (en este caso la Haag-Streit 900). Presenta dos opciones, la I, que se emplea para medir el espesor corneal, y la II, que mide anchuras de hasta $6 \mathrm{~mm}$ y se utiliza para medir 
profundidad de cámara anterior incluyendo o no el grosor corneal (Bourne y Alsbirk, 2006).

El paquímetro se une a la lámpara con una desviación de $40^{\circ}$ en la iluminación de la hendidura. La imagen que se obtiene se duplica mediante un biprisma situado delante de los objetivos del microscopio, y al hacer coincidir la doble imagen gracias al desplazamiento de uno de los espejos, obtenemos la medida real del espesor corneal que se lee en el instrumento.

Las ventajas que aporta son su sencillez y su bajo precio con respecto a otros paquímetros, además de la posibilidad de medir casi cualquier zona de la córnea.

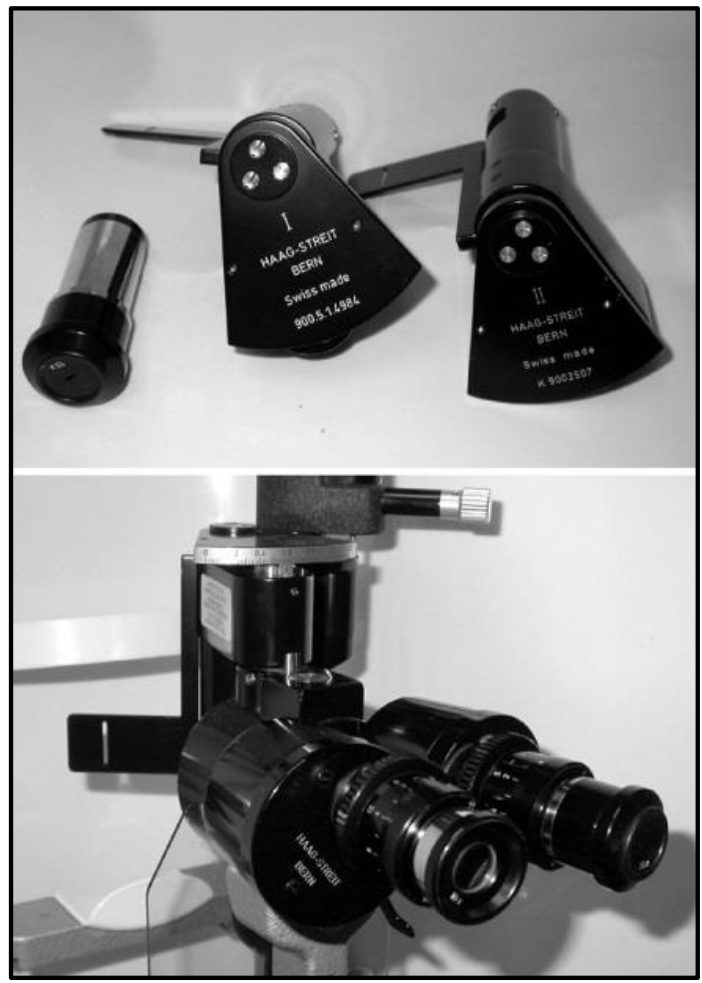

Figura 8: Paquímetro óptico Haag Streit acoplado a lámpara de hendidura Haag Streit 900 (Bourne y cols, 2006) 


\subsubsection{Tomografía de Coherencia Óptica:}

La tomografía de coherencia óptica (Optical Coherence Tomography: OCT) es un método de exploración no invasivo y de no contacto que proporciona imágenes transversales de alta resolución. La primera OCT de retina fue realizada en 1989 por David Huang y James Fujimoto (1991), que analizaron muestras de retina y de arterias coronarias ex vivo mediante OCT, consiguiendo resoluciones de $15 \mu \mathrm{m}$.

I. Principios de la tecnología OCT. El funcionamiento de la OCT es análogo al de la ecografía. Se basa en la medición de la latencia e intensidad de la onda reflejada tras hacer incidir una determinada onda sobre un tejido. La principal diferencia entre ambas es que la ecografía utiliza ultrasonidos y la OCT radiación luminosa. Esto implica una mayor velocidad de las ondas lumínicas y permite representar una imagen en dos dimensiones de una alta resolución espacial. Conforme la radiación penetra en profundidad en un tejido, se obtiene un registro axial de las variaciones que sufre dicha radiación; este registro se conoce como A-scan. Si obtenemos múltiples A-scans desplazando el haz incidente sobre el tejido, se consigue un corte transversal que se denomina B-scan. Del mismo modo, la obtención de varios B-scans en paralelo genera un cubo tridimensional que 
contiene toda la información en profundidad del tejido analizado (Losada y cols., 2011).

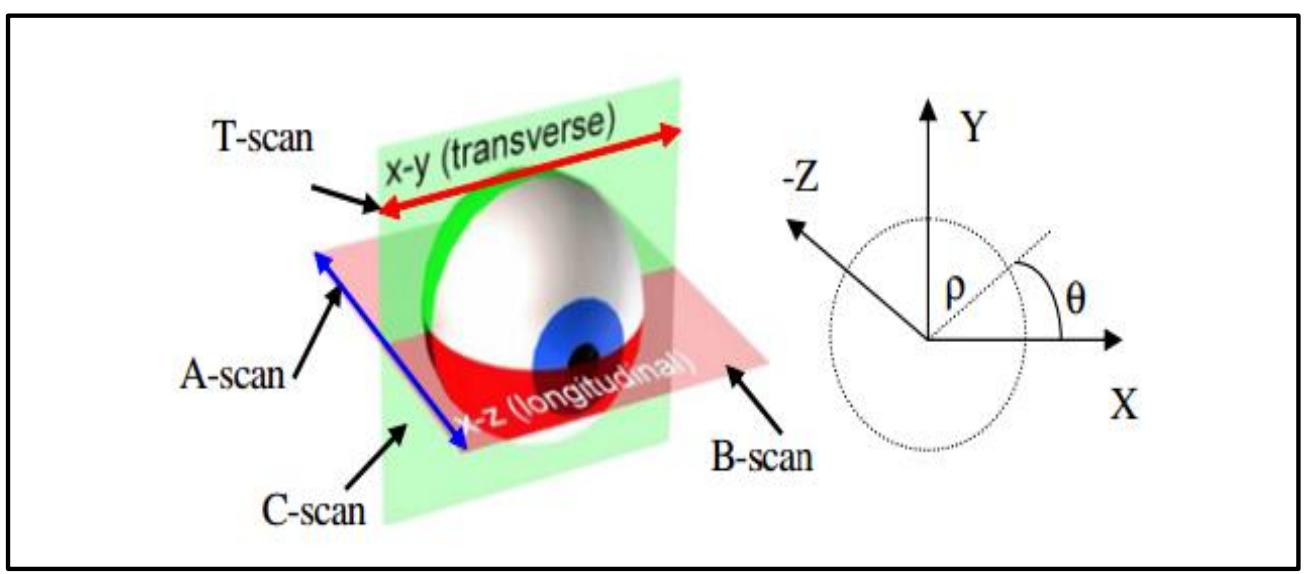

Figura 9: Orientación relativa del scan axial (A-scan), scan transversal (T-scan), longitudinal (B-scan) y corte transversal (C-scan). (Podoleanu y cols., 2008).

La OCT se basa en la interferometría de baja coherencia de Michelson, de tal forma que compara un rayo de referencia respecto del reflejado del tejido ocular (Maldonado y cols., 2000). Esta técnica consiste en la emisión de un rayo que es dividido en dos, uno que atraviesa las diferentes estructuras anatómicas y otro que se refleja en un espejo de referencia. Existe un detector capaz de analizar las diferencias entre ambos rayos reflejados tras recombinarse entre sí, y de traducir la información en términos de distancia y de dispersión, por lo que el tejido se puede caracterizar con mucha precisión (Fujimoto y cols., 1995). El OCT por tanto va a medir el retraso del tiempo de la reflexión luminosa y la intensidad de la reflectividad. Cada tejido tiene diferentes propiedades de reflectividad y el OCT las mide y las representa mediante escala de colores o grises en la pantalla. De este modo, las 
estructuras con una gran reflexión bloquean la transmisión de luz y se representan en rojo o blanco, mientras que las de media reflectividad se representan en verde y amarillo o gris, y en negro o azul las de baja reflectividad (Losada y cols., 2011).

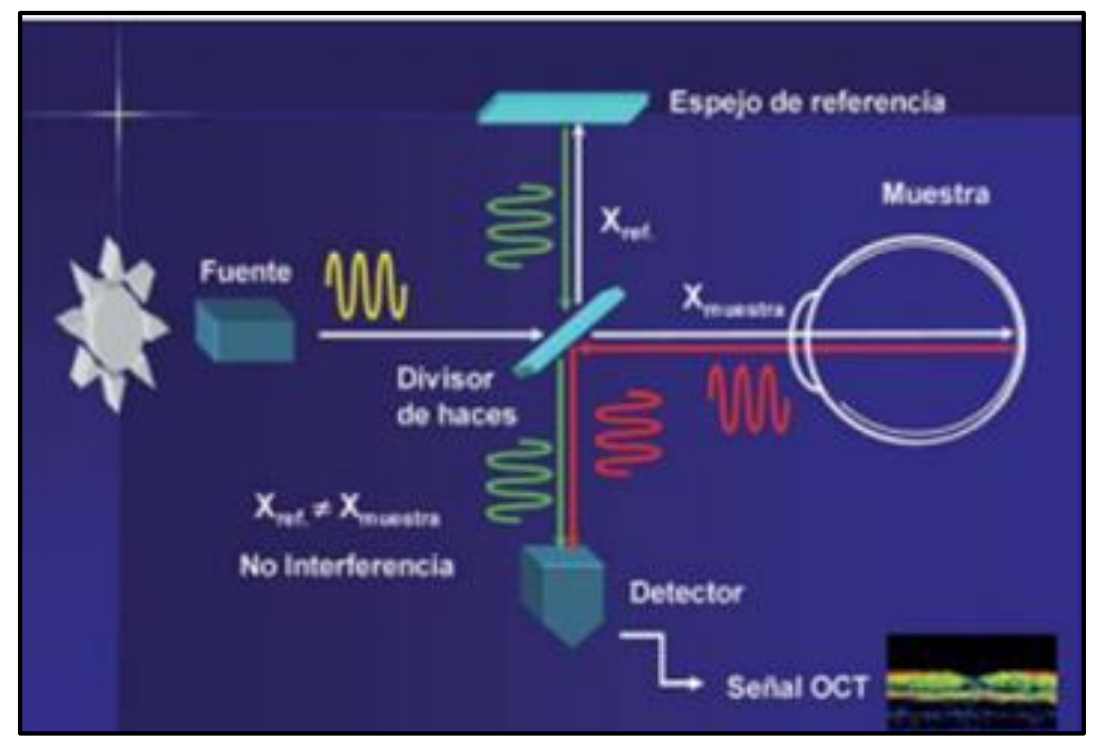

Figura 10: Interferómetro de Michelson aplicado a OCT (Losada y cols., 2011).

II. Dispositivos comerciales de OCT.

A. OCT de Dominio Temporal (Time Domain, TD-OCT):

Las primeras versiones TD-OCT se denominaron OCT1 y OCT2, y la más conocida fue el OCT III o Stratus (Zeiss Meditec). En este dispositivo, el espejo de referencia del interferómetro se mueve de modo que coincida con el retraso que sufre la señal de la muestra en las distintas capas retinianas, es decir, el sistema compara el retraso de la luz reflejada desde la retina con el retraso del haz 
proyectado desde el espejo de referencia a una distancia conocida, y al combinar ambos haces de luz, se produce una interferencia que es detectada y medida por un fotodetector usando interferometría de baja coherencia. Los A-scans (distancia de los ecos) se determinan modificando la posición del espejo de referencia, produciendo un perfil de reflectividad. En cada barrido axial, el espejo debe moverse un ciclo completo, a una velocidad de 400 barridos por segundo, lo que limita la velocidad de obtención de imágenes (Losada y cols., 2011; Ramos y cols., 2009).

B. OCT de Dominio Espectral (Spectral Domain, SD-OCT):

También llamado de dominio de Fourier (FD-OCT). En el SD-OCT el espejo de referencia se mantiene fijo por lo que, ante la ausencia de elementos mecánicos, se optimiza la velocidad de captación de imágenes. La señal de OCT se detecta modificando la longitud de onda de la fuente de luz aplicando el modelo matemático Fourier. La velocidad de captación de imágenes es de 18.000 a 40.000 A-scans por segundo, a diferencia de los 512 A-scans en 1.3 segundos del Stratus, y además reduce así los artefactos por el movimiento involuntario del ojo, permitiendo un mayor muestreo del tejido. Por otro lado, el SD-OCT permite la obtención de imágenes tridimensionales frente a las bidimiensionales del TD-OCT, que realiza 6 cortes transversales radiales y estima las áreas restantes mediante interpolación (Sakata y cols., 2009). 
La resolución es la mínima distancia a la que dos puntos próximos distintos se identifican como diferentes. La resolución axial, que depende de las propiedades de la luz utilizada, en el TD-OCT es de $10 \mu \mathrm{m}$ y en el SD-OCT de $5 \mu \mathrm{m}$. La resolución transversal, que depende de la anchura del haz incidente y por tanto de la calidad de los medios ópticos, es de $20 \mu \mathrm{m}$ en el TD-OCT y de entre 12 y $20 \mu \mathrm{m}$ en el SD-OCT. Se están comenzando a integrar óptica adaptativa en los sistemas OCT (Adaptive Optics OCT), que corrige aberraciones oculares mejorando aún más la resolución transversal (Hermann y cols., 2004).

Poco a poco se han introducido mejoras en el SD-OCT, como el Enhaced Depth Imaging OCT: EDI-OCT que permite la visualización de estructuras más profundas como la coroides (Wong y cols., 2011). Los sistemas de alta penetrancia (Swept Source OCT: SS-OCT ) utilizan longitudes de onda más altas y por tanto la visualización de tejidos profundos es de muy alta calidad, puesto que a mayor longitud de onda, menor dispersión del reflejo producido por el epitelio pigmentario de la retina (Hamzah y cols., 2014). Tanto el SDOCT como el SS-OCT ofrecen excelente visualización de la interfaz coroidoescleral cuando utilizan EDI (Waldstein y cols., 2015). 


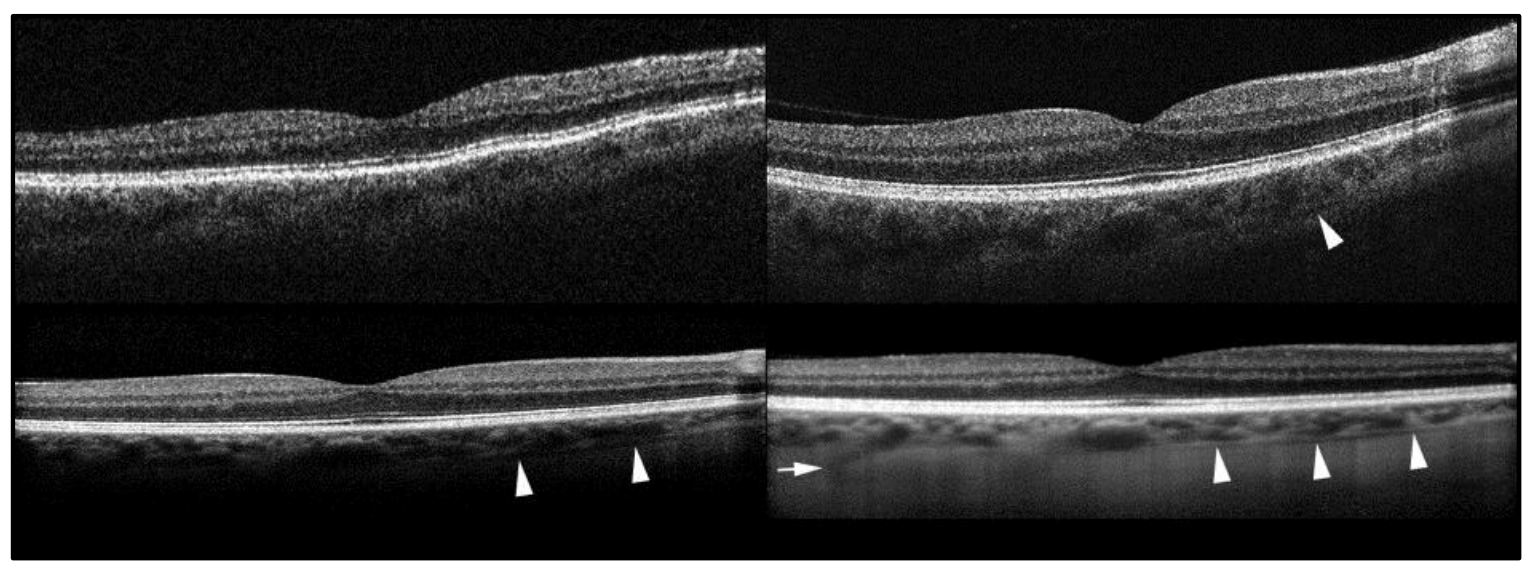

Figura 11: Comparación de la misma imagen con distintos tipos de OCT. Stratus OCT con menor resolución de la coroides (arriba izquierda); Cirrus HD-OCT, en el que se observa mayor detalle coroideo (arriba derecha); Spectralis, en el que observamos la línea hiporeflectante (abajo izquierda) y EDI-OCT, que permite clara visualización de espacio supracoroieo (abajo derecha) (Spaide y cols., 2009). 
Tabla 1: Características distintivas de dispositivos de Tomografía de Coherencia Óptica comercializados (Muñoz Negrete y cols., 2011).

\section{CARACTERÍSTICAS DE DISPOSITIVOS DE OCT COMERCIALIZADOS}

\begin{tabular}{|c|c|c|c|c|c|}
\hline Dispositivo & $\begin{array}{l}\text { Fabricante/ } \\
\text { Distribuidor }\end{array}$ & $\begin{array}{l}\text { Resolución } \\
\text { Axial } \\
(\mu \mathrm{m})\end{array}$ & $\begin{array}{c}\text { Resolución } \\
\text { Transversa } \\
(\mu \mathrm{m})\end{array}$ & $\begin{array}{l}\text { Velocidad } \\
\text { (A- } \\
\text { scan } / \text { seg) }\end{array}$ & $\begin{array}{l}\text { Características } \\
\text { adicionales }\end{array}$ \\
\hline OCT Stratus & Carl Zeiss Meditec & 10 & 20 & 400 & TD-OCT \\
\hline $\begin{array}{l}\text { CirruS } \quad H D- \\
\text { OCT }\end{array}$ & Carl Zeiss Meditec & 5 & 15 & 27.000 & $\begin{array}{l}\text { SD-OCT. Imagen SLO. } \\
\text { Segmentación MLI y EPR. } \\
\text { Módulo OCT-SA. GPA. } \\
\text { Imágenes-HD.TSNIT ANR }\end{array}$ \\
\hline RTVue OCT & OptoVue/OftalTech & 5 & 15 & 26.000 & $\begin{array}{l}\text { SD-OCT. Módulo SA. } \\
\text { Segmentación multiples } \\
\text { capas retina }\end{array}$ \\
\hline Spectralis & $\begin{array}{l}\text { Heidelberg } \\
\text { Eng/Bloss }\end{array}$ & $4-7$ & 14 & 40.000 & $\begin{array}{l}\text { SD-OCT. SLO alta } \\
\text { resolución. Eye tracking. } \\
\text { Sistema reducción ruido } \\
\text { Heidelberg. Imagen } \\
\text { infrarroja, módulo AFG, } \\
\text { ICG, autofluorescencia. } \\
\text { EDI }\end{array}$ \\
\hline $3 D$ OCT-1000 & Topcon & $5-6$ & 20 & 18.000 & $\begin{array}{l}\text { SD-OCT. Retinógrafo no } \\
\text { midriático ( } 3,1 \text { megapixels) }\end{array}$ \\
\hline $3 D$ OCT-2000 & Topcon & $5-6$ & 20 & 27.000 & $\begin{array}{l}\text { SD-OCT. Retinógrafo no } \\
\text { midriático } \\
\text { megapixels) Módulo SA. } \\
\text { Estereografía papila. }\end{array}$ \\
\hline $\begin{array}{l}3 D \text { OCT-2000 } \\
\text { FA plus }\end{array}$ & Topcon & 5 & 20 & 50.000 & $\begin{array}{lll}\text { SD-OCT. } & \text { AGF } & \text { y } \\
\text { autofluorescencia. } & \end{array}$ \\
\hline $\begin{array}{l}\text { SOCT } \\
\text { Copernicus } \\
\text { HR }\end{array}$ & Optopol/Canon/AJL & 3 & $12-18$ & 52.000 & \begin{tabular}{lr} 
SD-OCT. Doppler & vasos \\
retinianos. & Quistes \\
intrarretinianos. & Módulo \\
\multicolumn{2}{l}{ SA. DDLS glaucoma. }
\end{tabular} \\
\hline $\begin{array}{l}\text { SOCT } \\
\text { Copernicus + }\end{array}$ & Optopol/Canon/AJL & 5 & $12-18$ & 27.000 & \begin{tabular}{lr} 
SD-OCT. Doppler vasos \\
retinianos. & Quistes \\
intrarretinianos. & Módulo \\
\multicolumn{2}{l}{ SA. DDLS glaucoma }
\end{tabular} \\
\hline $\begin{array}{l}R S-3000 \text { OCT } \\
\text { RetinaScan }\end{array}$ & Nidek/Indo & 4 & 20 & 53.000 & $\begin{array}{l}\text { SD-OCT. SLO. Auto- } \\
\text { tracking. Medida complejo } \\
\text { céllas ganglionares. }\end{array}$ \\
\hline $\begin{array}{l}\text { Spectral OCT } \\
\text { and SLO }\end{array}$ & OTI/OPKO & 5 & 15 & 27.000 & $\begin{array}{l}\text { SD-OCT. microperimetría. } \\
\text { Lente adicional OCT-SA }\end{array}$ \\
\hline Bioptigen & Bioptigen & 4.5 & 10 & 20.000 & $\begin{array}{l}\text { SD-OCT. } \\
\text { flexiblerátil. Sonda } \\
\text { animal. Flujo Dopplestigación } \\
\text { Inver. }\end{array}$ \\
\hline
\end{tabular}

TD: Time domain. HD: High definition. SD: Spectral Domain. SLO: Scanning laser ophtalmoscope. MLI: membrana limitante interna. DDLS: Disk damage likely scale. EDI: Enhanced depth imaging(visualización estructuras posteriores). EPR: Epitelio pimentario de la retina. OCT-SA: Tomografía de coherencia óptica de segmento 
anterior. GPA: Glaucoma progression analysis. TSNIT: Temporal-superior-nasal-inferior-temporal. ANR: Anillo neurorretiniano. AGF: Angiofluoresecingrafía. ICG: Verde indocianina

Tabla 2: Características distintivas de dispositivos de Tomografía de Coherencia Óptica comercializados exclusivos de segmento anterior (Muñoz Negrete y cols., 2011).

\section{CARACTERÍSTICAS DE DISPOSITIVOS DE OCT EXCLUSIVOS DE SEGMENTO ANTERIOR}

\begin{tabular}{|c|c|c|c|c|c|}
\hline Dispositivo & Fabricante & $\begin{array}{c}\text { Resolución } \\
\text { Axial } \\
(\mu \mathrm{m})\end{array}$ & $\begin{array}{c}\text { Resolución } \\
\text { Transversa } \\
(\mu \mathrm{m})\end{array}$ & $\begin{array}{c}\text { Velocidad } \\
\text { (A- } \\
\text { scan/seg) }\end{array}$ & $\begin{array}{l}\text { Características } \\
\text { adicionales }\end{array}$ \\
\hline $\begin{array}{l}\text { Visante } \quad S A- \\
\text { OCT }\end{array}$ & Carl Zeiss Meditec & 18 & 60 & 2000 & $\begin{array}{l}\text { Exclusivo } \\
\text { anterior }\end{array}$ \\
\hline Slit-Lamp OCT & Heidelberg & 25 & 75 & 200 & $\begin{array}{l}\text { OCT-SA adaptado } \\
\text { lámpara de hendidura }\end{array}$ \\
\hline $\begin{array}{l}\text { CASSIA SS } \\
1000\end{array}$ & TOMEY/AJL & 10 & 30 & 30.000 & $\begin{array}{l}\text { SA. Plano corte } 16 \times 16 \\
\mathrm{~mm} \text {, profundidad } 6 \mathrm{~mm}\end{array}$ \\
\hline
\end{tabular}

OCT-SA: Tomografía de coherencia óptica de segmento anterior. SS: Swept source.

III. Aplicaciones médicas de la OCT. La aplicación inicial del OCT fue en el ámbito de la oftalmología en el estudio de la retina y sus enfermedades, como agujero macular, edema, coriorretinopatía serosa central, degeneración macular asociada a la edad o membrana epirretiniana, pero también se ha desarrollado posteriormente para el diagnóstico y monitorización del glaucoma con el análisis de la capa de fibras nerviosas de la retina (CFNR), del edema macular quístico en pacientes diabéticos y de patología coroidea (Morcillo, 2011).

El uso del módulo de segmento anterior (OCT-SA) permite el estudio de la córnea así como la medida de estructuras como la 
cámara anterior, ángulo iridocorneal o grosor del cristalino entre otras (Rio-Cristobal y Martin, 2014). La OCT-SA obtiene imágenes de una resolución mucho mayor a otras técnicas como la biomicroscopía ultrasónica (BMU). Se necesita un haz de luz de una longitud de onda mayor que para el análisis de retina (1310 nm frente a $830 \mathrm{~nm})$.

El primer estudio clínico utilizando la primitiva tecnología del OCT-I para medir la microestructura de la córnea lo llevaron a cabo Maldonado y cols. (2000). La medida de la córnea se obtenía separando el ojo a examen para que coincidiera con la distancia focal habitual de la retina.

La tecnología OCT tiene aplicaciones en otros ámbitos de la medicina como en el estudio de arterias coronarias ya que puede adaptarse a catéteres, endoscopios y microscopios (Fujimoto y James, 2001), lo que le hace útil en intervenciones oculares tanto de segmento anterior como de polo posterior. En este aspecto, también se puede usar un dispositivo portátil e incluso se ha descrito el uso de una sonda intraocular (Muñoz Negrete y cols., 2011).

IV. Cirrus HD-OCT. Cirrus HD-OCT (Carl Zeiss Meditec, Inc., Dublin, California, EEUU) es un OCT de exploración de segmento posterior y patología vitreorretiniana con un módulo de análisis de segmento anterior. 
Con tecnología "Fourier domain", tiene una velocidad de 27.000 Ascans por segundo, una resolución axial de $5 \mu \mathrm{m}$ y una resolución transversal de $15 \mu \mathrm{m}$ (Correa-Pérez y cols., 2012), es decir, proporciona imágenes de alta definición.

Como valores de referencia, el Cirrus HD-OCT presenta una base de datos compuesta por valores obtenidos en sujetos normales, que va a permitir la comparación de forma cuantitativa de la capa de fibras nerviosas de la retina y de la mácula.

Los algoritmos de procesamiento de la imagen del OCT permiten al aparato la detección automática de los límites internos y externos de la retina neurosensorial para así realizar mediciones; este tipo de análisis se denomina segmentación (Ruiz Casas y cols., 2011). Puesto que Stratus OCT y Cirrus HD-OCT presentan distinto algoritmo de segmentación, las medidas de ambos no son intercambiables, esto hace que el sistema Cirrus HD-OCT siempre haga medidas de 43-61 $\mu \mathrm{m}$ de grosor retiniano mayores que el dispositivo Stratus OCT (Ruiz Casas y cols., 2011). 


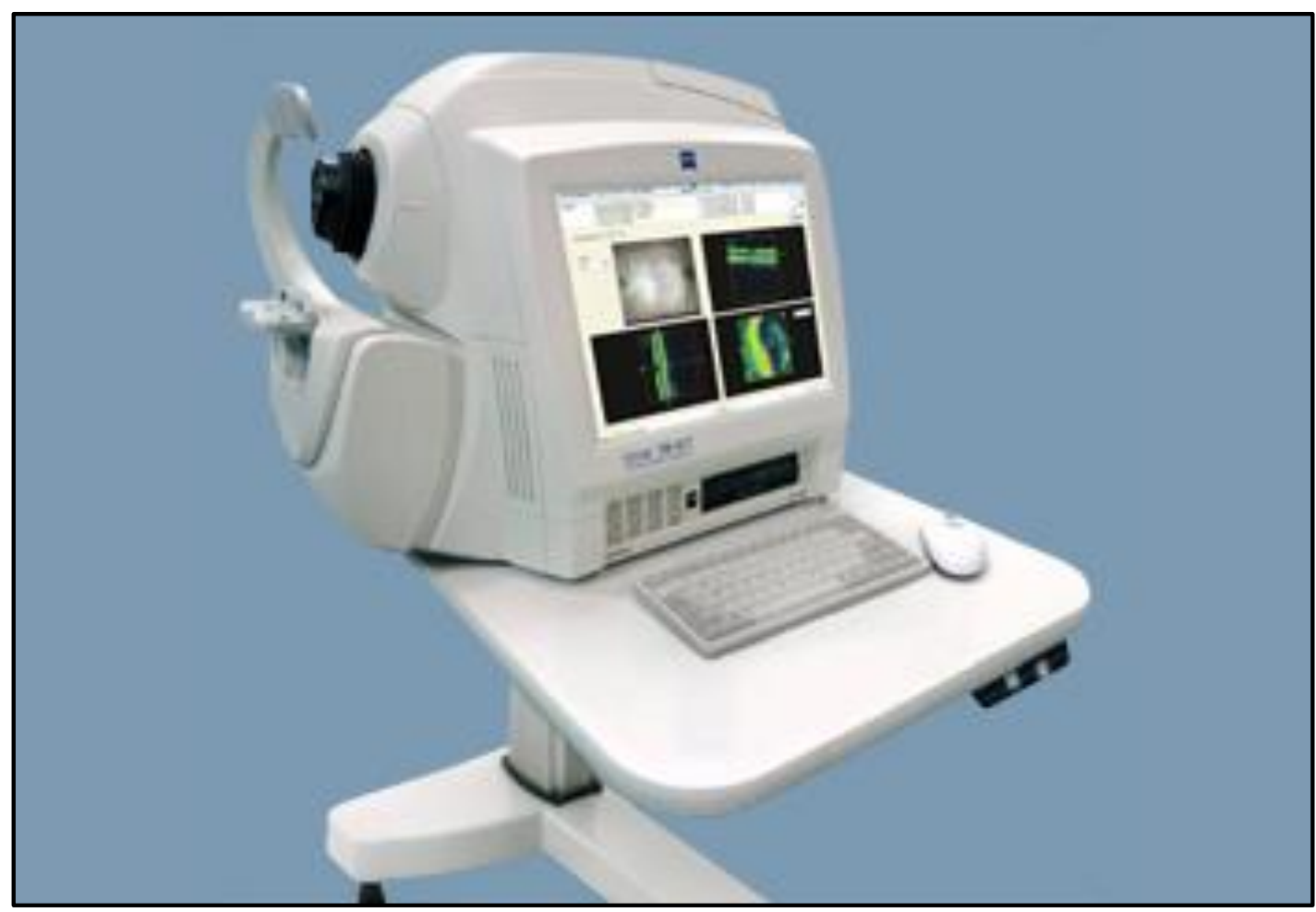

Figura 12: Dispositivo Cirrus HD-OCT de dominio espectral (Carl Zeiss Meditec, 2007).

Los protocolos de adquisición de imágenes son (Ruiz Casas y cols., 2011):

- "Macular Cube 512 x 128". Analiza un área de 6 × 6 mm y se obtiene una imagen de 128 líneas o B-scans compuestas por 512 A-scans cada una, excepto las líneas centrales horizontal y vertical que miden 1.024 A-scans cada una. Permite analizar espesor macular, visualización en 3D y la comparación manual o automática con antiguas imágenes.

- "Macular Cube 200 x 200". Analiza un área de 6 × 6 mm y se obtiene una imagen de 200 B-scans de 200 A-scans cada una salvo las líneas centrales vertical y horizontal que son de 
100 A-scans cada una. Tiene las mismas aplicaciones que la anterior.

- “Optic Disc Cube 200 x 200". Escanea un área de 6 × 6 mm y captura un cubo $200 \times 200$ barridos, es decir 40.000 puntos en 1.5 segundos. Se identifica automáticamente el centro de la papila y se crea un barrido artificial en modo $B$ que contiene 256 A-scans. Permite medir el espesor de la capa de fibras nerviosas de la retina y su desviación de los valores promedios, además de aportar datos por cuadrantes y sectores horarios.

- "5 line raster". Se escanean 5 líneas paralelas de la misma longitud compuestas de 4.096 A-scans cada una.

Principalmente, el Cirrus HD-OCT se utiliza para el análisis de estructuras de polo posterior pero, cambiando el foco del haz del OCT gracias a su módulo de segmento anterior, es posible también el análisis de estructuras más anteriores. Para el análisis de segmento anterior se utilizan dos protocolos de escaneo (Carl Zeiss Meditec, 2007):

- "Anterior Segment Cube 512 x 128". Se genera un cubo de 4 $\mathrm{mm}$ de lado y se obtienen 128 barridos horizontales compuesto cada uno de 512 A-scans.

- "Anterior Segment HD 5 Line Raster". La exploración se realiza mediante 5 líneas paralelas de la misma longitud (3 mm) compuestas de 4.096 A-scans cada una. Las líneas 
están separadas por $0.25 \mathrm{~mm}$ cada una de modo que abarcan un ancho de $1 \mathrm{~mm}$. Permite obtener imágenes de alta resolución de córnea y ángulo iridocorneal.

A diferencia de las imágenes obtenidas de polo posterior, las imágenes de polo anterior no presentan valores automáticos, y tendrá que realizarse la medida de manera manual (Correa-Pérez y cols., 2012).

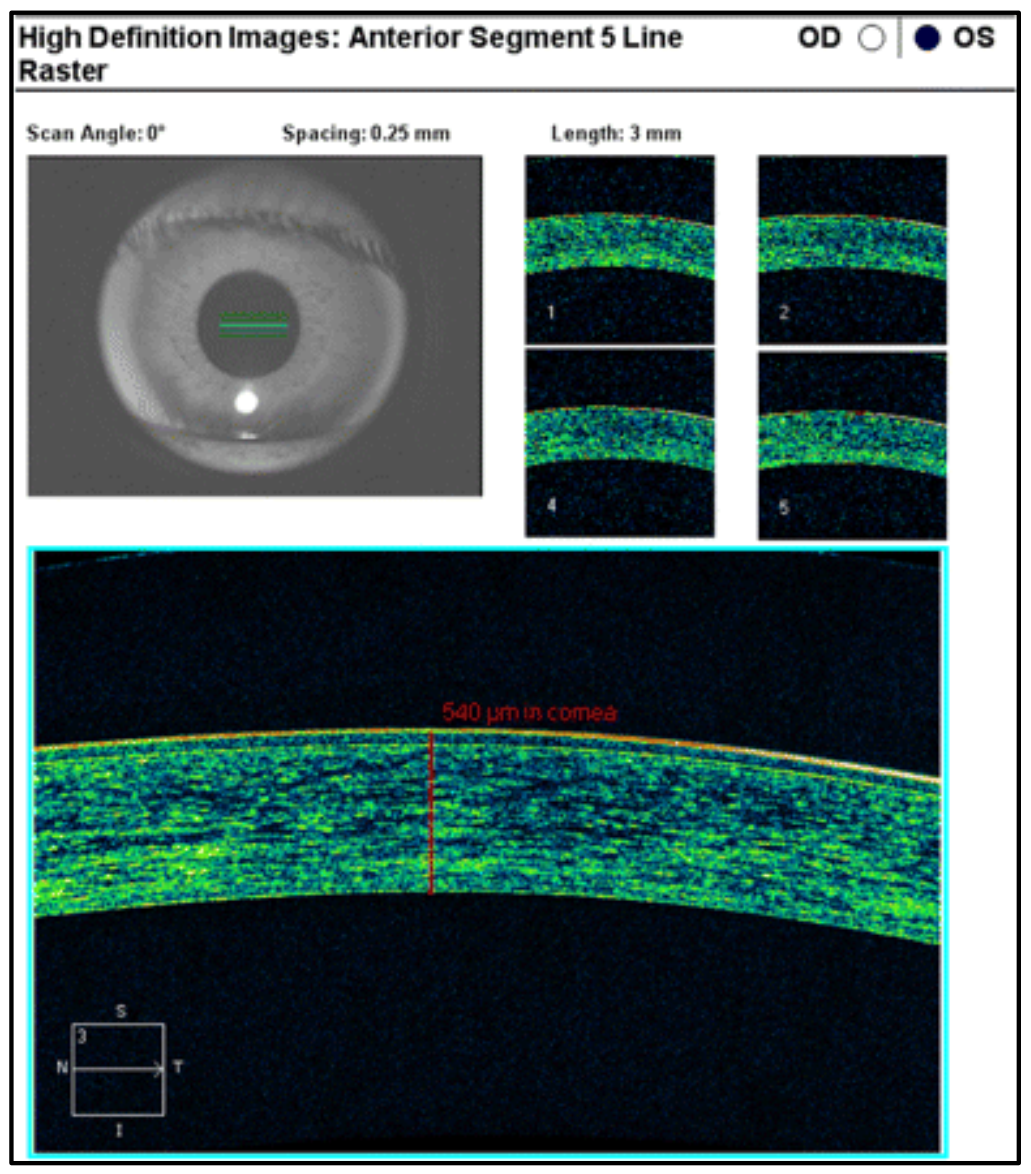

Figura 13: Ejemplo de medida de espesor corneal central mediante el módulo "Anterior Segment HD 5 line raster" de Cirrus HD-OCT (Correa-Pérez y cols, 2012). 


\subsubsection{Reflectometría Óptica de Baja Coherencia:}

Del inglés "Optical Low Coherence Reflectometry" (OLCR), se basa en el principio de interferometría de Michelson del mismo modo que el OCT, y utiliza un diodo super-luminiscente que produce una fuente de luz de $820 \mathrm{~nm}$ de longitud de onda. Sus propiedades ópticas se basan en la anchura de la fuente de luz, que mide entre 20 y $30 \mathrm{~nm}$, lo que permite a la técnica poseer una longitud de coherencia baja dando lugar a una resolución de aproximadamente $30 \mu \mathrm{m}$ (Cruysberg y cols., 2010). El sistema Lenstar LS 900 (Haag-Streit AG, Bern, Suiza), basado en esta técnica de adquisición, aporta información de la paquimetría corneal, profundidad de la cámara anterior y de la longitud axial (López-Miguel y cols., 2012).

\subsubsection{Fotografía Rotacional de Scheimpflug:}

Esta técnica utiliza una cámara rotatoria que emite una luz LED azul de $475 \mathrm{~nm}$ para la adquisición de imágenes de segmento anterior (Oliveira y cols., 2011). Proporciona no solo mapas de elevación corneal anterior y posterior sino también datos paquimétricos, topográficos, queratométricos o radios de curvatura entre otros (Rio-Cristobal y Martin, 2014).

El sistema Pentacam HR (Oculus Optikgeräte, Wetzlar, Alemania) se basa en esta técnica y es capaz de tomar más de 100 imágenes de segmento anterior en menos de 2 segundos. Extrae 500 puntos de elevación de cada una de estas imágenes, obteniendo 140.000 puntos verdaderos de elevación tanto de la superficie corneal anterior como posterior. Estas imágenes de alta 
resolución se reconstruyen tridimensionalmente y el software genera diferentes parámetros (Rio-Cristobal y Martin, 2014).

El dispositivo Sirius (Construzione Strumenti Oftalmici, Florencia, Italia) combina discos de Plácido y cámara de Scheimpflug y utiliza luz monocromática azul de $475 \mathrm{~nm}$ y rotación de la cámara 360ํjunto con 22 anillos para el estudio de la superficie corneal anterior y posterior.

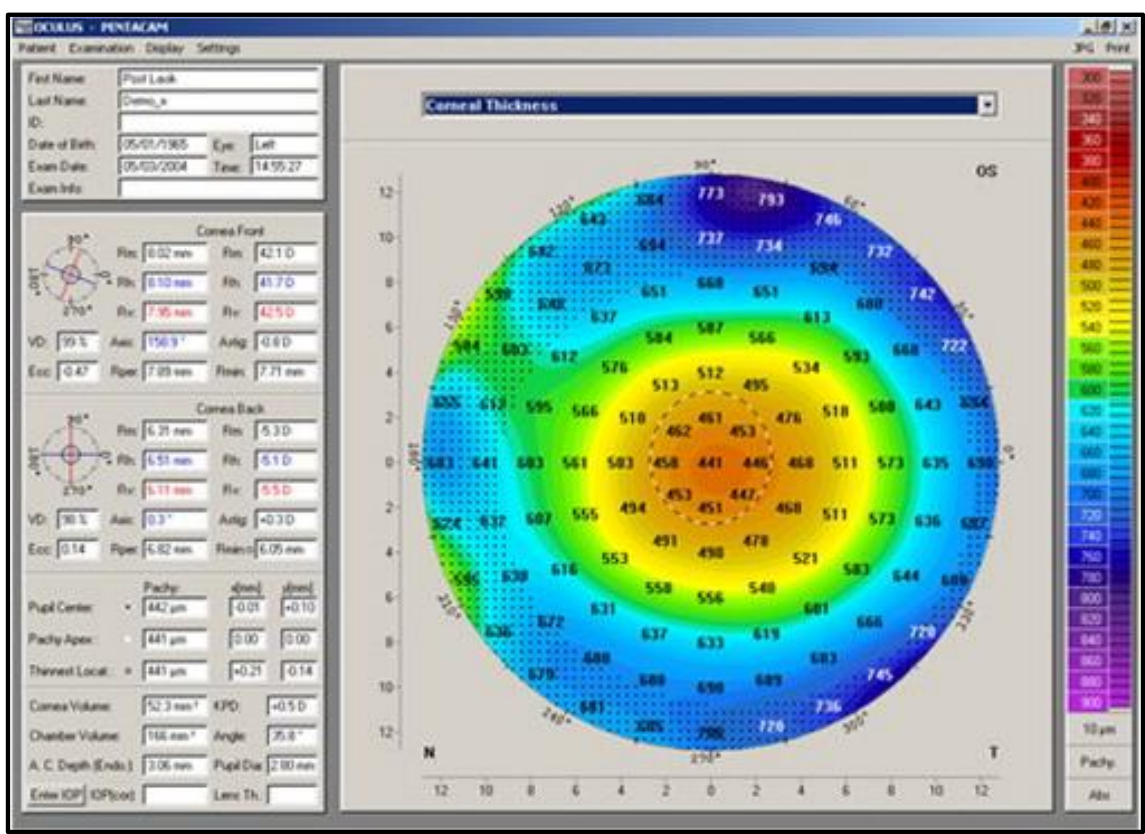

Figura 14: Valores paquimétricos proporcionados por el sistema Pentacam (Oculus) (Río- Cristobal y Martin, 2014).

El dispositivo Galilei (Ziemer Ophthalmic System AG, Zurich, Suiza) combina una doble cámara rotacional de Scheimpflug con topografía basada en discos de Plácido, que proporciona imágenes simultáneas y combinadas de ambos sistemas, aportando medidas de superficie corneal anterior y posterior, de cámara anterior y de cristalino. Tiene un sistema que compensa 
el descentramiento de la imagen debido al movimiento ocular ("eye-tracking") (Oliveira y cols., 2011).

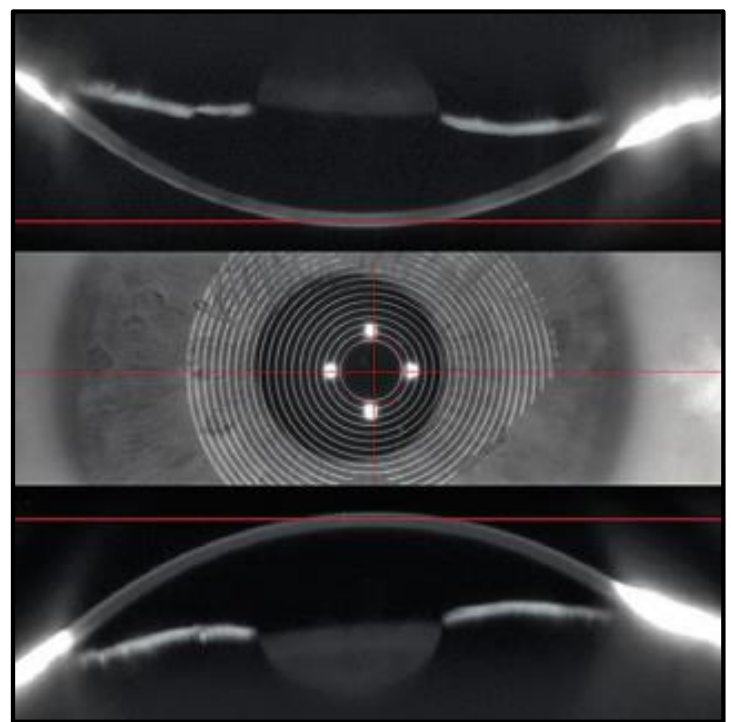

Figura 15: El dispositivo Gailei (Ziemer) utiliza simultáneamente una doble cámara Scheimpflug y discos de Plácido (Oliveira y cols, 2011).

\subsubsection{Microscopía Especular:}

La microscopía especular es una técnica que permite evaluar la características endoteliales in vivo y aporta información sobre la paquimetría corneal. A través de la proyección de una luz en forma de sección óptica se puede cuantificar la distancia entre el rayo reflejado por la cara anterior y posterior de la córnea, dando lugar al grosor corneal (McCarey y cols., 2008).

\subsubsection{Topografía de Barrido de Hendidura:}


Esta técnica, que ha caído en desuso, se basa en la proyección de 40 haces ópticos sobre la cámara anterior con una angulación de 45 grados. Tras atravesar la córnea, se produce una reflexión de los haces de luz sobre la cámara anterior y posterior, y posteriormente dicha proyección de haces es grabada y digitalizada para la reconstrucción tridimensional de la cámara anterior (Cairns y McGhee, 2005).

Como representante de esta técnica encontramos el Orbscan II (Bausch \& Lomb, Rochester, Nueva York, EEUU), que es un tomógrafo y topógrafo que combina escaneo por hendidura de la córnea con tecnología de discos de Plácido. El espesor corneal se calcula a partir de los datos proporcionados por mapas de elevación anterior y posterior (Cairns y McGhee, 2005). Su fiabilidad disminuye cuando existe pérdida de trasparencia corneal.

\subsection{TOPOGRAFÍA CORNEAL}

La topografía corneal se utiliza para la caracterización de la córnea, la determinación de aberraciones corneales, la adaptación de lentes de contacto y para la planificación de cirugía refractiva, aunque en este último caso es más útil en combinación con la tomografía corneal. La necesidad de realizar una adecuada selección de los pacientes candidatos a cirugía refractiva y la aparición de alteraciones corneales secundarias a este tipo de cirugía, hacen que se requieran instrumentos muy fiables y de alta precisión a la hora de caracterizar la potencia y la forma de la córnea (Maldonado-López y Nieto-Fernández, 2007). 
Los dispositivos precursores de la moderna topografía comienzan con el queratómetro, que permite estudiar la córnea central, es decir, sólo un $6 \%$ de la superficie corneal. Fue descrito por primera vez en 1854 por von Helmholtz. Su habilidad para medir cuantitativamente los radios de curvatura corneal se basa en el comportamiento de espejo convexo de la superficie corneal anterior reflejando la luz. En esto radica uno de sus principales inconvenientes, el asumir que la córnea es esférica. Los dispositivos modernos convierten los radios corneales en dioptrías y viceversa (Belin y Khachikian, 2009).

El queratoscopio es un método que evalúa cualitativamente la luz o la imagen reflejada por la superficie corneal. Descrito también en el siglo XIX, el queratoscopio se basa en la proyección de una pantalla iluminada cuyo reflejo en la superficie corneal es observado por el explorador a través de un orificio situado en el centro de esa pantalla que incorpora una lente convergente. Esto permite evaluar un $60 \%$ del área corneal total y analizar la regularidad corneal cualitativamente (Belin y Khachikian, 2009). La luz proyectada procede de una linterna o de un disco de Plácido. 


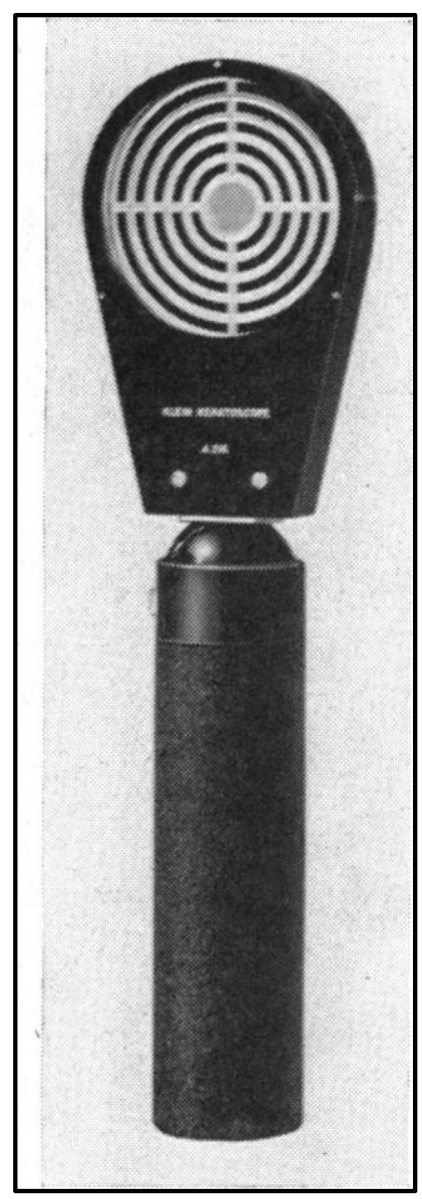

Figura 16: Imagen del primer queratoscopio con luz incorporada descrito por el Dr. Klein en 1957. (Klein, 1958).

Los llamados discos de Plácido son una serie de anillos concéntricos alternos blancos y negros, que se reflejan en la córnea, revelando anormalidades corneales como astigmatismo o queratocono en caso de distorsión de los anillos. Los datos de curvatura se obtienen a partir de las medidas entre los anillos. Sin embargo, este método proporciona limitada información cuantitativa de la córnea. Con la introducción de cámaras fotográficas surgieron los fotoqueratoscopios.

En la década de los 80, el doctor Klyce publicó un trabajo en el que describía la topografía corneal computerizada, también denominada videoqueratoscopía, que 
surgía para solucionar las carencias de sus precursores, proporcionando representaciones gráficas de la córnea acompañadas de datos cuantitativos (Klyce, 1984). Estos dispositivos son capaces de digitalizar la información de miles de puntos de la superficie corneal para producir mapas corneales (Belin y Khachikian, 2009). Los círculos concéntricos obtenidos por reflexión en la córnea son digitalizados creando puntos individuales medibles. El dispositivo determina la posición de cada punto y el software mide la distancia del centro corneal a cada punto de los círculos, y mediante algoritmos axiales o tangenciales se calcula la distancia axial y la curvatura. Posteriormente el software recompone las mediciones de curvatura y los miles de puntos generando mapas topográficos.

\subsubsection{CARACTERIZACIÓN TOPOGRÁFICA}

\subsubsection{Mapas:}

Las anomalías en la integridad corneal o los defectos de regularidad van a restar fiabilidad a la topografía y van a producir alteraciones en los mapas. Es necesaria una película lagrimal uniforme, un correcto posicionamiento de los párpados y un adecuado enfoque de la imagen para obtener un mapa topográfico fiable (Maldonado-López y Nieto-Fernández, 2007).

I. Mapas de Curvatura. Realizan una aproximación a la potencia corneal, expresada en dioptrías, a partir de los valores de 
curvatura de la superficie corneal anterior. Asume un índice de refracción corneal constante, lo que le resta exactitud.

A. Mapa Axial:

Basado en la distancia axial, considera la córnea como una superficie esférica, ya que asume que todos los centros de los radios de curvatura se sitúan sobre el eje óptico, por lo que no es fiable en la periferia corneal. Posee una alta repetibilidad.

B. Mapa Tangencial:

No asume que todos los centros de los radios de curvatura se sitúan sobre el eje óptico, de modo que sí facilita el valor real del radio de curvatura de cada localización y aporta información de posibles pequeños cambios locales.

II. Mapas de Elevación. Pueden ser de cara anterior y posterior de la córnea y cuantifican la elevación o la profundidad de un defecto corneal. Aproximan la superficie corneal a una esfera de referencia y permiten la reconstrucción en mapas paquimétricos (Belin y Khachikian, 2009). Aportan información que puede quedar oculta en un mapa de curvatura, puesto que variaciones mínimas en la elevación corneal pueden ser ópticamente significativas (Tanabe y cols., 2002).

III. Mapas Refractivos. Mediante la aplicación de la "Ley de Snell", aportan información sobre la potencia refractiva de la superficie 
corneal. Proporciona valores reales y es muy útil en la evaluación de la calidad óptica teniendo en cuenta el área corneal central.

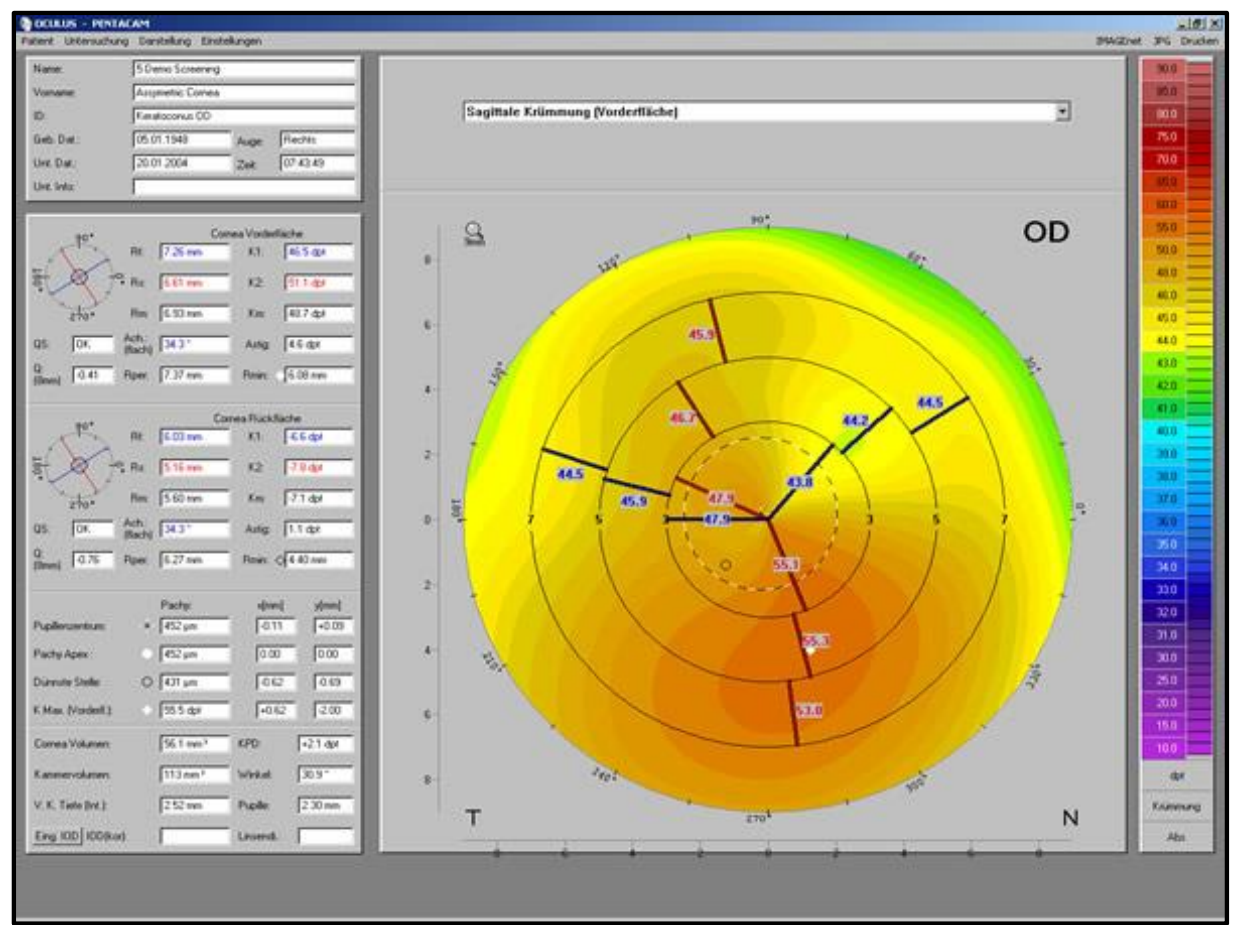

Figura 17: Mapa topográfico aportado por el dispositivo Oculus Pentacam (Oculus Optikgeräte, Wetzlar, Alemania).

\subsubsection{Escalas:}

Se basan en la asignación de mapas de color a diferentes valores de poder dióptrico corneal. Por tanto, la codificación de los puntos analizados se realiza en colores cálidos para los radios menores, es decir de mayor potencia, y en colores fríos para los radios mayores, es decir, de menor potencia. 
I. Escala Absoluta. Se asignan unos colores a un valor máximo y a un valor mínimo de medida con independencia del rango que se abarque en una exploración determinada. Esto implica la asignación de los mismos colores a valores dióptricos que son muy distantes. Permite comparación de topografías de distintos pacientes.

II. Escala Relativa. Atribuye como valor máximo de curvatura medida al que se corresponde con el área más curva y como valor mínimo a aquel más plano del caso examinado. Se utiliza para valorar independientemente a un paciente.

III. Escala Ajustable. Existe total libertad para el examinador a la hora de seleccionar los límites de la medida y el escalado dióptrico. No es comparable con otros mapas.

IV. Escala Uniforme. El dispositivo utiliza la información dióptrica de cada mapa seleccionado y escoge los límites de medida independientemente del rango. Además, realiza una sección del rango en intervalos dados, normalmente $\geq$ a $0.25 \mathrm{D}$. Hay autores que afirman que no se pierde información topográfica relevante cuando se utiliza un escalado de 1.5 D (Smolek y cols., 2002; Wilson y cols., 1993), sin embargo, los intervalos más cortos -de hasta $0.25 \mathrm{D}$ - son los recomendados para un diagnóstico más 
exhaustivo, evitando así los falsos negativos (Maldonado-López y Nieto-Fernández, 2007).

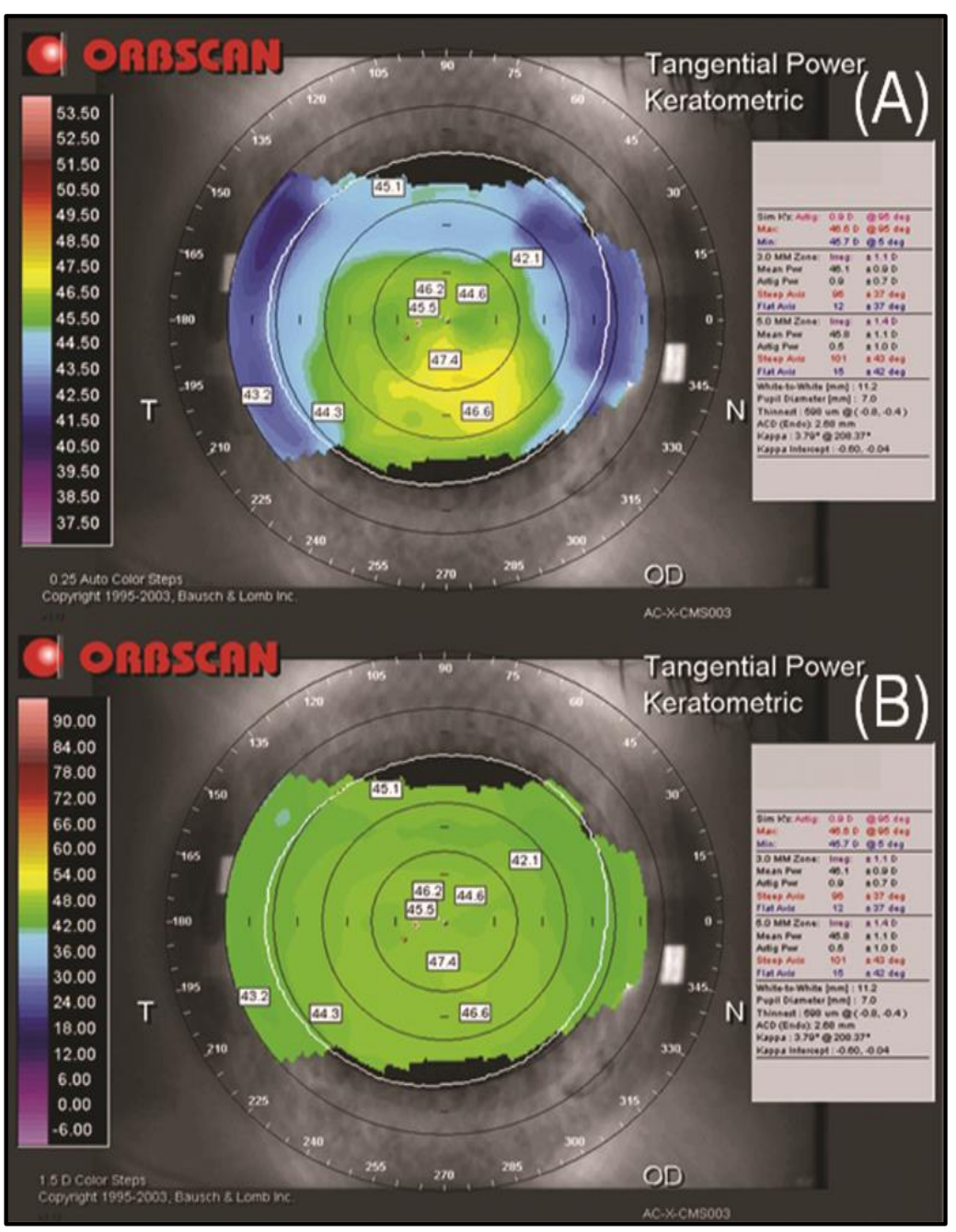

Figura 18: Diferencia entre mapa de escala relativa o autoescala (A) y absoluta (B) (Maldonado-López y Nieto-Fernández, 2007).

\subsubsection{Descriptores cuantitativos de la superficie corneal:}

I. Asfericidad corneal (Q). Se calcula a partir de algoritmos propios de los topógrafos y permiten definir la forma global de la 
superficie corneal anterior, analizando el cambio de curvatura desde el ápex corneal hasta la periferia. En aquellos casos en los que se da un aplanamiento desde el ápex a la periferia $(\mathrm{Q}$ negativa), que es en la mayoría de la población, hablaremos de elipse prolata, mientras que en los casos en los que la periferia es más curva que el ápex hablamos de superficie oblata $(Q$ positiva) (Davis y cols., 2005).

II. Excentricidad corneal (e). También describe la diferencia de curvatura entre el ápex corneal y la periferia mediante la cuantificación del aplanamiento. El valor medio para la población adulta es de 0.55 (superficie prolata) (Hansen, 2003). La fórmula que relaciona la asfericidad y la excentricidad es la siguiente: $Q=-e^{2}$

\subsubsection{SISTEMAS TOPOGRÁFICOS}

\subsubsection{Topografía de reflexión:}

Los sistemas de reflexión utilizan discos de Plácido que son proyectados sobre la córnea, y más concretamente sobre la película lagrimal. Los queratómetros, queratoscopios y videoqueratoscopios utilizan la película lagrimal como espejo convexo en el que se reflejan los discos de Plácido, mimetizando la forma de la superficie corneal. Miden la elevación corneal y la desviación de los anillos reflejados y a partir de ella calculan la curvatura y el 
poder refractivo de la superficie corneal anterior, es decir, no son datos reales sino indirectos. Los radios de curvatura obtenidos se utilizan para crear un mapa por aposición de los radios en el plano, por lo que el mapa obtenido es bidimensional (Garzón y Poyales, 2007). Se debe tener en cuenta que las técnicas de reflexión amplifican las distorsiones topográficas corneales.

Entre sus limitaciones destacamos la obtención de información a partir de la película lagrimal, la ausencia de información de la superficie corneal posterior, la alta sensibilidad al desenfoque y alineamiento, y que la exploración corneal no es completa sino que se evalúan los 8-9 mm centrales (Belin y Khachikian, 2009). Además, presenta una menor precisión a la hora de evaluar superficies irregulares (Roberts, 1994), presenta datos de excesivo aplanamiento, no puede detectar transiciones corneales sutiles presentando poca precisión en la periferia (Belin y Ratliff, 1996).

El topógrafo CTK 922 (Haag-Streit, USA) utiliza este sistema, con anillos de Plácido dispuestos en una hemiesfera. Consta de un sistema de 22 anillos de Plácido en un hemisferio y 22.000 puntos de medida para lograr máxima resolución. Proporciona reconstrucciones tridimensionales de la córnea y además dispone de un programa de adaptación de lentes de contacto (Belin y Khachikian, 2009). 


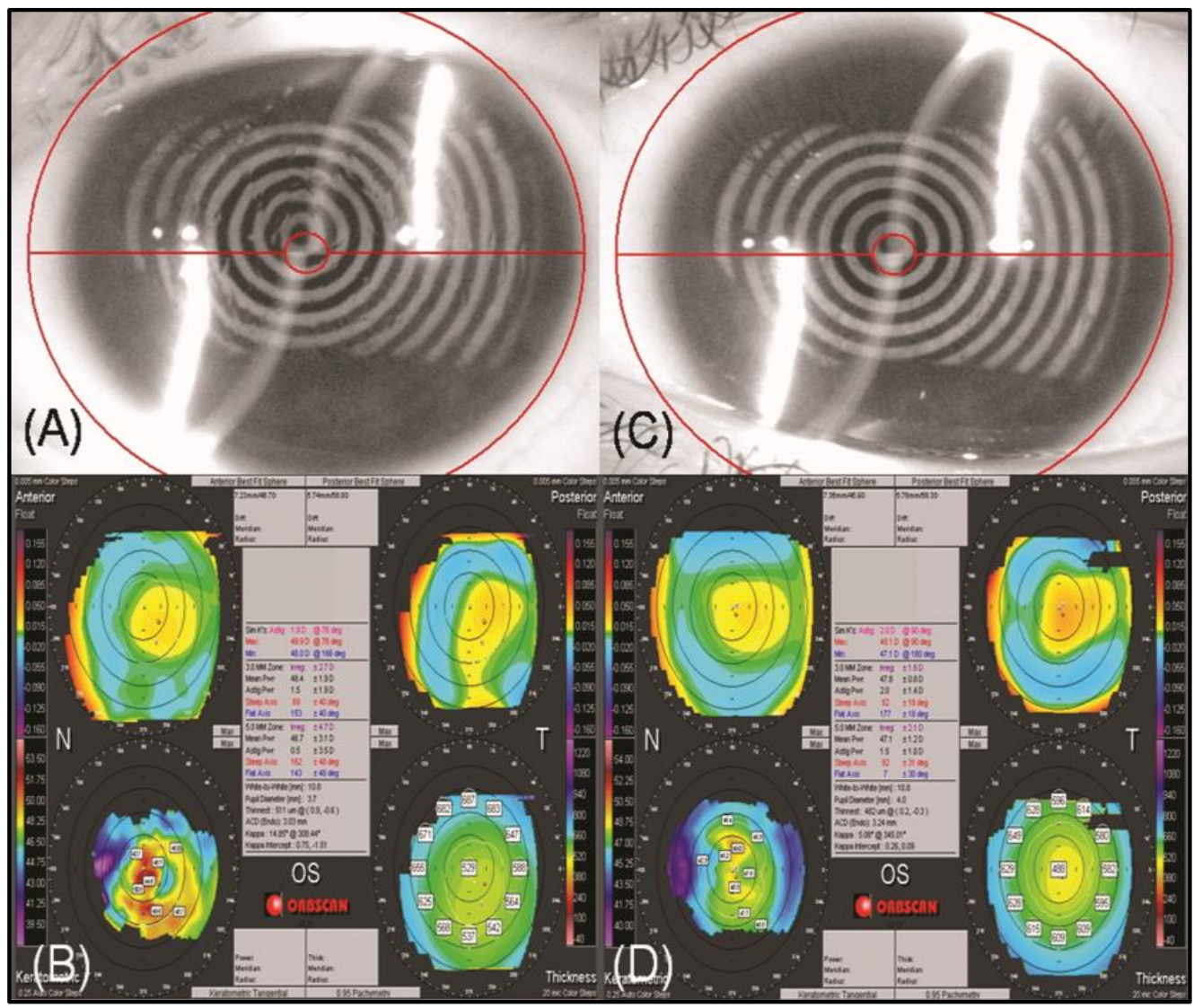

Figura 19: Diferencia entre topografía regular e irregular por alteración película

lagrimal. A: Aspecto de irregularidad que presentan los discos de Plácido al proyectarse sobre una película lagrimal donde se ha roto la capa lipídica. B: Aspecto que presentan los discos de Plácido inmediatamente después de aplicar lágrima artificial sin conservantes al paciente anterior. C: Mismo paciente de la imagen anterior. La topografía presenta claras irregularidades en el mapa de curvatura debido a la falta de homogeneidad de la película lagrimal. D: Misma topografía obtenida sin enfocar el instrumento en el momento de la adquisición. (Maldonado-López y Nieto-Fernández, 2007). 


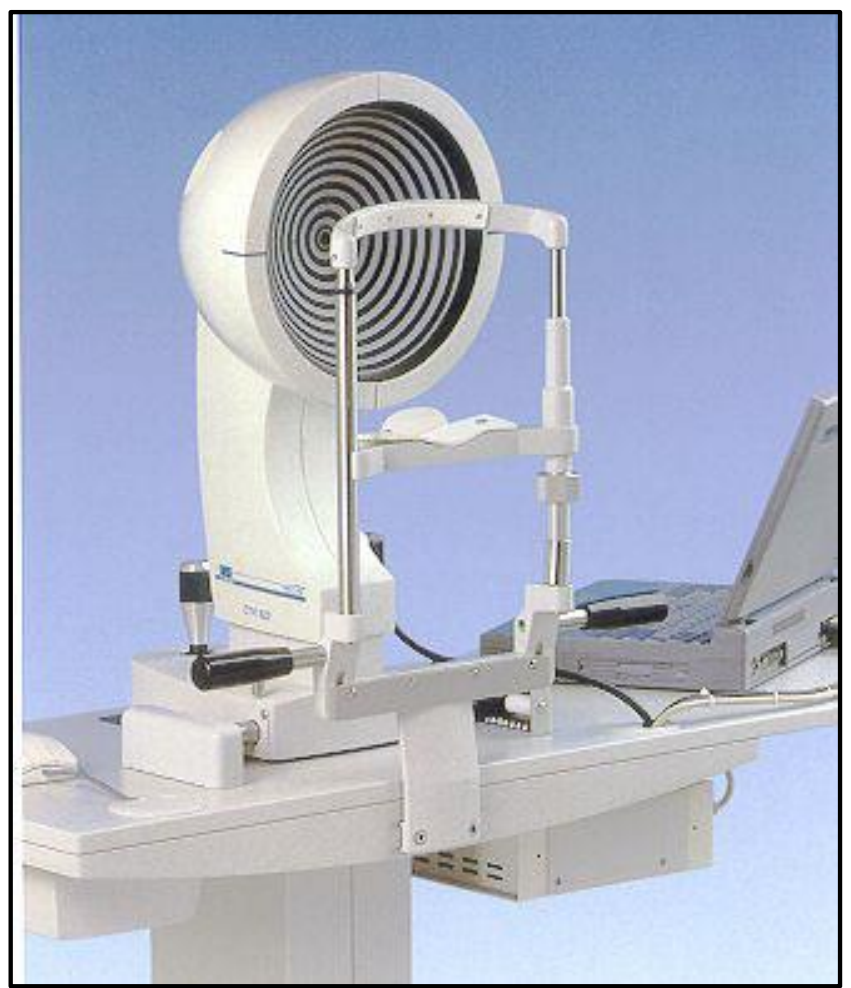

Figura 20: Queratógrafo CTK 922 (Haag Streit USA AG International).

\subsubsection{Topografía de Proyección:}

Los sistemas basados en la proyección o elevación calculan la forma de la córnea transformándola en puntos de altura a partir de los cuales se puede obtener la curvatura y la potencia corneal. Supera las limitaciones de la topografía especular o de reflexión puesto que permite obtener información de la superficie corneal posterior así como la obtención de datos paquimétricos.

Mientras que la técnica basada en discos de Plácido obtiene datos de elevación a partir de logaritmos, los sistemas basados en barrido de hendidura, fotografía rotacional de Scheimpflug y la rasterestereografía permiten la adquisición directa de esta información, obteniendo las 
coordenadas espaciales de múltiples puntos de la superficie corneal anterior y posterior (Gatinel y cols., 2011).

El topógrafo Pentacam (Oculus Optikgeräte, Wetzlar, Alemania), del que se han detallado los aspectos técnicos en el apartado 1.3.2.4., utiliza la fotografía rotacional de Scheimpflug. Los datos de elevación obtenidos de estas imágenes se combinan para crear reconstrucciones tridimensionales de la córnea. Mediante un software, esta información se transforma en datos de frente de onda utilizando polinomios de Zernike (Piñero y cols., 2009).

El Pentacam, que fue el segundo dispositivo en proporcionar datos de superficie corneal posterior (Swartz y cols., 2007), tiene múltiples utilidades como son el estudio de la superficie corneal post-LASIK (Ciolino, Belin, 2006), el estudio de pacientes con ectasias corneales (Ambrósio y cols., 2006), incluso se ha estudiado la variabilidad de la asfericidad de la superficie corneal anterior y posterior en relación con la edad (Dubbelman y cols., 2006). 


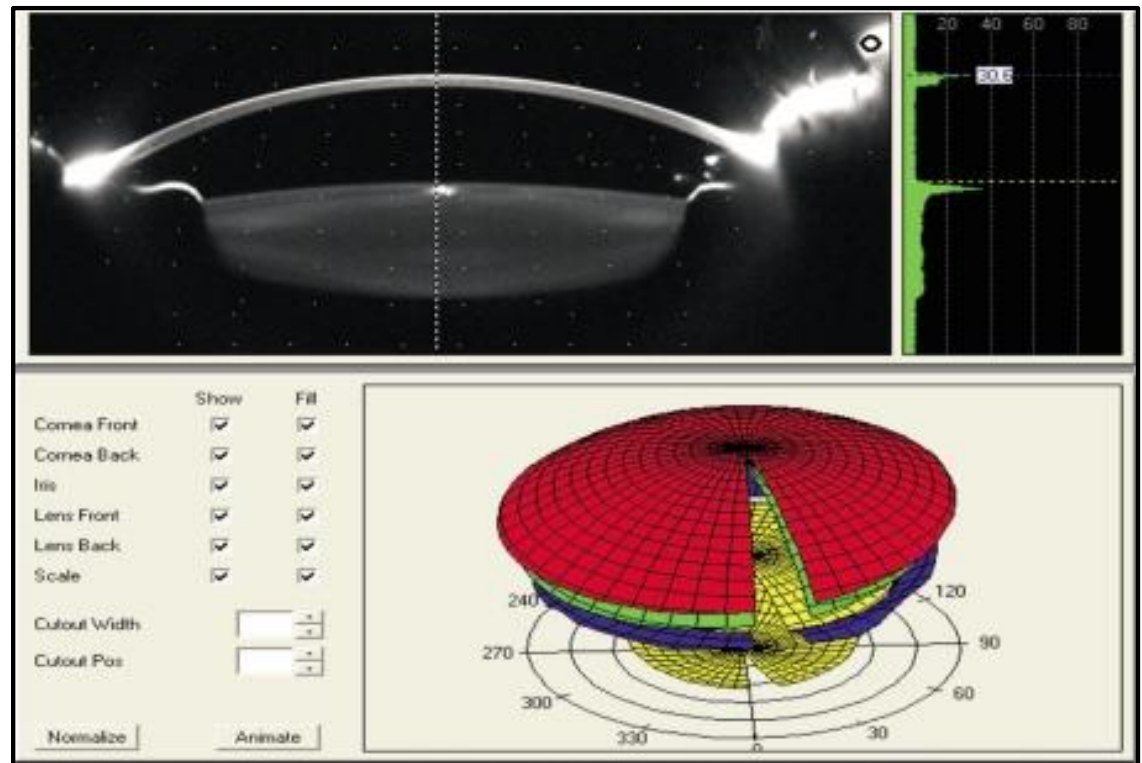

Figura 21: Imagen de la cámara de Scheimpflug del topógrafo Pentacam HR (Oculus) (Ni y cols, 2011).

\subsubsection{Topografía Combinada:}

Con topografía combinada nos referimos a aquellos dispositivos que utilizan distintas técnicas para obtener representaciones de la superficie corneal anterior y posterior y detectar irregularidades corneales.

El dispositivo Orbscan II (Bausch and Lomb, Rochester, Nueva York, EEUU) combina los discos de Plácido (topografía de reflexión) con el escaneo mediante lámpara de hendidura (topografía de proyección). El topógrafo proyecta los anillos de Plácido y realiza 40 imágenes, la mitad por cada haz de luz proyectado por la lámpara de hendidura, obteniendo 9.000 puntos en 1.5 segundos. Se basa en la reflexión difusa y la dispersión para conformar la superficie corneal anterior, y la superficie posterior se analiza tras producirse dispersión de la reflexión posterior (Garzón, Poyales, 2007). Así se obtienen mapas de curvatura y de elevación anterior y posterior (Cairns y McGhee, 
2005) y también se obtienen datos de profundidad de cámara anterior o análisis del tamaño pupilar en condiciones fotópicas (Garzón y Poyales, 2007). Por supuesto también resulta de utilidad en el estudio de la paquimetría en las distintas localizaciones (López-Miguel y cols., 2014) y de la curvatura corneal posterior tras cirugía sustractiva (Maldonado-López y cols., 2006).

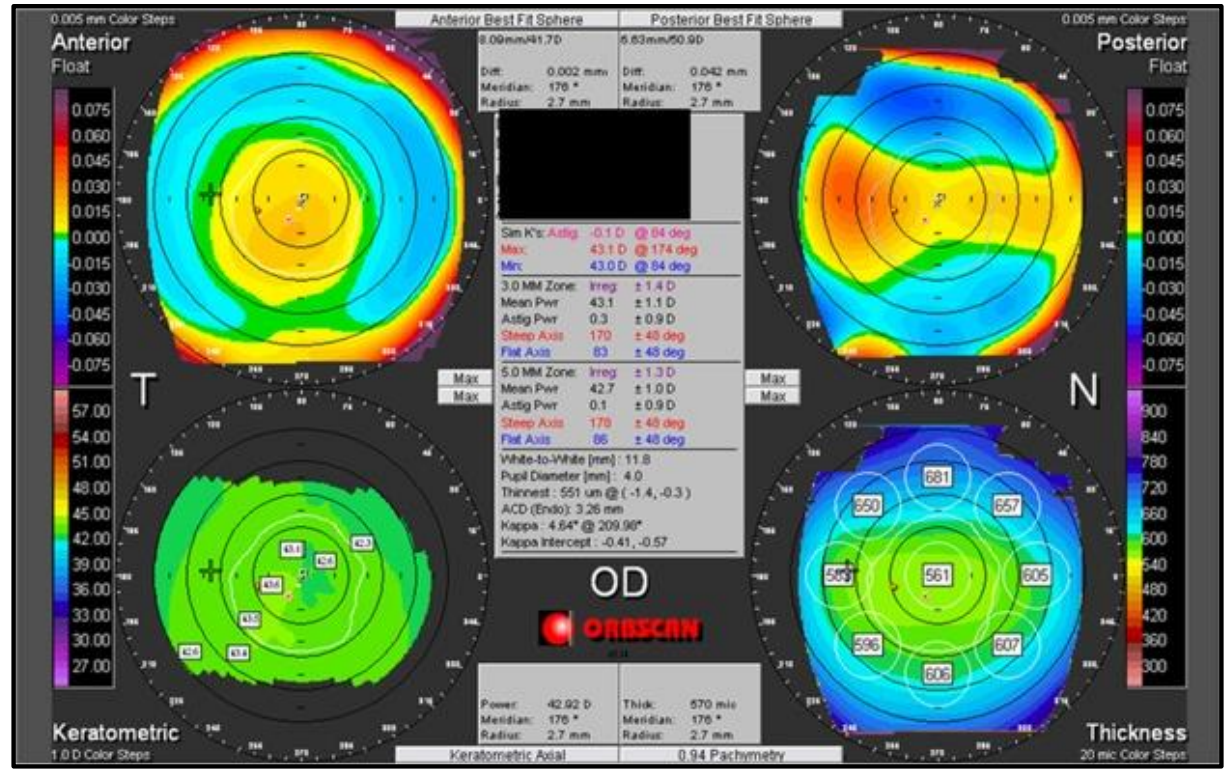

Figura 22: Superficie corneal anterior y posterior, queratometría y paquimetría proporcionadas por el dispositivo Orbscan II (Prakash y cols., 2012a).

El dispositivo Sirius (Construzione Strumenti Oftalmici, Florencia, Italia) consta de discos de Plácido y cámara de Scheimpflug. Utiliza luz monocromática azul de $475 \mathrm{~nm}$ y rotación de la cámara $360^{\circ}$ junto con 22 anillos para el estudio de la superficie corneal. Analiza 35.632 puntos de la superficie anterior y 30.000 de la posterior. Obtiene 25 cortes radiales de cámara anterior y córnea de los que se extraen datos de curvatura axial y tangencial, análisis de frente de onda, poder refractivo, paquimetría, valores 
biométricos como profundidad de cámara anterior, distancia blanco-blanco o grosor del cristalino entre otros (Chen y cols., 2012; Savini y cols., 2011a).

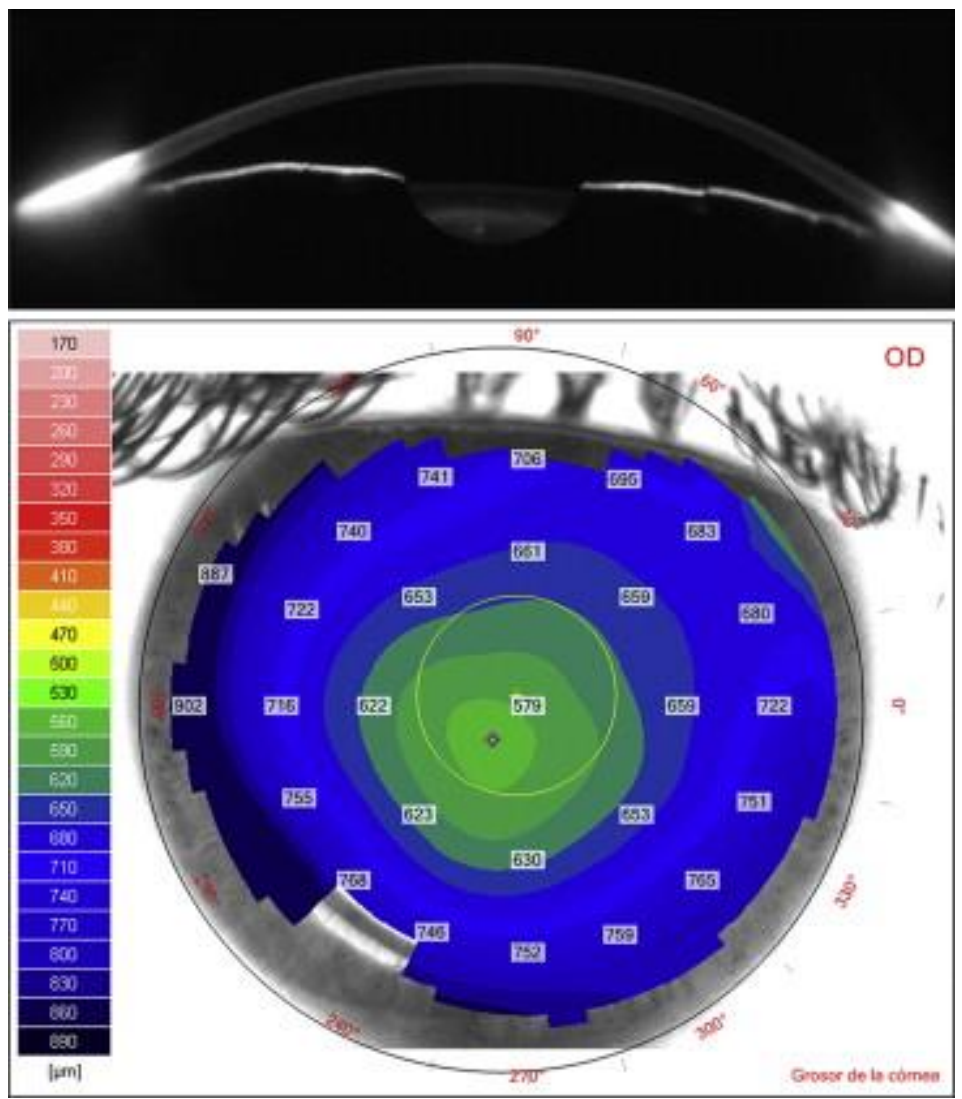

Figura 23: Fotografía de Scheimpflug y mapa paquímetrico obtenidos con el sistema Sirius. (Milla y cols., 2011).

El topógrafo Galilei (Ziemer Ophthalmic System AG, Zurich, Suiza) presenta como característica diferencial la incorporación de dos cámaras rotacionales de Scheimpflug ubicadas a $180^{\circ}$ la una de la otra asociadas a anillos de Plácido. Captura entre 30 y 60 imágenes y analiza 122.000 puntos del segmento anterior del ojo en un modelo tridimensional. El dispositivo adquiere una serie de imágenes Scheimpflug correspondientes a los 
meridianos y dos imágenes a partir de los anillos de Plácido a 90 grados de diferencia. Los datos de altura se obtienen de las imágenes Scheimpflug y los datos de pendiente de las imágenes de Plácido se transforman en datos de altura. Estos datos se combinan para crear una representación de la superficie anterior. Todas las demás mediciones (córnea posterior, anterior del cristalino, y el iris) derivan de los datos de Scheimpflug (Savini y cols., 2011b).

\subsubsection{ABERROMETRÍA OCULAR}

Para la percepción de una imagen no es solo necesario un buen funcionamiento del sistema neurorretininano, sino que también va a depender de la calidad visual del sistema óptico ocular. Las limitaciones que podemos encontrar en el sistema óptico son la difracción, el "scattering" o dispersión y las aberraciones. La difracción se define como una característica propia de las ondas basada en la desviación de las mismas al encontrar un obstáculo o al atravesar una apertura muy pequeña, por lo que la difracción juega un papel muy importante sobre la calidad visual en diámetros pupilares reducidos. La dispersión o "scattering" es un fenómeno por el cual dos ondas de distinta frecuencia se separan al atravesar un material; cuanto menos transparente sea éste, mayor dispersión de la luz habrá. Las aberraciones ópticas, que son aquéllas que impiden que los rayos se enfoquen en un mismo punto en la retina, son las que más degradan la formación de la imagen nítida en la retina en un ojo sano, se definen como la diferencia entre el frente de onda teórico (esférico) y el frente de onda real (no esférico). Pueden ser monocromáticas, asociadas a una longitud de onda $(\lambda)$ específica del espectro 
visible, o cromáticas, que se generan por la dependencia del índice de refracción de las distintas estructuras oculares para las diferentes longitudes de onda (NietoFernández y Maldonado-López, 2007).

Las aberraciones ópticas monocromáticas pueden ser de bajo o alto orden. Las de bajo orden comprenden el orden cero, el primer orden y el segundo. Las que corresponden al segundo orden, desenfoque y astigmatismo, se corrigen habitualmente con lentes oftálmicas, mientras que las aberraciones de alto orden (mayor o igual al tercer orden) no se pueden corregir con lentes oftálmicas pero si se pueden reducir considerablemente con la utilización de lentes de contacto semirrígidas permeables al gas.

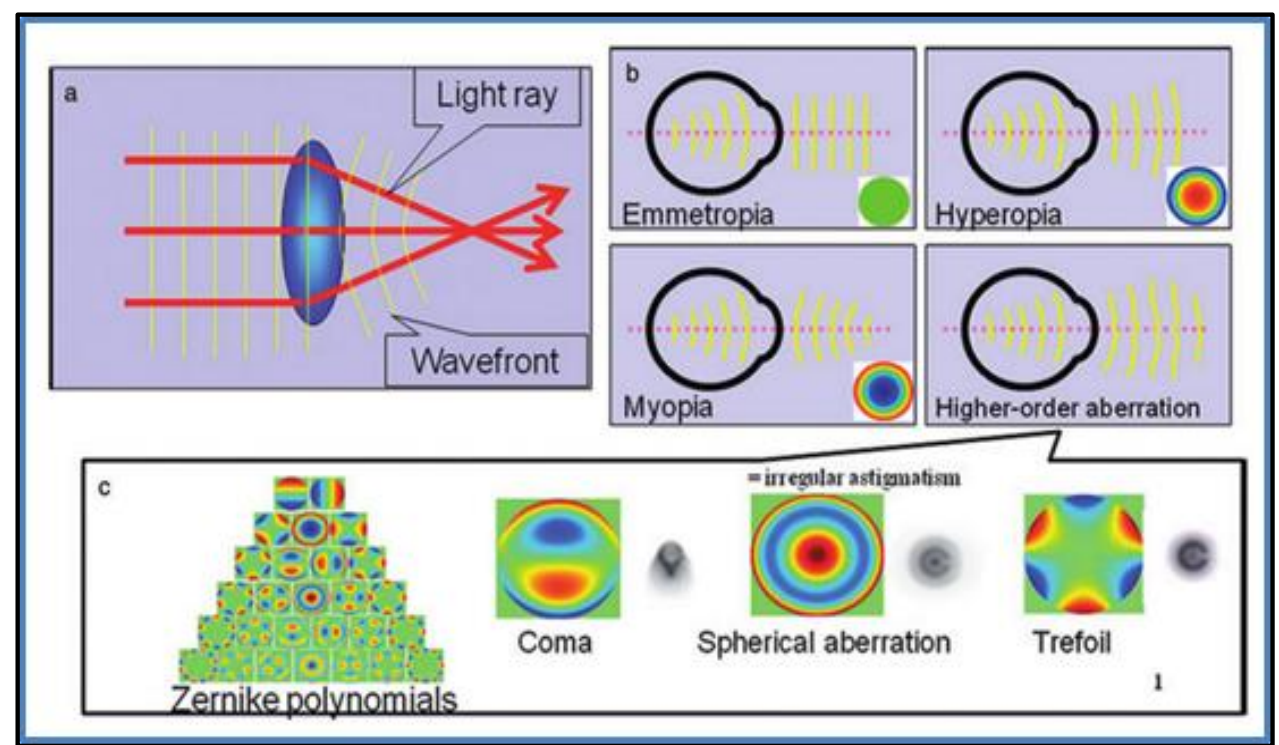

Figura 24: Efecto de los defectos refractivos en el frente de onda (Maeda, 2009).

En pacientes jóvenes, las aberraciones causadas por la córnea (aberración esférica positiva) y por el cristalino (aberración esférica negativa) tienen signo 
contrario y por tanto están compensadas. Sin embargo, en pacientes de mayor edad se produce un desequilibrio en este balance debido a la facoesclerosis. En este caso la córnea mantiene un valor positivo estable de la aberración esférica, pero el cristalino va reduciendo su magnitud negativa, por lo que se produce un aumento de la magnitud positiva total de la aberración esférica. Esta situación se agrava aún más cuando se produce la cirugía de cataratas y se implanta una LIO esférica dado que esta última posee aberración esférica positiva. Esto resulta en un aumento de la aberración esférica ocular total tras la cirugía de catarata (Mathur y cols., 2012).

En la figura 25 se muestra como las aberraciones externas, producidas por la superficie corneal anterior, y las aberraciones internas, producidas por la superficie corneal posterior y el cristalino pricipalmente, en un paciente joven pueden tener una magnitud y forma similares aunque de signo opuesto, lo que resulta en aberraciones oculares totales menores, circunstancia que no sucede en pacientes mayores (mapas inferiores) (Artal y cols, 2002). Las aberraciones oculares totales resultan de la suma de las aberraciones externas e internas. 


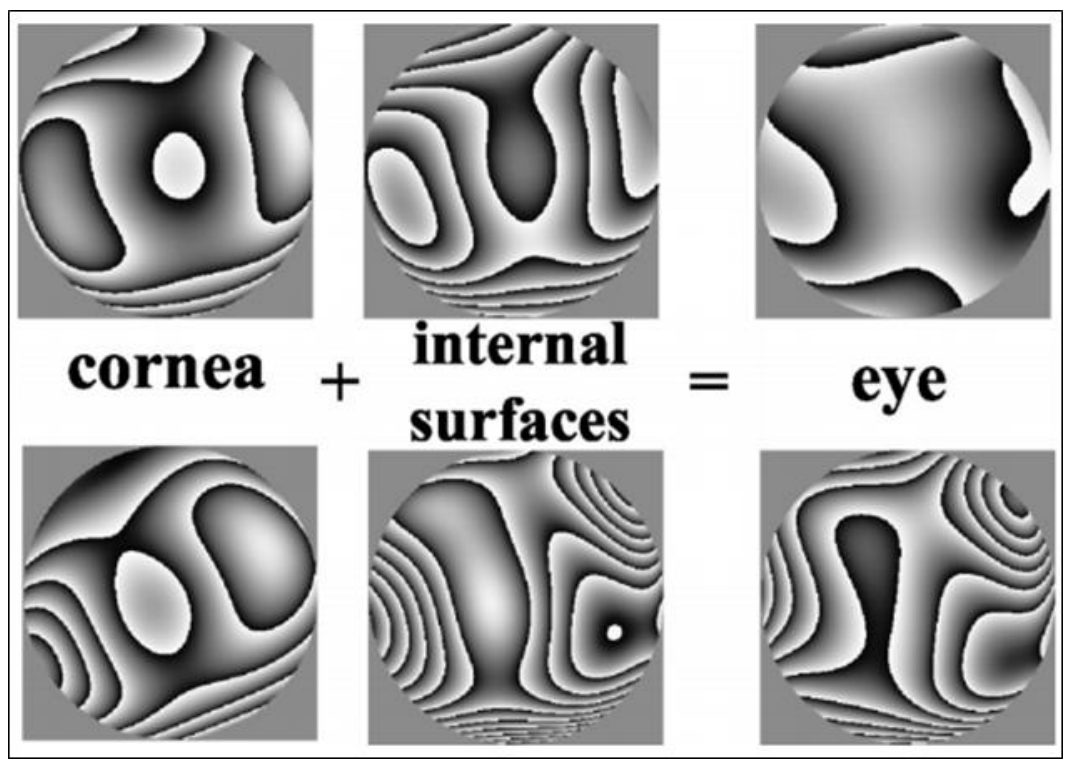

Figura 25: Representación de las aberraciones de frente de onda para la superficie corneal anterior, interna (córnea posterior y cristalino) y ocular en un paciente joven (superior) y un paciente anciano (inferior) (Artal y cols, 2002).

Las aberraciones del frente de onda causadas por la superficie corneal anterior pueden ser calculadas a partir de datos de elevación de los topógrafos (Maeda, 2009).

\subsubsection{1. $\quad$ Representación de las aberraciones ópticas:}

I. Mapas de Frentes de Ondas. Es la representación tridimensional resultante de la comparación entre una superficie esférica y el frente de ondas en el sistema óptico ocular. 


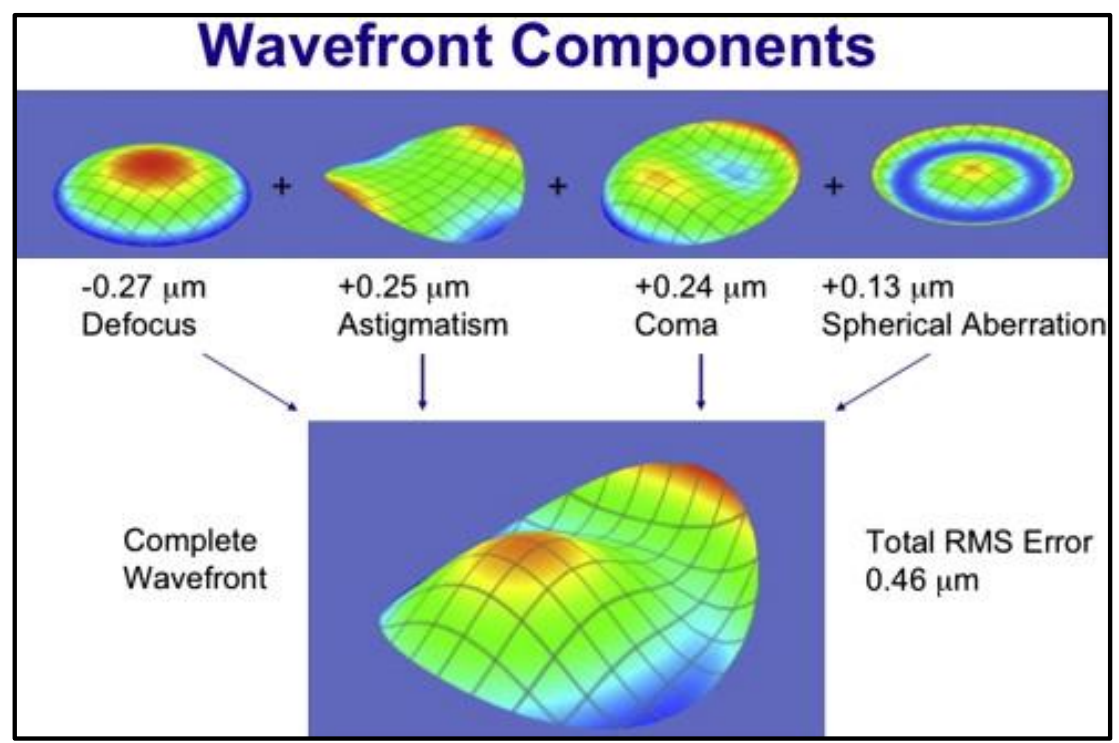

Figura 26: Mapa del error de frente de onda completo resultante de la suma de las aberraciones individuales (Mello y cols, 2012).

II. Polinomios de Zernike. El físico holandés Flitz Zernike publicó un artículo en el que describió una serie de polinomios, llamados coeficientes de Zernike (1934). Éstos son una combinación de funciones trigonométricas independientes, de base ortogonal y definidos en un círculo (Maeda, 2009; Nieto-Fernández y Madonado-López, 2007), de forma que cualquier frente de onda se puede descomponer en un conjunto de estos polinomios (también llamados modos de Zernike) con determinados coeficientes. Cada uno de estos polinomios representa una aberración corneal, llevando el nombre del defecto que representa, por ejemplo astigmatismo, coma, trefoil, o aberración esférica. Pero los polinomios de Zernike no se limitan al análisis del error del frente de onda, sino que también pueden aplicarse a 
otras superficies oculares, incluyendo la superficie ocular anterior (Carvalho, 2005a; Smolek y Klyce, 2003). Los datos obtenidos en el mapa de elevación corneal que proporciona el topógrafo se descomponen en polinomios de Zernike, obteniendo mapas residuales que reproducen formas corneales de diversa complejidad (Martinez-Finkelshtein y cols., 2009; Schwiegerling y Greivenkamp, 1997).

Sin embargo, aunque los polinomios de Zernike reconstruyen adecuadamente superficies en las que la aberración es mínima, resultan insuficientes y erróneos cuando hay cambios severos de curvatura por lo que deberían ser complementados con otros polinomios, como los de Bathia-Wolf (Carvalho, 2005b; MartinezFinkelshtein y cols., 2009) o seguir un análisis de Fourier.

Los polinomios $\left(Z_{n}{ }^{f}\right)$ se clasifican en base a dos subíndices, donde " $n$ " es el orden de aberración y "f" se refiere a la localización de la aberración, que es más periférica a mayor "f". 


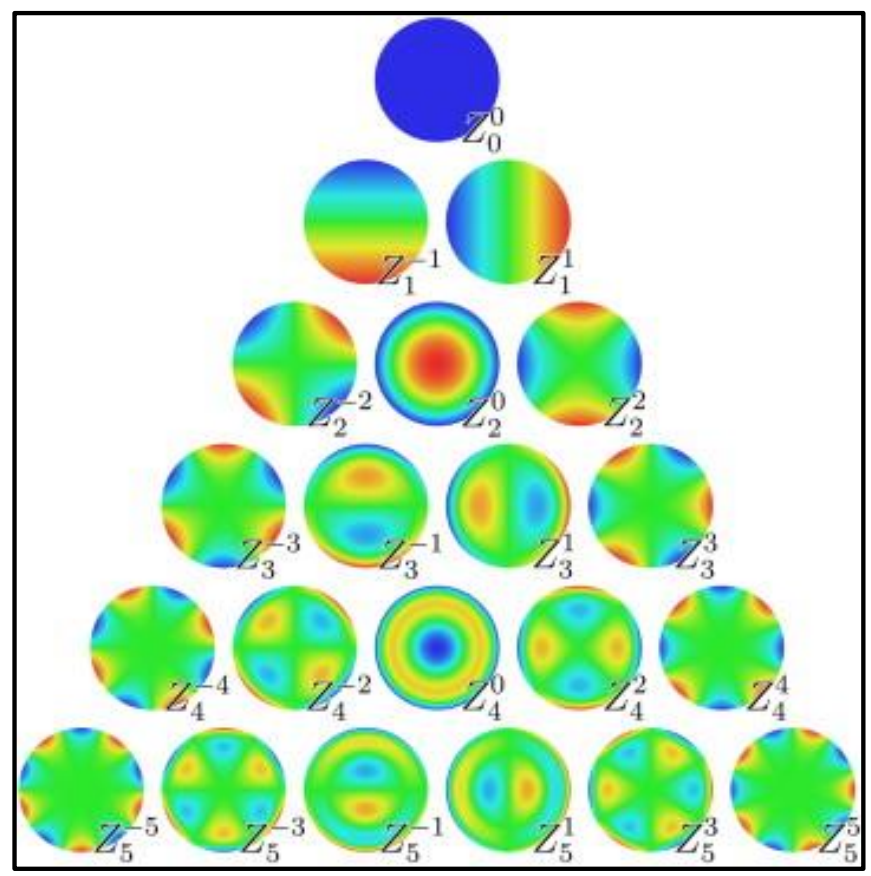

Figura 27: Descomposición en los Polinomios de Zernike hasta el 5o orden (Mello y cols, 2009).

III. Valor cuadrático medio (Root Mean Square RMS). La magnitud total del frente de ondas también puede ser calculado como la raíz cuadrada de la suma de los cuadrados de los coeficientes de Zernike para cada orden considerado (Mello y cols., 2009). Con el RMS obtenemos una aproximación de la desviación del frente de onda teórico frente al real, por tanto a mayor RMS mayor aberración. El RMS puede ser calculado para la aberración total o para cada una de las aberraciones de alto orden. El RMS total disminuye progresivamente con la edad desde la infancia llegando a valores mínimos en la $4^{\text {a }}$ década de la vida, momento en el cual vuelve a aumentar. (Brunette y cols., 2003). 


\section{JUSTIFICACIÓN}





\section{JUSTIFICACIÓN}

La evolución de la cirugía de catarata ha traído consigo un cambio de tendencias en las complicaciones derivadas de este procedimiento (Clark y cols., 2011). La facoemulsificación del cristalino representa la técnica de elección en los últimos años dadas las ventajas que aportan el tamaño de la incisión, pequeña y autosellable, y la utilización de ultrasonidos para la extracción del cristalino (Jaycock y cols., 2009).

El edema corneal es una de las complicaciones que puede aparecer en el postoperatorio inmediato o tardío de la cirugía de catarata (Erie y cols., 2007). Ésta es una complicación frecuente cuya incidencia varía según las series (Lundberg y cols., 2005; Schultz y cols., 1986; Walkow y cols., 2002). Las mejoras introducidas en la técnica quirúrgica, en el diseño de la LIO, del instrumental quirúrgico o el uso de materiales viscoelásticos, han contribuido a disminuir el daño del endotelio corneal y a mejorar los resultados visuales postquirúrgicos (Javitt y cols., 2000). El edema corneal se produce por la pérdida de células endoteliales (Lundberg y cols., 2005) derivada de la toxicidad y del fenómeno de lavado por el uso de soluciones intracamerulares y por el trauma ultrasónico y/o mecánico que puede producirse durante la cirugía (Walkow y cols., 2002). El resultado es una disfunción de la barrera y bomba endoteliales y un aumento de la hidratación estromal con la consiguiente pérdida de transparencia, que por otro lado suele resolverse en unas semanas (Lundberg y cols., 2005; Walkow y cols., 2002; Behnding y col., 2002).

Para la medida del espesor corneal disponemos de diversos paquímetros ópticos de no contacto y de contacto, principalmente basados en ultrasonografía, 
técnica aún considerada el sistema de referencia de medida paquimétrico (Ishibazawa y cols., 2011). El edema corneal postquirúrgico se ha medido con paquímetros ultrasónicos (Behnding y col., 2002), topografía de barrido de hendidura (Morikubo y cols., 2004) y tomografía de coherencia óptica (OCT) entre otros (Li y cols., 2011). La SD-OCT permite una evaluación rápida y precisa del segmento anterior (Correa y cols., 2012), con la ventaja añadida de no requerir contacto corneal, y además proporciona imágenes de alta resolución (Reinstein y cols., 2012a), por lo que esta tecnología se ha utilizado también para medir el espesor epitelial corneal en sujetos sanos (Prakash y cols., 2012) y en pacientes con queratocono (Li y cols., 2012).

Dado que existe un incremento del grosor corneal total transitorio tras facoemulsificación en pacientes operados de catarata senil, es necesario determinar si dicho cambio en el grosor afecta igualmente a nivel epitelial o solamente a nivel estromal, ya que es un hecho que se desconoce. Paralelamente, la fiabilidad de medida paquimétrica total del aparato denominado Cirrus HD-OCT ya ha sido previamente determinada por nuestro grupo de investigación. Hay autores que han evaluado la repetibilidad y reproducibilidad del Cirrus HD-OCT como paquímetro de no contacto (Correa y cols., 2014) al igual que su fiabilidad en el caso del grosor epitelial en sujetos sanos. Sin embargo, se ha observado igualmente que dicha fiabilidad de medida en sujetos operados de LASIK (Ma y cols., 2013) o diagnosticados de queratocono (Li y cols., 2012) tiende a ser inferior, por lo que se considera igualmente necesario determinar si la consistencia de medida (fiabilidad) del espesor epitelial central varía con el aparato Cirrus HD-OCT y cómo se compara frente a otros sistemas de no contacto, como el Lenstar LS 900 (López-Miguel y cols., 2012). No hay trabajos publicados en los que se evalúe el OCT como 
instrumento de medición epitelial y estromal en las zonas paracentrales. Por otro lado, tampoco se ha estudiado previamente con detalle la relación entre los cambios en la paquimetría total y por capas y las modificaciones en variables que afectan a la calidad óptica, como son la excentricidad y las aberraciones de alto orden corneales, tras cirugía de cataratas mediante facoemulsificación con el fin de conocer y predecir posibles cambios en la calidad visual final de los pacientes. 

HIPÓTESIS 



\section{HIPÓTESIS}

El espesor corneal total, epitelial y no epitelial evaluado mediante tomografía de coherencia óptica de dominio espectral presenta una buena repetibilidad y reproducibilidad interobservador, a la vez que muestra una variación transitoria postquirúrgica de su morfología de distinta magnitud según el área corneal analizada en pacientes operados de catarata senil mediante facoemulsificación, alterando así las aberraciones de alto orden corneales anteriores. 

OBJETIVOS 



\section{OBJETIVOS}

\subsection{OBJETIVO GENERAL}

Evaluar las variaciones producidas en el espesor corneal epitelial y corneal total no epitelial en el área central y paracentral mediante tomografía de coherencia óptica de dominio espectral en pacientes operados de catarata senil mediante facoemulsificación.

\subsection{OBJETIVOS ESPECífICOS}

- Cuantificar los cambios que suceden en el grosor epitelial corneal y en la paquimetría total exceptuando el epitelio durante el postoperatorio de cirugía de catarata senil realizando la técnica de facoemulsifación.

- Estimar las diferencias en la evolución del grosor del epitelio corneal y el grosor corneal total no epitelial en el ápex y las áreas paracentrales corneales durante el tiempo postoperatorio temprano e intermedio de la cirugía de cataratas.

- Determinar la repetibilidad intra-observador y la reproducibilidad interobservador en la medida manual del espesor epitelial y corneal total no epitelial mediante tomografía de coherencia óptica de dominio espectral.

- Evaluar las modificaciones en las aberraciones de alto orden corneales anteriores durante el postoperatorio temprano e intermedio de la cirugía de cataratas con facoemulsificación. 

PACIENTES, MATERIALES Y MÉTODOS 



\section{PACIENTES, MATERIALES Y MÉTODOS}

\section{1. ÁMBITO DE ESTUDIO}

Este estudio clínico se ha llevado a cabo en el servicio de Oftalmología del Hospital Universitario Río Hortega de Valladolid. Todos los procedimientos fueron llevados a cabo de acuerdo a la Declaración de Helsinki. El Comité de Ética Institucional del Hospital Universitario Rio Hortega aprobó el presente estudio (Anexo I). Todos los sujetos incluidos en este estudio lo hicieron de forma voluntaria y recibieron información detallada acerca de la naturaleza de la investigación antes de firmar el consentimiento informado para su inclusión en el estudio. Del mismo modo, los pacientes que fueron operados de catarata mediante facoemulsificación del cristalino e implante de lente intraocular firmaron el consentimiento informado de la propia cirugía.

\subsection{PARTICIPANTES}

\subsubsection{PACIENTES}

\subsubsection{Criterios de inclusión:}

Los pacientes incluidos en el estudio fueron aquellos a los que se les realizó facoemulsificación estándar coaxial sin complicaciones para tratar cataratas seniles en grado $\geq 2$ de la clasificación LOCS III. Los criterios 
generales de inclusión fueron presentar la mayoría de edad y firmar el correspondiente consentimiento informado.

\subsubsection{2. $\quad$ Criterios de exclusión:}

Los pacientes excluidos del estudio fueron aquellos con las siguientes características:

- Historia previa de cirugía ocular.

- Portadores de lentes de contacto.

- Sospecha de queratectasia clínica o subclínica.

- Patología aguda de segmento anterior o posterior distinta a catarata.

- Contaje endotelial inferior a 2000 células $/ \mathrm{mm}^{2}$ (Lundberg y cols., 2005).

- Sutura de la incisión principal.

- Implante de LIO en sulcus.

- Complicaciones intraoperatorias o postoperatorias.

- Tratamiento postoperatorio con fármacos hipotensores ó antiedema.

- Enfermedad cognitiva que impidiera la comprensión de la naturaleza del estudio e impidiera el consentimiento informado.

Todos los sujetos fueron sometidos a una exploración oftalmológica completa previa a la cirugía que incluía medida de la refracción, biomicroscopía de lámpara anterior, neumotonometría y oftalmoscopía indirecta. 


\subsubsection{SUJETOS CONTROL}

\subsubsection{1. $\quad$ Criterios de inclusión:}

Los pacientes voluntarios incluidos en el estudio poseían un ojo sano sin catarata o con catarata senil con grado $\leq 1$ en la clasificación LOCS III. Los criterios generales de inclusión fueron presentar la mayoría de edad y firmar el correspondiente consentimiento informado.

\subsubsection{2. $\quad$ Criterios de exclusión:}

Los pacientes excluidos del estudio fueron aquellos con las siguientes características:

- Historia previa de cirugía ocular incluida la cirugía de catarata.

- Portadores de lentes de contacto.

- Sospecha de queratectasia clínica o subclínica.

- Patología aguda de segmento anterior o posterior distinta a catarata.

- Contaje endotelial inferior a 2000 células $/ \mathrm{mm}^{2}$ (Lundberg y cols., 2005).

- Enfermedad cognitiva que impidiera la comprensión de la naturaleza del estudio e impidiera el consentimiento informado. 


\subsection{TÉCNICA QUIRÚRGICA DE LA CIRUGÍA DE CATARATA}

El mismo cirujano (MCG) realizó todas las cirugías de catarata utilizando anestesia tópica (Tetracaína al $0.1 \%$ y Oxibuprocaína al 0.4\%, Alcon, Barcelona, España) e intracamerular (Lidocaína al 2\% sin conservantes diluida al 1\%, Braun, Barcelona, España). Una incisión accesoria se realizó mediante cuchillete de acero de 15 grados. Un dispositivo de viscoelástico oftálmico (hialuronato sódico al 1\%, Biolon, Bio-Technology General Ltd., Kiryat Malachi, Israel) fue inyectado en cámara anterior antes de crear la incisión principal. La incisión principal uniplanar fue creada en córnea clara a $180^{\circ}$ (temporal en ojos derechos y nasal en ojos izquierdos) con un cuchillete de acero de 2,75 milímetros. La facoemulsificación fue realizada mediante el sistema de energía torsional Ozil (Alcon, Fort Worth, Texas, EEUU) de la plataforma Infiniti Vision System de facoemulsificación (Alcon). Una lente intraocular (Acrysof SN60WF, Alcon) fue implantada en el saco utilizando el inyector precargado Acrysert C (Alcon). Tras la aspiración del material viscoelástico utilizando un sistema de irrigación y aspiración, las paredes laterales y el techo de las incisiones fueron hidratadas utilizando solución de suero fisiológico hasta que el estroma visiblemente blanqueaba. Mediante una esponjeta de celulosa se chequeaba la filtración de suero. El tratamiento postoperatorio incluía la suspensión oftálmica Tobradex (Tobramicina $0.3 \%$, Dexametasona $0.1 \%$, Alcon) con una frecuencia de cuatro veces al día durante la primera semana, y una pauta descendente en las sucesivas tres semanas. 


\subsection{INSTRUMENTOS DE MEDICIÓN OCULAR}

\subsubsection{TOMOGRAFÍA DE COHERENCIA ÓPTICA}

El instrumento de evaluación de los diferentes grosores corneales fue el sistema Cirrus HD-OCT (Carl Zeiss Meditec, Inc., Dublin, California, EEUU) utilizando su módulo de análisis de exploración de segmento anterior denominado "Anterior Segment 5 line raster", que produce cinco líneas de alta resolución (de 4.096 A-scans cada una) horizontales de $3 \mathrm{~mm}$ de longitud (Carl Zeiss Meditec, 2007) separadas cada una de ellas $0.25 \mathrm{~mm}$ y abarcando $1 \mathrm{~mm}$ de ancho. El Cirrus HD-OCT utiliza tecnología de dominio espectral. En la práctica clínica se utiliza más habitualmente para obtener imágenes de mácula y de capa de fibras nerviosas de la retina en el análisis estructural del nervio óptico, aunque como ya se ha mencionado anteriormente también tiene la capacidad de proporcionar imágenes de segmento anterior de alta resolución cambiando el foco en el instrumento (Singh y cols., 2009). Sin embargo, este módulo no posee segmentación automática y las medidas se deben obtener de forma manual.

Siempre que se realizó la prueba se intentó centrar la imagen capturada en el vertex corneal; no obstante, si la tomografía estaba descentrada o inclinada o la calidad de la imagen era pobre, se realizaba una segunda adquisición. Sólo las imágenes con una intensidad de señal igual o superior a siete sobre una escala de uno a diez, fueron aceptadas.

Para la óptima adquisición de imágenes de segmento anterior con el Cirrus HD-OCT, se requería una mínima colaboración por parte de los pacientes. Éstos 
debían concentrarse en un punto de fijación presente en este aparato y debían parpadear tras cada toma de imagen para favorecer una película lagrimal homogénea.

De los cinco escáneres que proporcionaba el tomógrafo por defecto, siempre se elegía el que estuviera más centrado en el ápex corneal para proceder a la posterior medición manual de los grosores corneales. Las medidas de los diferentes espesores corneales se obtenían manualmente después de la adquisición de la imagen utilizando la herramienta del caliper que proporciona el software (CorreaPérez y cols., 2012), de modo que la distancia vertical comprendida entre los dos indicadores del caliper en la imagen corresponde a la magnitud real.

La figura 28 muestra las imágenes obtenidas al realizar la exploración de segmento anterior. La herramienta del caliper (marcada en rojo en la figura) se utilizaba delimitando ambos extremos de la estructura corneal a estudiar. Se obviaba la línea hiperrefringente más externa que correspondía a la película lagrimal. Por otro lado, el epitelio se distinguía claramente del estroma por una banda de mayor reflectividad. 


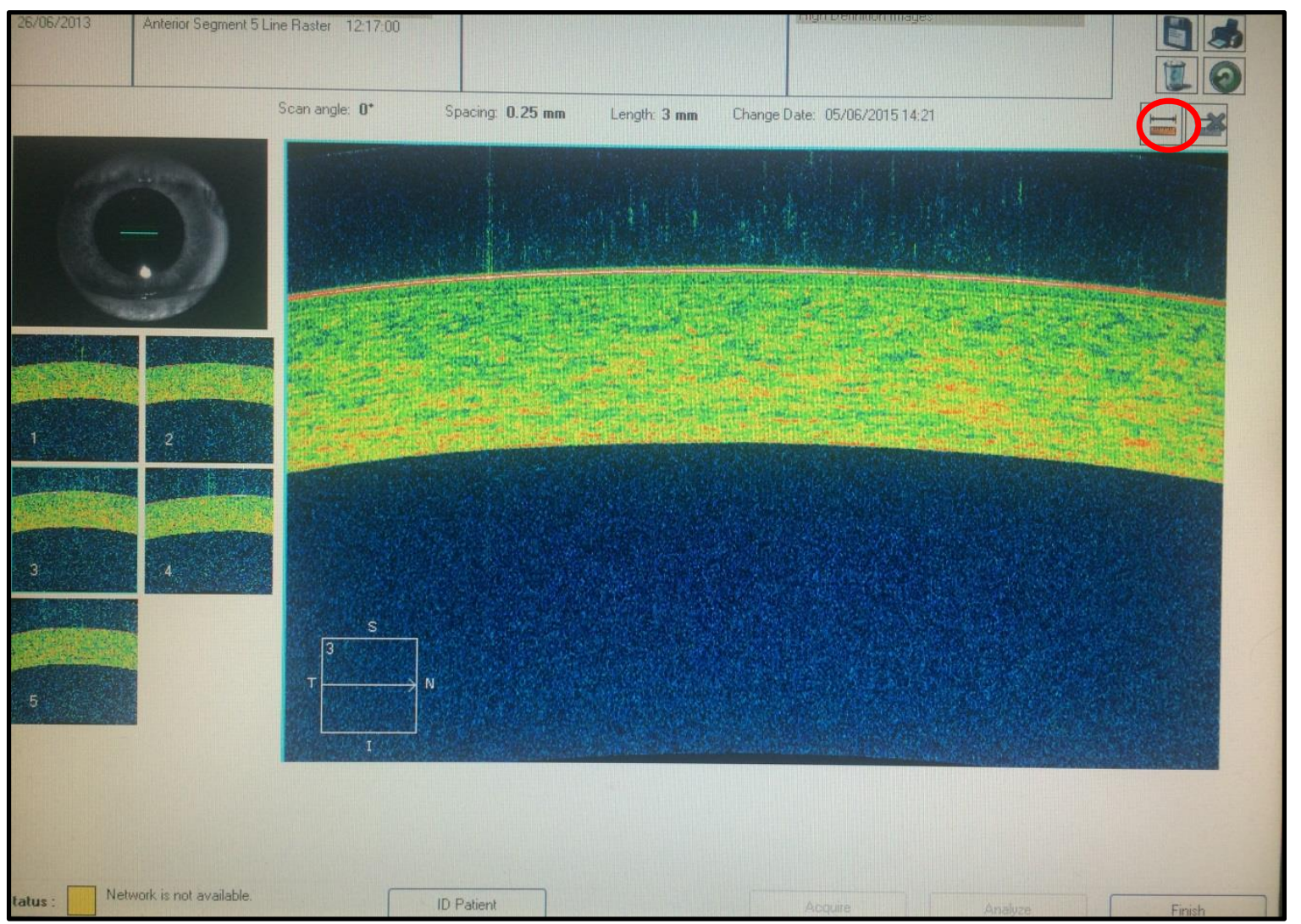

Figura 28: Imagen obtenida al realizar OCT de segmento anterior en la modalidad “Anterior Segment HD 5 line raster" de Cirrus HD-OCT. 


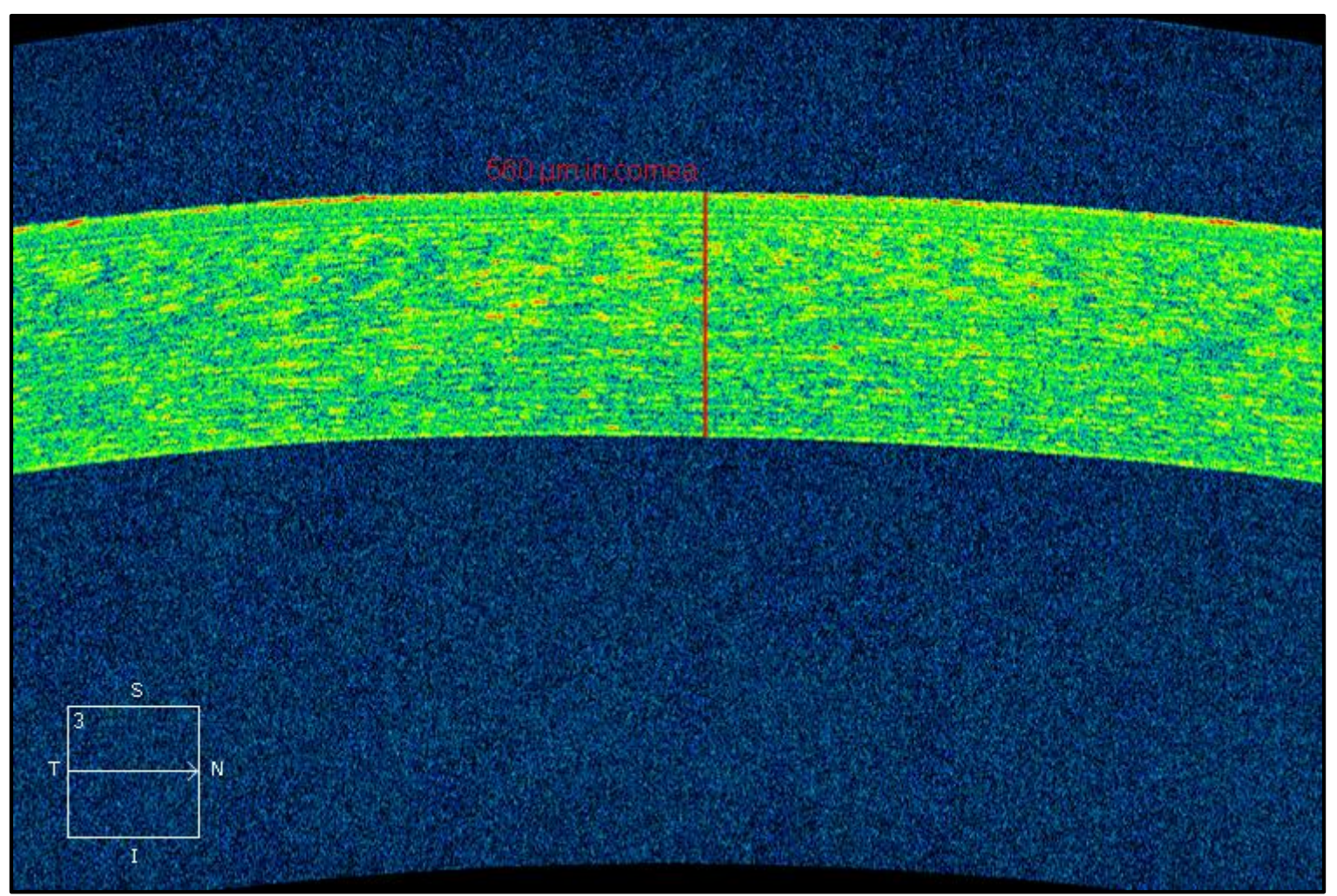

Figura 29: Espesor corneal total central medido manualmente con el sistema Cirrus HDOCT. 


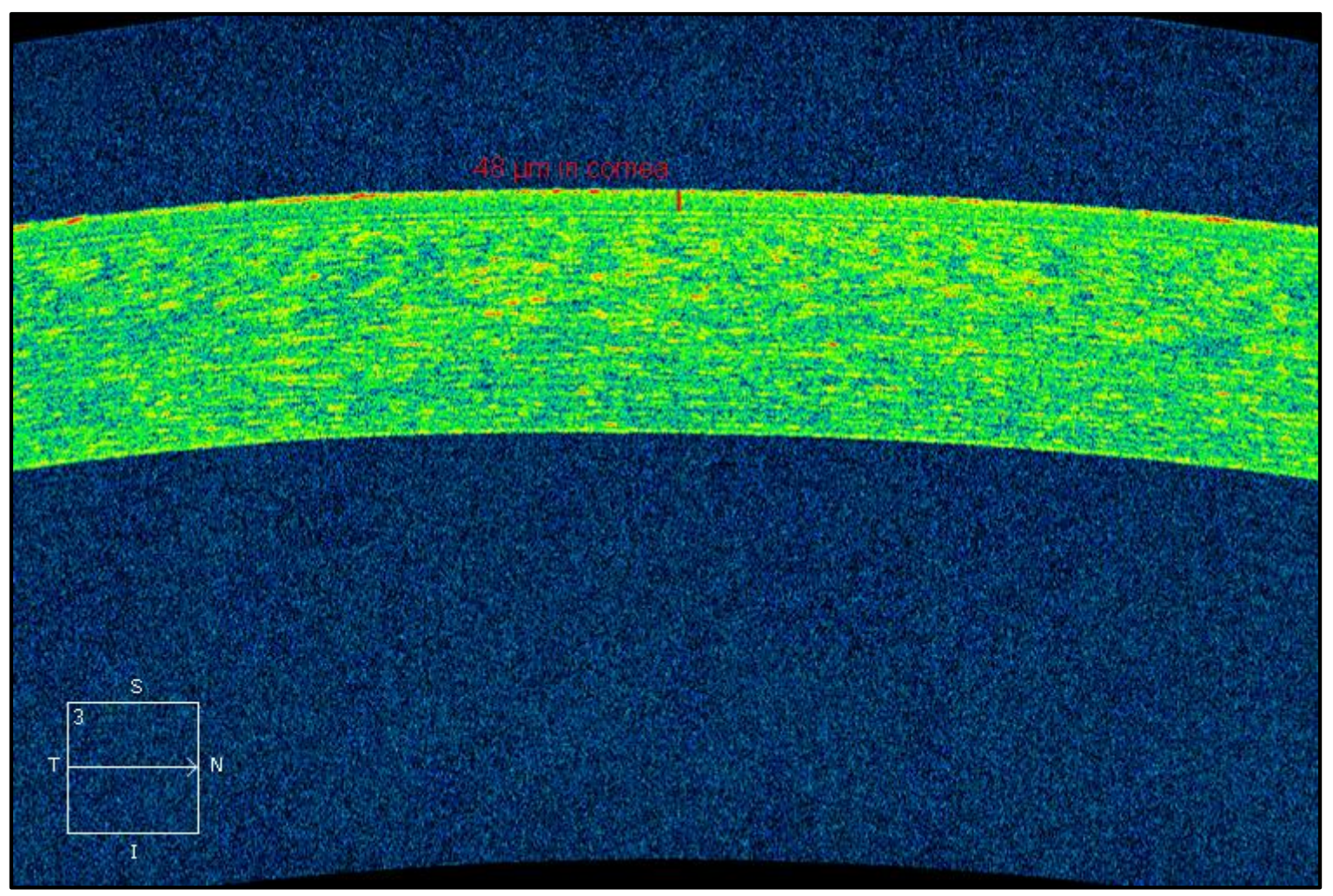

Figura 30: Grosor del espesor epitelial corneal medido manualmente con el sistema Cirrus HD-OCT. 


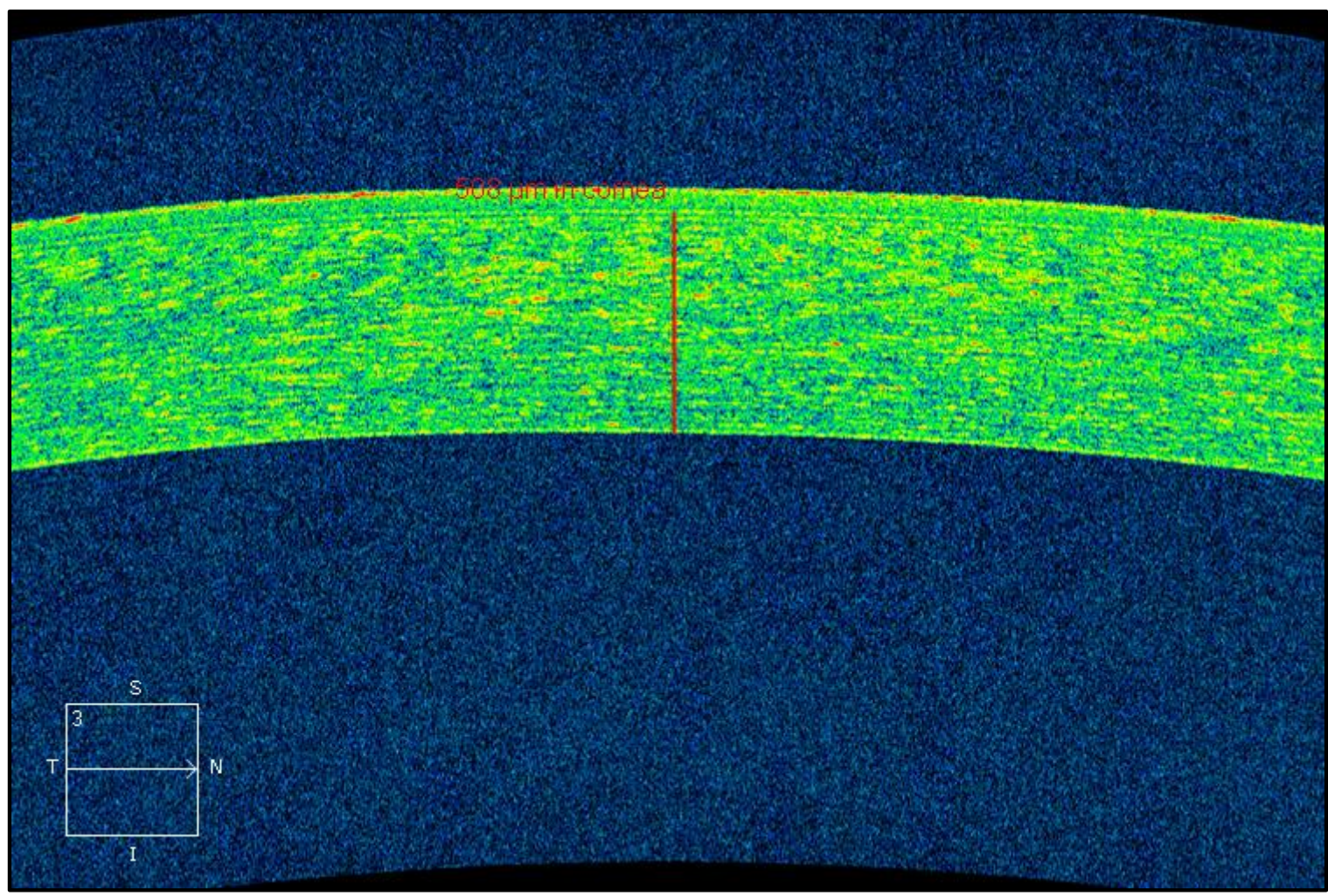

Figura 31: Grosor del espesor corneal total no epitelial medido manualmente con el sistema Cirrus HD-OCT.

\subsubsection{TOPOGRAFÍA Y ABERROMETRÍA CORNEAL}

El queratógrafo CTK-922 (Haag-Streit, USA) utiliza un sistema integrado de topografía corneal de reflexión y queratometría. Realiza medidas topográficas y queratométricas con un solo instrumento y realiza análisis comparativo de diferentes exámenes. Consta de un sistema de 22 anillos de Plácido en un hemisferio y 22.000 puntos de medida para lograr máxima resolución. Este instrumento tiene una gran cantidad de aplicaciones en la práctica clínica, como por ejemplo, la determinación del astigmatismo postoperatorio en la cirugía de la catarata (Arkins y Roper, 1985). 
Este topógrafo proporciona datos no solo queratométricos, si no que a partir de la topografía obtenida con discos de Plácido reconstruye polinomios de Zernike. El análisis de Zernike se utiliza como forma de expresión del error de frente de onda estimado en una función polinómica (Klyce y cols., 2004). La información obtenida de ambas tecnologías puede ser integrada para proporcionar una imagen más completa sobre las aberraciones de alto orden que pueden existir en ojos normales y en el pre y postoperatorio de la cirugía de cataratas.

El instrumento cuenta con una mentonera de modo que el paciente queda colocado a una distancia de unos 8 centímetros. Consta de una luz cálida que evita el deslumbramiento del paciente. Es muy importante que el ojo del paciente esté bien abierto, puesto que una mala apertura palpebral puede reducir el área a analizar.

La imagen se obtuvo siempre en unas condiciones similares de iluminación, aproximando el aparato al paciente hasta que automáticamente se realizaba la captura. El paciente debía parpadear antes de la captura para favorecer la homogénea distribución de la película lagrimal sobre la superficie corneal, ya que la rotura de la película lagrimal distorsiona la imagen de los anillos y puede resultar en valores oculares erróneos. Se obtenía una única imagen en cada visita y posteriormente se procesaban los datos. 


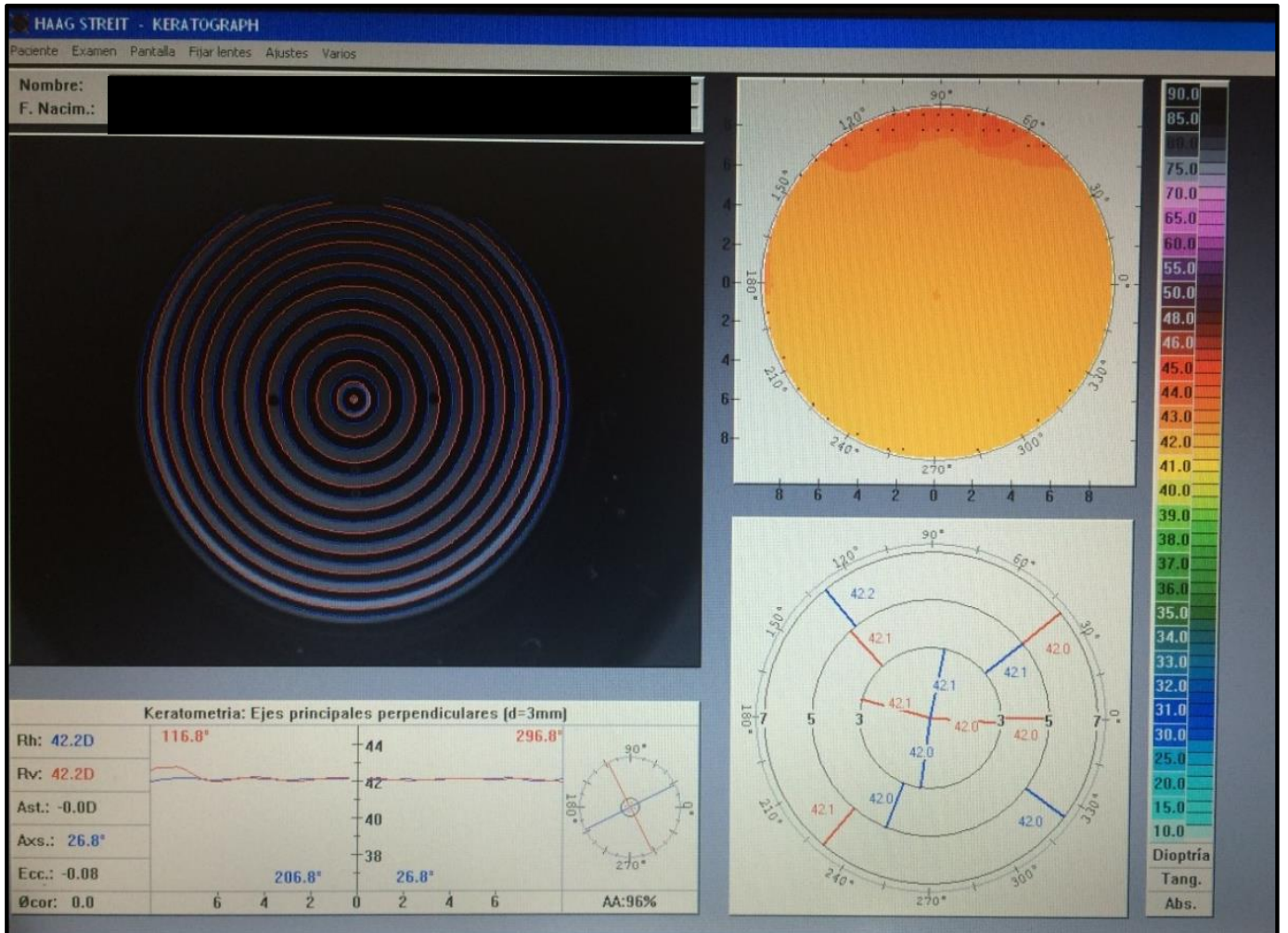

Figura 32: Datos queratométricos proporcionados por CTK-922 (Haag-Streit). 


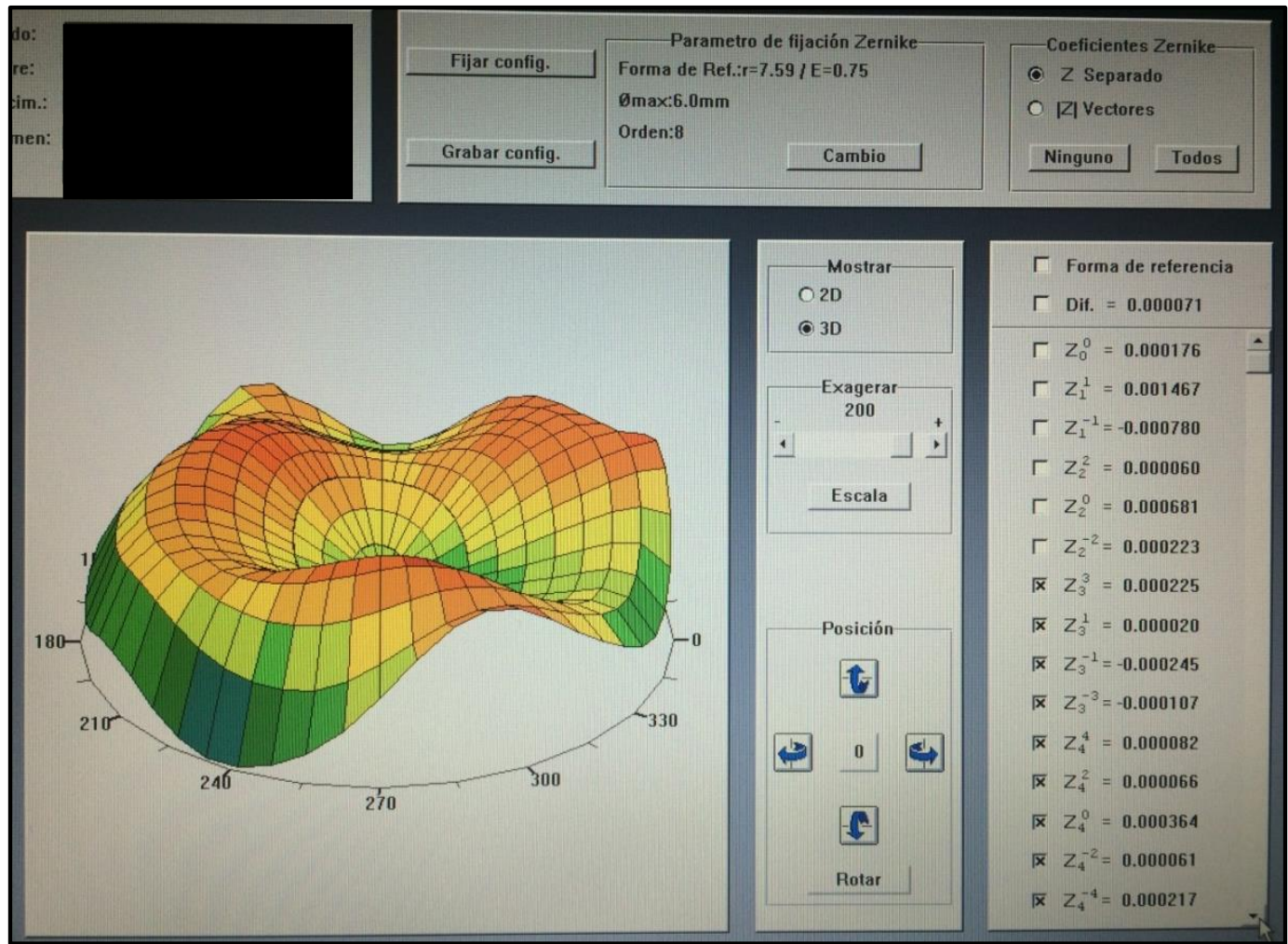

Figura 33: Análisis de los coeficientes de Zernike en el queratógrafo CTK-922 (HaagStreit).

\subsection{DISEÑO DE LOS ESTUDIOS}

\subsubsection{DISEÑO DEL ESTUDIO PILOTO DEL ANÁLISIS DEL ESPESOR CORNEAL POR CAPAS EN PACIENTES OPERADOS DE CATARATA}

Un primer esudio piloto se planteó para confirmar la puesta a punto de la técnica y explorar la viabiliadad de los objetivos propuestos, que se abordarían entonces en un estudio de mayor magnitud. El estudio piloto incluyó veinte ojos de 
veinte pacientes que fueron operados de catarata senil mediante facoemulsificación. A estos pacientes se les realizó una medición del espesor corneal previo a la cirugía y en el postoperatorio, en el periodo de una semana y un mes. El instrumento de medición corneal fue el Cirrus HD-OCT en su módulo de análisis de exploración de segmento anterior mediante 5 escáneres de alta resolución (“5 line raster”).

En estos pacientes se midió el espesor corneal total, epitelial y corneal total no epitelial. El grosor epitelial se midió de la forma previamente descrita por Prakash y cols. (Prakash y cols., 2012b). Se midió el espesor corneal total excluyendo el epitelio (refiriéndonos entonces al grosor total no epitelial, es decir, la distancia entre la membrana de Bowman y el endotelio) e incluyendo membrana de Bowman, estroma, membrana de Descemet y endotelio, al igual que fue descrito por Prakash y cols. (Prakash y cols., 2012b). A este grosor le denominamos grosor total no epitelial. La paquimetría total también se midió de manera manual.

Los pacientes incluidos en este grupo fueron operados de catarata senil mediante facoemulsificación coaxial estándar sin incidencias. La catarata de estos pacientes era grado $\geq 2$ según la clasificación Lens Opacities Classification System III (LOCS III), pudiendo ser la opacidad nuclear, cortical o subcapsular posterior. Los criterios de exclusión de los pacientes han sido expuestos previamente.

En este grupo de pacientes examinados en situación preoperatoria y tras la cirugía de catarata, un único observador experimentado realizó una medida del espesor corneal en la consulta preoperatoria, a la semana y al mes de la cirugía. Las medidas del espesor corneal total, espesor epitelial y espesor corneal total no epitelial fueron tomadas en tres localizaciones en cada tomografía, una en el ápex corneal, y las otras dos en ambos extremos de la imagen, que representan los $3 \mathrm{~mm}$ 
de diámetro corneal en los hemi-meridianos de $180^{\circ}$ y $0^{\circ}$, es decir, la zona paracentral más próxima al área perincisional y la zona paracentral más próxima al área de la paracentesis que nos proporcionaba la imagen de la tomografía. De este modo se realizó la medición tanto en el centro de la imagen como en ambos extremos; esto sería a 1,5 mm a ambos lados del ápex corneal real (Figura 34). En la figura 35 se presenta un esquema de la localización de los hemimeridianos de $180^{\circ}$ y $0^{\circ}$ en ambos ojos.

Se analizaron las áreas corneales central y paracentrales del meridiano horizontal para determinar si el edema corneal postoperatorio era mayor en las zonas próximas a la incisión principal. Para monitorizar el espesor corneal las tomografías se tomaban antes, a la semana y al mes de la cirugía. Las mediciones se intentaron realizar siempre entre las 11:00 y 13:00 horas para evitar variaciones diurnas (Feng y cols., 2001). 


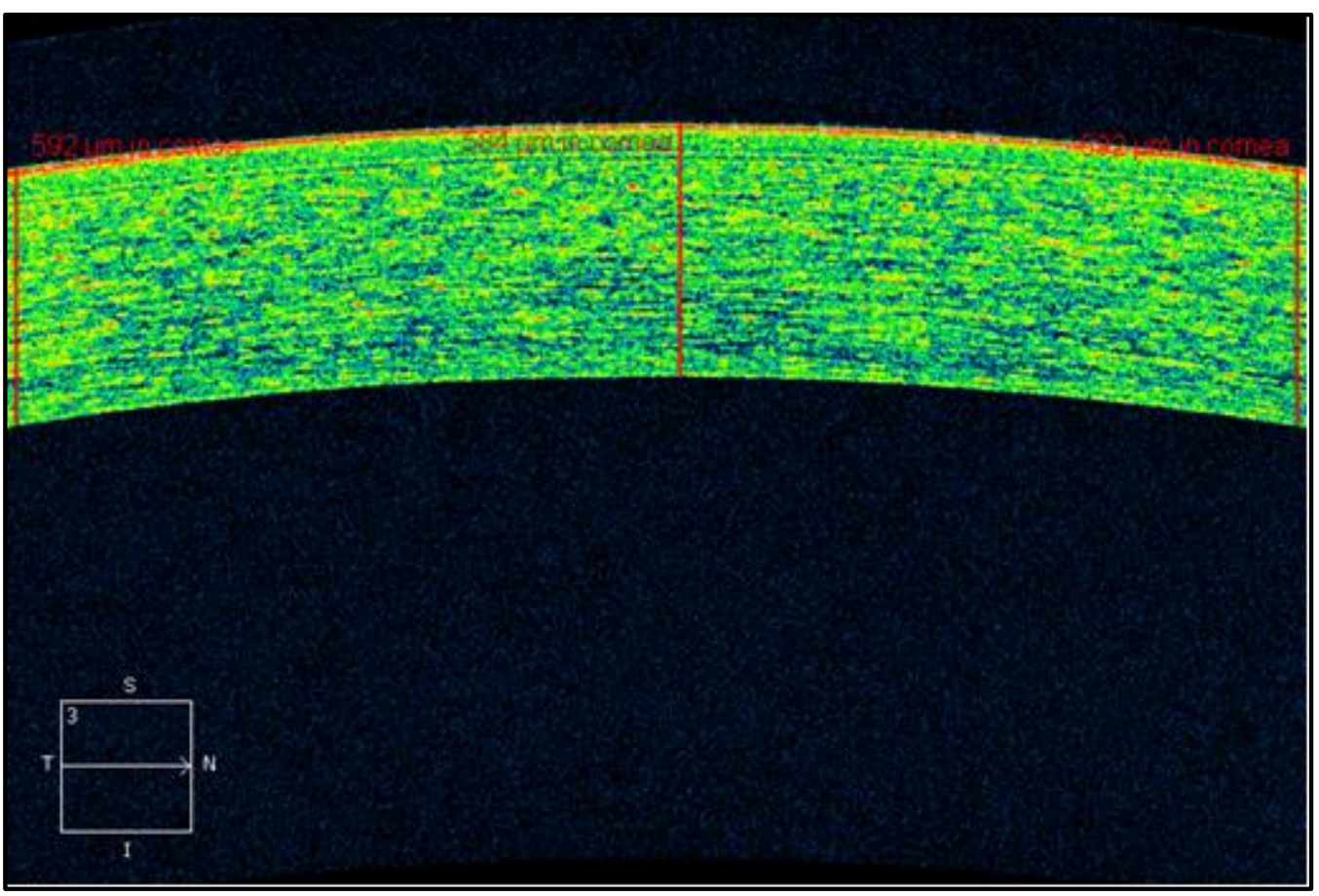

Figura 34: Medida del espesor corneal a nivel central y ambos lados paracentrales.

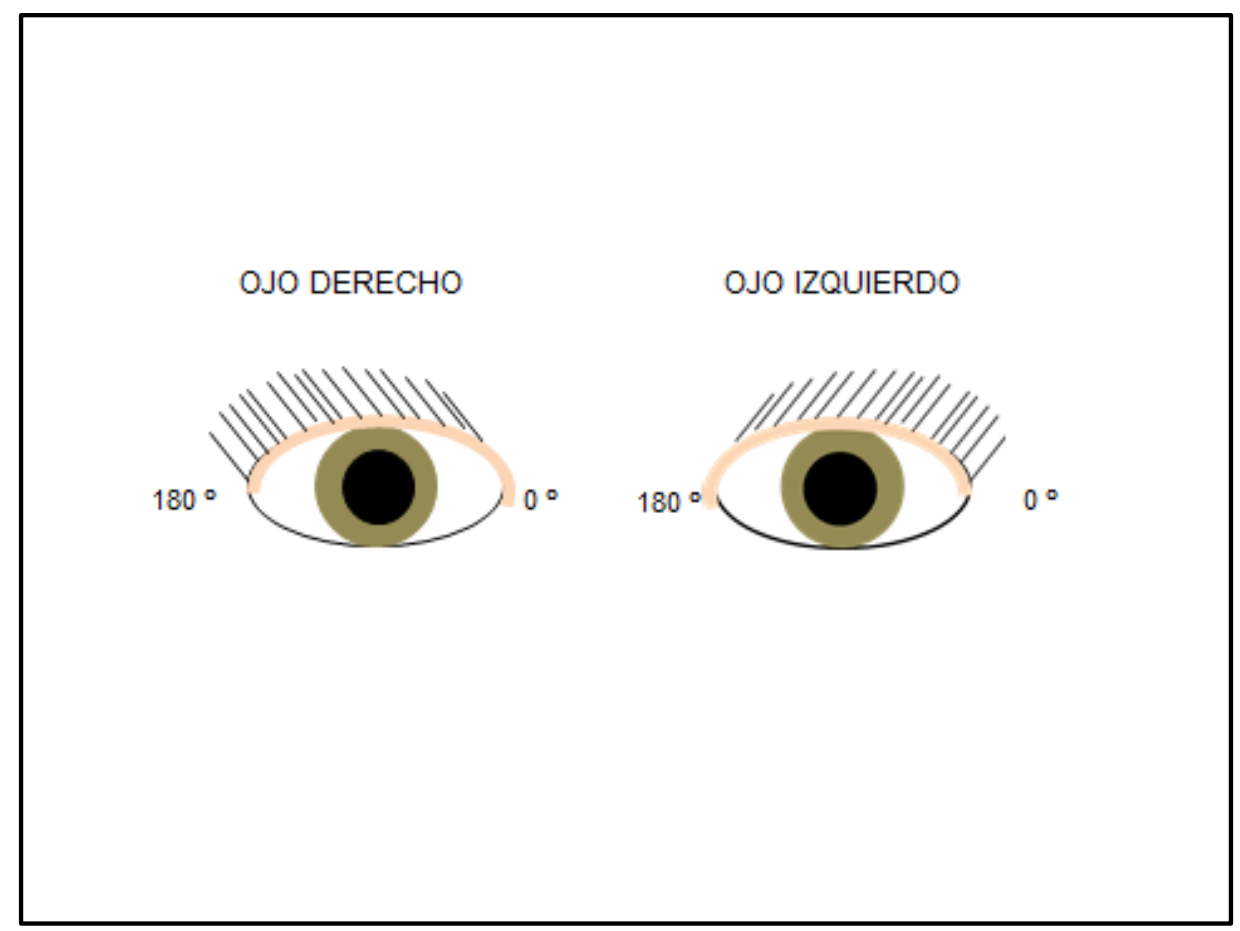

Figura 35: Representación esquemática de la localización de los hemi-meridianos de $180^{\circ}$ (área paracentral más próxima a la incisión principal) y 0 o (área paracentral más próxima a la paracentesis de ayuda) en ojo derecho y ojo izquierdo. 


\subsubsection{DISEÑO DEL ESTUDIO DE FIABILIDAD DE MEDIDA:}

REPETIBILIDAD

REPRODUCIBILIDAD
INTRAOBSERVADOR

INTEROBSERVADOR

DE

LAS

\section{CIRRUS HD-OCT}

Con el objetivo de determinar la fiabilidad de medida manual de los diferentes grosores corneales utilizando un sistema de tomografía de coherencia óptica de dominio espectral (Cirrus HD-OCT), se estimó la repetibilidad intraobservador y reproducibilidad interobservador en pacientes operados de catarata mediante facoemulsificación tras un mes de la cirugía y en sujetos controles.

Con este propósito, el espesor corneal total, el grosor epitelial y el corneal total no epitelial fueron medidos de forma manual en 80 ojos de 80 participantes, 40 estaban operados de cataratas mediante facoemulsificación e implante de LIO, mientras que otros 40 eran sujetos sanos (no operados de catarata). Las mediciones se realizaron al mes de la cirugía en los pacientes operados.

Los pacientes del grupo de operados habían sido intervenidos mediante facoemulsificación coxial estándar sin complicaciones de catarata grado $\geq 2$ según la clasificación LOCS III. Los voluntarios que comprendieron el grupo de no operados habían acudido a consulta de Oftalmología para una revisión oftalmológica y no fueron diagnosticados de ninguna anomalía ocular. El ojo seleccionado para el estudio fue elegido de forma aleatoria siguiendo una tabla de aleatorización generada por ordenador en el caso de los sujetos control. 
Para la ejecución del estudio de fiabilidad se necesitaron dos examinadores, uno de ellos (MCG) realizó cinco medidas consecutivas de los espesores corneales mediante el instrumento Cirrus HD-OCT con el objetivo de determinar la repetibilidad intra-observador de la técnica. Otro observador (VMF) participó realizando una sola medida del espesor corneal con el mismo sistema tomográfico con el objetivo de poder determinar la reproducibilidad inter-observador. El orden de adquisición de las tomografías por cada observador fue aleatorizado para evitar sesgos.

Según las recomendaciones de Bland y Altman, nuestras definiciones de repetibilidad y reproducibilidad se han basado en las adoptadas por la British Standards Institution y la International Standards Organization (Bland y Altman, 1998; Muscat y cols., 2002).

La repetibilidad intraobservador indica el grado de acuerdo entre los resultados mutuamente independientes del estudio, obtenidos usando el mismo método, idénticos materiales, en el mismo laboratorio, por el mismo operador, usando el mismo equipo y en un corto intervalo de tiempo. En este estudio se evaluó la repetibilidad realizando el examinador principal medidas consecutivas en el mismo aparato en un mismo paciente en el menor tiempo posible (Bhan y cols., 2003; Boxer-Watchler y Krueger, 2002). De este modo, el examinador principal (MCG) obtuvo las cinco tomografías consecutivas.

La reproducibilidad interobservador indica el grado de acuerdo entre los resultados mutuamente independientes del estudio, obtenidos bajo el mismo método, pero por distintos examinadores. En este estudio, esta evaluación se realizó obteniendo dos observadores independientes las tomografías en el mismo paciente (Blumenthal y cols., 2000; Miglior y cols., 2004). La primera de las cinco medidas de 
espesor corneal, epitelial y corneal total no epitelial a nivel central tomadas por el examinador 1 (MCG) fue comparada con las medidas tomadas por un segundo examinador (VMF) para determinar la concordancia entre ambos.

Al igual que en el estudio piloto, las tomografías se intentaron realizar entre las 11:00 y 13:00 horas para evitar variaciones diurnas en el espesor corneal (Feng y cols., 2001).

Para evitar una influencia del examinador al realizar las medidas manuales de los grosores corneales de manera consecutiva para el estudio de repetibilidad, en primer lugar, las imágenes corneales no fueron medidas hasta que todos los pacientes estuvieron incluidos en el estudio, y en segundo lugar, el examinador no midió los grosores consecutivamente en todas las imágenes corneales obtenidas del mismo paciente, sino que lo realizó primero en todas las primeras imágenes tomográficas corneales de todos los pacientes, después en todas las segundas, y así sucesivamente, con el objetivo de evitar sesgos que alterasen el resultado final del estudio (Correa-Pérez y cols., 2012). Igualmente cada observador desconocía las medidas obtenidas por el otro observador para evitar sesgos.

\subsubsection{DISEÑO DEL ESTUDIO CLÍNICO: DETERMINACIÓN DE LOS CAMBIOS ABERROMÉTRICOS Y EN EL GROSOR POR CAPAS DE LA CÓRNEA TRAS CIRUGÍA DE CATARATA CON FACOEMULSIFICACIÓN}

El estudio experimental fue realizado por un único observador (MCG) y en él se incluyeron 100 ojos de 100 pacientes distintos que fueron operados de catarata 
senil mediante facoemulsificación e implante de LIO por el mismo cirujano (MCG). Estos 100 pacientes seguían los mismos criterios de exclusión anteriormente mencionados y la técnica quirúrgica fue la ya descrita previamente. El seguimiento de los pacientes comenzó en la consulta preoperatoria y se extendió al periodo postoperatorio a la semana, al mes y a los tres meses de la cirugía. De estos 100 pacientes, se seleccionaron 30 de forma consecutiva para que el ojo contralateral actuase como control siempre que cumpliese los criterios de inclusión y exclusión previamente definidos. Los exámenes oculares realizados en el ojo control fueron los mismos que en el incluido en el grupo caso.

En este estudio clínico se utilizó igualmente un sistema de tomografía de coherencia óptica de dominio espectral (Cirrus HD-OCT), ya descrito anteriormente, para medir el espesor epitelial, corneal total no epitelial y corneal total a nivel central y en ambas localizaciones paracentrales $(1.5 \mathrm{~mm}$ de radio respecto del ápex corneal).

El otro instrumento de caracterización ocular utilizado fue el topógrafo denominado Queratógrafo CTK-922. Los datos topográficos obtenidos fueron las queratometrías y la excentricidad media en los $30^{\circ}$.

Por otro lado se recogieron datos correspondientes a las aberraciones oculares de alto orden a través del análisis individualizado de los polinomios de Zernike. Las aberraciones individuales computadas en nuestros pacientes fueron el coma primario $\left(Z_{3}^{1}\right.$ y $\left.Z_{3}^{-1}\right)$ y el coma secundario $\left(Z_{5}^{1}\right.$ y $\left.Z_{5}^{-1}\right)$ para calcular el "comalike"; la aberración esférica primaria $\left(Z_{4}{ }^{0}\right)$ y la aberración esférica secundaria $\left(Z_{6}{ }^{0}\right)$ para calcular el "spherical-like"; igualmente, se obtuvieron el resto de términos de Zernike de tercer, cuarto y quinto orden $\left(Z_{3}{ }^{3}, Z_{3}{ }^{-3}, Z_{4}{ }^{2}, Z_{4}{ }^{-2}, Z_{4}{ }^{4}, Z_{4}{ }^{-4}, Z_{5}{ }^{3}, Z_{5}{ }^{-3}, Z_{5}{ }^{5} y\right.$ 
$\mathrm{Z}_{5}{ }^{-5}$ ) con el objetivo de calcular los valores correspondientes a las aberraciones de alto orden totales en términos de "RMS" (Root Mean Square). Tanto la tomografía de coherencia óptica como la topografía se intentaron obtener siempre entre las 11:00 y las 13:00 horas, y siempre las realizó el mismo observador (MCG) y en las mismas condiciones de iluminación.

Tanto en el grupo caso como control también se obtuvieron los siguientes datos: agudeza visual corregida y auto-refracción (esfera, cilindro y eje) en todas las visitas preoperatorias y a la semana, al mes y a los tres meses de la cirugía de catarata, aunque pasados 3 meses no es de esperar que ocurra ninguna variación en la paquimetría relacionada con una facoemulsificación no complicada.

\subsection{ANÁLISIS ESTADÍSTICO}

Los datos obtenidos en los diferentes estudios fueron procesados y analizados mediante el programa SPSS versión 19.0 y el programa R versión 3.1.1 para Windows.

\subsubsection{ESTUDIO PILOTO DEL ANÁLISIS DEL ESPESOR CORNEAL POR CAPAS EN PACIENTES OPERADOS DE CATARATA}

Se utilizaron los siguientes estadísticos descriptivos: media y desviación estándar (DE) para variables que seguían una distribución normal, mientras que para variables que no seguían distribución normal se calcularon la mediana (percentil 50) 
y rango intercuartil (valores comprendidos entre los percentiles 25 y 75). En todos los casos también se determinó el rango de la muestra.

Se comprobó la distribución normal de las distintas variables con el test Saphiro-Wilk. En las variables que mostraron normalidad se realizó metodología estadística de análisis de varianza para muestras relacionadas (termino anglosajón ANOVA) (Bland, 2000) y un ajuste de comparaciones múltiples (Bonferroni). En las variables que no mostraron normalidad, se utilizó el test de Friedman y posteriormente el test de rangos de Wilcoxon. Para todos los test estadísticos se consideró significativamente estadística una probabilidad $p \leq 0.05$.

\subsubsection{ESTUDIO DE FIABILIDAD DE MEDIDA: REPETIBILIDAD INTRAOBSERVADOR $\quad Y \quad$ REPRODUCIBILIDAD INTEROBSERVADOR DE LAS MEDIDAS DE ESPESOR CORNEAL POR CAPAS CON CIRRUS HD-OCT.}

\subsubsection{1. $\quad$ Repetibilidad Intraobservador:}

Para evaluar la concordancia entre las medidas por el observador principal (Observador 1), calculamos la media global y la desviación estándar intrasujeto $\left(\mathrm{DE}_{\mathrm{i}}\right)$ de cada una de las medias para las variables espesor corneal total, epitelio y córnea total no epitelial. La $\mathrm{DE}_{\mathrm{i}}$ corresponde a la raíz cuadrada de los cuadrados medios intra-sujetos (Bland y Altman, 1996a) y se define como la media de las desviaciones típicas de las 5 mediciones realizadas en 
cada sujeto. También se calculó un intervalo de confianza (IC) del 95\% para este estimador.

Por otro lado se calculó la repetibilidad, que se define como 2.77 veces la $D E_{1}$ y representa el valor máximo esperable de la diferencia entre dos medidas consecutivas con una probabilidad de un 95\% (Altman, 1983; Bland, Altman, 1996a; Bland, 2000).

También se calculó el coeficiente de correlación intraclase $(\mathrm{CCl})$ (Bland, 2000) y el coeficiente de variación intrasujeto $\left(\mathrm{CV}_{\mathrm{i}}\right)$, que se define como $\mathrm{DE}_{\mathrm{i}} /$ media $\times 100$, y se expresa de manera porcentual. El CCI expresa la proporción de la variabilidad total atribuible a diferencias entre individuos. Sus valores oscilan entre 0 y 1 , siendo 1 el valor de máxima concordancia. Dicha interpretación es justo la contraria para el $\mathrm{CV}_{\mathrm{i}}$, cuanto menor sea éste mayor será el grado de repetibilidad.

Se calculó la media y la DE para las variables. La normalidad de la distribución se comprobó mediante el test Shapiro-Wilk. El coeficiente de correlación de Spearman se utilizó para evaluar la asociación entre la media de las medidas paquimétricas y la DE de las 5 lecturas previamente al análisis de fiabilidad. Se consideró significativa una $p \leq 0.05$.

\subsubsection{Reproducibilidad Interobservador:}

Para estimar la concordancia entre dos observadores, un segundo observador (Observador 2) obtuvo una única imagen corneal mediante Cirrus HD-OCT. Las medidas de la primera imagen tomada por el observador 1 fueron comparadas con las del observador 2. El orden de las medias 
realizadas por cada uno de los observadores fue aleatorio y en un corto periodo de tiempo para evitar la fatiga del paciente.

En primer lugar la normalidad de la distribución se comprobó mediante el test Shapiro-Wilk. También se realizó el test t de Student para muestras pareadas para establecer si hubo errores sistemáticos significativos entre el observador 1 y el observador 2 empleando un mismo dispositivo de medición. En caso de variables no paramétricas se utilizó el test de Wilcoxon. Se calculó la media de las diferencias entre las medidas de los observadores 1 y 2 con un intervalo de confianza del 95\%, así como la DE y la significación estadística de las diferencias ( $p \leq 0.05)$.

Se calcularon igualmente la $D E_{i}$, la reproducibilidad $\left(2.77 \times D E_{i}\right)$ y el $C_{i}$ expresado como un porcentaje.

Se utilizó el gráfico de Bland y Altman (Altman y Bland, 1983) para evaluar la concordancia entre dos métodos de medida, en este caso entre los dos observadores. En este gráfico se representa la diferencia de las medidas obtenidas por ambos observadores frente a la magnitud media de las medidas. Permite visualizar gráficamente el grado de concordancia entre dos observadores y establecer por tanto el grado de acuerdo entre ellos, de tal forma que no solo se pueden observar las diferencias sistemáticas, sino también las posibles modificaciones de la concordancia en función de la magnitud media. Se espera que la diferencia promedio sea de 0 y que el $95 \%$ de las diferencias se encuentren dentro de 1.96 veces la DE de dicho promedio. Se representan tanto la media de las diferencias como los límites de concordancia (LC) superior e inferior. 
Los LC se definieron como la media de la diferencia de las mediciones entre ambos examinadores \pm 1.96 veces la $\mathrm{DE}$ de la diferencia entre examinadores, donde el LC superior es la media + 1.96 DE y el LC inferior la media - 1.96 DE. La amplitud de los LC es la diferencia entre ambos límites (Bland, 2000).

En el caso en que el análisis gráfico convencional tipo Bland \& Altman demostrase que las diferencias en las medidas de los distintos grosores corneales obtenidos por ambos observadores tendían a ser mayores y/o menores en función de la magnitud de dichos grosores de forma significativa, conjuntamente con el análisis Bland \& Altman convencional, también se aplicó el modelo de regresión basado en los residuos absolutos descrito igualmente por Bland \& Altman (1999), para conseguir un mejor ajuste tanto para la diferencia media entre observadores como para los LC calculados. Dicho modelo de regresión define de mejor forma la relación entre la diferencia y la magnitud media de las medidas de los grosores corneales, dando lugar a una mejor descripción de la diferencia media entre ambos observadores (Bland \& Altman, 1999).

Se calculó la media y la DE para las variables con distribución normal. La distribución fue analizada mediante el test Shapiro-Wilk. El coeficiente de correlación de Spearman se utilizó para evaluar la asociación entre la media de las medidas paquimétricas y la DE de las 2 lecturas (reproducibilidad interobservador) previamente al análisis de fiabilidad. Se consideró significativa una $p \leq 0.05$. 


\subsubsection{DISEÑO DEL ESTUDIO CLÍNICO: DETERMINACIÓN DE LOS CAMBIOS ABERROMÉTRICOS Y EN EL GROSOR POR CAPAS DE LA CÓRNEA TRAS CIRUGÍA DE CATARATA CON FACOEMULSIFICACIÓN}

Se utilizaron los siguientes estadísticos descriptivos para el análisis: media, intervalo de confianza para la media al 95\% (límite superior, límite inferior) y DE para variables que seguían una distribución normal, mientras que para variables que no seguían distribución normal se calcularon la mediana (percentil 50) y el rango intercuartil (valores comprendidos entre los percentiles 25 y 75). Se consideró significativa una $p \leq 0.05$.

En el estudio clínico utilizamos modelos lineales de efectos mixtos (Linear Mixed Effects Models). Estos modelos se basan en la idea de que los patrones individuales de las respuestas van a depender, probablemente, de muchas características de cada individuo, incluyendo algunas que no son observadas. Para incluir estas características en el modelo se utilizan los efectos aleatorios. Aparecen como una generalización de los modelos lineales en los que no es posible asumir la independencia, y en estos casos, con medidas repetidas, es muy difícil pensar que la medición de un individuo en un momento concreto, va a ser independiente de lo que se observó en momentos anteriores.

Una posible desventaja de este tipo de modelos es que si se utiliza la variable tiempo como variable cuantitativa, se asume que la evolución en el tiempo de la variable de interés es una función lineal y esto no tiene por qué ser cierto. Para evitar este sesgo se puede modelizar el tiempo como variable categórica. 
Para cada una de las variables cuantitativas analizadas, ajustamos un modelo en el que se incluían dos factores, el grupo y el tiempo, junto con todas las interacciones.

Los efectos se contrastaron de manera global utilizando una tabla ANOVA. Para cuantificar los efectos se estimaron las medias marginales (Least Squares Means) y sus diferencias para los efectos que resultaran estadísticamente significativos, junto con intervalos de confianza y p-valores.

De este modo, analizamos a) si la media de cada variable cambiaba a lo largo del tiempo, b) si la media de cada variable se modificaba según el grupo al que perteneciera el paciente -caso o control-, y c) si la evolución en el tiempo de cada variable se modificaba según el grupo.

El análisis se realizó con el software $R$ versión 3.1.1, utilizando el package Ime4 (Bates y cols., 2014) para el ajuste de los modelos mixtos y el package ImerTest (Kuznetsova y cols., 2014) para la estimación de las medias y sus diferencias.

Posteriormente, se realizó un análisis post-hoc para determinar si existían asociaciones entre las variables en las que se produjeron modificaciones significativas en los diferentes grosores corneales y aquellas que variaron significativamente en relación a la calidad óptica de la córnea. Para ello se realizaron análisis de correlación de Pearson y de Spearman en función de la normalidad de cada variable. 

RESULTADOS 



\section{RESULTADOS}

\subsection{ESTUDIO PILOTO DEL ANÁLISIS DEL ESPESOR CORNEAL POR CAPAS EN PACIENTES OPERADOS DE CATARATA}

La variación en el grosor epitelial y corneal total no epitelial tras cirugía de cataratas mediante facoemulsificación se estudió en una muestra de 20 pacientes, 9 mujeres y 11 varones, con una media de edad de $72.2 \pm 8.8$ años (Rango: $55-86$ ). De los 20 ojos analizados, 9 eran ojos derechos y 11 izquierdos. La media de la potencia de la LIO fue $21.00 \pm 2.81$ dioptrías (Rango 13.00-25.00 D). La agudeza visual corregida (AVC) media antes de la cirugía, a la semana y al mes fue $0.42 \pm$ 0.21, $0.11 \pm 0.13$ y $0.05 \pm 0.07$ logaritmo del mínimo ángulo de resolución (LogMAR) respectivamente. Existieron diferencias significativas $(p \leq 0.001)$ entre la AVC media preoperatoria y la medida a la semana y al mes; además, la AVC al mes fue también significativamente mayor $(p=0.01)$ que a la semana.

En la Tablas 3, 4 y 5 se presentan los valores para la paquimetría total, el espesor epitelial y el espesor corneal total no epitelial medidos en la zona central, peri-incisional o paracentral a $180^{\circ}$ y contra-incisional o paracentral a $0^{\circ}$, antes de la cirugía, a la semana y al mes de la misma. La variable epitelio corneal no cumplió criterios de normalidad por lo que se presentan los valores de mediana y rango intercuartil (Tabla 3). Los valores del espesor epitelial variaron significativamente $(\mathrm{p}<$ 0.01) al mes de la cirugía frente a los valores preoperatorios en cualquiera de las localizaciones analizadas. No se encontraron diferencias significativas cuando se compararon con los valores a la semana de la cirugía. 
Encontramos diferencias estadísticamente significativas entre el espesor no epitelial en el periodo preoperatorio y una semana después de la cirugía para las tres localizaciones analizadas, sin embargo, tras un mes de la cirugía el incremento no fue significativo (Tabla 4). Además, los incrementos del espesor corneal total no epitelial fueron significativamente mayores $(p=0.02)$ a la semana en las localizaciones central y paracentral a $180^{\circ}$ comparados con la localización paracentral a $0^{\circ}$.

El espesor corneal total medio preoperatorio era ligeramente menor a nivel central $(543 \pm 35.4 \mu \mathrm{m})$ que en las zonas paracentrales $(556 \pm 35.5 \mu \mathrm{m}$ y $554.1 \pm$ 35.1 $\mu \mathrm{m})$ como se aprecia en la tabla 5. La paquimetría total se incrementó significativamente una semana tras la cirugía en las localizaciones central y paracentrales, sin embargo no encontramos diferencias significativas entre el incremento acontecido en cada localización (central, paracentral a $180^{\circ}$ y paracentral a $0^{\circ}$ ) como ocurría en el caso del espesor corneal total no epitelial (Tabla 4). Los valores del espesor corneal total al mes de la cirugía no fueron significativamente mayores a los valores preoperatorios. 
Tabla 3: Estadísticos descriptivos para el espesor epitelial, en las tres zonas de medida en los tres periodos de tiempo.

\begin{tabular}{|c|c|c|c|c|c|}
\hline \multirow{3}{*}{$\begin{array}{l}\text { Localización } \\
\text { Grosor } \\
\text { Epitelial }\end{array}$} & \multicolumn{5}{|c|}{ Momento de Adquisición } \\
\hline & \multirow{2}{*}{$\begin{array}{c}\text { Preoperatorio } \\
\\
\text { Media } \pm \text { DE } \\
\text { Mediana (RI) } \\
\text { (Rango) }(\mu \mathrm{m})\end{array}$} & \multicolumn{2}{|l|}{1 Semana } & \multicolumn{2}{|l|}{1 Mes } \\
\hline & & $\begin{array}{l}\text { Media } \pm \text { DE } \\
\text { Mediana (RI) } \\
\text { (Rango) }(\mu \mathrm{m})\end{array}$ & $\begin{array}{c}\text { Cambio } \\
\text { respecto a } \\
\text { basal } \\
\text { Media } \pm \text { DE } \\
\text { Mediana } \\
(\mathrm{RI})(\mu \mathrm{m})\end{array}$ & $\begin{array}{l}\text { Media } \pm \text { DE } \\
\text { Mediana }(\mathrm{RI}) \\
\text { Rango }(\mu \mathrm{m})\end{array}$ & $\begin{array}{c}\text { Cambio } \\
\text { respecto a } \\
\text { basal } \\
\text { Media } \pm \mathrm{DE} \\
\text { Mediana (RI) } \\
(\mu \mathrm{m})\end{array}$ \\
\hline Central & $\begin{array}{c}57.2 \pm 4.8 \\
56.0(52.0 / 56.0) \\
(48 / 64) \\
\end{array}$ & $\begin{array}{c}57.6 \pm 4.7 \\
58.0(53.0 / 58.0) \\
(48 / 64) \\
\end{array}$ & $\begin{array}{c}0.4 \pm 7.4 \\
0.0(-4.0 / 0.0)\end{array}$ & $\begin{array}{c}52.7 \pm 3.8 \dagger \\
52.0(48.0 / 52.0) \\
(48 / 60)\end{array}$ & $\begin{array}{c}-4.5 \pm 5.5 \\
-4.0(-8.0 /-4.0)\end{array}$ \\
\hline $\begin{array}{l}\text { Paracentral } \\
\left(180^{\circ}\right)\end{array}$ & $\begin{array}{c}58.0 \pm 5.7 \\
56.0(48.0 / 72.0) \\
(48 / 72) \\
\end{array}$ & $\begin{array}{c}59.2 \pm 6.8 \\
60.0(56.0 / 60.0) \\
(44 / 72) \\
\end{array}$ & $\begin{array}{c}1.2 \pm 9.3 \\
0.0(-4.0 / 0.0)\end{array}$ & $\begin{array}{c}53.1 \pm 5.4 \dagger \\
52.0(48.0 / 52.0) \\
(44 / 64)\end{array}$ & $\begin{array}{c}-4.9 \pm 5.5 \\
-4.0(-8.0 /-4.0)\end{array}$ \\
\hline $\begin{array}{l}\text { Paracentral } \\
\left(0^{\circ}\right)\end{array}$ & $\begin{array}{c}56.6 \pm 5.3 \\
58.0(52.0 / 58.0) \\
(48 / 68) \\
\end{array}$ & $\begin{array}{c}59.2 \pm 6.3 \\
60.0(56.0 / 60.0) \\
(44 / 72) \\
\end{array}$ & $\begin{array}{c}2.6 \pm 7.4 \\
4.0(0.0 / 4.0)\end{array}$ & $\begin{array}{c}\mathbf{5 2 . 7} \pm \mathbf{5 . 3 \dagger} \\
52.0(48.0 / 53.0) \\
(44 / 68)\end{array}$ & $\begin{array}{c}-3.9 \pm 5.5 \\
-4.0(-9.0 /-4.0)\end{array}$ \\
\hline
\end{tabular}

DE: Desviación estándar; RI: Rango intercuartil; † $\mathrm{p}<0.01$, test de Wilcoxon tras test de Friedman en el que se comparan valores preoperatorios con 1 semana y 1 mes. 
Tabla 4: Estadísticos descriptivos para el espesor corneal total no epitelial, en las tres zonas de medida en los tres periodos de tiempo.

\begin{tabular}{|c|c|c|c|c|c|}
\hline \multirow{3}{*}{$\begin{array}{l}\text { Localización } \\
\text { Grosor Total } \\
\text { no } \\
\text { Epitelial }\end{array}$} & \multicolumn{5}{|c|}{ Momento de Adquisición } \\
\hline & \multirow{2}{*}{$\begin{array}{c}\text { Preoperatorio } \\
\text { Media } \pm \text { DE } \\
\text { (Rango) }(\mu \mathrm{m})\end{array}$} & \multicolumn{2}{|c|}{1 Semana } & \multicolumn{2}{|l|}{1 Mes } \\
\hline & & $\begin{array}{c}\text { Media } \pm \mathrm{DE} \\
(\text { Rango) }(\mu \mathrm{m})\end{array}$ & $\begin{array}{l}\text { Cambio } \\
\text { respecto a } \\
\text { basal }(\mu \mathrm{m})\end{array}$ & $\begin{array}{l}\text { Media } \pm \text { DE } \\
\text { Rango }(\mu \mathrm{m})\end{array}$ & $\begin{array}{l}\text { Cambio } \\
\text { respecto a } \\
\text { basal }(\mu \mathrm{m})\end{array}$ \\
\hline Central & $\begin{array}{c}486.2 \pm 34.7 \\
(424 / 548)\end{array}$ & $\begin{array}{c}\mathbf{5 1 5 . 5} \pm \mathbf{3 9 . 6} \\
(435 / 584) \\
\end{array}$ & $29.3 \pm 17.2 ¥$ & $\begin{array}{c}493.1 \pm 37.3 \\
(428 / 576)\end{array}$ & $6.9 \pm 12.2$ \\
\hline $\begin{array}{l}\text { Paracentral } \\
\left(180^{\circ}\right)\end{array}$ & $\begin{array}{c}498.2 \pm 33.8 \\
(416 / 548)\end{array}$ & $\begin{array}{c}534.3 \pm \mathbf{4 5 . 6} \\
(452 / 618)\end{array}$ & $36.1 \pm 28.79$ & $\begin{array}{c}507.5 \pm 36.8 \\
(440 / 568)\end{array}$ & $9.3 \pm 30.1$ \\
\hline $\begin{array}{l}\text { Paracentral } \\
\left(0^{\circ}\right)\end{array}$ & $\begin{array}{c}497.5 \pm 32.3 \\
(436 / 548)\end{array}$ & $\begin{array}{c}\mathbf{5 2 1 . 3} \pm \mathbf{3 6 . 9} \ddagger \\
(456 / 592)\end{array}$ & $23.8 \pm 16.5$ & $\begin{array}{c}503.3 \pm 38.7 \\
(440 / 588)\end{array}$ & $5.8 \pm 19.5$ \\
\hline
\end{tabular}

DE: Desviación estándar; RI: Rango intercuartil; $\ddagger \mathrm{P}<0.01$, test de comparaciones múltiples de Bonferroni posthoc tras analisis de varianza en el que se comparan valores preoperatorios con 1 semana y 1 mes; $¥ \mathrm{P}=0.02$, test de Wilcoxon tras test de Friedman en el que se comparan los cambios del espesor no epitelial entre la zona central y la zona paracentral a $0^{\circ}$; ๆ $\mathrm{P}=0.02$, test de Wilcoxon tras test de Friedman en el que se comparan los cambios del espesor no epitelial entre la zona paracentral a $180^{\circ}$ y la zona paracentral a $0^{\circ}$. 
Tabla 5: Estadísticos descriptivos para el espesor corneal total, en las tres zonas de medida en los tres periodos de tiempo.

\begin{tabular}{|c|c|c|c|c|c|}
\hline \multirow{3}{*}{$\begin{array}{l}\text { Localización } \\
\text { Grosor Total }\end{array}$} & \multicolumn{5}{|c|}{ Momento de Adquisición } \\
\hline & \multirow{2}{*}{$\begin{array}{c}\text { Preoperatorio } \\
\text { Media } \pm \text { DE } \\
\text { (Rango) }(\mu \mathrm{m})\end{array}$} & \multicolumn{2}{|c|}{1 Semana } & \multicolumn{2}{|l|}{$1 \mathrm{Mes}$} \\
\hline & & $\begin{array}{c}\text { Media } \pm \text { DE } \\
\text { (Rango) }(\mu \mathrm{m})\end{array}$ & $\begin{array}{l}\text { Cambio } \\
\text { respecto a } \\
\text { basal }(\mu \mathrm{m})\end{array}$ & $\begin{array}{l}\text { Media } \pm \text { DE } \\
\text { Rango }(\mu \mathrm{m})\end{array}$ & $\begin{array}{l}\text { Cambio } \\
\text { respecto a } \\
\text { basal }(\mu \mathrm{m})\end{array}$ \\
\hline Central & $\begin{array}{c}543.4 \pm 35.4 \\
(476 / 600)\end{array}$ & $\begin{array}{c}573.0 \pm 39.2 \ddagger \\
(496 / 644)\end{array}$ & $29.6 \pm 17.1$ & $\begin{array}{c}545.8 \pm 38.9 \\
(476 / 636)\end{array}$ & $2.4 \pm 14.2$ \\
\hline $\begin{array}{l}\text { Paracentral } \\
\left(180^{\circ}\right)\end{array}$ & $\begin{array}{c}556.2 \pm 35.5 \\
(476 / 604)\end{array}$ & $\begin{array}{c}590.8 \pm 41.9 \ddagger \\
(520 / 664)\end{array}$ & $34.6 \pm 26.2$ & $\begin{array}{c}560.6 \pm 37.7 \\
(492 / 624)\end{array}$ & $4.4 \pm 31.5$ \\
\hline $\begin{array}{l}\text { Paracentral } \\
\left(0^{\circ}\right)\end{array}$ & $\begin{array}{c}554.1 \pm 35.1 \\
(488 / 612)\end{array}$ & $\begin{array}{c}\mathbf{5 8 0 . 4} \mathbf{5} \mathbf{3 6 . 7} \ddagger \\
(512 / 652)\end{array}$ & $26.3 \pm 16.5$ & $\begin{array}{c}556.0 \pm 41.7 \\
(488 / 656)\end{array}$ & $1.9 \pm 20.7$ \\
\hline
\end{tabular}

DE: Desviación estándar; RI: Rango intercuartil; $¥ \mathrm{P}<0.01$, test de comparaciones múltiples de Bonferroni posthoc tras analisis de varianza en el que se comparan valores preoperatorios con 1 semana y 1 mes.

6.2. ESTUDIO DE FIABILIDAD DE MEDIDA: REPETIBILIDAD INTRAOBSERVADOR Y REPRODUCIBILIDAD INTEROBSERVADOR DE LAS MEDIDAS DE ESPESOR CORNEAL POR CAPAS CON CIRRUS HD-OCT

40 ojos (20 izquierdos, 20 derechos) de 40 pacientes operados de catarata (19 mujeres, 21 varones), y 40 ojos (17 izquierdos, 23 derechos) de 40 voluntarios no operados (23 mujeres, 17 varones) fueron evaluados. La media de edad en el 
grupo de pacientes operados fue $72.8 \pm 8.9$ años (Rango: $48-87$ ) y de $67.3 \pm 11.8$ años (Rango: 42-76) en el grupo de no operados.

\subsubsection{REPETIBILIDAD INTRAOBSERVADOR}

En la tabla 6 se presentan la media global, la $D E_{i}$, el $C V_{i}$, la repetibilidad intraobservador y el CCl para el espesor corneal total central, espesor epitelial central y espesor corneal total no epitelial central para ambos grupos (operados y no operados). El $\mathrm{CV}_{\mathrm{i}}$ intraobservador (0.8\%) así como el $\mathrm{CCl}(0.97)$ para el espesor no epitelial y el espesor corneal central fueron excelentes, mientras que para el epitelio fueron aceptables (3.8\% y 0.73 respectivamente). No se encontraron diferencias estadísticamente significativas $(p>0.05)$ en los valores de repetibilidad entre el grupo de operados y no operados. 
Tabla 6: Repetibilidad intraobservador para la medida del espesor corneal por capas.

\begin{tabular}{|c|c|c|c|c|c|}
\hline \multirow[b]{2}{*}{$\begin{array}{l}\text { ESPESOR } \\
\text { CENTRAL }\end{array}$} & \multicolumn{5}{|c|}{ Repetibilidad Intraobservador } \\
\hline & $\begin{array}{c}\text { Media global } \\
\text { (Rango) } \\
(\mu \mathrm{m})\end{array}$ & $\begin{array}{c}\mathrm{DE}_{\mathrm{i}} \\
(95 \% \mathrm{IC} \\
\mathrm{LS}-\mathrm{LI}) \\
(\mu \mathrm{m})\end{array}$ & $\begin{array}{c}\text { Repetibilidad } \\
2.77 \mathrm{DE}_{\mathrm{i}} \\
(95 \% \text { IC LS-LI) } \\
(\mu \mathrm{m}) \\
\end{array}$ & $\begin{array}{c}\mathrm{CV}_{\mathrm{i}}(\%) \\
(95 \% \mathrm{IC} \\
\text { LS-LI) }\end{array}$ & $\begin{array}{c}\text { CCI } \\
\text { (95\% IC } \\
\text { LS-LI) }\end{array}$ \\
\hline \multicolumn{6}{|l|}{ Epitelio } \\
\hline No operados & $\begin{array}{c}51.4 \\
(45-57) \\
\end{array}$ & $\begin{array}{c}1.9 \\
(1.6-2.3)\end{array}$ & $\begin{array}{c}5.2 \\
(4.4-6.4)\end{array}$ & $\begin{array}{c}3.8 \\
(3.1-4.4) \\
\end{array}$ & $\begin{array}{c}0.73 \\
(0.61-0.80) \\
\end{array}$ \\
\hline Operados & $\begin{array}{c}53.6 \\
(44-64) \\
\end{array}$ & $\begin{array}{c}2.0 \\
(1.6-2.4) \\
\end{array}$ & $\begin{array}{c}5.5 \\
(4.4-7.5) \\
\end{array}$ & $\begin{array}{c}3.7 \\
(2.9-4.4) \\
\end{array}$ & $\begin{array}{c}0.80 \\
(0.71-0.87) \\
\end{array}$ \\
\hline \multicolumn{6}{|c|}{ Córnea Total no Epitelial } \\
\hline No operados & $\begin{array}{c}496.4 \\
(486-506) \\
\end{array}$ & $\begin{array}{c}4.2 \\
(3.4-5.1) \\
\end{array}$ & $\begin{array}{c}11.6 \\
(9.4-14.1) \\
\end{array}$ & $\begin{array}{c}0.8 \\
(0.7-1.0) \\
\end{array}$ & $\begin{array}{c}0.97 \\
(0.96-0.98) \\
\end{array}$ \\
\hline Operados & $\begin{array}{c}482.5 \\
(471-493)\end{array}$ & $\begin{array}{c}3.6 \\
(2.8-4.5)\end{array}$ & $\begin{array}{c}9.9 \\
(7.7-12.4)\end{array}$ & $\begin{array}{c}0.7 \\
(0.6-0.9)\end{array}$ & $\begin{array}{c}0.98 \\
(0.97-0.99)\end{array}$ \\
\hline \multicolumn{6}{|l|}{ Córnea Total } \\
\hline No operados & $\begin{array}{c}547.6 \\
(478-618) \\
\end{array}$ & $\begin{array}{c}3.6 \\
(2.7-4.5) \\
\end{array}$ & $\begin{array}{c}9.9 \\
(7.5-12.4)\end{array}$ & $\begin{array}{c}0.7 \\
(0.5-0.8)\end{array}$ & $\begin{array}{c}0.98 \\
(0.97-0.98) \\
\end{array}$ \\
\hline Operados & $\begin{array}{c}536.0 \\
(473-611) \\
\end{array}$ & $\begin{array}{c}3.0 \\
(2.1-3.8) \\
\end{array}$ & $\begin{array}{c}8.3 \\
(5.8-10.5) \\
\end{array}$ & $\begin{array}{c}0.6 \\
(0.4-0.7) \\
\end{array}$ & $\begin{array}{c}0.99 \\
(0.98-0.99)\end{array}$ \\
\hline
\end{tabular}

$\mathrm{DE}_{\mathrm{i}}$ : Desviación estándar intra-sujeto; IC: Intervalo de confianza; LS: Límite Superior; LI: Límite Inferior; $\mathrm{CV}_{\mathrm{i}}$ :

Coeficiente de variación intra-sujeto; CCI: Coeficiente de correlación intraclase.

\subsubsection{REPRODUCIBILIDAD INTEROBSERVADOR}

En la tabla 7 se presentan la media global interobservador, la $\mathrm{DE}_{\mathrm{i}}$, el $\mathrm{CV}_{\mathrm{i}}$, la reproducibilidad interobservador y el $\mathrm{CCl}$ para el espesor corneal central, espesor epitelial central y espesor corneal total no epitelial a nivel central para ambos grupos 
(operados y no operados). De la misma forma que ocurría en el análisis de la repetibilidad intraobservador, los valores de $\mathrm{CV}_{\mathrm{i}}$ y $\mathrm{CCl}$ para el espesor corneal total no epitelial fueron excelentes. La media de las diferencias entre observadores para el espesor epitelial en el grupo de no operados y de operados fue de 0.08 (IC 95\%: $-0.59 / 0.75) \mu \mathrm{m}$ y 0.45 (IC 95\%: -0.28/1.18) $\mu \mathrm{m}$; para el espesor corneal total no epitelial fue 1.81 (IC 95\%: 0.17/3.44) $\mu \mathrm{m}$ y -0.9 (IC 95\%: -2.69/0.89) $\mu \mathrm{m}$; y para el espesor corneal total fue de 1.7 (IC 95\%: 0.43/2.97) $\mu \mathrm{m}$ y -0.56 (IC 95\%: -2.13/1.01) $\mu \mathrm{m}$, respectivamente. No se encontraron diferencias estadísticamente significativas ( $p>0.05)$ entre el grupo de operados y no operados en el análisis de la reproducibilidad interobservador a la hora de comparar las distintas medidas realizadas. 
Tabla 7: Reproducibilidad Interobservador para el análisis de espesor corneal por capas.

\begin{tabular}{|c|c|c|c|c|c|}
\hline \multirow[b]{2}{*}{$\begin{array}{l}\text { ESPESOR } \\
\text { CENTRAL }\end{array}$} & \multicolumn{5}{|c|}{ Reproducibilidad Interobservador } \\
\hline & $\begin{array}{c}\text { Media global } \\
(\text { Rango }) \\
(\mu \mathrm{m})\end{array}$ & $\begin{array}{c}\mathrm{DE}_{\mathrm{i}} \\
(95 \% \mathrm{IC} \\
\mathrm{LS}-\mathrm{LI}) \\
(\mu \mathrm{m})\end{array}$ & $\begin{array}{c}\text { Reproducibilidad } \\
2.77 \mathrm{DE}_{\mathrm{i}} \\
(95 \% \mathrm{IC} \\
\text { LS-LI) }\end{array}$ & $\begin{array}{c}\mathrm{CV}_{\mathrm{i}}(\%) \\
\text { (95\% IC } \\
\text { LS-LI) }\end{array}$ & $\begin{array}{c}\mathrm{CCI} \\
\text { (95\% IC } \\
\text { LS-LI) }\end{array}$ \\
\hline \multicolumn{6}{|l|}{ Epitelio } \\
\hline No operados & $\begin{array}{c}51.4 \\
(44-58)\end{array}$ & $\begin{array}{c}1.2 \\
(0.9-1.5)\end{array}$ & $\begin{array}{c}3.3 \\
(2.5-4.1)\end{array}$ & $\begin{array}{c}2.3 \\
(1.7-2.8)\end{array}$ & $\begin{array}{c}0.62 \\
(0.54-0.75)\end{array}$ \\
\hline Operados & $\begin{array}{c}53.4 \\
(42-64) \\
\end{array}$ & $\begin{array}{c}1.3 \\
(1.0-1.6)\end{array}$ & $\begin{array}{c}3.6 \\
(2.8-4.4)\end{array}$ & $\begin{array}{c}2.6 \\
(2.0-3.2)\end{array}$ & $\begin{array}{c}0.82 \\
(0.70-0.88)\end{array}$ \\
\hline \multicolumn{6}{|c|}{ Córnea Total no Epitelial } \\
\hline No operados & $\begin{array}{c}494.6 \\
(484-504)\end{array}$ & $\begin{array}{c}2.7 \\
(1.9-3.6)\end{array}$ & $\begin{array}{c}7.5 \\
(5.2-9.9)\end{array}$ & $\begin{array}{c}0.5 \\
(0.4-0.7)\end{array}$ & $\begin{array}{c}0.98 \\
(0.97-0.98)\end{array}$ \\
\hline Operados & $\begin{array}{c}483.4 \\
(473-493) \\
\end{array}$ & $\begin{array}{c}3.2 \\
(2.4-3.9)\end{array}$ & $\begin{array}{c}8.8 \\
(7.5-10.8)\end{array}$ & $\begin{array}{c}0.7 \\
(0.5-0.8)\end{array}$ & $\begin{array}{c}0.98 \\
(0.97-0.99)\end{array}$ \\
\hline \multicolumn{6}{|l|}{ Córnea Total } \\
\hline No operados & $\begin{array}{c}546.7 \\
(476-624) \\
\end{array}$ & $\begin{array}{c}2.2 \\
(1.5-2.8) \\
\end{array}$ & $\begin{array}{c}6.1 \\
(4.1-7.7) \\
\end{array}$ & $\begin{array}{c}0.4 \\
(0.3-0.5) \\
\end{array}$ & $\begin{array}{c}0.99 \\
(0.98-0.99)\end{array}$ \\
\hline Operados & $\begin{array}{c}536.2 \\
(473-612) \\
\end{array}$ & $\begin{array}{c}2.6 \\
(1.8-3.3)\end{array}$ & $\begin{array}{c}7.2 \\
(4.9-9.1)\end{array}$ & $\begin{array}{c}0.5 \\
(0.3-0.6)\end{array}$ & $\begin{array}{c}0.99 \\
(0.98-0.99)\end{array}$ \\
\hline
\end{tabular}

$\mathrm{DE}_{\mathrm{i}}$ : Desviación estándar intra-sujeto; IC: Intervalo de confianza; LS: Límite superior; LI: Límite inferior; $\mathrm{CV}_{\mathrm{i}}$ :

Coeficiente de variación intra-sujeto; CCl:Coeficiente de correlación intraclase.

El análisis de Bland y Altman representa gráficamente las diferencias entre las dos mediciones frente a su media. Los límites de acuerdo nos ofrecen el rango dentro del cual se espera que estén el 95\% de los errores de medición. La amplitud de los LC para el espesor central epitelial, corneal total no epitelial y corneal total en los grupos de pacientes operados y no operados fue de 10.4 y $10.9 \mu \mathrm{m} ; 24.6$ y 24.2 $\mu \mathrm{m}$ y 19.2 y $21.9 \mu \mathrm{m}$ respectivamente. Los límites superiores e inferiores de los LC 
para el espesor central epitelial, corneal total no epitelial y corneal total en ambos grupos se presentan en la tabla 8.

Tabla 8: Límites de concordancia al $95 \%$ superior e inferior correspondientes a la reproducibilidad interobservador.

\begin{tabular}{|c|c|c|c|c|c|c|}
\hline & \multicolumn{6}{|c|}{ Límites de Concordancia Interobservador } \\
\hline & \multicolumn{2}{|c|}{$\begin{array}{l}\text { Grosor Epitelial (95\% IC) } \\
\qquad(\mu \mathrm{m})\end{array}$} & \multicolumn{2}{|c|}{$\begin{array}{l}\text { Grosor Corneal Total no } \\
\text { Epitelial }(95 \% \text { IC) }(\mu \mathrm{m})\end{array}$} & \multicolumn{2}{|c|}{$\begin{array}{l}\text { Grosor Corneal Total (95\% } \\
\text { IC) }(\mu \mathrm{m})\end{array}$} \\
\hline GRUPO & $\begin{array}{l}\text { Límite } \\
\text { Superior }\end{array}$ & $\begin{array}{l}\text { Límite } \\
\text { Inferior }\end{array}$ & $\begin{array}{l}\text { Límite } \\
\text { Superior }\end{array}$ & $\begin{array}{l}\text { Límite } \\
\text { Inferior }\end{array}$ & $\begin{array}{l}\text { Límite } \\
\text { Superior }\end{array}$ & $\begin{array}{l}\text { Límite } \\
\text { Inferior }\end{array}$ \\
\hline $\begin{array}{l}\text { No } \\
\text { operados }\end{array}$ & $\begin{array}{c}5.3 \\
(4.1 / 6.5) \\
\end{array}$ & $\begin{array}{c}-5.1 \\
(-6.3 /-3.9) \\
\end{array}$ & $\begin{array}{c}14.1 \\
(11.2 / 16.9) \\
\end{array}$ & $\begin{array}{c}-10.5 \\
(-13.3 /-7.6) \\
\end{array}$ & $\begin{array}{c}11.3 \\
(9.1 / 13.5)\end{array}$ & $\begin{array}{c}-7.9 \\
(-10.1 /-5.7)\end{array}$ \\
\hline Operados & $\begin{array}{c}5.9 \\
(4.6 / 7.2)\end{array}$ & $\begin{array}{c}-5.0 \\
(-6.2 /-3.7)\end{array}$ & $\begin{array}{c}11.7 \\
(8.8 / 14.6)\end{array}$ & $\begin{array}{c}-13.5 \\
(-16.5 /-10.6)\end{array}$ & $\begin{array}{c}10.4 \\
(7.8 / 12.9)\end{array}$ & $\begin{array}{c}-11.5 \\
(-14.0 /-8.9)\end{array}$ \\
\hline
\end{tabular}

IC: Intervalo de confianza.

En los gráficos de Bland \& Altman para la variable espesor epitelial corneal se observa que en el grupo de operados, la nube de dispersión de los valores (puntos) es relativamente homogénea. Además, prácticamente no existen diferencias sistemáticas dado que la diferencia media se encuentra cercana al cero tanto en el grupo de operados como en el de no operados (Figuras 36 y 37 ). 


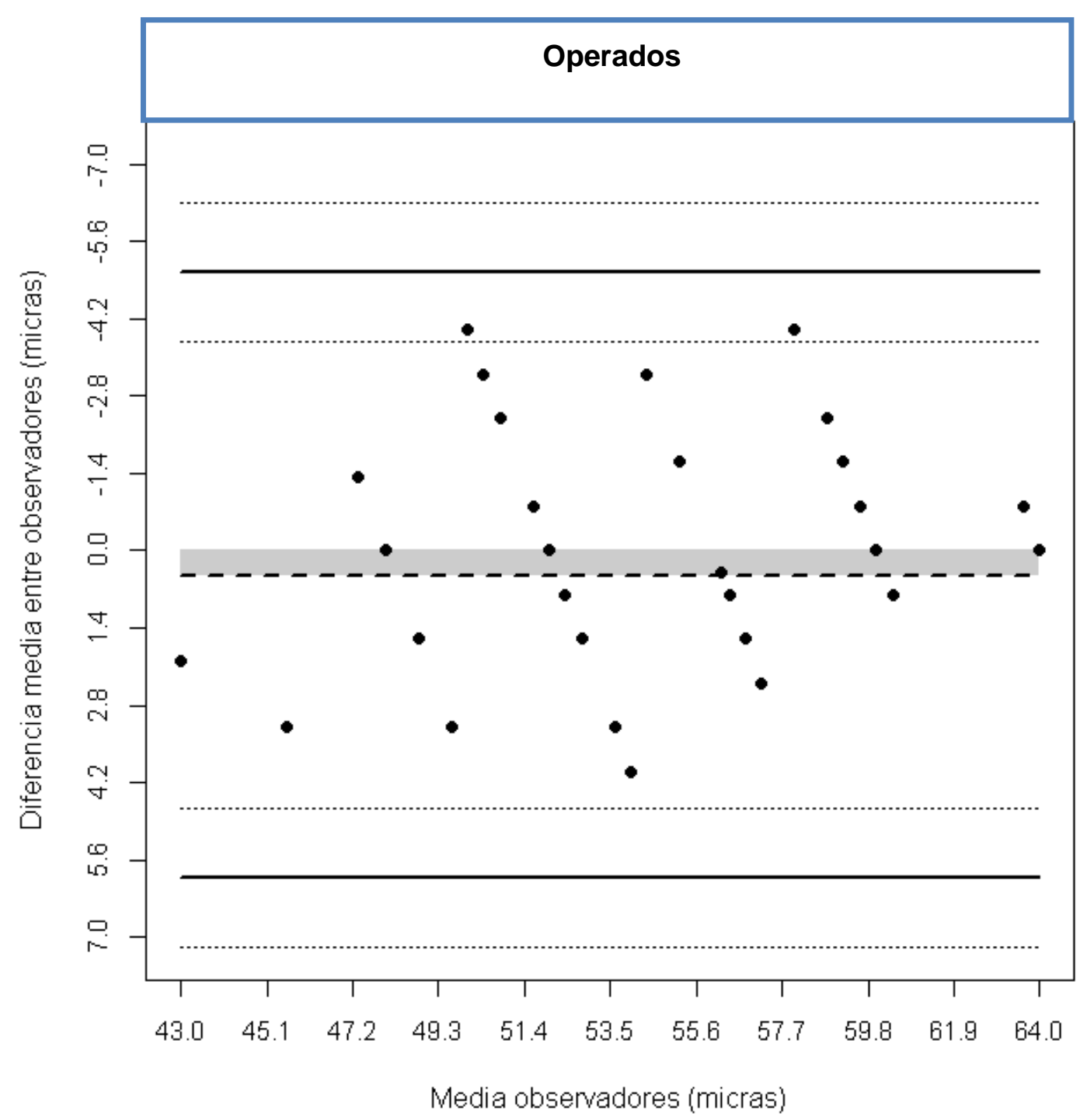

Figura 36: Gráfico tipo Bland \& Altman mostrando la distribución de las diferencias de las medias de la medida del espesor epitelial corneal en el grupo de pacientes operados entre el observador 1 y el observador 2. La línea central horizontal discontinua detalla la diferencia media, mientras que la zona sombreada en gris indica la diferencia de esa media respecto de cero. Las dos líneas horizontales continuas superior e inferior indican los límites de concordancia al 95\%, y las dos líneas discontinuas por encima y debajo de los límites de concordancia son los intervalos de confianza al 95\% para cada límite de concordancia estimado. 


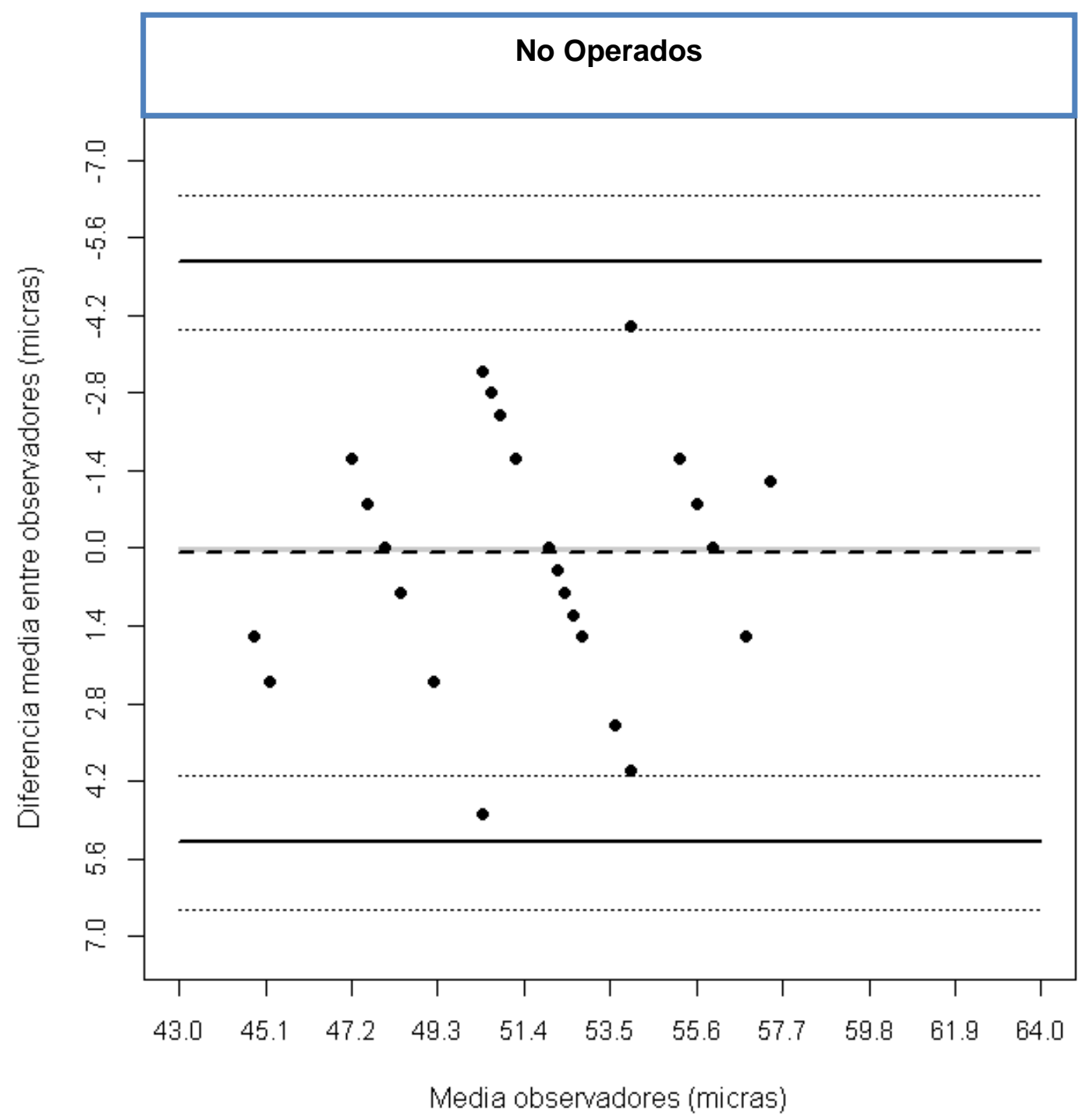

Figura 37: Gráfico tipo Bland \& Altman mostrando la distribución de las diferencias de las medias de la medida del espesor epitelial corneal en el grupo de pacientes no operados entre el observador 1 y el observador 2. La línea central horizontal discontinua detalla la diferencia media, mientras que la zona sombreada en gris (prácticamente no apreciable) indica la diferencia de esa media respecto de cero. Las dos líneas horizontales continuas superior e inferior indican los límites de concordancia al 95\%, y las dos líneas discontinuas por encima y debajo de los límites de concordancia son los intervalos de confianza al 95\% para cada límite de concordancia estimado. 
Al analizar el espesor corneal total no epitelial, se observó en los gráficos de Bland \& Altman que tanto en el grupo de operados como de no operados se rechazó la hipótesis de ausencia de correlación entre la diferencia y la media de los valores obtenidos. Existía una correlación positiva para el grupo de operados, es decir, existían diferencias cada vez más positivas a medida que la magnitud aumentaba $(p=0.04)$, mientras que para el grupo de no operados, existía una correlación negativa ( $p=0.031$ ). Es por ello por lo que se evaluó el acuerdo entre observadores en ambos grupos mediante un modelo de regresión de Bland \& Altman (1999) (Figuras 38 y 39).

Este análisis de regresión resultó en las siguientes ecuaciones para el cálculo de las rectas de regresión de los LC mostradas en las figuras 38 y 39:

\section{Grupo Operados:}

- Límite superior del LC= $-38.55+0.1 \times$ Media espesor corneal total no epitelial - Límite inferior del $\mathrm{LC}=-15.3+0.008 \times$ Media espesor corneal no epitelial

Grupo No operados:

- Límite superior del LC= $5.934-0.09 \times$ Media espesor corneal total no epitelial

- Límite inferior del $\mathrm{LC}=-33.909-0.082 \times$ Media espesor corneal total no epitelial 


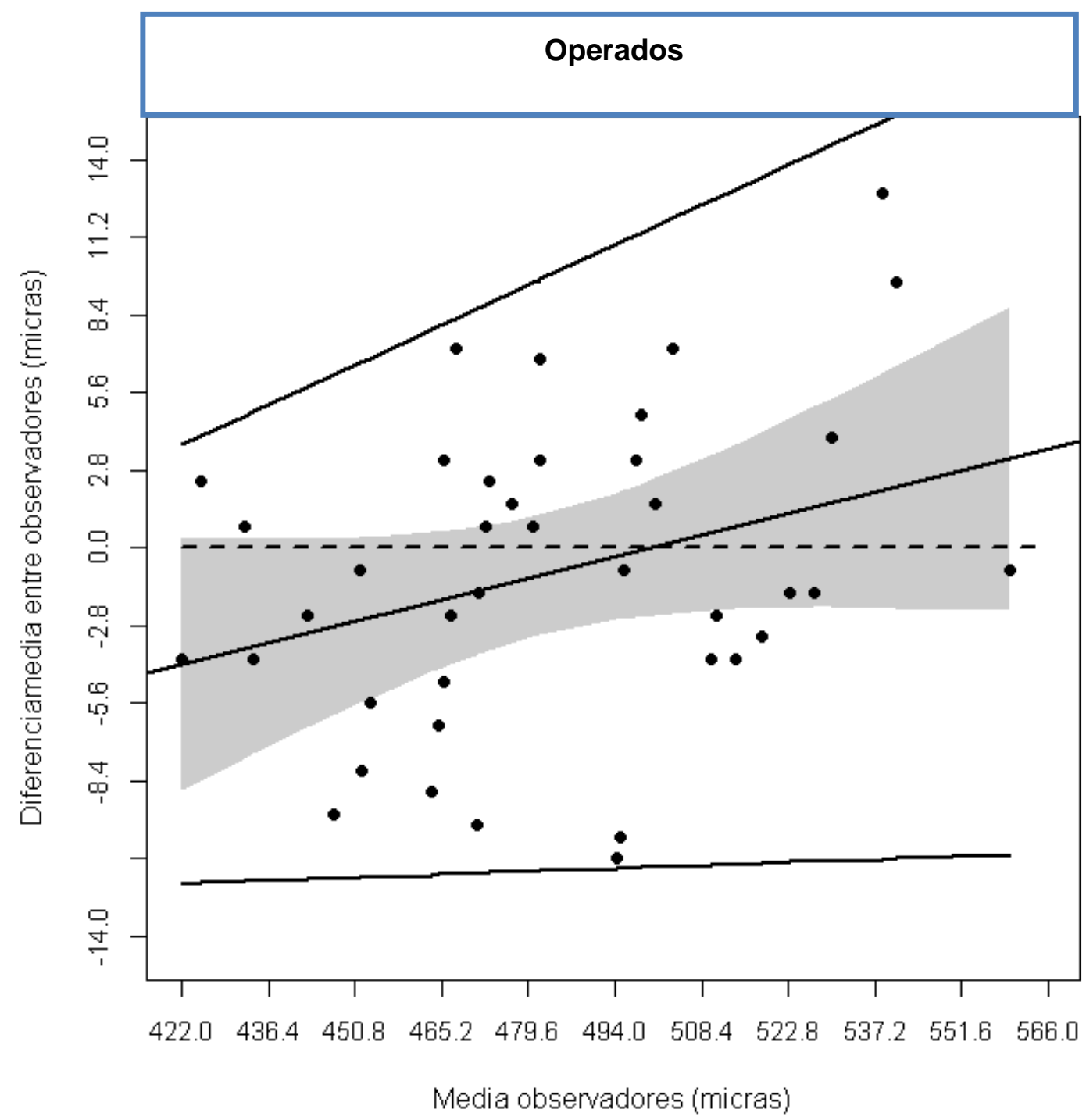

Figura 38: Gráfico de análisis de regresión tipo Bland \& Altman entre los dos observadores en la medida del espesor corneal total no epitelial en el grupo de pacientes operados. La línea horizontal continua describe la diferencia media entre sistemas. La línea superior indica el límite de concordancia superior y la línea inferior muestra el límite de concordancia inferior. 


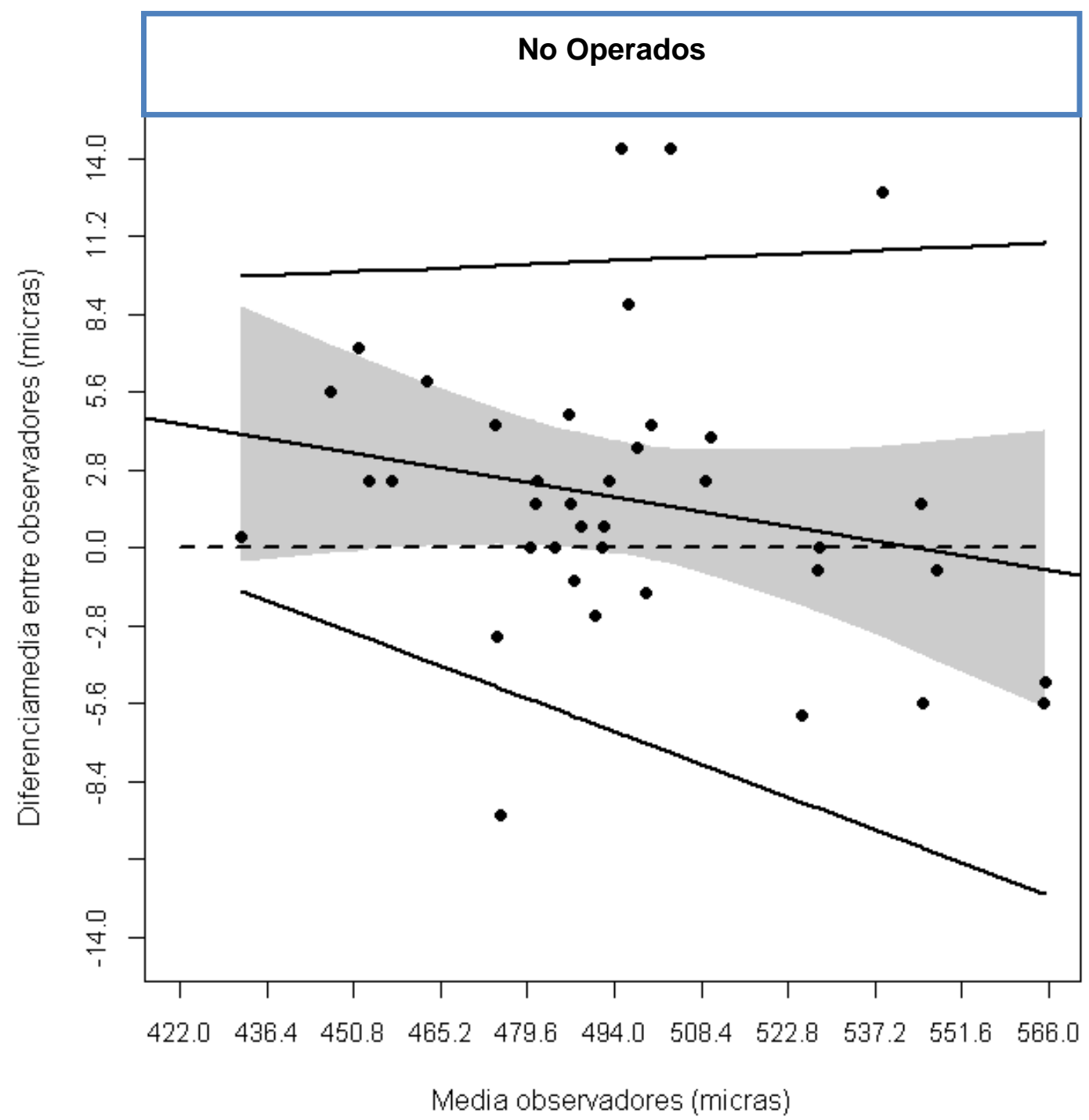

Figura 39: Gráfico de análisis de regresión tipo Bland \& Altman entre los dos observadores en la medida del espesor corneal total no epitelial en el grupo de pacientes no operados. La línea horizontal continua describe la diferencia media entre sistemas. La línea superior indica el límite de concordancia superior y la línea inferior muestra el límite de concordancia inferior.

La asunción de normalidad de la distribución de los residuos del modelo de regresión de Bland \& Altman que relaciona las diferencias y las medias paquimétricas, se confirmó a través de las figuras 40 y 41. 

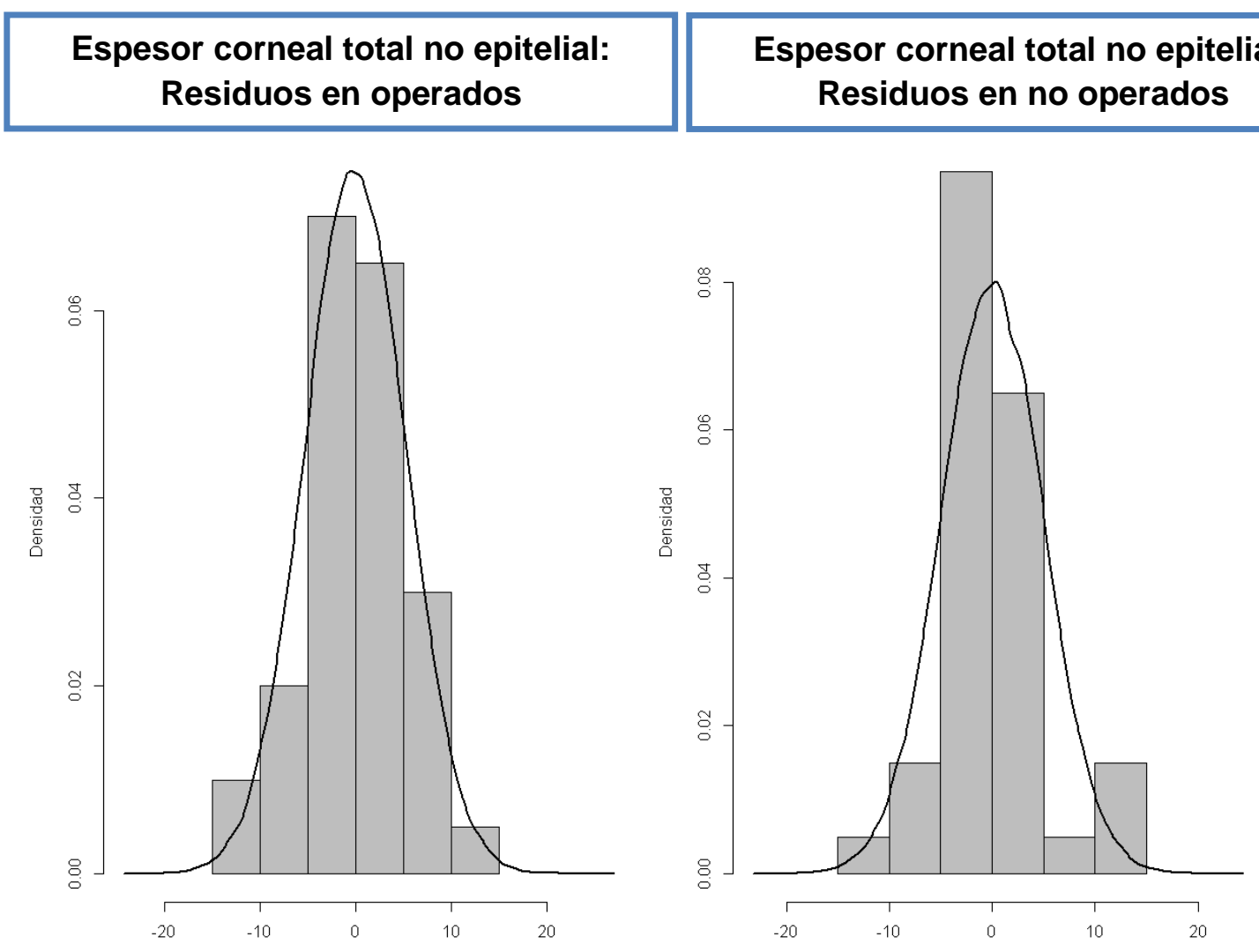

Figuras 40 y 41: Distribución de los residuos sobre la diferencia de las medias de los dos observadores en la medida del espesor no epitelial corneal en los grupos de pacientes operados y no operados.

Finalmente, en el caso del análisis de Bland \& Altman para la medida del espesor corneal total, se observó una distribución de los valores relativamente homogénea (Figuras 42 y 43$)$. 


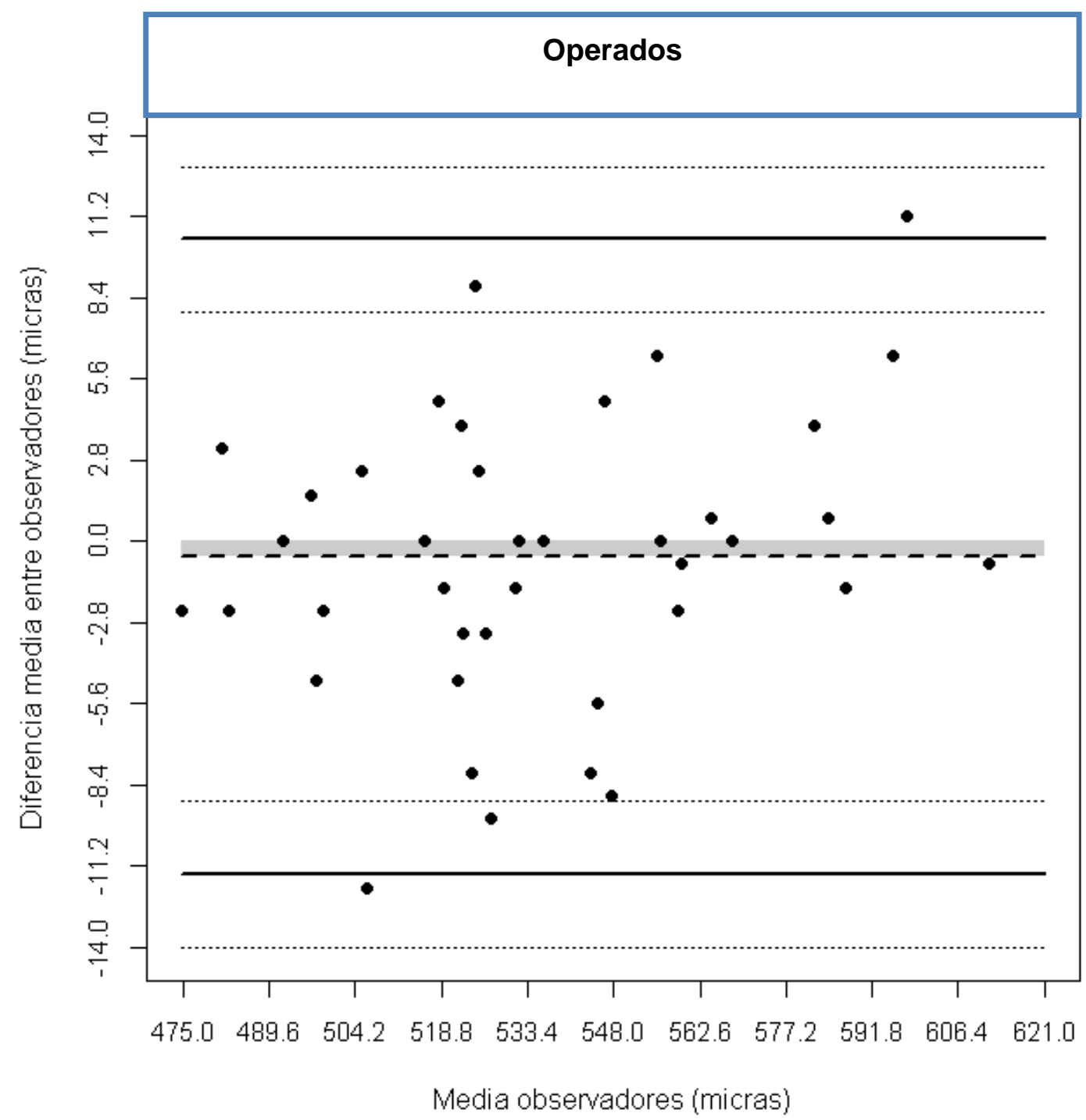

Figura 42: Gráfico tipo Bland \& Altman mostrando la distribución de las diferencias de las medias de la medida del espesor corneal total en el grupo de pacientes operados entre el observador 1 y el observador 2. La línea central horizontal discontinua detalla la diferencia media, mientras que la zona sombreada en gris indica la diferencia de esa media respecto de cero. Las dos líneas horizontales continuas superior e inferior indican los límites de concordancia al 95\%, y las dos líneas discontinuas por encima y debajo de los límites de concordancia son los intervalos de confianza al 95\% para cada límite de concordancia estimado. 


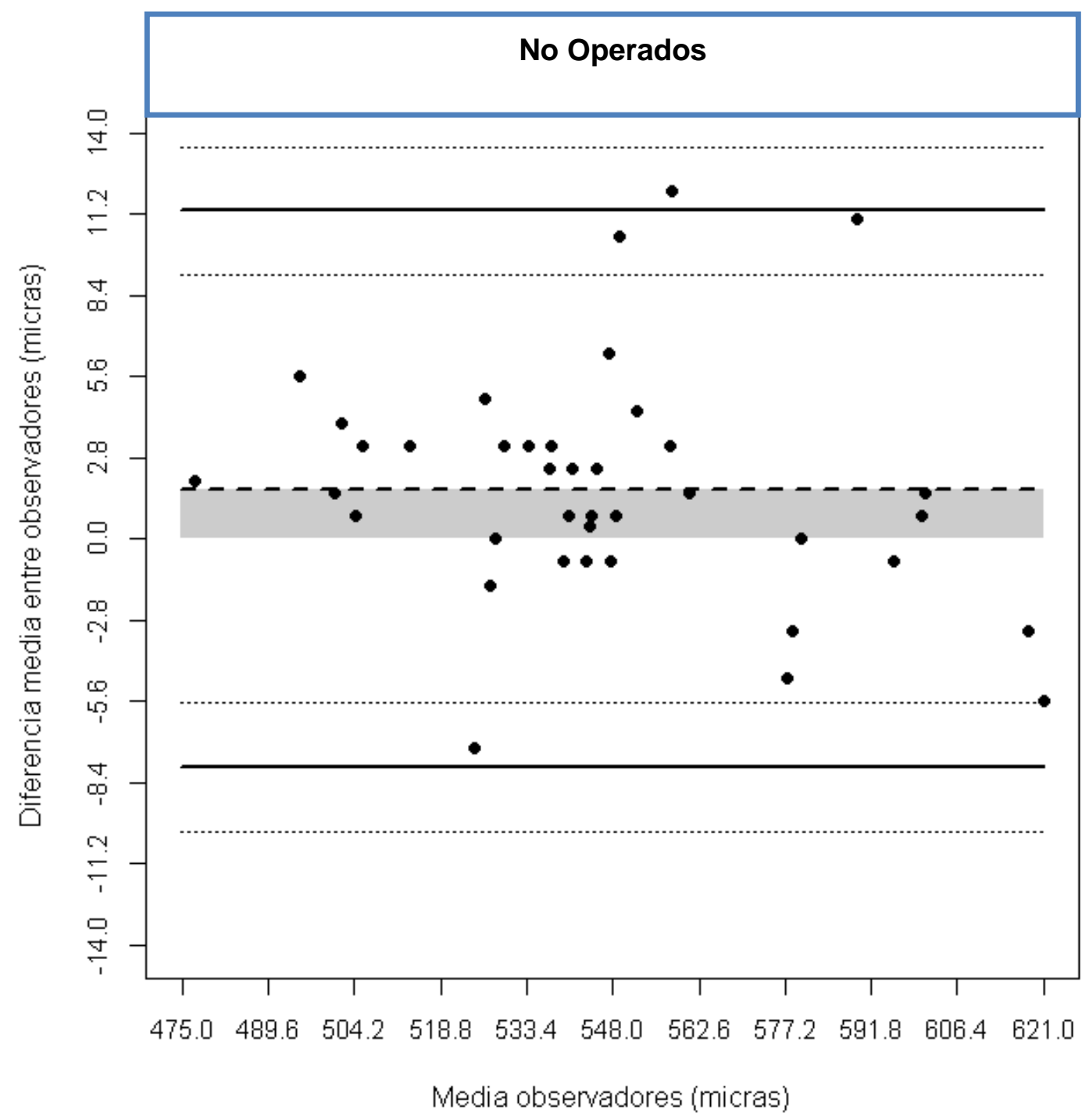

Figura 43: Gráfico tipo Bland \& Altman mostrando la distribución de las diferencias de las medias de la medida del espesor corneal total en el grupo de pacientes no operados entre el observador 1 y el observador 2. La línea central horizontal discontinua detalla la diferencia media, mientras que la zona sombreada en gris indica la diferencia de esa media respecto de cero. Las dos líneas horizontales continuas superior e inferior indican los límites de concordancia al 95\%, y las dos líneas discontinuas por encima y debajo de los límites de concordancia son los intervalos de confianza al 95\% para cada límite de concordancia estimado. 
En este caso también se demostró la distribución cercana a la normal para la confirmar la idoneidad del análisis grafico de Bland \& Altman como se muestra en los gráficos 44 y 45 .

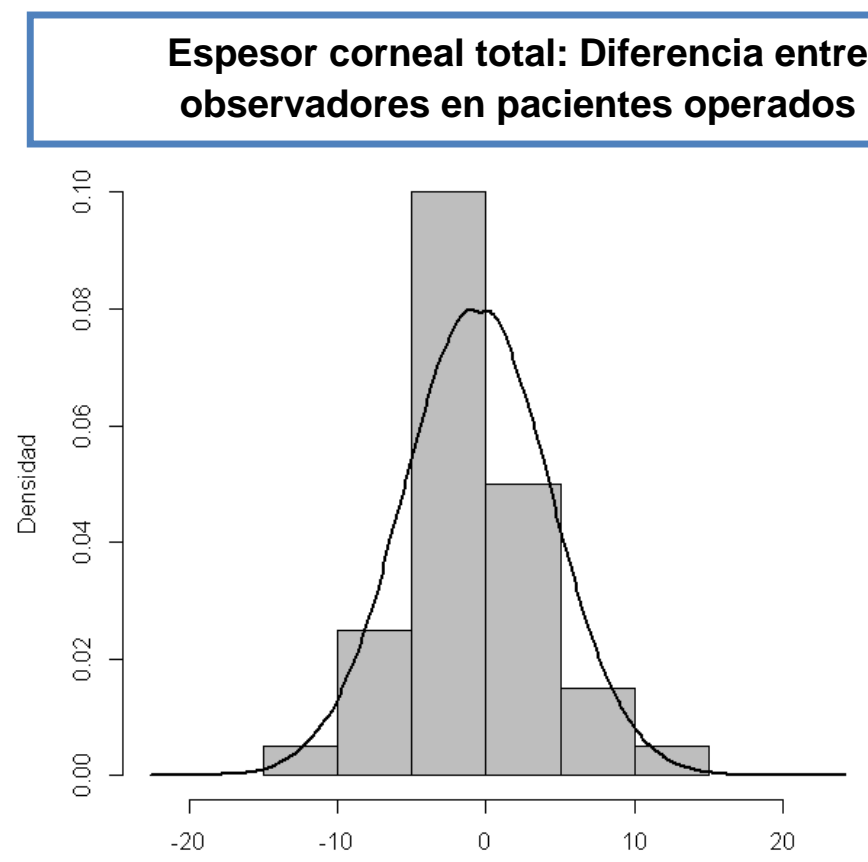

Figura 44: Distribución de las diferencias en la medida del espesor corneal total en pacientes operados entre el observador 1 y el observador 2. 


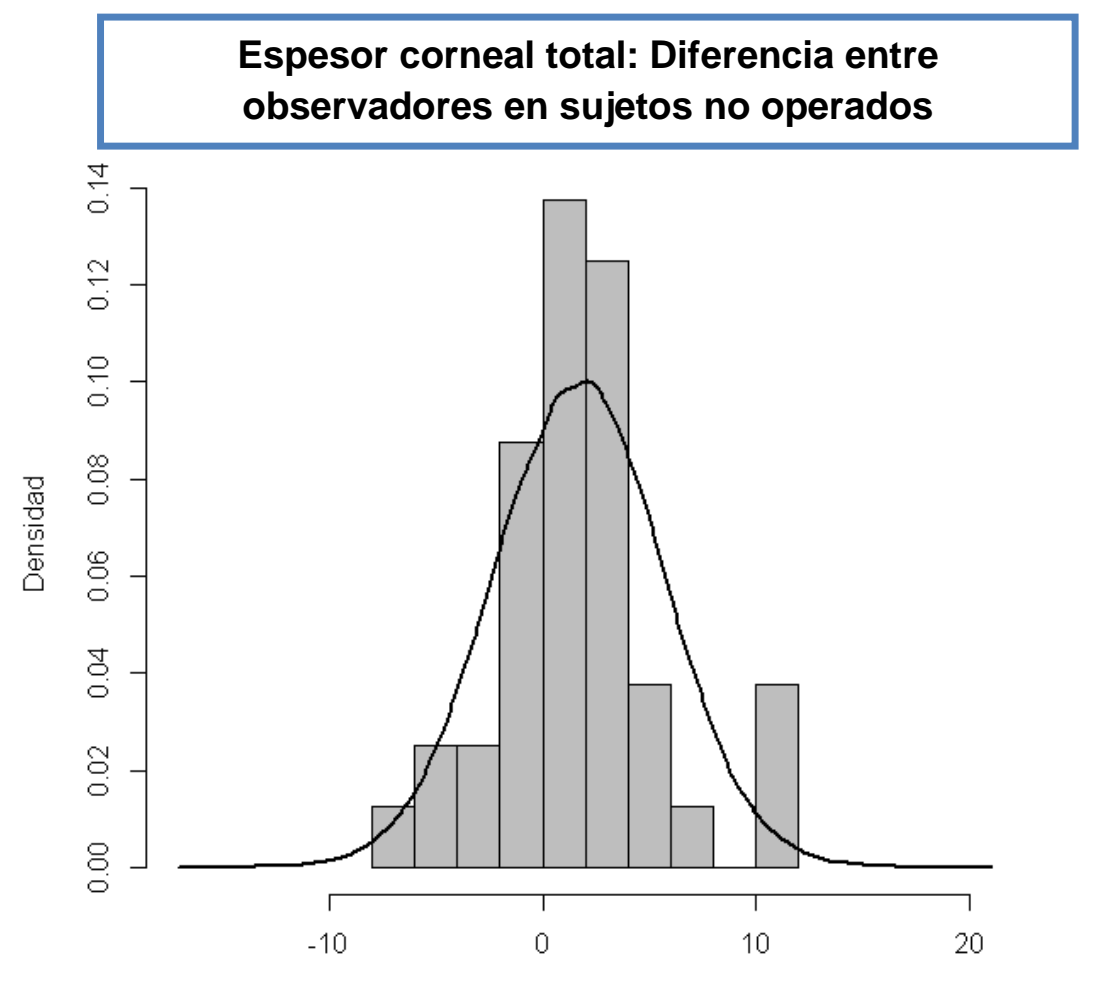

Figura 45: Distribución de las diferencias en la medida del espesor corneal total en sujetos no operados entre el observador 1 y el observador 2.

6.3. ESTUdIO CLÍNICO: DETERMINACIÓN DE LOS CAMBIOS ABERROMÉTRICOS Y EN EL GROSOR POR CAPAS DE LA CÓRNEA TRAS CIRUGÍA DE CATARATA CON FACOEMULSIFICACIÓN

En el grupo de casos se incluyeron en el estudio 100 ojos (56 derechos, 44 izquierdos) de 100 pacientes (57 mujeres, 43 varones) operados de catarata mediante facoemulsificación del cristalino e implante de LIO sin incidencias intra ni post-operatorias, con una edad media de $72.2 \pm 10$ años (Rango: 42-88). Se descartaron 4 pacientes por las siguientes complicaciones intraoperatorias: 2 roturas 
de saco con implante de LIO en sulcus y 2 síndromes de iris flácido que requirieron sutura corneal de la incisión principal, y 4 pacientes por las siguientes complicaciones postoperatorias: 3 pacientes presentaron hipertensión ocular aguda que requirió tratamiento con hipotensores tópicos y/o sistémicos y 1 paciente presentó descompensación corneal con edema corneal crónico residual. En el grupo de controles se analizaron 30 ojos no operados (18 derechos, 12 izquierdos) de 30 pacientes (22 mujeres, 8 varones) con una edad media de $74.8 \pm 6.9$ años (Rango: 58-86).

\subsubsection{CAMBIOS ABERROMÉTRICOS Y EN LOS GROSORES} CORNEALES

\section{Componente Esférico de la Refracción}

La variable esfera no presentó diferencias estadísticamente significativas ni en la evolución temporal $(p=0.99)$, ni según el grupo $(p=0.85)$ ni al estudiar la interacción entre la evolución temporal y el grupo ( $p=0.39)$, tal y como se observa en la figura 46. 


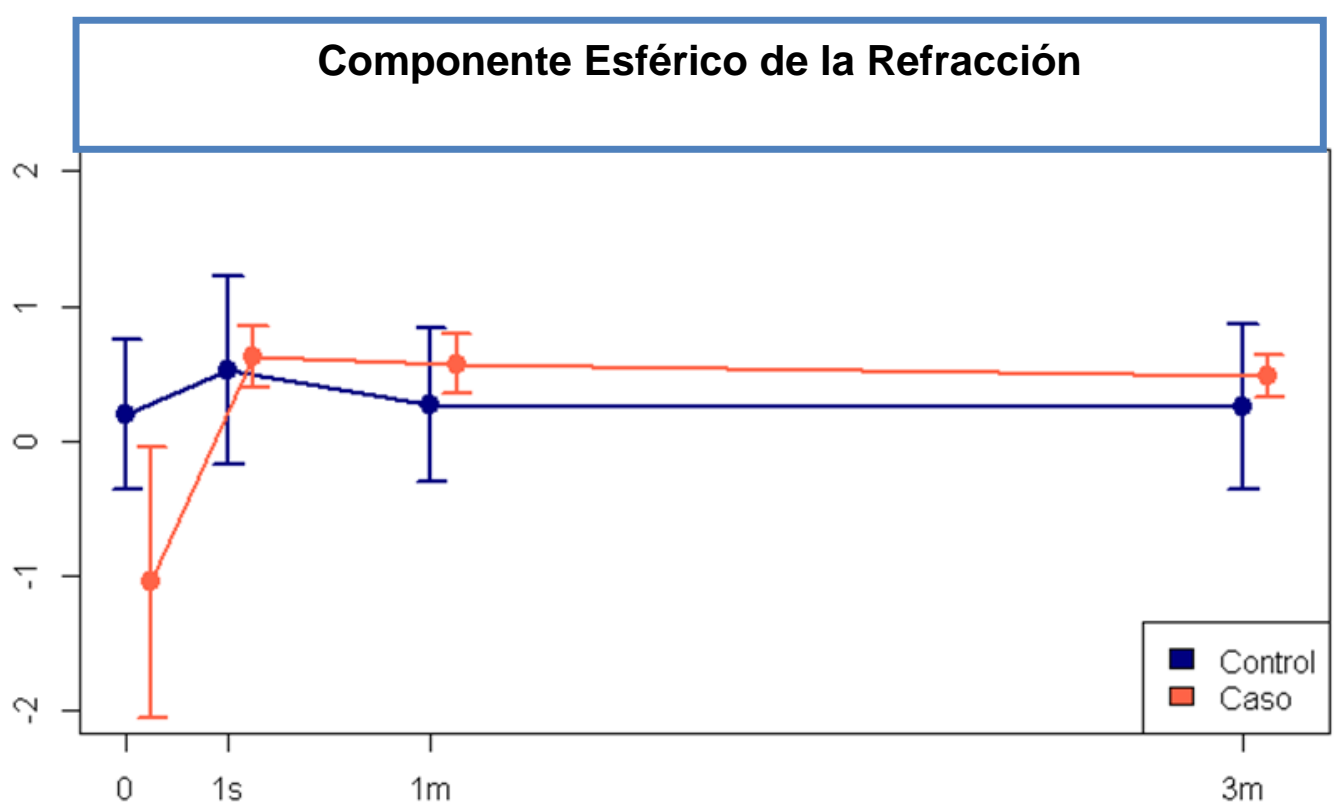

Figura 46: Evolución en el tiempo del componente esférico de la refracción para los grupos de casos y controles. Se representa la media y el intervalo de confianza al $95 \%$.

\section{Componente Cilíndrico de la Refracción}

Por otro lado, encontramos diferencias significativas $(p=0.015)$ en la media de la variable cilindro entre la semana después de la cirugía y los 3 meses, siendo la diferencia de $-0.20 \pm 0.08(95 \% \mathrm{IC}-0.36 / 0.04) \mathrm{D}$, es decir, el cilindro era menor a los 3 meses. En el resto de medias no encontramos variaciones según la evolución temporal $(p \geq 0.07)$. 


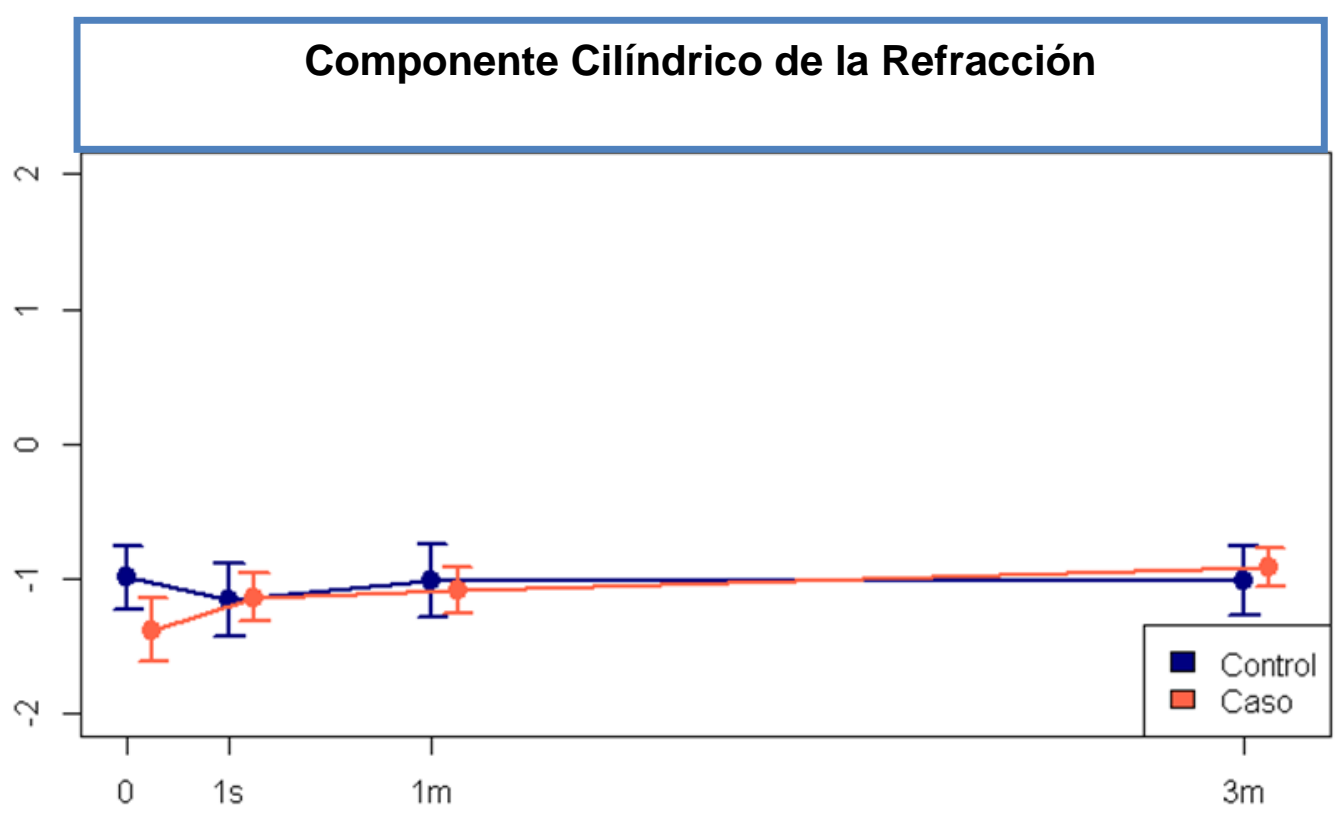

Figura 47: Evolución en el tiempo del componente cilíndrico de la refracción para los grupos de casos y controles. Se representa la media y el intervalo de confianza al $95 \%$.

\section{Agudeza visual}

La media de la agudeza visual AV (logMAR) presentó diferencias significativas en todas las visitas salvo entre las visitas del mes y los 3 meses postcirugía en el grupo de pacientes operados (casos). Estos resultados se muestran en la tabla 9 y gráficamente se describen en la figura 48 . 


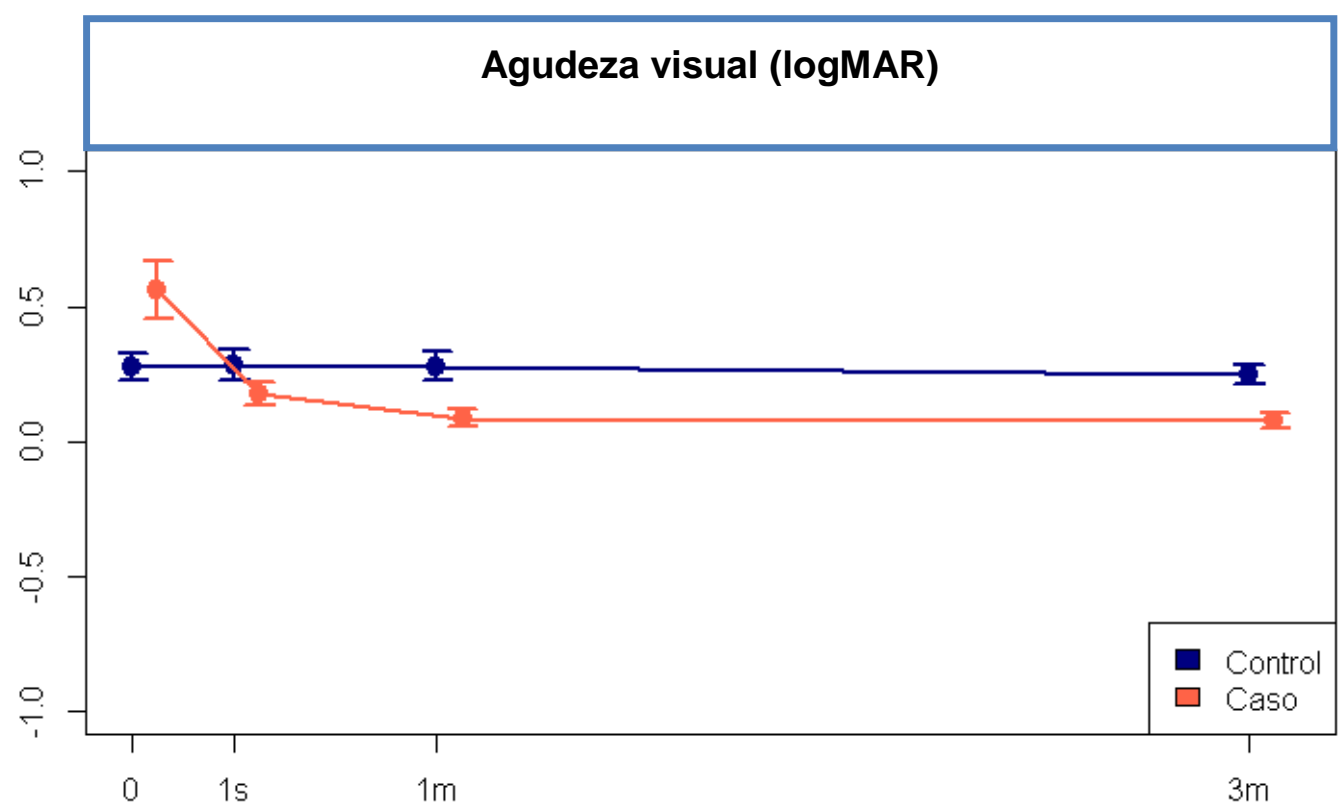

Figura 48: Evolución en el tiempo de la agudeza visual para los grupos de casos y controles. Se representa la media y el intervalo de confianza al $95 \%$. 
Tabla 9: Diferencias de las medias marginales de la agudeza visual (logMAR) para los efectos estadísticamente significativos, en este caso el tiempo y la interacción tiempo y grupo.

\begin{tabular}{|c|c|c|c|c|c|c|c|c|}
\hline \multicolumn{9}{|c|}{ Diferencias de medias marginales } \\
\hline \multirow{2}{*}{ Efecto } & \multirow{2}{*}{$\begin{array}{c}\text { Nivel } \\
\text { Tiempo } \\
\text { (I) }\end{array}$} & \multirow{2}{*}{$\begin{array}{c}\text { Nivel } \\
\text { Tiempo } \\
\text { (II) }\end{array}$} & \multirow{2}{*}{$\begin{array}{c}\text { Nivel } \\
\text { Grupo } \\
\text { (I) }\end{array}$} & \multirow{2}{*}{$\begin{array}{l}\text { Nivel } \\
\text { Grupo } \\
\text { (II) }\end{array}$} & \multirow{2}{*}{$\begin{array}{c}\text { Diferencias } \\
\text { (I) - (II) } \\
\text { (logMAR) }\end{array}$} & \multicolumn{2}{|c|}{$\begin{array}{l}\text { IC 95\% para la } \\
\text { Diferencia }\end{array}$} & \multirow[t]{2}{*}{ p-valor } \\
\hline & & & & & & Inf. & Sup. & \\
\hline \multirow{6}{*}{ Tiempo } & \multirow{3}{*}{0} & $1 \mathrm{~s}$ & ${ }^{\circ}$ & . & 0.19 & 0.10 & 0.28 & $<0.0001$ \\
\hline & & $1 \mathrm{~m}$ & . & . & 0.24 & 0.15 & 0.33 & $<0.0001$ \\
\hline & & $3 m$ & . & . & 0.25 & 0.16 & 0.34 & $<0.0001$ \\
\hline & \multirow{2}{*}{$1 \mathrm{~s}$} & $1 \mathrm{~m}$ & . & . & 0.05 & 0.02 & 0.07 & 0.002 \\
\hline & & $3 m$ & . & . & 0.06 & 0.02 & 0.09 & 0.0005 \\
\hline & $1 \mathrm{~m}$ & $3 m$ & . & . & 0.01 & -0.02 & 0.04 & 0.49 \\
\hline \multirow{16}{*}{$\begin{array}{l}\text { Tiempo } \\
\text { y Grupo }\end{array}$} & \multirow{5}{*}{$1 \mathrm{~s}$} & $1 \mathrm{~s}$ & \multirow{6}{*}{\multicolumn{2}{|c|}{ Control }} & -0.005 & -0.16 & 0.15 & 0.95 \\
\hline & & $1 \mathrm{~m}$ & & & -0.002 & -0.16 & 0.15 & 0.98 \\
\hline & & $3 m$ & & & 0.01 & -0.15 & 0.17 & 0.91 \\
\hline & & $1 \mathrm{~m}$ & & & 0.003 & -0.05 & 0.05 & 0.90 \\
\hline & & $3 m$ & & & 0.015 & -0.04 & 0.07 & 0.61 \\
\hline & $1 \mathrm{~m}$ & $3 m$ & & & 0.01 & -0.04 & 0.06 & 0.67 \\
\hline & & 1s & \multirow{6}{*}{\multicolumn{2}{|c|}{ Caso }} & 0.39 & 0.30 & 0.48 & $<0.0001$ \\
\hline & 0 & $1 \mathrm{~m}$ & & & 0.48 & 0.39 & 0.57 & $<0.0001$ \\
\hline & & $3 m$ & & & 0.49 & 0.4 & 0.58 & $<0.0001$ \\
\hline & \multirow{2}{*}{$1 \mathrm{~s}$} & $1 \mathrm{~m}$ & & & 0.09 & 0.06 & 0.12 & $<0.0001$ \\
\hline & & $3 m$ & & & 0.1 & 0.07 & 0.13 & $<0.0001$ \\
\hline & $1 \mathrm{~m}$ & $3 m$ & & & 0.01 & -0.02 & 0.04 & 0.51 \\
\hline & \multicolumn{2}{|c|}{0} & Control & Caso & -0.28 & -0.48 & -0.09 & 0.006 \\
\hline & \multicolumn{2}{|c|}{ 1semana } & Control & Caso & 0.11 & 0.03 & 0.19 & 0.008 \\
\hline & \multicolumn{2}{|c|}{$1 \mathrm{mes}$} & Control & Caso & 0.2 & 0.13 & 0.26 & $<0.0001$ \\
\hline & \multicolumn{2}{|c|}{3 meses } & Control & Caso & 0.19 & 0.13 & 0.26 & $<0.0001$ \\
\hline
\end{tabular}

LogMAR: logaritmo del mínimo ángulo de resolución; 1s: 1 semana; 1m: 1 mes; 3m: 3 meses; IC: intervalo de confianza; Inf: inferior; Sup: superior; p: probabilidad.

\section{Grosores Corneales en el Hemi-meridiano Cercano a la Incisión (Periincisional)}

\section{Grosor Corneal Total Periincisional}

El análisis del espesor corneal por capas se realizó primero en el área más próxima a la incisión (hemi-meridiano de 180ำ). Se encontraron diferencias significativas en el espesor corneal total en el tiempo y en la interacción de grupo y 
tiempo, es decir hubo variación a lo largo del tiempo y estos cambios no fueron los mismos en ambos grupos. Estas diferencias se encontraron entre la visita de la semana, en la cual alcanzó valores máximos, y el resto de visitas; también hubo diferencias significativas entre la visita del mes y de los 3 meses, en la que el valor era menor. En el grupo de controles no hubo diferencias mientras que en el de casos resultaron significativas todas las diferencias salvo entre la visita inicial y a los 3 meses. Estas diferencias se muestran en la tabla 10 y en la figura 49.

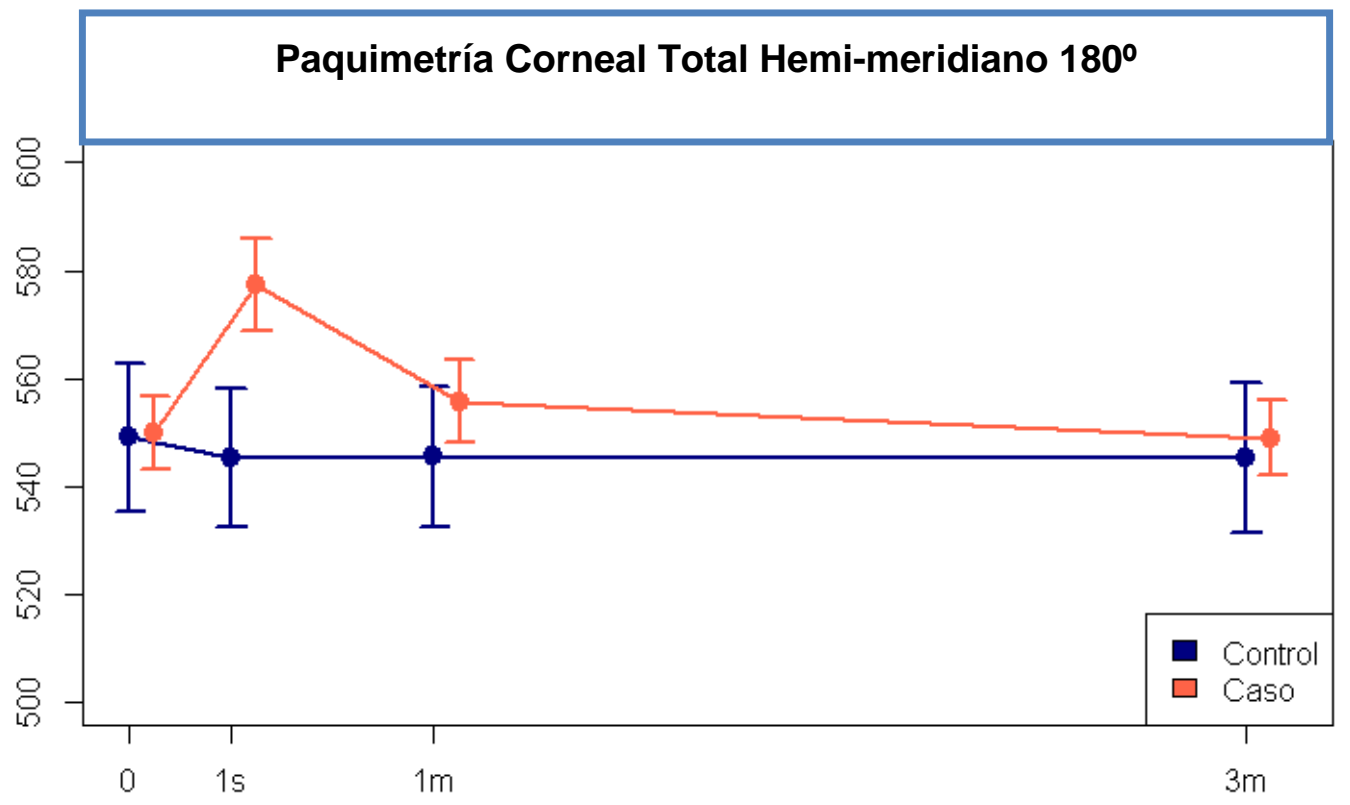

Figura 49: Evolución en el tiempo del espesor corneal total en el área paracentral más cercana a la incisión (hemi-meridiano $180^{\circ}$ ) para los grupos de casos y controles. Se representa la media y el intervalo de confianza al $95 \%$. 
Tabla 10: Diferencias de las medias marginales del espesor corneal total en el área paracentral más próxima a la incisión para los efectos estadísticamente significativos, en este caso el tiempo y la interacción tiempo y grupo.

\begin{tabular}{|c|c|c|c|c|c|c|c|c|}
\hline \multicolumn{9}{|c|}{ Diferencias de medias marginales } \\
\hline \multirow[t]{2}{*}{ Efecto } & \multirow{2}{*}{$\begin{array}{c}\text { Nivel } \\
\text { Tiempo } \\
\text { (I) }\end{array}$} & \multirow{2}{*}{$\begin{array}{l}\text { Nivel } \\
\text { Tiempo } \\
\text { (II) }\end{array}$} & \multirow{2}{*}{$\begin{array}{l}\text { Nivel } \\
\text { Grupo } \\
\text { (I) }\end{array}$} & \multirow{2}{*}{$\begin{array}{l}\text { Nivel } \\
\text { Grupo } \\
\text { (II) }\end{array}$} & \multirow{2}{*}{$\begin{array}{c}\text { Diferencias } \\
\text { (I) - (II) } \\
\text { (Micras) }\end{array}$} & \multicolumn{2}{|c|}{$\begin{array}{c}\text { IC 95\% para } \\
\text { la } \\
\text { Diferencia } \\
\end{array}$} & \multirow[t]{2}{*}{ p-valor } \\
\hline & & & & & & Inf & Sup. & \\
\hline \multirow{6}{*}{ Tiempo } & \multirow{3}{*}{0} & $1 \mathrm{~s}$ & . & . & -11.7 & -16.1 & -7 & $<0.0001$ \\
\hline & & $1 \mathrm{~m}$ & . & . & -1.0 & -4.4 & 2.3 & 0.54 \\
\hline & & $3 m$ & . & . & 2.6 & -0.4 & 5.5 & 0.09 \\
\hline & \multirow{2}{*}{$1 \mathrm{~s}$} & $1 \mathrm{~m}$ & . & . & 10.7 & 6.6 & 14.7 & $<0.0001$ \\
\hline & & $3 m$ & . & . & 14.3 & 10.0 & 18.5 & $<0.0001$ \\
\hline & $1 \mathrm{~m}$ & $3 m$ & . & . & 3.6 & 0.3 & 6.9 & 0.03 \\
\hline \multirow{16}{*}{$\begin{array}{l}\text { Tiempo } \\
\text { y Grupo }\end{array}$} & \multirow{3}{*}{0} & 1s & \multirow{6}{*}{\multicolumn{2}{|c|}{ Control }} & 3.9 & -3.7 & 11.4 & 0.32 \\
\hline & & $1 \mathrm{~m}$ & & & 3.6 & -2.3 & 9.5 & 0.23 \\
\hline & & $3 m$ & & & 4.1 & -1.1 & 9.3 & 0.13 \\
\hline & \multirow{2}{*}{$1 \mathrm{~s}$} & $1 \mathrm{~m}$ & & & -0.3 & -7.4 & 6.8 & 0.94 \\
\hline & & $3 m$ & & & 0.2 & -7.2 & 7.7 & 0.95 \\
\hline & $1 \mathrm{~m}$ & $3 m$ & & & 0.5 & -5.4 & 6.4 & 0.87 \\
\hline & & $1 \mathrm{~s}$ & \multirow{6}{*}{\multicolumn{2}{|c|}{ Caso }} & -27.3 & -31.6 & -23.0 & $<0.0001$ \\
\hline & 0 & $1 \mathrm{~m}$ & & & -5.7 & -9.0 & -2.4 & 0.001 \\
\hline & & $3 m$ & & & 1.0 & -1.6 & 3.7 & 0.44 \\
\hline & \multirow{2}{*}{$1 \mathrm{~s}$} & $1 \mathrm{~m}$ & & & 21.6 & 17.6 & 25.6 & $<0.0001$ \\
\hline & & $3 m$ & & & 28.3 & 24.2 & 32.4 & $<0.0001$ \\
\hline & $1 \mathrm{~m}$ & $3 m$ & & & 6.7 & 3.6 & 9.8 & $<0.0001$ \\
\hline & \multicolumn{2}{|c|}{0} & Control & Caso & -0.6 & -15.4 & 14.3 & 0.94 \\
\hline & \multicolumn{2}{|c|}{ 1semana } & Control & Caso & -31.7 & -48.7 & -14.6 & 0.0003 \\
\hline & \multicolumn{2}{|c|}{$1 \mathrm{mes}$} & Control & Caso & -9.8 & -25.8 & 6.1 & 0.22 \\
\hline & \multicolumn{2}{|c|}{3 meses } & Control & Caso & -3.6 & -18.5 & 11.3 & 0.63 \\
\hline
\end{tabular}

1s: 1 semana; 1m: 1 mes; 3m: 3 meses; IC: intervalo de confianza; Inf: inferior; Sup: superior; $p$ : probabilidad.

\section{Grosor Epitelial Periincisional}

No se encontraron diferencias significativas en el espesor epitelial corneal próximo a la incisión a lo largo de las distintas visitas ( $p>0.12$ ), aunque resultaron 
significativas las diferencias entre grupos, siendo esta diferencia de $-4.3 \pm 0.79$ (95\% IC -5.85/-2.71) con una significación estadística de $\mathrm{p}<0.001$ (Figura 50).

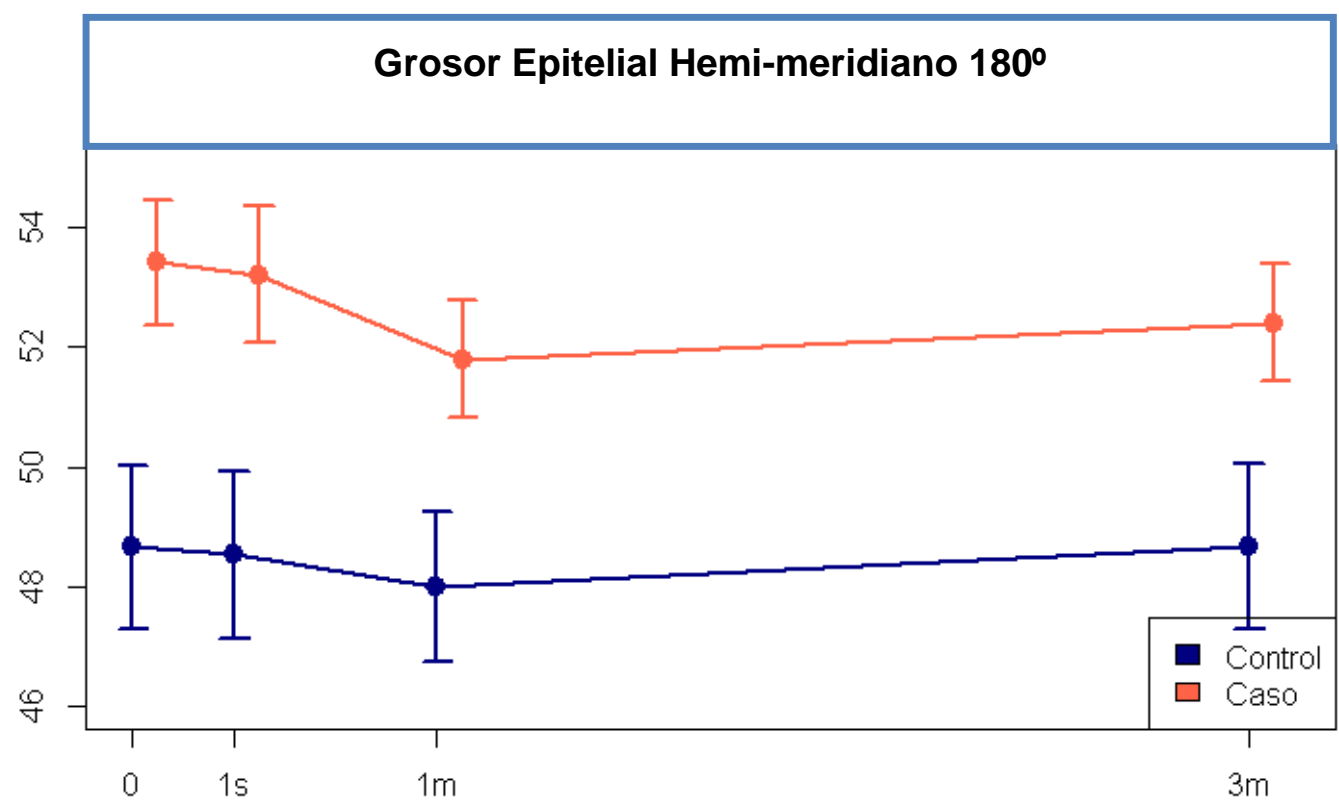

Figura 50: Evolución en el tiempo del espesor epitelial corneal en el área más próxima a la incisión (hemi-meridiano 180) $^{\circ}$ para los grupos de casos y controles. Se representa la media y el intervalo de confianza al 95\%.

\section{Grosor Corneal Total no Epitelial Periincisional}

En análisis del espesor no epitelial corneal total medido en la zona más próxima a la incisión se encontraron diferencias significativas en la evolución temporal $(p<0.0001)$, siendo los valores significativamente mayores a la semana de la cirugía. Esta diferencia también resultó significativa entre el mes y los 3 meses post-cirugía. También el efecto de la interacción tiempo y grupo resultó significativo 
en el grupo de los casos $(p<0.0001)$, tal y como se muestra en la tabla 11 y en la figura 51 .

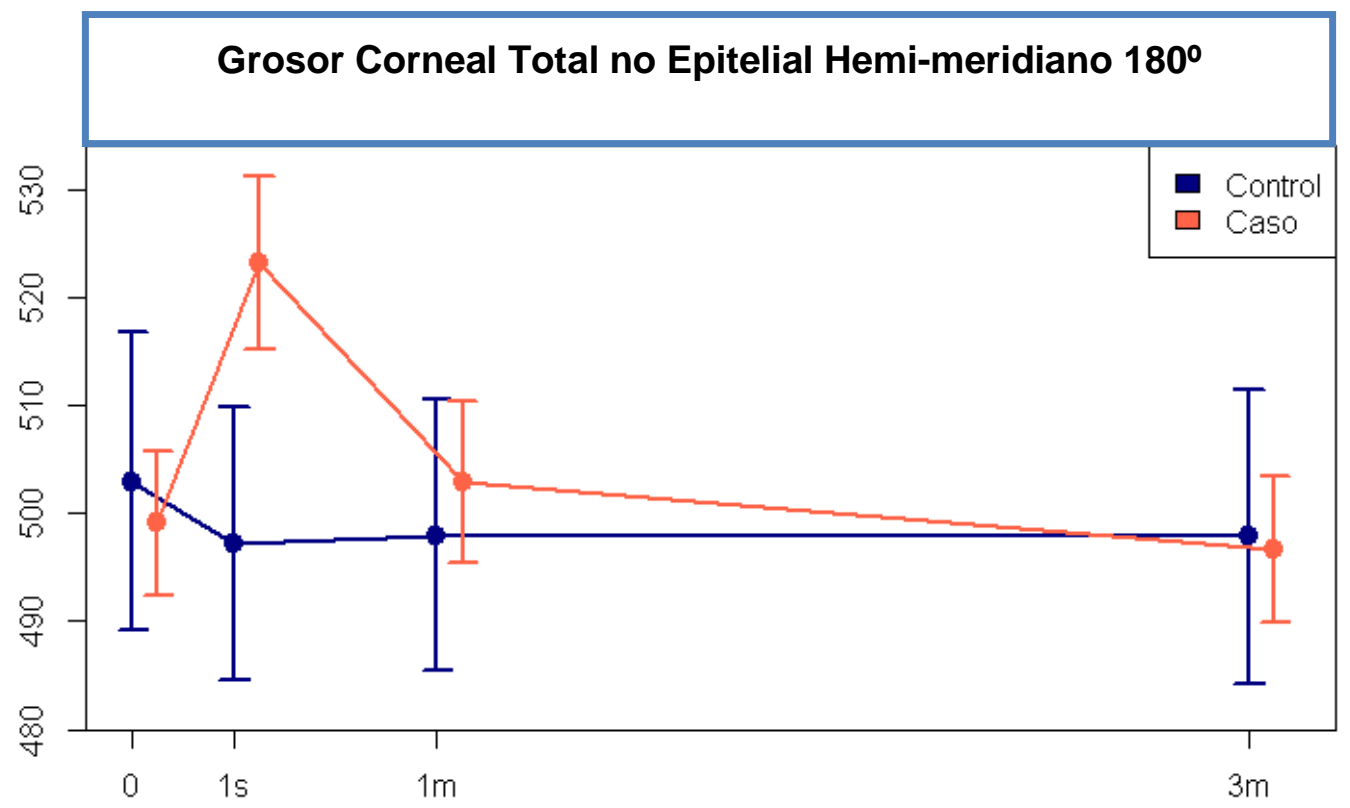

Figura 51: Evolución en el tiempo del espesor corneal total no epitelial en el área más cercana a la incisión (hemi-meridiano $180^{\circ}$ ) para los grupos de casos y controles. Se representa la media y el intervalo de confianza al $95 \%$. 
Tabla 11: Diferencias de las medias marginales del espesor corneal total no epitelial en el área paracentral más próxima a la incisión para los efectos estadísticamente significativos, en este caso el tiempo y la interacción tiempo y grupo.

\begin{tabular}{|c|c|c|c|c|c|c|c|c|}
\hline \multicolumn{9}{|c|}{ Diferencias de medias marginales } \\
\hline \multirow{2}{*}{ Efecto } & \multirow{2}{*}{$\begin{array}{c}\text { Nivel } \\
\text { Tiempo } \\
\text { (I) }\end{array}$} & \multirow{2}{*}{$\begin{array}{c}\text { Nivel } \\
\text { Tiempo } \\
\text { (II) }\end{array}$} & \multirow{2}{*}{$\begin{array}{l}\text { Nivel } \\
\text { Grupo } \\
\text { (I) }\end{array}$} & \multirow{2}{*}{$\begin{array}{l}\text { Nivel } \\
\text { Grupo } \\
\text { (II) }\end{array}$} & \multirow{2}{*}{$\begin{array}{c}\text { Diferencias } \\
\text { (I) - (II) } \\
\text { (Micras) }\end{array}$} & \multicolumn{2}{|c|}{$\begin{array}{l}\text { IC 95\% para } \\
\text { la diferencia }\end{array}$} & \multirow{2}{*}{ p-valor } \\
\hline & & & & & & Inf. & Sup. & \\
\hline \multirow{6}{*}{ Tiempo } & \multirow{3}{*}{0} & $1 \mathrm{~s}$ & . & . & -9.1 & -14.4 & -3.8 & 0.001 \\
\hline & & $1 \mathrm{~m}$ & . & . & 0.8 & -3.9 & 5.4 & 0.75 \\
\hline & & $3 m$ & . & . & 4.0 & -0.1 & 8.1 & 0.06 \\
\hline & \multirow{2}{*}{ 1s } & $1 \mathrm{~m}$ & \multirow{2}{*}{. } & \multirow[t]{2}{*}{. } & 9.8 & 5.9 & 13.8 & $<0.0001$ \\
\hline & & $3 m$ & & & 13.1 & 9.1 & 17.1 & $<0.0001$ \\
\hline & $1 \mathrm{~m}$ & $3 m$ & \multicolumn{2}{|l|}{. } & 3.2 & 0.002 & 6.5 & 0.05 \\
\hline \multirow{16}{*}{$\begin{array}{l}\text { Tiempo } \\
\text { y Grupo }\end{array}$} & \multirow{3}{*}{0} & $1 \mathrm{~s}$ & \multirow{6}{*}{\multicolumn{2}{|c|}{ Control }} & 5.7 & -3.5 & 14.9 & 0.22 \\
\hline & & $1 \mathrm{~m}$ & & & 5 & -3.1 & 13.1 & 0.23 \\
\hline & & $3 m$ & & & 5.4 & -1.9 & 12.7 & 0.14 \\
\hline & \multirow{2}{*}{$1 \mathrm{~s}$} & $1 \mathrm{~m}$ & & & -0.7 & -7.5 & 6.1 & 0.84 \\
\hline & & $3 m$ & & & -0.3 & -7.4 & 6.8 & 0.93 \\
\hline & $1 \mathrm{~m}$ & $3 m$ & & & 0.4 & -5.4 & 6.1 & 0.89 \\
\hline & \multirow{3}{*}{0} & $1 \mathrm{~s}$ & \multirow{6}{*}{\multicolumn{2}{|c|}{ Caso }} & -23.8 & -29.1 & -18.6 & $<0.0001$ \\
\hline & & $1 \mathrm{~m}$ & & & -3.5 & -8.1 & 1.1 & 0.14 \\
\hline & & $3 m$ & & & 2.6 & -1.3 & 6.5 & 0.19 \\
\hline & \multirow{2}{*}{$1 \mathrm{~s}$} & $1 \mathrm{~m}$ & & & 20.4 & 16.5 & 24.2 & $<0.0001$ \\
\hline & & $3 m$ & & & 26.5 & 22.6 & 30.3 & $<0.0001$ \\
\hline & $1 \mathrm{~m}$ & $3 m$ & & & 6.1 & 3.1 & 9.0 & 0.0001 \\
\hline & \multicolumn{2}{|c|}{0} & Control & Caso & 3.9 & -10.7 & 18.5 & 0.6 \\
\hline & \multicolumn{2}{|c|}{ 1semana } & Control & Caso & -25.6 & -41.9 & -9.3 & 0.002 \\
\hline & \multicolumn{2}{|c|}{$1 \mathrm{mes}$} & Control & Caso & -4.6 & -20.1 & 11.0 & 0.57 \\
\hline & \multicolumn{2}{|c|}{ 3meses } & Control & Caso & 1.1 & -13.5 & 15.7 & 0.88 \\
\hline
\end{tabular}

1s: 1 semana; 1m: 1 mes; 3m: 3 meses; IC: intervalo de confianza; Inf: inferior; Sup: superior; p: probabilidad.

Grosores Corneales en el Hemi-meridiano Contrario a la Incisión (Contraincisional) 


\section{Grosor Corneal Total Contraincisional}

El análisis del espesor corneal por capas en la zona más alejada de la incisión (hemi-meridiano $0^{\circ}$ ) resultó similar a la zona próxima a la incisión. Encontramos diferencias estadísticamente significativas $(p<0.0001)$ en la evolución temporal (mayor a la semana que en el resto de visitas) y en la interacción del tiempo y grupo $(p=0.0004)$. En el grupo de casos había diferencias entre la visita de la semana y las demás visitas y entre el mes y los 3 meses (Figura 52 y tabla 12).

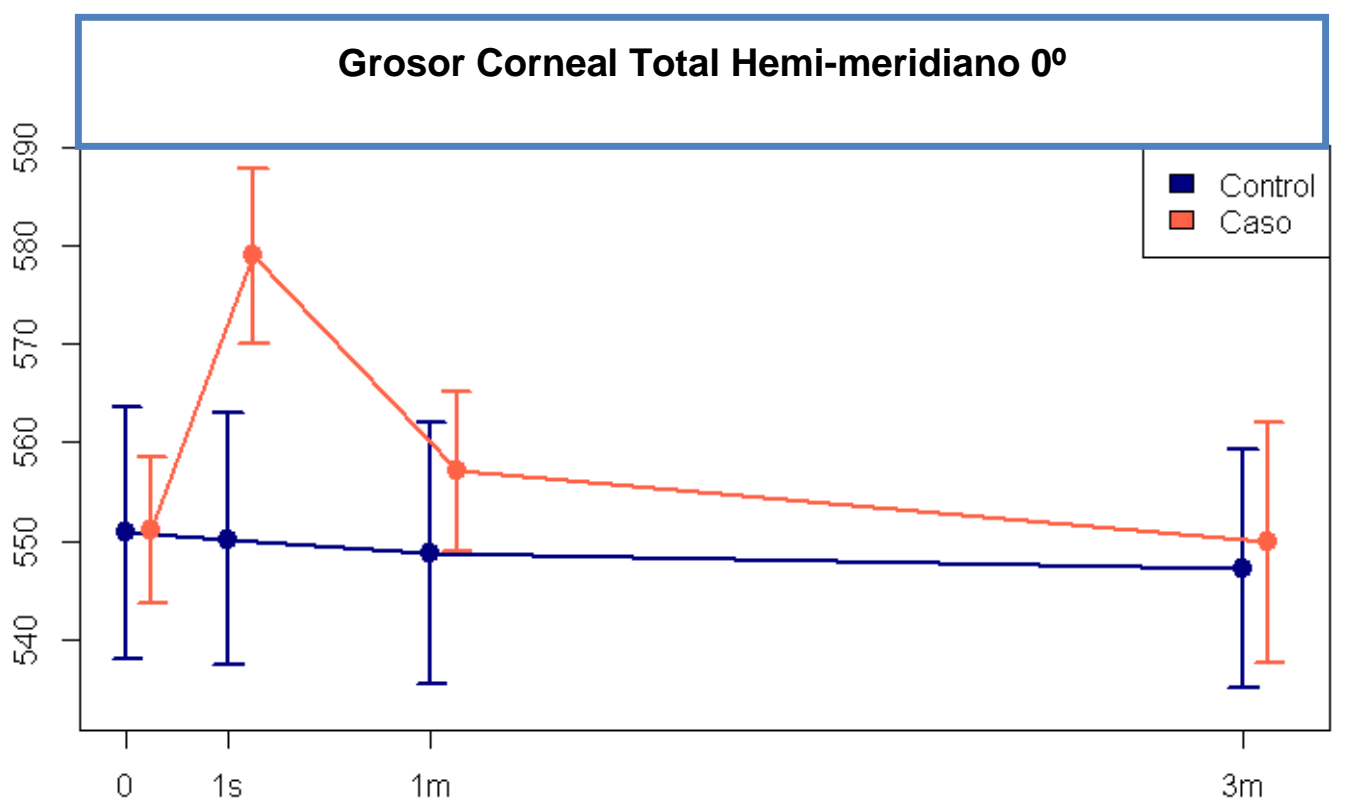

Figura 52: Evolución en el tiempo del espesor corneal total en el área más alejada de la incisión (hemi-meridiano $0^{\circ}$ ) para los grupos de casos y controles. Se representa la media y el intervalo de confianza al 95\%. 
Tabla 12: Diferencias de las medias marginales del espesor corneal total en el área paracentral más alejada de la incisión para los efectos estadísticamente significativos, en este caso el tiempo y la interacción tiempo y grupo.

\begin{tabular}{|c|c|c|c|c|c|c|c|c|}
\hline \multicolumn{9}{|c|}{ Diferencias de medias marginales } \\
\hline \multirow[t]{2}{*}{ Efecto } & \multirow{2}{*}{$\begin{array}{c}\text { Nivel } \\
\text { Tiempo } \\
\text { (I) }\end{array}$} & \multirow{2}{*}{$\begin{array}{l}\text { Nivel } \\
\text { Tiempo } \\
\text { (II) }\end{array}$} & \multirow{2}{*}{$\begin{array}{l}\text { Nivel } \\
\text { Grupo } \\
\text { (I) }\end{array}$} & \multirow{2}{*}{$\begin{array}{l}\text { Nivel } \\
\text { Grupo } \\
\text { (II) }\end{array}$} & \multirow{2}{*}{$\begin{array}{c}\text { Diferencias } \\
\text { (I) - (II) } \\
\text { (Micras) }\end{array}$} & \multicolumn{2}{|c|}{$\begin{array}{c}\text { IC 95\% para } \\
\text { la } \\
\text { Diferencia }\end{array}$} & \multirow[t]{2}{*}{ p-valor } \\
\hline & & & & & & Inf. & Sup. & \\
\hline \multirow{6}{*}{ Tiempo } & \multirow{3}{*}{0} & 1s & . & . & -13.6 & -20.7 & -6.6 & 0.0002 \\
\hline & & $1 \mathrm{~m}$ & . & . & -2.0 & -9.1 & 5.1 & 0.58 \\
\hline & & $3 m$ & . & . & 2.8 & -4.7 & 10.4 & 0.46 \\
\hline & \multirow{2}{*}{$1 \mathrm{~s}$} & $1 \mathrm{~m}$ & . & . & 11.7 & 4.6 & 18.8 & 0.001 \\
\hline & & $3 m$ & . & . & 16.5 & 9.0 & 24.0 & $<0.0001$ \\
\hline & $1 \mathrm{~m}$ & $3 m$ & . & & 4.8 & -2.7 & 12.3 & 0.21 \\
\hline \multirow{16}{*}{$\begin{array}{c}\text { Tiempo } \\
y \\
\text { Grupo }\end{array}$} & \multirow{3}{*}{0} & 1s & \multirow{6}{*}{\multicolumn{2}{|c|}{ Control }} & 0.7 & -11.8 & 13.1 & 0.92 \\
\hline & & $1 \mathrm{~m}$ & & & 2.1 & -10.4 & 14.5 & 0.74 \\
\hline & & $3 m$ & & & 4.4 & -9.0 & 17.8 & 0.52 \\
\hline & \multirow{2}{*}{$1 \mathrm{~s}$} & $1 \mathrm{~m}$ & & & 1.4 & -11.0 & 13.8 & 0.83 \\
\hline & & $3 m$ & & & 3.8 & -9.6 & 17.2 & 0.58 \\
\hline & $1 \mathrm{~m}$ & $3 m$ & & & 2.4 & -11.0 & 15.8 & 0.73 \\
\hline & \multirow{3}{*}{0} & $1 \mathrm{~s}$ & \multirow{6}{*}{\multicolumn{2}{|c|}{ Caso }} & -27.9 & -34.8 & -21.1 & $<0.0001$ \\
\hline & & $1 \mathrm{~m}$ & & & -6.0 & -12.8 & 0.8 & 0.08 \\
\hline & & $3 m$ & & & 1.3 & -5.6 & 8.1 & 0.72 \\
\hline & \multirow{2}{*}{$1 \mathrm{~s}$} & $1 \mathrm{~m}$ & & & 21.9 & 15.1 & 28.7 & $<0.0001$ \\
\hline & & $3 m$ & & & 29.2 & 22.4 & 36.0 & $<0.0001$ \\
\hline & $1 \mathrm{~m}$ & $3 m$ & & & 7.3 & 0.5 & 14.1 & 0.04 \\
\hline & \multicolumn{2}{|c|}{0} & Control & Caso & 0.003 & -18.6 & 18.6 & 1.0 \\
\hline & \multicolumn{2}{|c|}{ 1semana } & Control & Caso & -28.6 & -47.2 & -10.0 & 0.003 \\
\hline & \multicolumn{2}{|c|}{$1 \mathrm{mes}$} & Control & Caso & -8.1 & -26.7 & 10.5 & 0.4 \\
\hline & \multicolumn{2}{|c|}{3 meses } & Control & Caso & -3.2 & -22.5 & 16.1 & 0.75 \\
\hline
\end{tabular}

1s: 1 semana; 1m: 1 mes; 3m: 3 meses; IC: intervalo de confianza; Inf: inferior; Sup: superior; p:probabilidad.

\section{Grosor Epitelial Contraincisional}

El espesor epitelial más alejado de la incisión presentó diferencias significativas entre grupos $(p<0.0001)$ pero no en la evolución temporal $(p=0.79)$. Esta diferencia fue de $-4.75 \pm 0.82(95 \%$ IC $-6.4 /-3.1)$. 


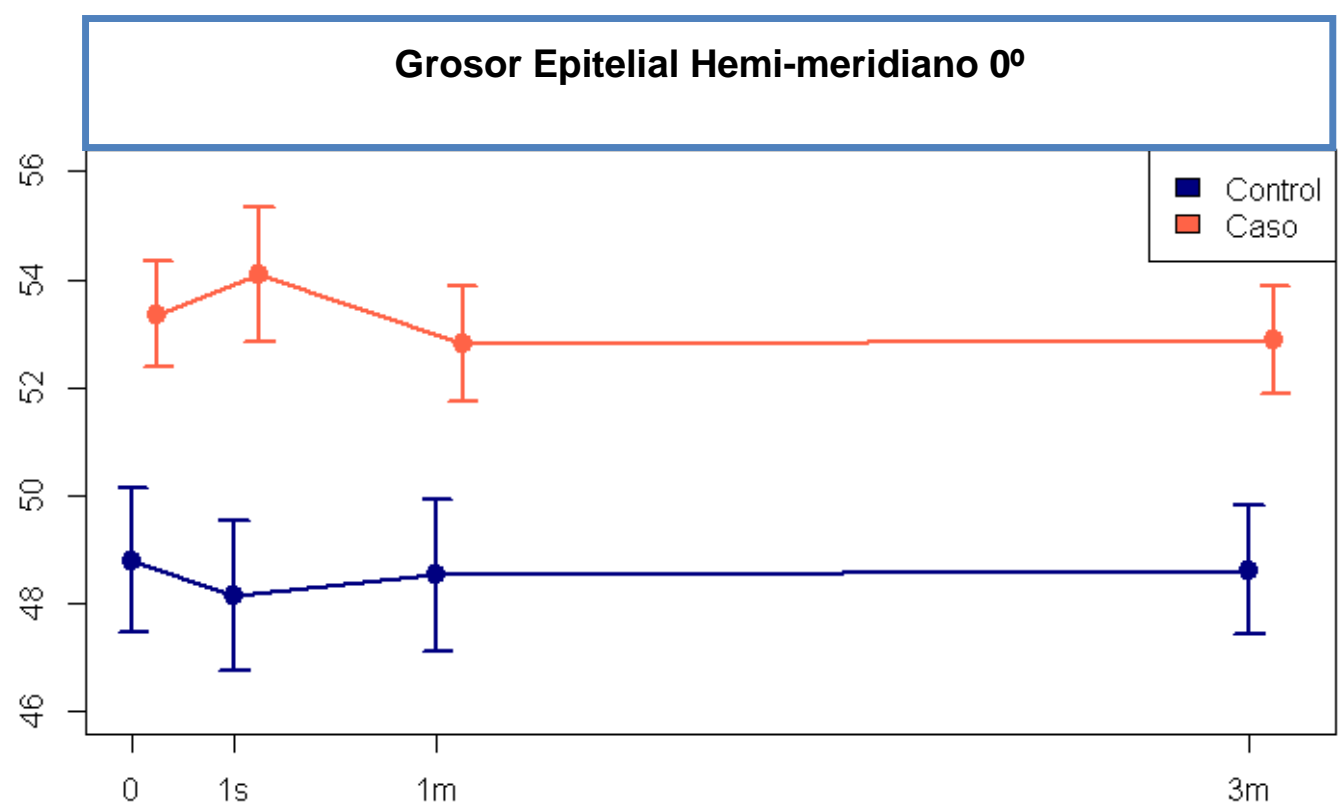

Figura 53: Evolución en el tiempo del espesor epitelial corneal en el área más alejada de la incisión (hemi-meridiano $0^{\circ}$ ) para los grupos de casos y controles. Se representa la media y el intervalo de confianza al 95\%.

\section{Grosor Corneal Total no Epitelial Contraincisional}

El espesor no epitelial en el área más alejada de la incisión presentó diferencias significativas en la evolución temporal $(p<0.0001)$ y en la interacción tiempo y grupo $(p<0.0001)$. Estos valores reflejados en la tabla 13 muestran las diferencias del espesor no epitelial a la semana de la cirugía respecto al resto de visitas y también al mes de la cirugía respecto a las demás visitas. Estas diferencias tienen lugar en el grupo de casos, en el que la diferencia entre la visita inicial y a los 3 meses tiene una $p$ al borde de la significación $(p=0.051)$. 


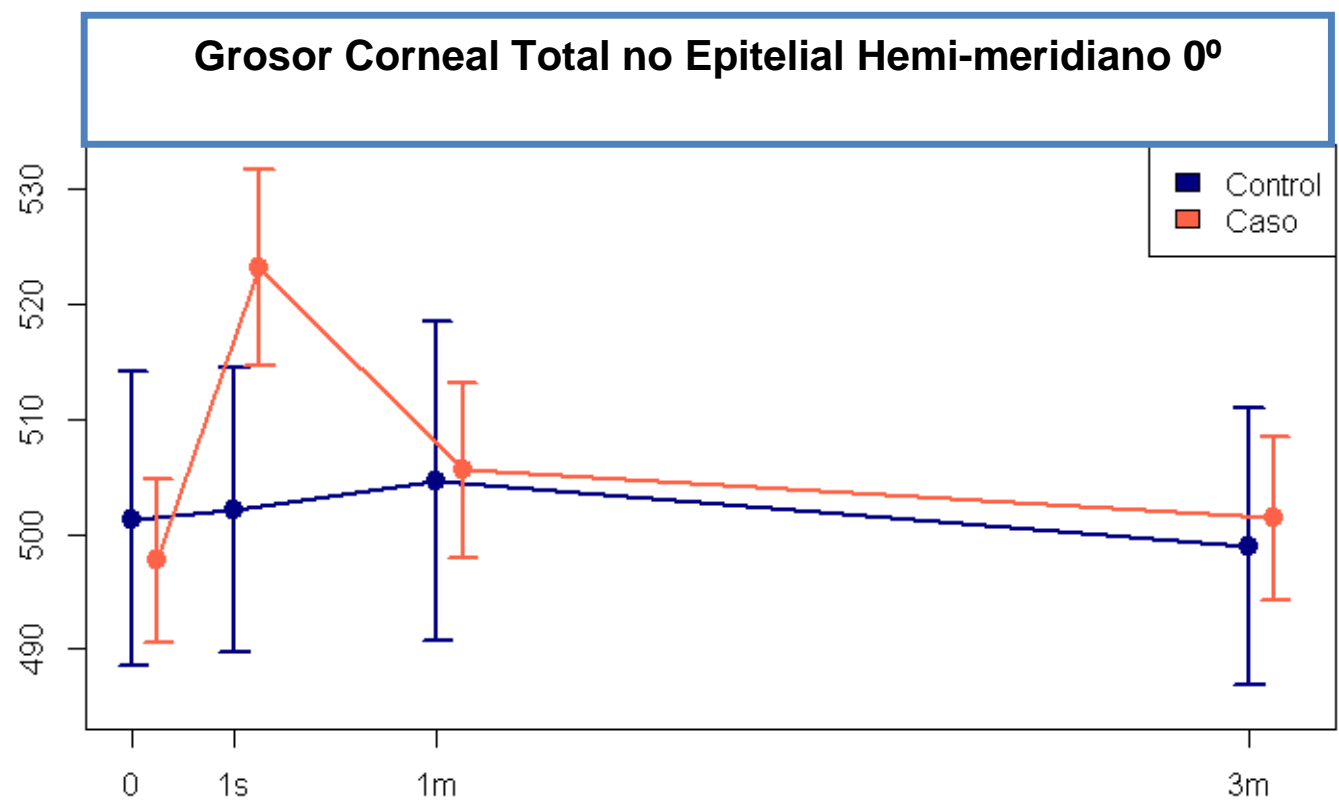

Figura 54: Evolución en el tiempo del espesor corneal total no epitelial en la zona más alejada de la incisión (hemi-meridiano $0^{\circ}$ ) para los grupos de casos y controles. Se representa la media y el intervalo de confianza al $95 \%$. 
Tabla 13: Diferencias de las medias marginales del espesor corneal total no epitelial en el área paracentral más alejada de la incisión para los efectos estadísticamente significativos, en este caso el tiempo y la interacción tiempo y grupo.

\begin{tabular}{|c|c|c|c|c|c|c|c|c|}
\hline \multicolumn{9}{|c|}{ Diferencias de medias marginales } \\
\hline \multirow[t]{2}{*}{ Efecto } & \multirow{2}{*}{$\begin{array}{l}\text { Nivel } \\
\text { Tiempo } \\
\text { (I) }\end{array}$} & \multirow{2}{*}{$\begin{array}{l}\text { Nivel } \\
\text { Tiempo } \\
\text { (II) }\end{array}$} & \multirow{2}{*}{$\begin{array}{l}\text { Nivel } \\
\text { Grupo } \\
\text { (I) }\end{array}$} & \multirow{2}{*}{$\begin{array}{l}\text { Nivel } \\
\text { Grupo } \\
\text { (II) }\end{array}$} & \multirow{2}{*}{$\begin{array}{c}\text { Diferencias } \\
\text { (I) - (II) } \\
\text { (Micras) }\end{array}$} & \multicolumn{2}{|c|}{$\begin{array}{c}\text { IC 95\% para } \\
\text { la } \\
\text { Diferencia }\end{array}$} & \multirow[t]{2}{*}{ p-valor } \\
\hline & & & & & & Inf. & Sup. & \\
\hline \multirow{6}{*}{ Tiempo } & \multirow{3}{*}{0} & $1 \mathrm{~s}$ & & . & -13.2 & -18.4 & -8.0 & $<0.0001$ \\
\hline & & $1 \mathrm{~m}$ & & . & -5.6 & -10.0 & 1.3 & 0.01 \\
\hline & & $3 m$ & & . & -0.1 & -4.1 & 4.0 & 1.0 \\
\hline & \multirow{2}{*}{$1 \mathrm{~s}$} & $1 \mathrm{~m}$ & & . & 7.6 & 2.4 & 12.8 & 0.005 \\
\hline & & $3 m$ & & . & 13.1 & 8.3 & 18.0 & $<0.0001$ \\
\hline & $1 \mathrm{~m}$ & $3 m$ & & . & 5.5 & 1.2 & 9.9 & 0.01 \\
\hline \multirow{16}{*}{$\begin{array}{c}\text { Tiempo } \\
y \\
\text { Grupo }\end{array}$} & \multirow{3}{*}{0} & 1s & \multirow{6}{*}{\multicolumn{2}{|c|}{ Control }} & -0.8 & -9.9 & 8.3 & 0.9 \\
\hline & & $1 \mathrm{~m}$ & & & -3.3 & -10.9 & 4.3 & 0.4 \\
\hline & & $3 m$ & & & 3.6 & -3.7 & 10.8 & 0.3 \\
\hline & \multirow{2}{*}{$1 \mathrm{~s}$} & $1 \mathrm{~m}$ & & & -2.5 & -11.6 & 6.6 & 0.6 \\
\hline & & $3 m$ & & & 4.4 & -4.3 & 13.0 & 0.3 \\
\hline & $1 \mathrm{~m}$ & $3 m$ & & & 6.9 & -0.8 & 14.6 & 0.08 \\
\hline & \multirow{3}{*}{0} & 1s & \multirow{6}{*}{\multicolumn{2}{|c|}{ Caso }} & -25.6 & -30.7 & -20.5 & $<0.0001$ \\
\hline & & $1 \mathrm{~m}$ & & & -7.9 & -12.1 & -3.6 & 0.004 \\
\hline & & $3 m$ & & & -3.7 & -7.4 & 0.0 & 0.05 \\
\hline & \multirow{2}{*}{$1 \mathrm{~s}$} & $1 \mathrm{~m}$ & & & 17.7 & 12.6 & 22.9 & $<0.0001$ \\
\hline & & $3 m$ & & & 21.9 & 17.3 & 26.5 & $<0.0001$ \\
\hline & $1 \mathrm{~m}$ & $3 m$ & & & 4.2 & 0.2 & 8.2 & 0.04 \\
\hline & \multicolumn{2}{|c|}{0} & Control & Caso & 3.8 & -11.2 & 18.8 & 0.6 \\
\hline & \multicolumn{2}{|c|}{ 1semana } & Control & Caso & -21.0 & -38.2 & -3.9 & 0.02 \\
\hline & \multicolumn{2}{|c|}{$1 \mathrm{mes}$} & Control & Caso & -0.8 & -16.8 & 15.2 & 0.9 \\
\hline & \multicolumn{2}{|c|}{ 3meses } & Control & Caso & -3.5 & -18.6 & 11.7 & 0.7 \\
\hline
\end{tabular}

1s: 1 semana; 1m: 1 mes; 3m: 3 meses; IC: intervalo de confianza; Inf: inferior; Sup: superior; p:probabilidad.

\section{Grosores Corneales en el Ápex Corneal}




\section{Grosor Corneal Total Central}

Por último, el análisis de grosores corneales por capas se realizó en las medidas tomadas a nivel central. En el caso del espesor corneal total, los efectos del tiempo y la interacción grupo y tiempo resultaron estadísticamente significativos ( $p<0.0001$ en ambos casos), al igual que en las otras dos localizaciones evaluadas observándose el mismo comportamiento. Curiosamente se encontraron en el grupo de controles diferencias $(5.6 \mu \mathrm{m})$ significativas $(p=0.03)$ entre la visita inicial y a los 3 meses.

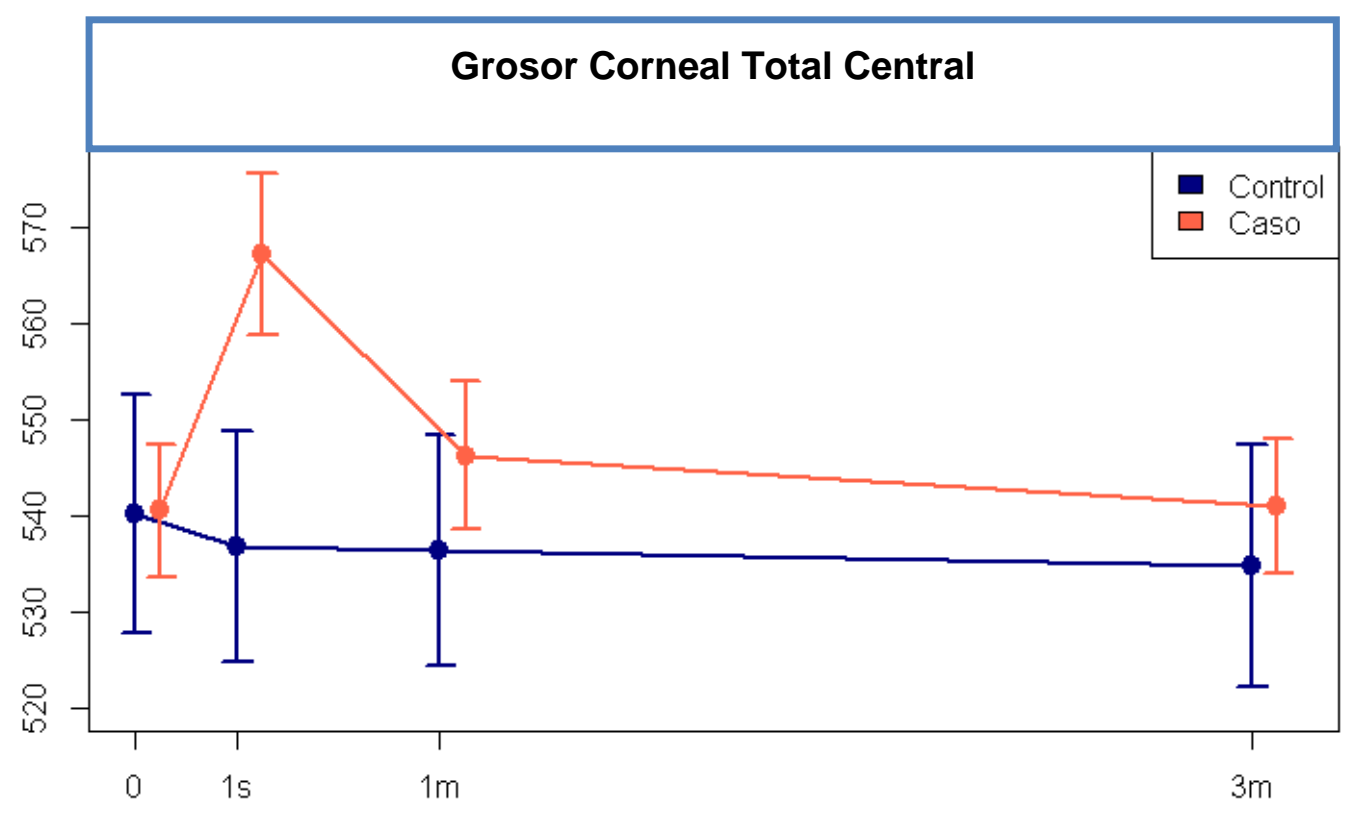

Figura 55: Evolución en el tiempo del espesor corneal total en el área central para los grupos de casos y controles. Se representa la media y el intervalo de confianza al $95 \%$. 
Tabla 14: Diferencias de las medias marginales del espesor corneal total en el área central para los efectos estadísticamente significativos, en este caso el tiempo y la interacción tiempo y grupo.

\begin{tabular}{|c|c|c|c|c|c|c|c|c|}
\hline \multicolumn{9}{|c|}{ Diferencias de medias marginales } \\
\hline \multirow{2}{*}{ Efecto } & \multirow{2}{*}{$\begin{array}{c}\text { Nivel } \\
\text { Tiempo } \\
\text { (I) }\end{array}$} & \multirow{2}{*}{$\begin{array}{c}\text { Nivel } \\
\text { Tiempo } \\
\text { (II) }\end{array}$} & \multirow{2}{*}{$\begin{array}{c}\text { Nivel } \\
\text { Grupo } \\
\text { (I) }\end{array}$} & \multirow{2}{*}{$\begin{array}{l}\text { Nivel } \\
\text { Grupo } \\
\text { (II) }\end{array}$} & \multirow{2}{*}{$\begin{array}{c}\text { Diferencias } \\
\text { (I) - (II) } \\
\text { (Micras) }\end{array}$} & \multicolumn{2}{|c|}{$\begin{array}{l}\text { IC 95\% para la } \\
\text { Diferencia }\end{array}$} & \multirow{2}{*}{ p-valor } \\
\hline & & & & & & Inf. & Sup. & \\
\hline \multirow{6}{*}{ Tiempo } & \multirow{3}{*}{0} & 1s & . & . & -11.6 & 15.6 & -7.6 & $<0.0001$ \\
\hline & & $1 \mathrm{~m}$ & . & . & -0.9 & -3.9 & 2.1 & 0.54 \\
\hline & & $3 m$ & . & . & 2.6 & -0.2 & 5.4 & 0.07 \\
\hline & \multirow{2}{*}{ 1s } & $1 \mathrm{~m}$ & $\cdot$ & ${ }^{\circ}$ & 10.6 & 6.8 & 14.5 & $<0.0001$ \\
\hline & & $3 m$ & . & . & 14.2 & 10.1 & 18.2 & $<0.0001$ \\
\hline & $1 \mathrm{~m}$ & $3 m$ & . & . & 3.5 & 0.7 & 6.3 & 0.016 \\
\hline \multirow{16}{*}{$\begin{array}{l}\text { Tiempo } \\
\text { y Grupo }\end{array}$} & \multirow{3}{*}{0} & $1 \mathrm{~s}$ & \multirow{6}{*}{\multicolumn{2}{|c|}{ Control }} & 3.3 & -3.6 & 10.3 & 0.35 \\
\hline & & $1 \mathrm{~m}$ & & & 3.7 & -1.5 & 8.9 & 0.16 \\
\hline & & $3 m$ & & & 5.6 & 0.6 & 10.7 & 0.03 \\
\hline & \multirow{2}{*}{ 1s } & $1 \mathrm{~m}$ & & & 0.4 & -6.4 & 7.2 & 0.91 \\
\hline & & $3 m$ & & & 2.3 & -4.8 & 9.4 & 0.53 \\
\hline & $1 \mathrm{~m}$ & $3 m$ & & & 1.9 & -3.2 & 6.9 & 0.46 \\
\hline & & $1 \mathrm{~s}$ & \multirow{6}{*}{\multicolumn{2}{|c|}{ Caso }} & -26.5 & 30.4 & -22.5 & $<0.0001$ \\
\hline & 0 & $1 \mathrm{~m}$ & & & -5.6 & -8.5 & -2.7 & 0.0002 \\
\hline & & $3 m$ & & & -0.4 & -3.0 & 2.2 & 0.75 \\
\hline & \multirow{2}{*}{$1 \mathrm{~s}$} & $1 \mathrm{~m}$ & & & 20.9 & 17.1 & 24.7 & $<0.0001$ \\
\hline & & $3 m$ & & & 26.0 & 22.1 & 29.9 & $<0.0001$ \\
\hline & $1 \mathrm{~m}$ & $3 m$ & & & 5.1 & 2.6 & 7.7 & 0.0001 \\
\hline & \multicolumn{2}{|c|}{0} & Control & Caso & -0.1 & 14.8 & 14. & 0.99 \\
\hline & \multicolumn{2}{|c|}{ 1semana } & Control & Caso & -29.9 & 46.8 & -13.0 & 0.0007 \\
\hline & \multicolumn{2}{|c|}{$1 \mathrm{mes}$} & Control & Caso & -9.4 & 25.0 & 6.2 & 0.23 \\
\hline & \multicolumn{2}{|c|}{3 meses } & Control & Caso & -6.1 & 20.9 & 8.6 & 0.41 \\
\hline
\end{tabular}

1s: 1 semana; 1m: 1 mes; 3m: 3 meses; IC: intervalo de confianza; Inf: inferior; Sup: superior; p: probabilidad. 


\section{Grosor Epitelial Central}

El espesor epitelial corneal a nivel central presentó, al igual que en las lacalizaciones paracentrales más próxima y más alejada del área incisional, diferencias significativas $(p<0.0001)$ entre el grupo de casos y de controles, siendo esta diferencia de $-4.96 \pm 0.8$ (95\% IC -6.52/-3.38). Sin embargo no se encontraron cambios significativos $(p=0.31)$ a lo largo del tiempo.

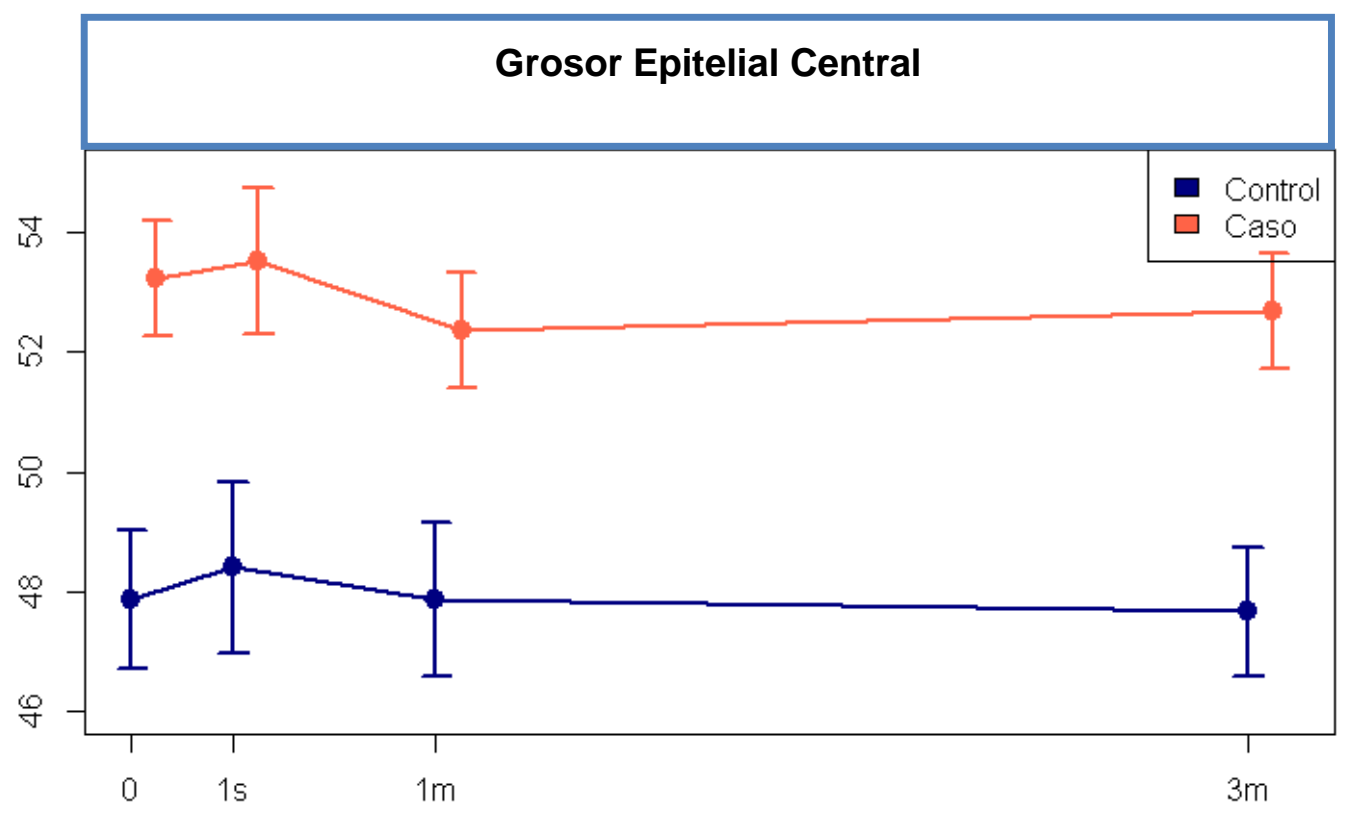

Figura 56: Evolución en el tiempo del espesor epitelial corneal en el área central para los grupos de casos y controles. Representa la media y el intervalo de confianza al 95\%.

\section{Grosor Corneal Total no Epitelial Central}

El espesor corneal total no epitelial a nivel central presentó diferencias significativas en el análisis de las medias en función del tiempo $(p<0.0001)$ y de la 
interacción tiempo y grupo $(\mathrm{p}<0.0001)$. A la semana de la cirugía se encontraron los valores más altos, y a los 3 meses el espesor no epitelial corneal presentó diferencias significativas con la visita inicial y al mes. En el grupo de los controles en la visita inicial los espesores fueron significativamente mayores que a los 3 meses $(p=0.01)$. En el grupo de controles no se encontraron diferencias significativas entre la visita inicial y la final $(p=0.94)$.

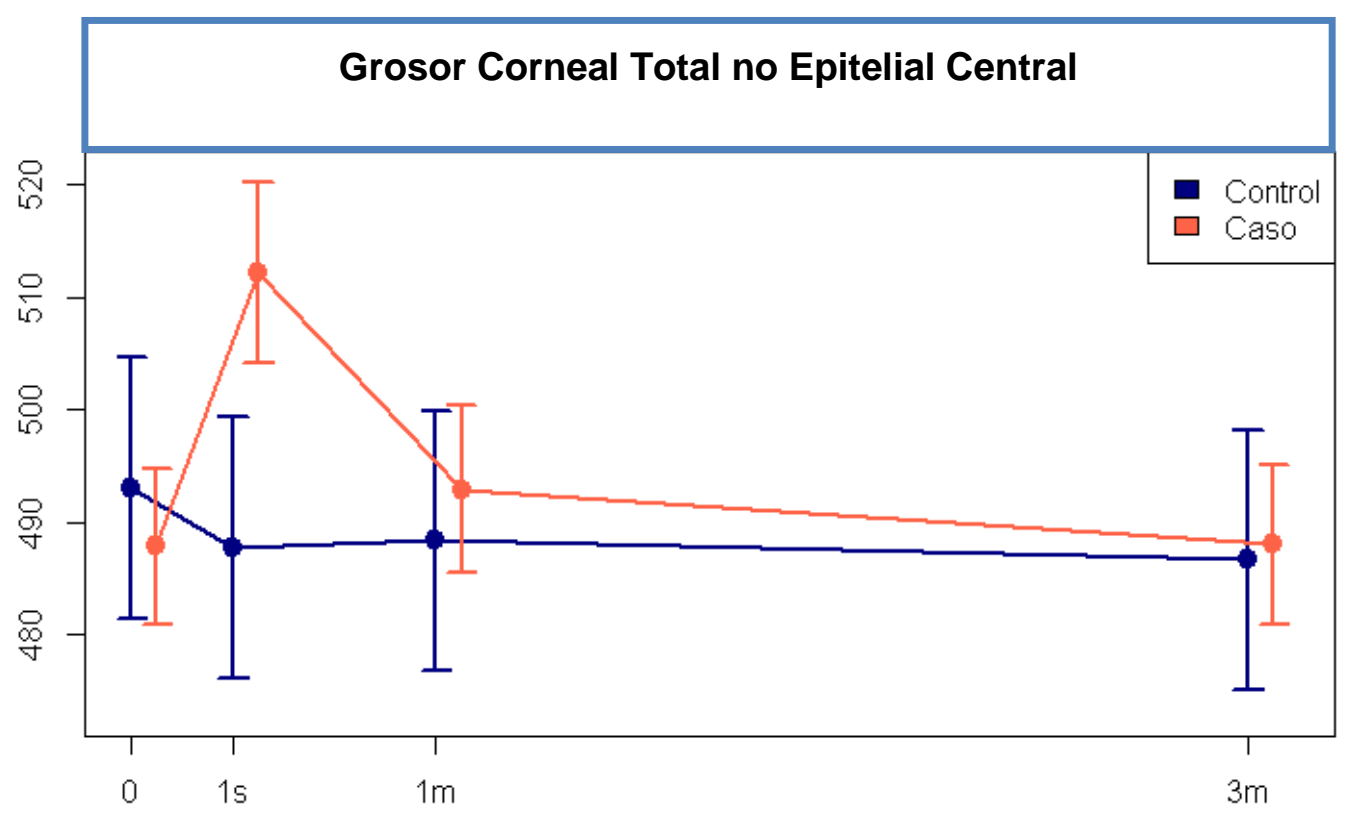

Figura 57: Evolución en el tiempo del espesor corneal total no epitelial en el área central para los grupos de casos y controles. Se representa la media y el intervalo de confianza al $95 \%$. 
Tabla 15: Diferencias de las medias marginales del espesor corneal total no epitelial en el área central para los efectos estadísticamente significativos, en este caso el tiempo y la interacción tiempo y grupo.

\begin{tabular}{|c|c|c|c|c|c|c|c|c|}
\hline \multicolumn{9}{|c|}{ Diferencias de medias marginales } \\
\hline \multirow[t]{2}{*}{ Efecto } & \multirow{2}{*}{$\begin{array}{c}\text { Nivel } \\
\text { Tiempo } \\
\text { (I) }\end{array}$} & \multirow{2}{*}{$\begin{array}{c}\text { Nivel } \\
\text { Tiempo } \\
\text { (II) }\end{array}$} & \multirow{2}{*}{$\begin{array}{c}\text { Nivel } \\
\text { Grupo } \\
\text { (I) }\end{array}$} & \multirow{2}{*}{$\begin{array}{l}\text { Nivel } \\
\text { Grupo } \\
\text { (II) }\end{array}$} & \multirow{2}{*}{$\begin{array}{l}\text { Diferencias } \\
\text { (I) - (II) } \\
\text { (Micras) }\end{array}$} & \multicolumn{2}{|c|}{$\begin{array}{c}\text { IC 95\% para } \\
\text { la } \\
\text { diferencia }\end{array}$} & \multirow[t]{2}{*}{ p-valor } \\
\hline & & & & & & Inf. & Sup. & \\
\hline \multirow{6}{*}{ Tiempo } & \multirow{3}{*}{0} & 1s & & . & -9.5 & -13.1 & -5.9 & $<0.0001$ \\
\hline & & $1 \mathrm{~m}$ & . & . & -0.2 & -2.9 & 2.6 & 0.9 \\
\hline & & $3 m$ & . & . & 3.3 & 0.4 & 6.2 & 0.02 \\
\hline & \multirow{2}{*}{$1 \mathrm{~s}$} & $1 \mathrm{~m}$ & . & . & 9.3 & 5.5 & 13.2 & $<0.0001$ \\
\hline & & $3 m$ & . & . & 12.8 & 8.9 & 16.8 & $<0.0001$ \\
\hline & $1 \mathrm{~m}$ & $3 m$ & . & . & 3.5 & 0.7 & 6.4 & 0.015 \\
\hline \multirow{16}{*}{$\begin{array}{l}\text { Tiempo } \\
\text { y Grupo }\end{array}$} & & $1 \mathrm{~s}$ & \multirow{6}{*}{\multicolumn{2}{|c|}{ Control }} & 5.3 & -0.9 & 11.6 & 0.09 \\
\hline & 0 & $1 \mathrm{~m}$ & & & 4.7 & -0.2 & 9.5 & 0.06 \\
\hline & & $3 m$ & & & 6.8 & 1.6 & 12.0 & 0.01 \\
\hline & \multirow{2}{*}{$1 \mathrm{~s}$} & $1 \mathrm{~m}$ & & & -0.7 & -7.3 & 6.0 & 0.8 \\
\hline & & $3 m$ & & & 1.5 & -5.5 & 8.4 & 0.7 \\
\hline & $1 \mathrm{~m}$ & $3 m$ & & & 2.1 & -2.9 & 7.2 & 0.41 \\
\hline & & $1 \mathrm{~s}$ & \multirow{6}{*}{\multicolumn{2}{|c|}{ Caso }} & -24.3 & -27.9 & -20.8 & $<0.0001$ \\
\hline & 0 & $1 \mathrm{~m}$ & & & -5.0 & -7.7 & -2.4 & 0.0003 \\
\hline & & $3 m$ & & & -0.1 & -2.7 & 2.5 & 0.94 \\
\hline & \multirow{2}{*}{$1 \mathrm{~s}$} & $1 \mathrm{~m}$ & & & 19.3 & 15.5 & 23.1 & $<0.0001$ \\
\hline & & $3 m$ & & & 24.2 & 20.5 & 28.0 & $<0.0001$ \\
\hline & $1 \mathrm{~m}$ & $3 m$ & & & 4.9 & 2.4 & 7.5 & 0.0002 \\
\hline & \multicolumn{2}{|c|}{0} & Control & Caso & 5.4 & -9.0 & 19.8 & 0.46 \\
\hline & \multicolumn{2}{|c|}{ 1semana } & Control & Caso & -24.3 & -40.5 & -8.0 & 0.004 \\
\hline & \multicolumn{2}{|c|}{$1 \mathrm{mes}$} & Control & Caso & -4.3 & -19.4 & 10.8 & 0.6 \\
\hline & \multicolumn{2}{|c|}{ 3meses } & Control & Caso & -1.5 & -16.3 & 13.3 & 0.84 \\
\hline
\end{tabular}

1s: 1 semana; 1m: 1 mes; 3m: 3 meses; IC: intervalo de confianza; Inf: inferior; Sup: superior; $p$ : probabilidad.

\section{Queratometría}




\section{Meridianos de Menor y Mayor Potencia}

Los datos queratométricos proporcionados por el topógrafo ( $\mathrm{K}$ meridiano plano y K meridiano curvo) no presentaron diferencias estadísticamente significativas ni en la evolución ni según el grupo ni en la interacción entre evolución y grupo $(p \geq 0.08)$ (Figuras 58 y 59$)$.

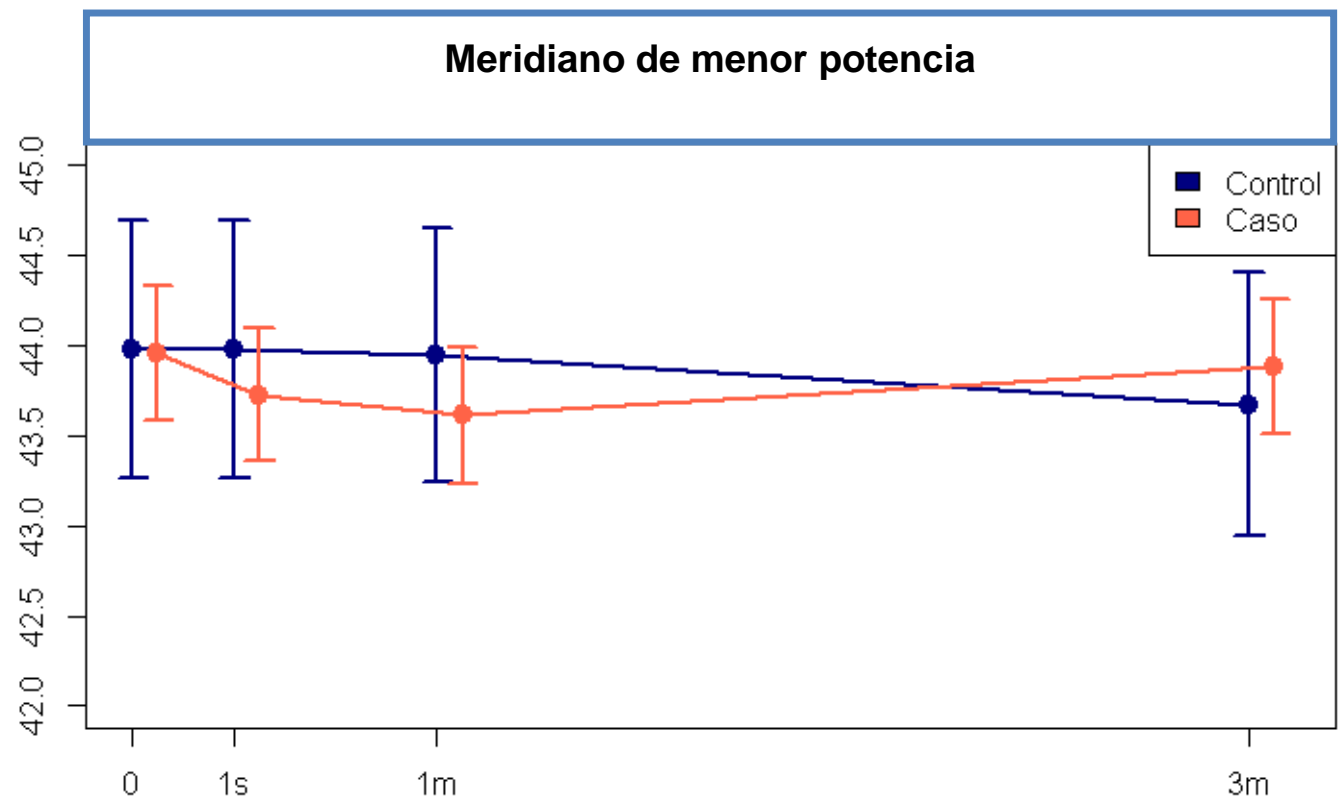

Figura 58: Evolución en el tiempo de los valores queratométricos en el meridiano de menor potencia. Se representa la media y el intervalo de confianza al 95\%. 


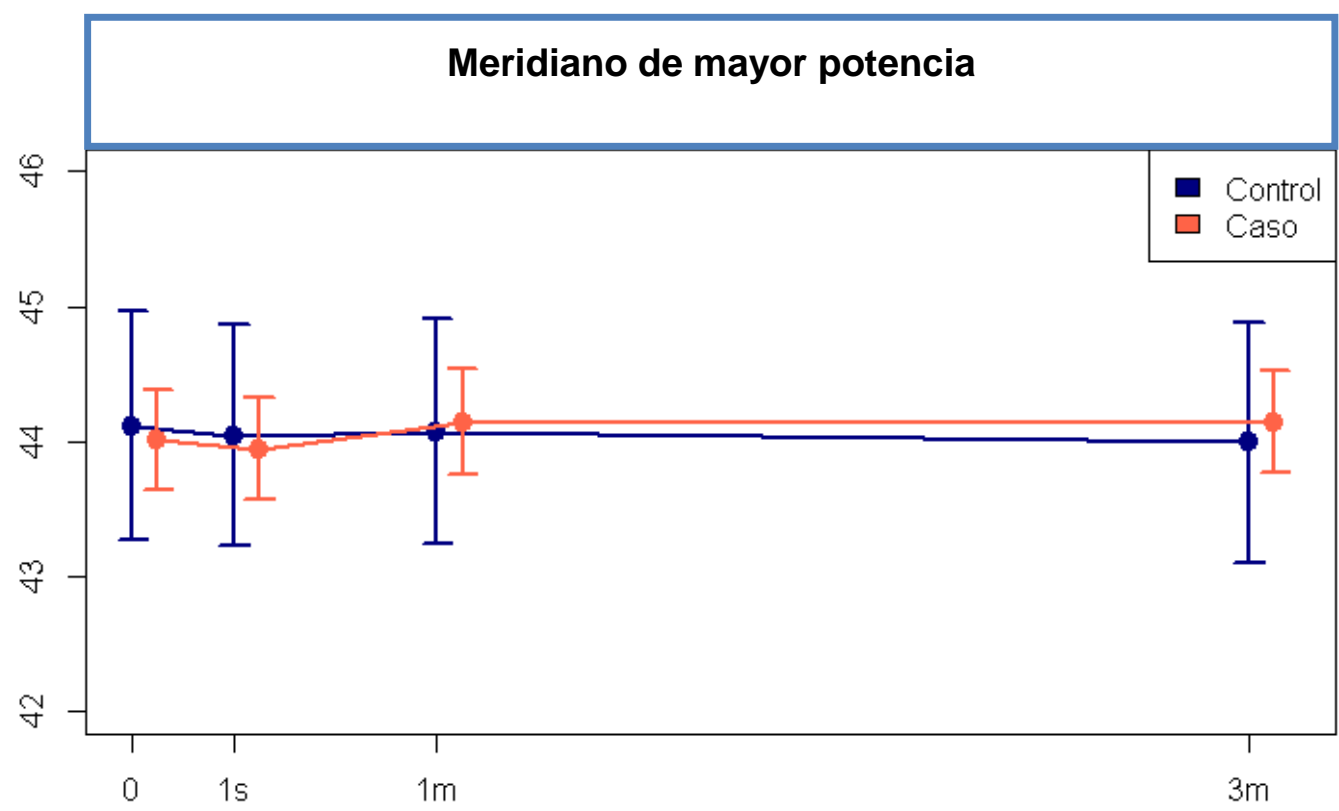

Figura 59: Evolución en el tiempo de los valores queratométricos en el meridiano de mayor potencia. Se representa la media y el intervalo de confianza al 95\%.

\section{Astigmatismo Corneal}

Tampoco se encontraron diferencias significativas ni efectos significativos en el análisis del astigmatismo ( $p \geq 0.09)$ (Figura 60). 


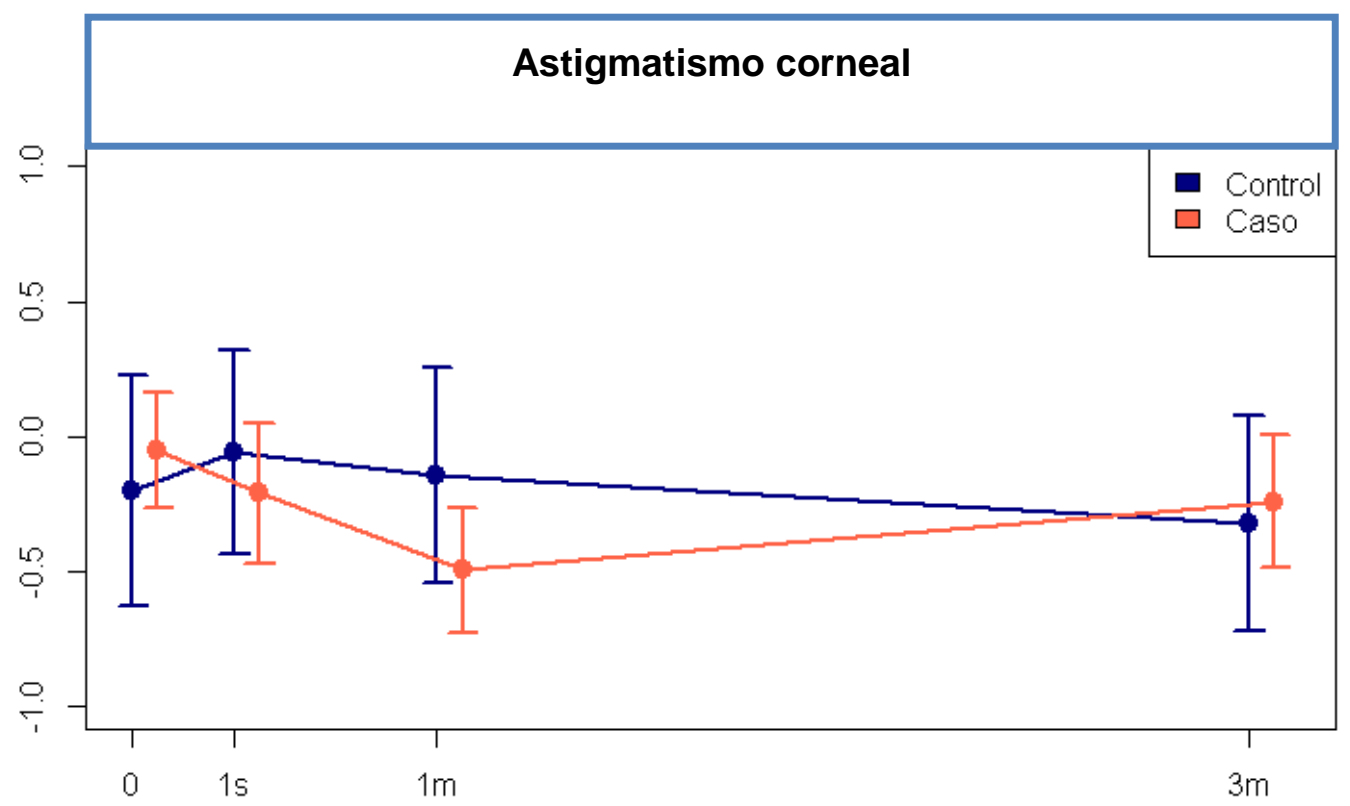

Figura 60: Evolución en el tiempo del astigmatismo corneal para los grupos de casos y controles. Se representa la media y el intervalo de confianza al $95 \%$.

\section{Excentricidad Corneal}

Los valores de excentricidad presentaron diferencias significativas tanto en la evolución, como en el grupo, como en la interacción de la evolución y el grupo. La excentricidad fue significativamente mayor a los 3 meses que en el resto de visitas $(p=0.02)$. En el grupo de casos, resultaron significativas las diferencias entre la última visita y el resto $(p \leq 0.02)$. También fue significativa $(p=0.003)$ la diferencia entre la semana y el mes, con mayor excentricidad al mes. Se encontraron diferencias significativas $(p<0.0001)$ entre los casos y los controles en todas las visitas, siendo menores en el grupo de casos. 


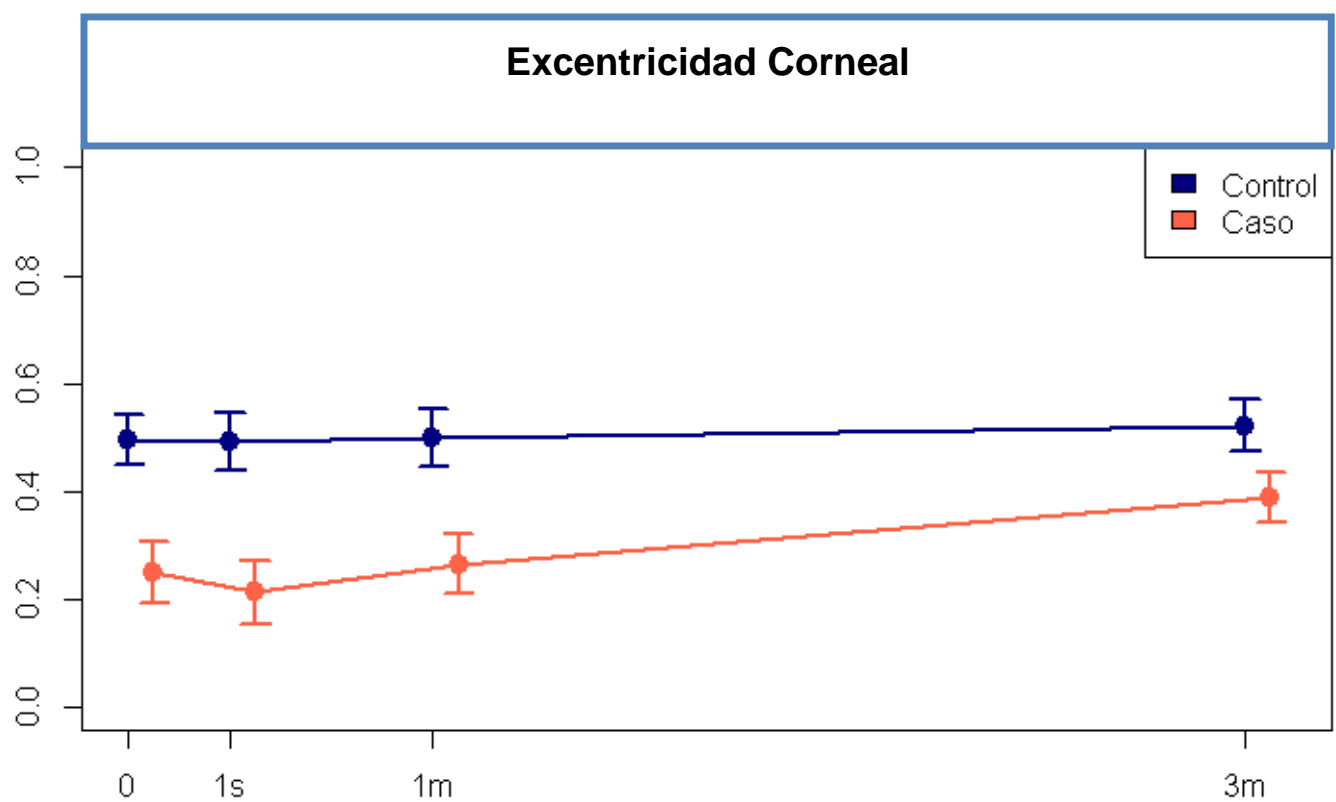

Figura 61: Evolución en el tiempo de la excentricidad corneal para los grupos de casos y controles. Se representa la media y el intervalo de confianza al $95 \%$. 
Tabla 16: Diferencias de las medias marginales de la excentricidad corneal para los efectos estadísticamente significativos, en este caso el tiempo, grupo e interacción tiempo y grupo.

\begin{tabular}{|c|c|c|c|c|c|c|c|c|}
\hline \multicolumn{9}{|c|}{ Diferencias de medias marginales } \\
\hline \multirow[t]{2}{*}{ Efecto } & \multirow{2}{*}{$\begin{array}{c}\text { Nivel } \\
\text { Tiempo } \\
\text { (I) }\end{array}$} & \multirow{2}{*}{$\begin{array}{c}\text { Nivel } \\
\text { Tiempo } \\
\text { (II) }\end{array}$} & \multirow{2}{*}{$\begin{array}{l}\text { Nivel } \\
\text { Grupo } \\
\text { (I) }\end{array}$} & \multirow{2}{*}{$\begin{array}{l}\text { Nivel } \\
\text { Grupo } \\
\text { (II) }\end{array}$} & \multirow[t]{2}{*}{$\begin{array}{l}\text { Diferencias } \\
\text { (I) - (II) }\end{array}$} & \multicolumn{2}{|c|}{$\begin{array}{c}\text { IC 95\% para } \\
\text { la } \\
\text { Diferencia }\end{array}$} & \multirow[t]{2}{*}{ p-valor } \\
\hline & & & & & & Inf. & Sup. & \\
\hline \multirow{6}{*}{ Tiempo } & \multirow{3}{*}{0} & 1s & & . & 0.02 & -0.03 & 0.07 & 0.4 \\
\hline & & $1 \mathrm{~m}$ & & . & -0.01 & -0.06 & 0.05 & 0.8 \\
\hline & & $3 m$ & & . & -0.07 & -0.1 & -0.01 & 0.02 \\
\hline & \multirow{2}{*}{$1 \mathrm{~s}$} & $1 \mathrm{~m}$ & & . & -0.03 & -0.08 & 0.02 & 0.24 \\
\hline & & $3 m$ & & . & -0.09 & -0.1 & -0.04 & 0.001 \\
\hline & $1 \mathrm{~m}$ & $3 m$ & & . & -0.06 & -0.1 & -0.01 & 0.009 \\
\hline Grupo & . &. & Control & Caso & 0.2 & 0.1 & 0.3 & $<0.0001$ \\
\hline \multirow{16}{*}{$\begin{array}{c}\text { Tiempo } \\
\text { y } \\
\text { Grupo }\end{array}$} & \multirow{3}{*}{0} & $1 \mathrm{~s}$ & \multirow{6}{*}{\multicolumn{2}{|c|}{ Control }} & 5.3 & 0.04 & -0.09 & 0.09 \\
\hline & & $1 \mathrm{~m}$ & & & 4.7 & -0.1 & -0.1 & 0.09 \\
\hline & & $3 m$ & & & 6.8 & -0.2 & -0.1 & 0.09 \\
\hline & \multirow{2}{*}{$1 \mathrm{~s}$} & $1 \mathrm{~m}$ & & & -0.01 & -0.09 & 0.08 & 0.9 \\
\hline & & $3 m$ & & & -0.02 & -0.1 & 0.08 & 0.8 \\
\hline & $1 \mathrm{~m}$ & $3 m$ & & & -0.01 & -0.09 & 0.08 & 0.8 \\
\hline & \multirow{3}{*}{0} & $1 \mathrm{~s}$ & \multirow{6}{*}{\multicolumn{2}{|c|}{ Caso }} & 0.04 & -0.01 & 0.09 & 0.09 \\
\hline & & $1 \mathrm{~m}$ & & & -0.01 & -0.06 & 0.05 & 0.8 \\
\hline & & $3 m$ & & & -0.1 & -0.2 & -0.07 & $<0.0001$ \\
\hline & \multirow{2}{*}{$1 \mathrm{~s}$} & $1 \mathrm{~m}$ & & & -0.05 & -0.09 & -0.00 & 0.03 \\
\hline & & $3 m$ & & & -0.2 & -0.2 & -0.1 & $<0.0001$ \\
\hline & $1 \mathrm{~m}$ & $3 m$ & & & -0.1 & -0.2 & -0.08 & $<0.0001$ \\
\hline & \multicolumn{2}{|c|}{0} & Control & Caso & 0.2 & 0.1 & 0.3 & $<0.0001$ \\
\hline & \multicolumn{2}{|c|}{ 1semana } & Control & Caso & 0.3 & 0.2 & 0.4 & $<0.0001$ \\
\hline & \multicolumn{2}{|c|}{$1 \mathrm{mes}$} & Control & Caso & 0.2 & 0.1 & 0.3 & $<0.0001$ \\
\hline & \multicolumn{2}{|c|}{ 3meses } & Control & Caso & 0.1 & 0.03 & 0.2 & 0.01 \\
\hline
\end{tabular}

1s: 1 semana; 1m: 1 mes; 3m: 3 meses; IC: intervalo de confianza; Inf: inferior; Sup: superior; $p$ : probabilidad.

\section{Aberraciones de Alto Orden}




\section{Coma primario}

Los componentes del coma primario $\left(Z_{3}^{1}\right.$ y $\left.Z_{3}^{-1}\right)$ no presentaron diferencias estadísticamente significativas $(p \geq 0.08)$ ni en el tiempo, ni en el grupo ni en la interacción tiempo-grupo.

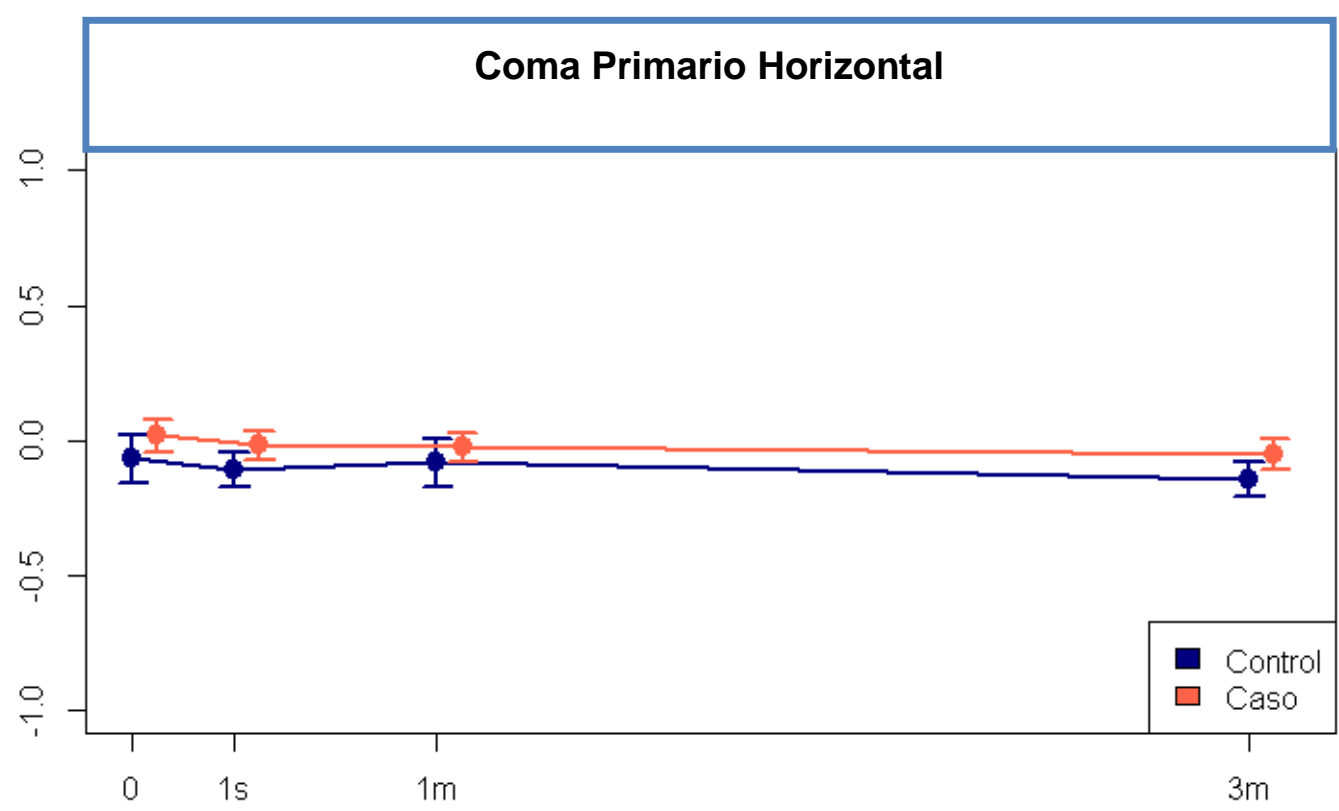

Figura 62: Evolución en el tiempo del valor de $\mathrm{Z}_{3}{ }^{1}$ corneal anterior para los grupos de casos y controles. Se representa la media y el intervalo de confianza al 95\%. 


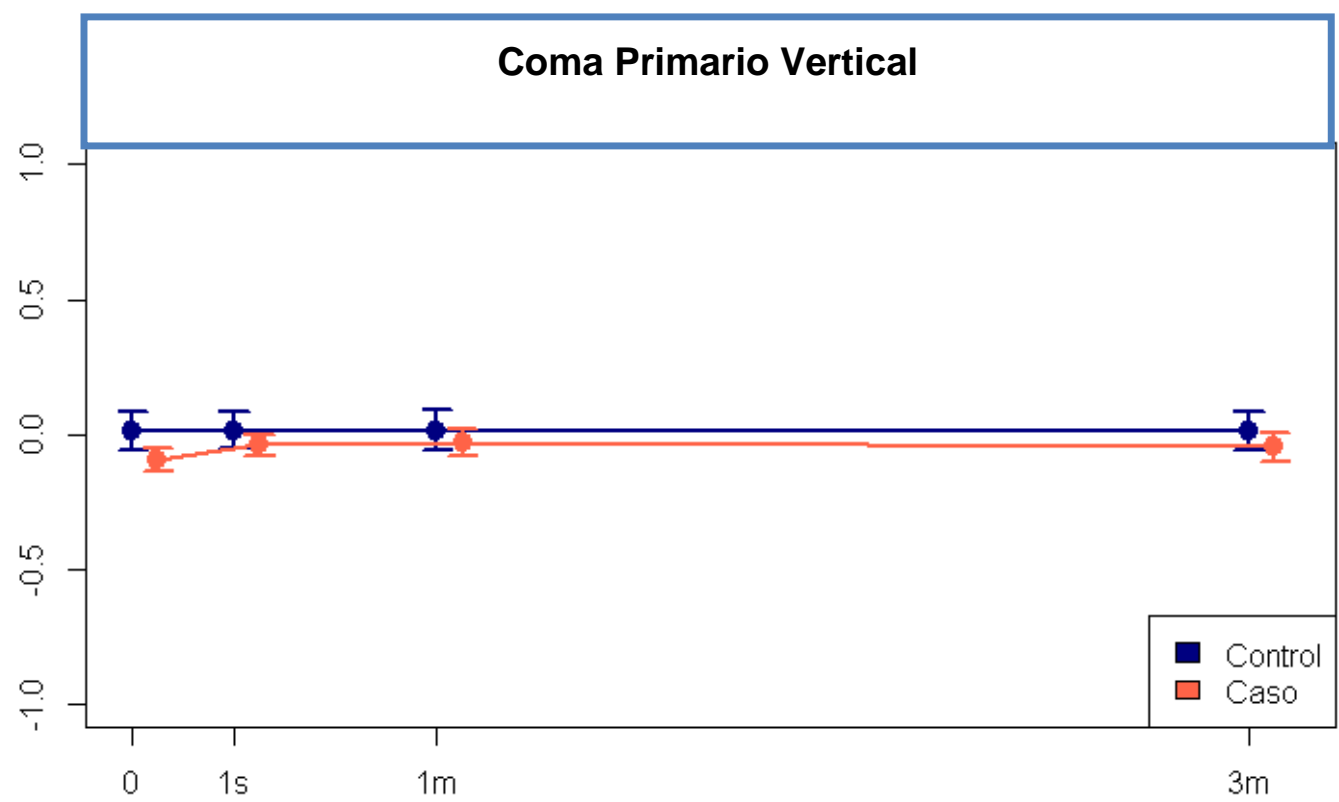

Figura 63: Evolución en el tiempo del valor de $Z_{3}^{-1}$ corneal anterior para los grupos de casos y controles. Se representa la media y el intervalo de confianza al 95\%.

\section{Coma Secundario}

El componente $Z_{5}{ }^{1}$ del coma secundario presentó diferencias significativas en la evolución temporal y según el grupo. Sin embargo el valor de $Z_{5}^{-1}$ no mostró diferencias significativas ni en la evolución, ni entre grupos ni en la interacción de la evolución y los grupos $(p \geq 0.09)$. 


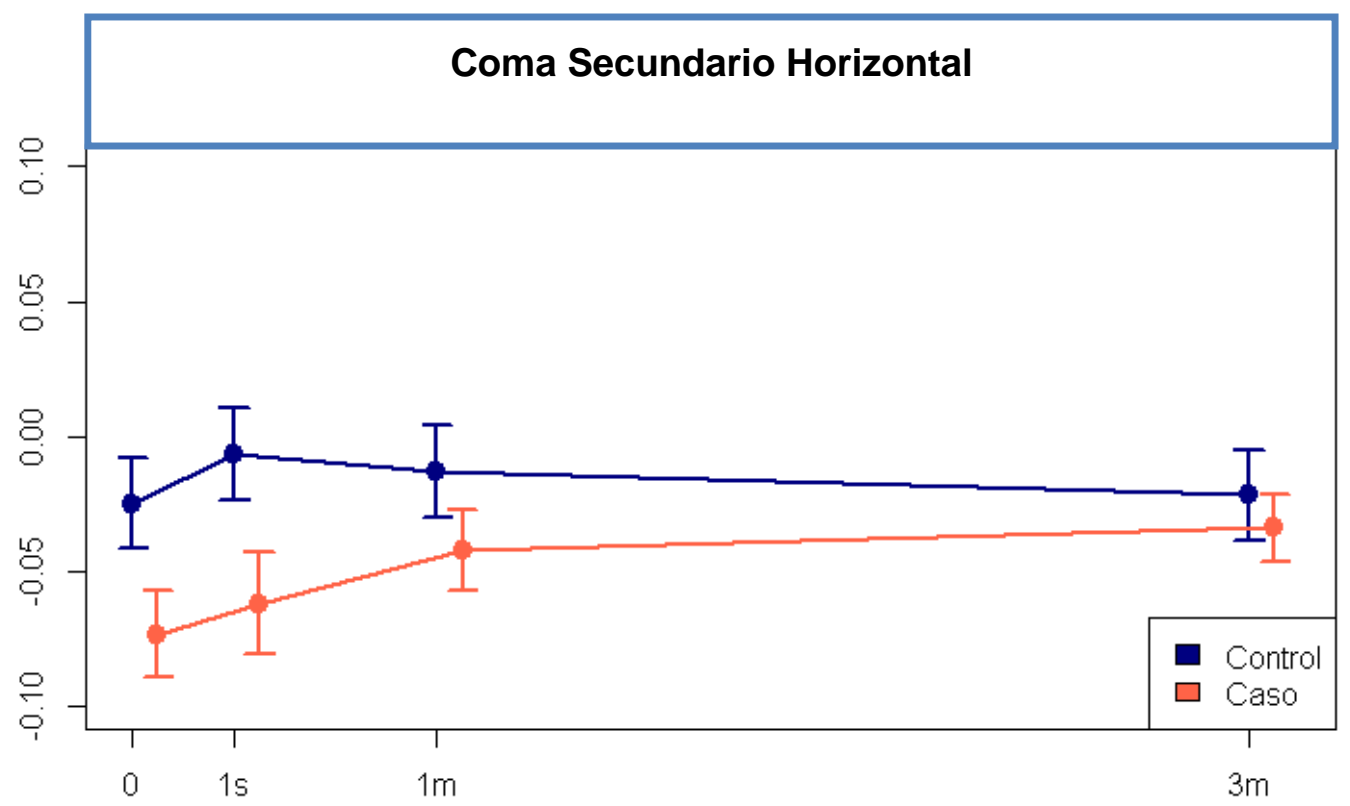

Figura 64: Evolución en el tiempo del valor de $Z_{5}{ }^{1}$ corneal anterior para los grupos de casos y controles. Se representa la media y el intervalo de confianza al 95\%.

Tabla 17: Diferencias de las medias marginales del coma secundario horizontal para los efectos estadísticamente significativos, en este caso el tiempo y grupo.

\begin{tabular}{|c|c|c|c|c|c|c|c|c|}
\hline \multicolumn{9}{|c|}{ Diferencias de medias marginales } \\
\hline \multirow[t]{2}{*}{ Efecto } & \multirow{2}{*}{$\begin{array}{l}\text { Nivel } \\
\text { Tiempo } \\
\text { (I) }\end{array}$} & \multirow{2}{*}{$\begin{array}{c}\text { Nivel } \\
\text { Tiempo } \\
\text { (II) }\end{array}$} & \multirow{2}{*}{$\begin{array}{l}\text { Nivel } \\
\text { Grupo } \\
\text { (I) }\end{array}$} & \multirow{2}{*}{$\begin{array}{l}\text { Nivel } \\
\text { Grupo } \\
\text { (II) }\end{array}$} & \multirow{2}{*}{$\begin{array}{c}\text { Diferencia } \\
\text { (I) - (II) } \\
\text { (Micras) }\end{array}$} & \multicolumn{2}{|c|}{$\begin{array}{c}\text { IC 95\% para la } \\
\text { diferencia }\end{array}$} & \multirow[t]{2}{*}{ p-valor } \\
\hline & & & & & & Inf. & Sup. & \\
\hline \multirow{6}{*}{ Tiempo } & \multirow{3}{*}{0} & 1s & . & . & -0.01 & -0.03 & 0.001 & 0.07 \\
\hline & & $1 \mathrm{~m}$ & . & . & -0.02 & -0.04 & -0.005 & 0.01 \\
\hline & & $3 m$ & . & . & -0.02 & -0.04 & -0.005 & 0.01 \\
\hline & \multirow{2}{*}{$1 \mathrm{~s}$} & $1 \mathrm{~m}$ & . & . & -0.01 & -0.02 & 0.009 & 0.43 \\
\hline & & $3 m$ & . & . & -0.01 & -0.02 & 0.01 & 0.46 \\
\hline & $1 \mathrm{~m}$ & $3 m$ & . & . & -0.00 & -0.02 & 0.02 & 0.97 \\
\hline Grupo & . & . & Control & Caso & 0.03 & 0.01 & 0.06 & 0.004 \\
\hline
\end{tabular}

1s: 1 semana; 1m: 1 mes; 3m: 3 meses; IC: intervalo de confianza; Inf: inferior; Sup: superior; $\mathrm{p}$ : probabilidad. 


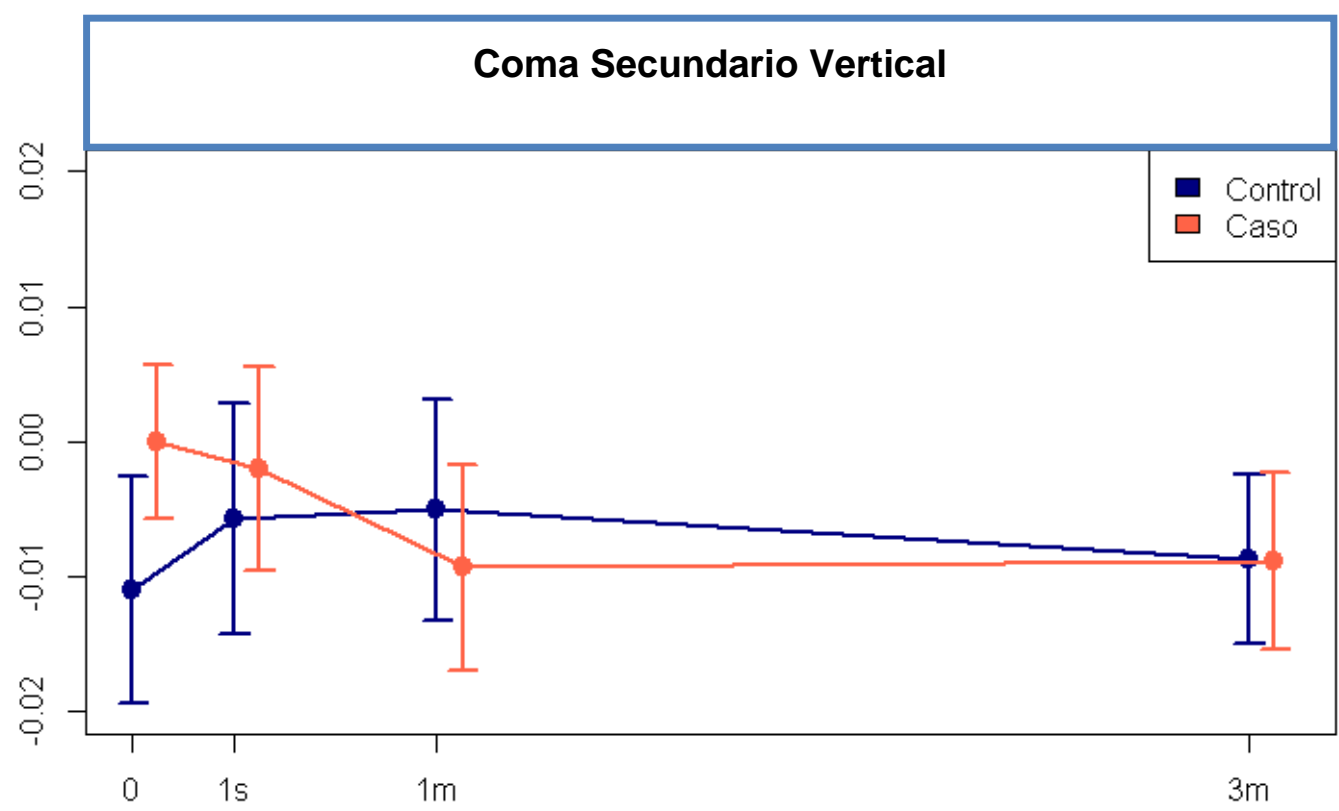

Figura 65: Evolución en el tiempo del valor de $Z_{5}^{-1}$ corneal anterior para los grupos de casos y controles. Se representa la media y el intervalo de confianza al 95\%.

\section{"Coma-like"}

En el "coma-like" $\left(Z_{3}{ }^{1}, Z_{3}{ }^{-1}, Z_{5}{ }^{1}, Z_{5}{ }^{-1}\right)$ resultó significativo $(p=0.01)$ el efecto del grupo, con una diferencia de $-0.07 \pm 0.03(95 \%$ IC $-0.12 /-0.01)$ a favor del grupo de casos, no observándose variaciones significativas $(p \geq 0.24)$ a lo largo del tiempo. 


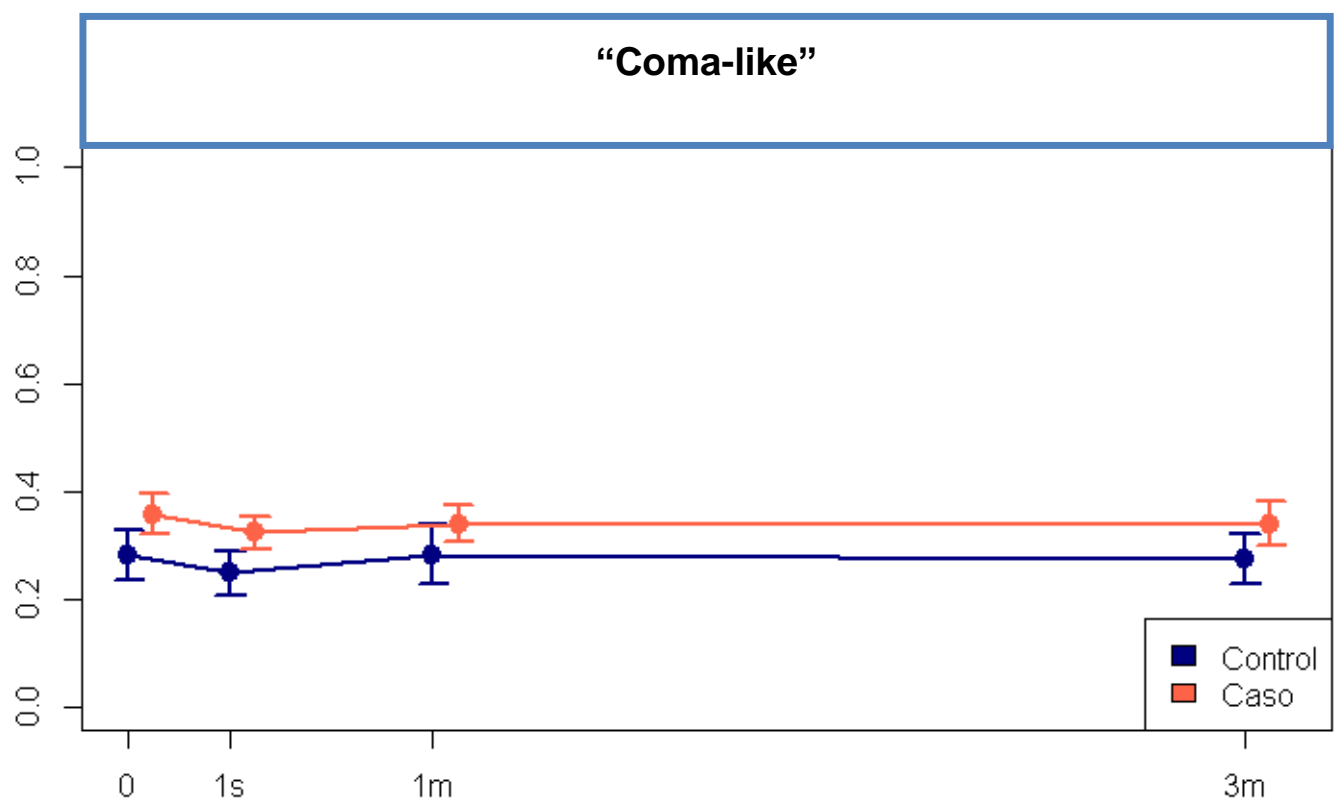

Figura 66: Evolución en el tiempo del valor de "coma-like" corneal anterior para los grupos de casos y controles. Se representa la media y el intervalo de confianza al 95\%.

\section{Aberración Esférica Primaria}

La aberración esférica primaria $\mathrm{Z}_{4}{ }^{0}$ presentó en su análisis diferencias significativas en los efectos de tiempo $(p=0.01)$ y grupo $(p<0.0001)$, siendo menor en la visita a los 3 meses en comparación con el resto de visitas y presentando mayores valores en el grupo de casos. 


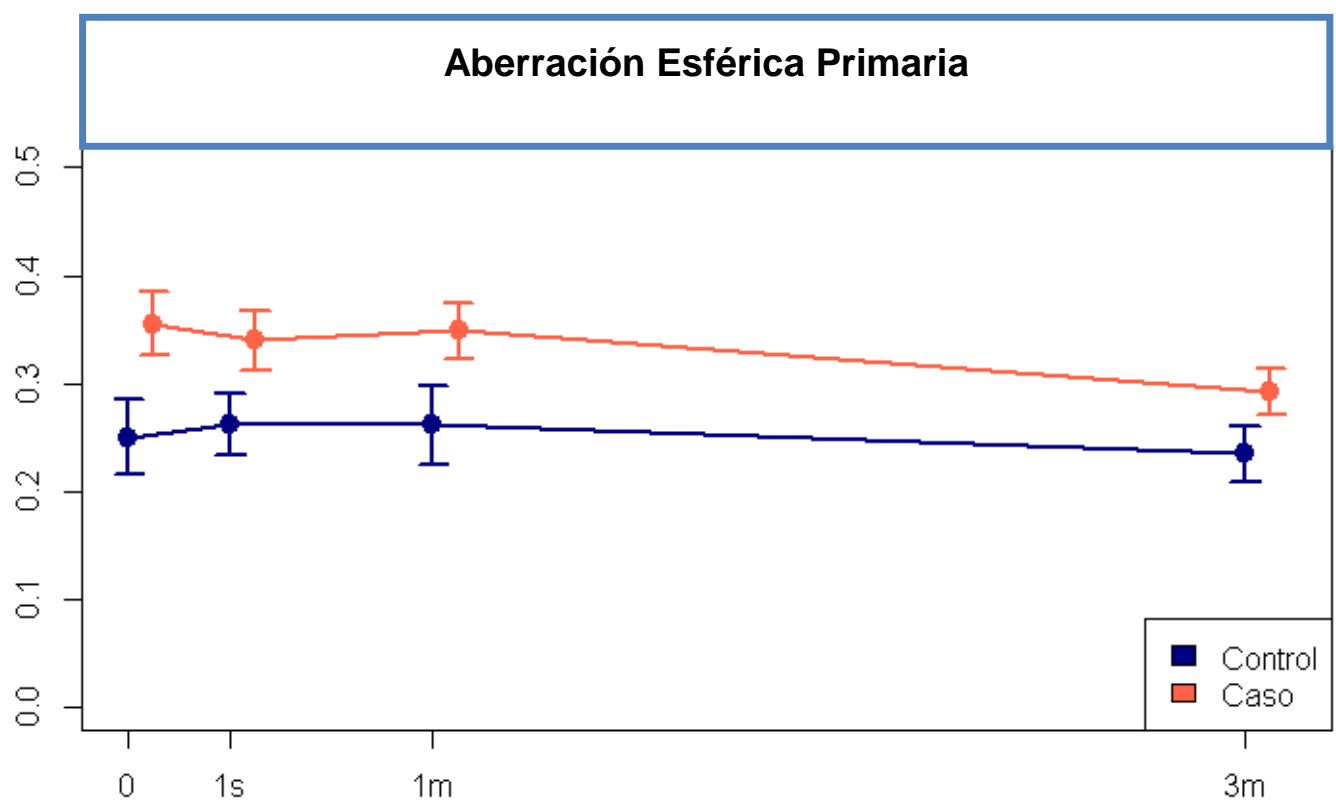

Figura 67: Evolución en el tiempo del valor de la aberración esférica primaria corneal anterior para los grupos de casos y controles. Se representa la media y el intervalo de confianza al $95 \%$. 
Tabla 18: Diferencias de las medias marginales de la aberración esférica primaria corneal para los efectos estadisticamente significativos, en este caso el tiempo y grupo.

\begin{tabular}{|c|c|c|c|c|c|c|c|c|}
\hline \multicolumn{9}{|c|}{ Diferencias de medias marginales } \\
\hline \multirow{2}{*}{ Efecto } & \multirow{2}{*}{$\begin{array}{c}\text { Nivel } \\
\text { Tiempo } \\
\text { (I) }\end{array}$} & \multirow{2}{*}{$\begin{array}{c}\text { Nivel } \\
\text { Tiempo } \\
\text { (II) }\end{array}$} & \multirow{2}{*}{$\begin{array}{l}\text { Nivel } \\
\text { Grupo } \\
\text { (I) }\end{array}$} & \multirow{2}{*}{$\begin{array}{c}\text { Nivel } \\
\text { Grupo } \\
\text { (II) }\end{array}$} & \multirow{2}{*}{$\begin{array}{c}\text { Diferencias } \\
\text { (I) - (II) } \\
\text { (Micras) }\end{array}$} & \multicolumn{2}{|c|}{$\begin{array}{l}\text { IC 95\% para la } \\
\text { Diferencia }\end{array}$} & \multirow[t]{2}{*}{ p-valor } \\
\hline & & & & & & Inf. & Sup. & \\
\hline \multirow{6}{*}{ Tiempo } & \multirow{3}{*}{0} & $1 \mathrm{~s}$ & & . & 0.002 & -0.03 & 0.03 & 0.9 \\
\hline & & $1 \mathrm{~m}$ & & . & -0.003 & -0.03 & 0.03 & 0.8 \\
\hline & & $3 m$ & . & . & 0.04 & 0.009 & 0.07 & 0.01 \\
\hline & \multirow{2}{*}{$1 \mathrm{~s}$} & $1 \mathrm{~m}$ & & . & -0.005 & -0.03 & 0.02 & 0.7 \\
\hline & & $3 m$ & . & . & 0.04 & 0.007 & 0.06 & 0.013 \\
\hline & $1 \mathrm{~m}$ & $3 m$ & . & . & 0.04 & 0.01 & 0.06 & 0.002 \\
\hline Grupo & & . & Control & Caso & -0.08 & -0.12 & -0.04 & 0.0001 \\
\hline
\end{tabular}

1s: 1 semana; 1m: 1 mes; 3m: 3 meses; IC: intervalo de confianza; Inf: inferior; Sup: superior; $p$ : probabilidad.

\section{Aberración Esférica Secundaria}

La aberración esférica secundaria $Z_{6}{ }^{0}$ presentó diferencias significativas en el efecto del grupo, siendo significativamente $(p=0.0007)$ menor en el grupo de los casos, con una diferencia de $0.02 \pm 0.05$ (95\% IC 0.01/0.03). No se observaron variaciones significativas $(p \geq 0.098)$ a lo largo del tiempo. 


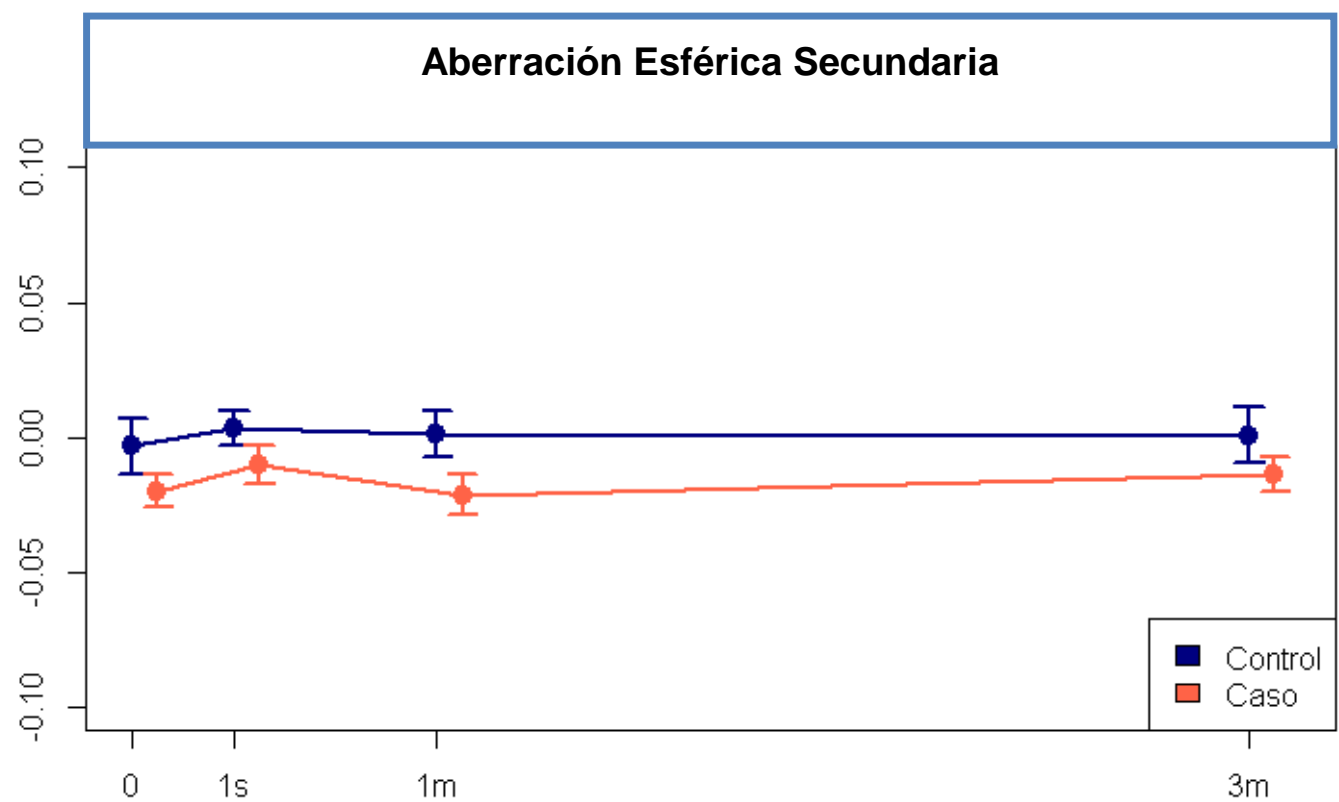

Figura 68: Evolución en el tiempo del valor de la aberración esférica secundaria corneal anterior para los grupos de casos y controles. Se representa la media y el intervalo de confianza al $95 \%$.

\section{"Spherical-like"}

Para el "spherical-like" $\left(Z_{4}{ }^{0}, Z_{6}{ }^{0}\right)$ resultaron significativas $(p<0.012)$ las diferencias encontradas entre la visita de los 3 meses, en la que la media era menor, y el resto de vistas. El "spherical-like" fue mayor en el grupo de los casos. 


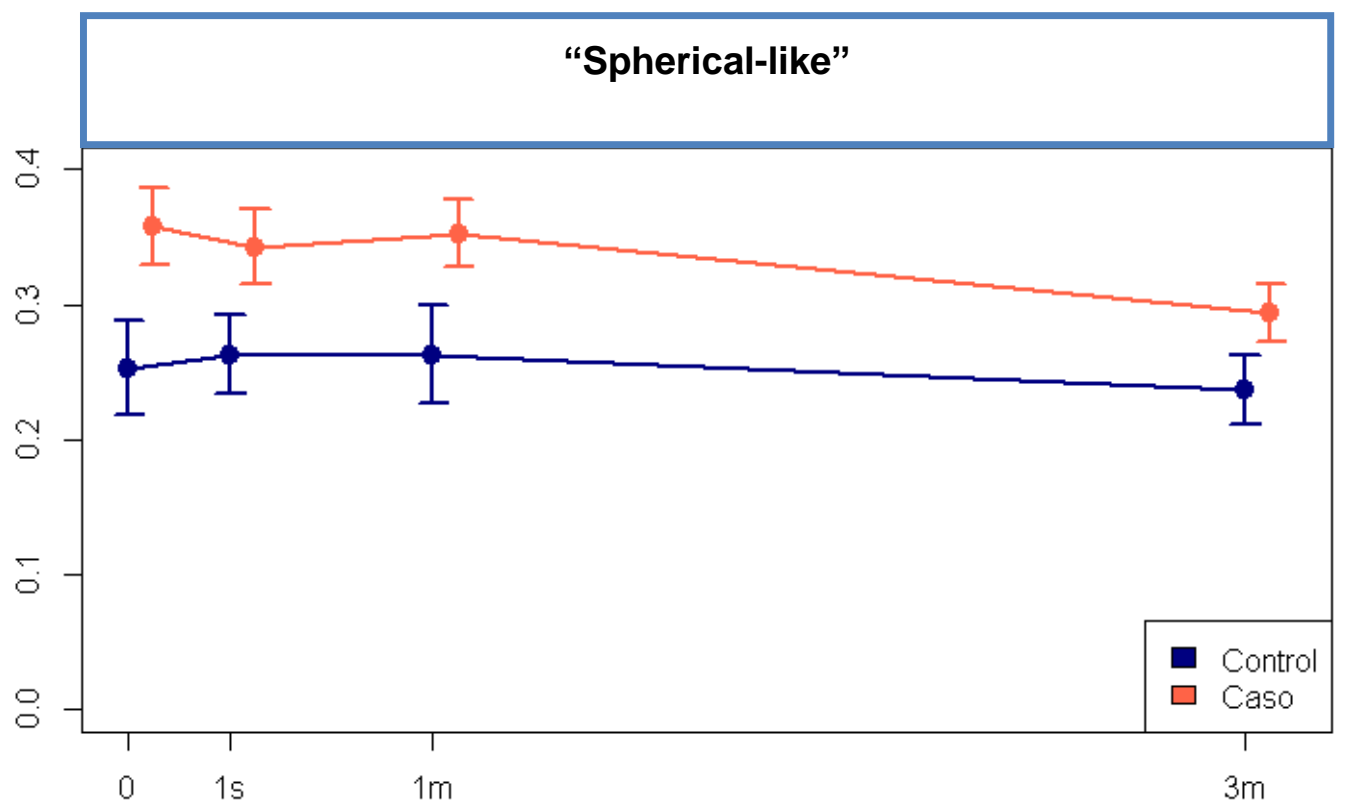

Figura 69: Evolución en el tiempo del valor de "spherical-like" corneal anterior para los grupos de casos y controles. Se representa la media y el intervalo de confianza al 95\%.

Tabla 19: Diferencias de las medias marginales del "spherical like" para los efectos estadísticamente significativos, en este caso el tiempo y grupo.

\begin{tabular}{|c|c|c|c|c|c|c|c|c|}
\hline \multicolumn{9}{|c|}{ Diferencias de medias marginales } \\
\hline \multirow{2}{*}{ Efecto } & \multirow{2}{*}{$\begin{array}{l}\text { Nivel } \\
\text { Tiempo } \\
\text { (I) }\end{array}$} & \multirow{2}{*}{$\begin{array}{l}\text { Nivel } \\
\text { Tiempo } \\
\text { (II) }\end{array}$} & \multirow{2}{*}{$\begin{array}{l}\text { Nivel } \\
\text { Grupo } \\
\text { (I) }\end{array}$} & \multirow{2}{*}{$\begin{array}{l}\text { Nivel } \\
\text { Grupo } \\
\text { (II) }\end{array}$} & \multirow{2}{*}{$\begin{array}{c}\text { Diferencias } \\
\text { (I) - (II) } \\
\text { (Micras) }\end{array}$} & \multicolumn{2}{|c|}{$\begin{array}{l}\text { IC } 95 \% \text { para } \\
\text { la dif }\end{array}$} & \multirow{2}{*}{ p-valor } \\
\hline & & & & & & Inf. & Sup. & \\
\hline \multirow{6}{*}{ Tiempo } & \multirow{3}{*}{0} & 1s & . & & 0.002 & -0.02 & 0.03 & 0.86 \\
\hline & & $1 \mathrm{~m}$ & . & & -0.003 & -0.03 & 0.03 & 0.83 \\
\hline & & $3 m$ & . & . & 0.04 & 0.009 & 0.07 & 0.01 \\
\hline & \multirow{2}{*}{$1 \mathrm{~s}$} & $1 \mathrm{~m}$ & . & & -0.005 & -0.03 & 0.02 & 0.64 \\
\hline & & $3 m$ & . & . & 0.03 & 0.008 & 0.07 & 0.01 \\
\hline & $1 \mathrm{~m}$ & $3 m$ & . & . & 0.04 & 0.02 & 0.07 & 0.002 \\
\hline Grupo & & & Control & Caso & -0.08 & -0.1 & -0.04 & 0.0001 \\
\hline
\end{tabular}

1s: 1 semana; 1m: 1 mes; 3m: 3 meses; IC: intervalo de confianza; Inf: inferior; Sup: superior; $p$ : probabilidad. 


\section{Aberraciones de Alto Orden Corneales Anteriores Totales}

Todos los efectos (evolución, grupo e interacción evolución-grupo) resultaron estadísticamente significativos $(p \leq 0.0049)$ para las aberraciones de alto orden corneales anteriores totales. Resultaron significativas $(p \leq 0.028)$ las diferencias entre la visita de la semana y el mes respecto de la visita inicial y los 3 meses, siendo menores los valores en la visita inicial. Se encontraron diferencias significativas $(p<0.0001)$ en las aberraciones de alto orden totales entre los grupos de casos y controles. En el grupo control no se encontraron diferencias significativas $(p \geq 0.29)$ entre ningún par de visitas. En el grupo de casos, resultaron significativas $(p \leq 0.0018)$ todas las diferencias salvo entre la visita inicial y la final. A la semana se produjo un incremento del valor de las aberraciones totales y al mes descendió hasta llegar a un valor similar al inicial a los 3 meses. La evolución de las aberraciones totales fue significativamente mayor $(p \leq 0.0004)$ en el grupo de casos. 


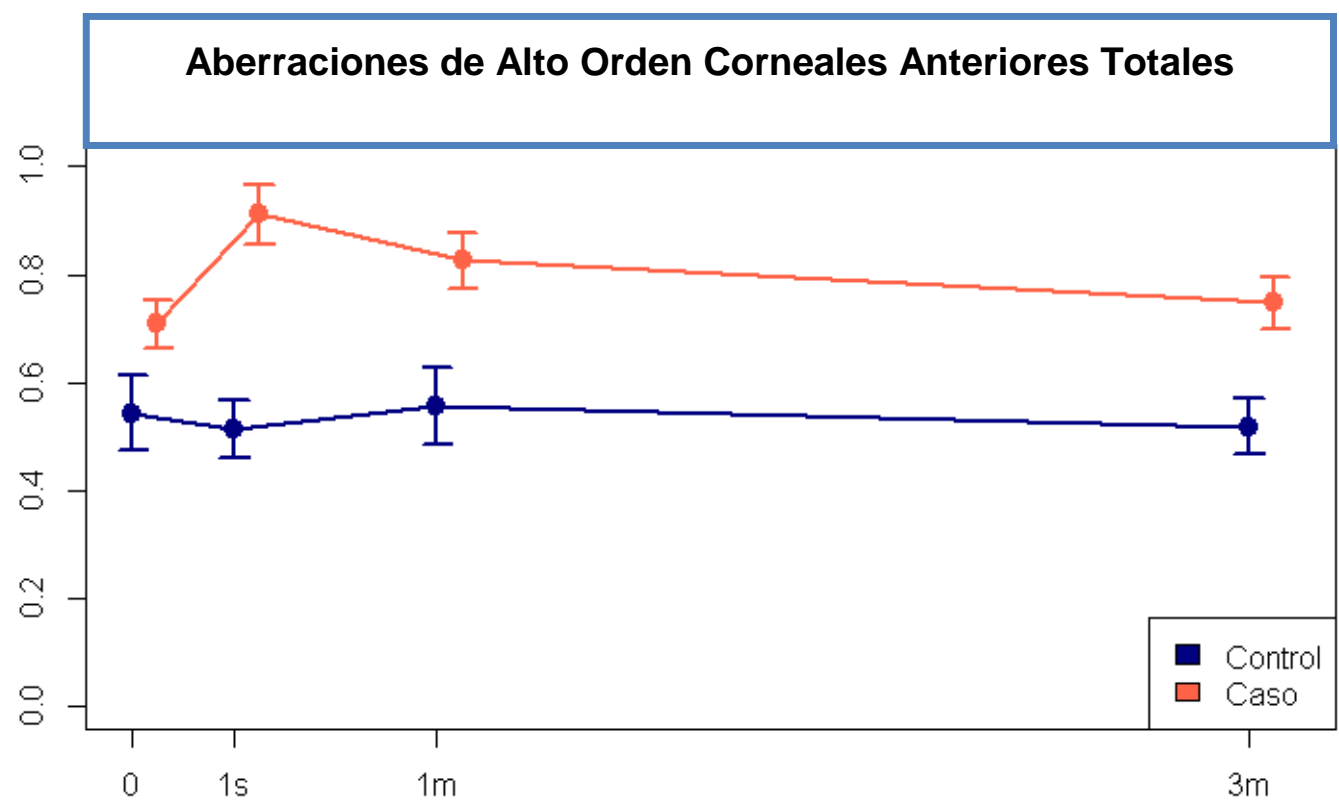

Figura 70: Evolución en el tiempo del valor de las aberraciones de alto orden corneales anteriores totales para los grupos de casos y controles. Se representa la media y el intervalo de confianza al $95 \%$. 
Tabla 20: Diferencias de las medias marginales de las aberraciones de alto orden corneales anteriores totales para los efectos estadísticamente significativos, en este caso el tiempo, grupo e interacción grupo y tiempo.

\begin{tabular}{|c|c|c|c|c|c|c|c|c|}
\hline \multicolumn{9}{|c|}{ Diferencias de medias marginales } \\
\hline \multirow[t]{2}{*}{ Efecto } & \multirow{2}{*}{$\begin{array}{c}\text { Nivel } \\
\text { Tiempo } \\
\text { (I) }\end{array}$} & \multirow{2}{*}{$\begin{array}{c}\text { Nivel } \\
\text { Tiempo } \\
\text { (II) }\end{array}$} & \multirow{2}{*}{$\begin{array}{l}\text { Nivel } \\
\text { Grupo } \\
\text { (I) }\end{array}$} & \multirow{2}{*}{$\begin{array}{l}\text { Nivel } \\
\text { Grupo } \\
\text { (II) }\end{array}$} & \multirow{2}{*}{$\begin{array}{c}\text { Diferencias } \\
\text { (I) - (II) } \\
\text { (Micras) }\end{array}$} & \multicolumn{2}{|c|}{$\begin{array}{c}\text { IC 95\% para } \\
\text { la } \\
\text { Diferencia }\end{array}$} & \multirow[t]{2}{*}{ p-valor } \\
\hline & & & & & & Inf. & Sup. & \\
\hline \multirow{6}{*}{ Tiempo } & \multirow{3}{*}{0} & $1 \mathrm{~s}$ & & . & -0.09 & -0.15 & -0.03 & 0.003 \\
\hline & & $1 \mathrm{~m}$ & . & . & -0.07 & -0.12 & $\begin{array}{c}0.00 \\
7\end{array}$ & 0.03 \\
\hline & & $3 m$ & . & . & -0.002 & -0.06 & 0.05 & 0.96 \\
\hline & \multirow{2}{*}{$1 \mathrm{~s}$} & $1 \mathrm{~m}$ & • & . & 0.02 & -0.03 & 0.07 & 0.37 \\
\hline & & $3 m$ & & . & 0.09 & 0.03 & 0.14 & 0.002 \\
\hline & $1 \mathrm{~m}$ & $3 m$ & . & . & 0.06 & 0.01 & 0.11 & 0.02 \\
\hline Grupo & & 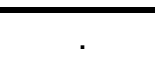 & Control & Caso & -0.3 & -0.3 & -0.2 & $<0.0001$ \\
\hline \multirow{16}{*}{$\begin{array}{c}\text { Tiempo } \\
y \\
\text { Grupo }\end{array}$} & \multirow{3}{*}{0} & $1 \mathrm{~s}$ & \multirow{6}{*}{\multicolumn{2}{|c|}{ Control }} & 0.03 & -0.07 & 0.13 & 0.56 \\
\hline & & $1 \mathrm{~m}$ & & & -0.01 & -0.1 & 0.09 & 0.82 \\
\hline & & $3 m$ & & & 0.04 & -0.06 & 0.14 & 0.44 \\
\hline & \multirow{2}{*}{$1 \mathrm{~s}$} & $1 \mathrm{~m}$ & & & -0.04 & -0.1 & 0.04 & 0.32 \\
\hline & & $3 m$ & & & 0.008 & -0.09 & 0.11 & 0.87 \\
\hline & $1 \mathrm{~m}$ & $3 m$ & & & 0.05 & -0.04 & 0.14 & 0.3 \\
\hline & \multirow{3}{*}{0} & 1s & \multirow{6}{*}{\multicolumn{2}{|c|}{ Caso }} & -0.2 & -0.26 & -0.15 & $<0.0001$ \\
\hline & & $1 \mathrm{~m}$ & & & -0.12 & -0.18 & -0.06 & 0.0001 \\
\hline & & $3 m$ & & & -0.04 & -0.09 & 0.01 & 0.11 \\
\hline & \multirow{2}{*}{$1 \mathrm{~s}$} & $1 \mathrm{~m}$ & & & 0.09 & 0.04 & 0.14 & 0.0003 \\
\hline & & $3 m$ & & & 0.16 & 0.1 & 0.21 & $<0.0001$ \\
\hline & $1 \mathrm{~m}$ & $3 m$ & & & 0.08 & 0.03 & 0.13 & 0.002 \\
\hline & \multicolumn{2}{|c|}{0} & Control & Caso & -0.17 & -0.26 & -0.07 & 0.0004 \\
\hline & \multicolumn{2}{|c|}{$1 \mathrm{~s}$} & Control & Caso & -0.4 & -0.51 & -0.3 & $<0.0001$ \\
\hline & \multicolumn{2}{|c|}{$1 \mathrm{~m}$} & Control & Caso & -0.28 & -0.38 & -0.17 & $<0.0001$ \\
\hline & \multicolumn{2}{|c|}{$3 m$} & Control & Caso & -0.24 & -0.34 & -0.15 & $<0.0001$ \\
\hline
\end{tabular}

1s: 1 semana; 1m: 1 mes; 3m: 3 meses; IC: intervalo de confianza; Inf: inferior; Sup: superior; $p$ : probabilidad.

6.3.2. ANÁLISIS POST-HOC DE ASOCIACIÓN ENTRE LOS CAMBIOS ABERROMÉTRICOS Y EN LOS GROSORES CORNEALES 
El espesor epitelial no presentó diferencias significativas en los distintos periodos analizados por lo que se seleccionaron los cambios significativos del espesor corneal total no epitelial para enfrentarlos con cambios significativos en esos mismos periodos en las variables relacionadas con la calidad óptica. Estas variables fueron la excentricidad, el componente horizontal del coma secundario, la aberración esférica primaria, el "spherical-like" y las aberraciones de alto orden corneales anteriores totales.

Encontramos correlaciones significativas entre la diferencia del espesor corneal total no epitelial en el periodo comprendido entre la semana postcirugía y el preoperatorio a nivel periincisional (hemi-meridiano $180^{\circ}$ ) y las aberraciones de alto orden corneales anteriores totales en ese periodo ( $\rho=0.2, p=0.05)$, como se muestra en la figura 71. 


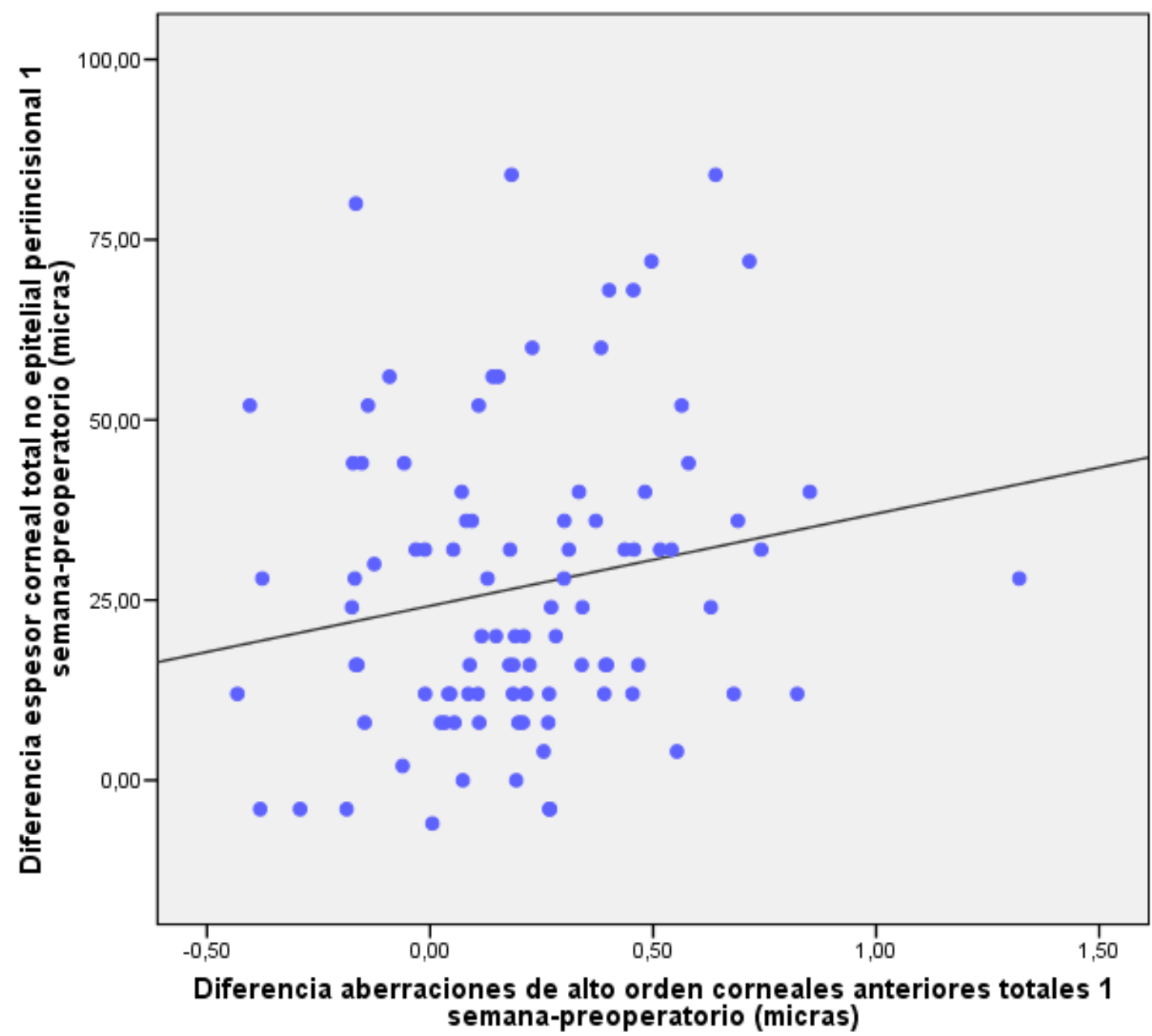

Figura 71: Asociación entre las variaciones encontradas en el espesor corneal total no epitelial en el hemi-meridiano de $180^{\circ}$ y las aberraciones de alto orden corneales anteriores totales en el periodo comprendido entre el preoperatorio y una semana postcirugía. Se representa la correlación mediante el gráfico de dispersión de puntos y la recta de regresión lineal de mejor ajuste.

Existió igualmente una asociación significativa entre la diferencia del espesor corneal total no epitelial y las aberraciones de alto orden corneales anteriores totales en el periodo comprendido entre el mes postcirugía y el preoperatorio a nivel contraincisional (hemi-meridiano $\left.0^{\circ}\right)(\rho=0.22, p=0.031)$, representada en la figura 72. 


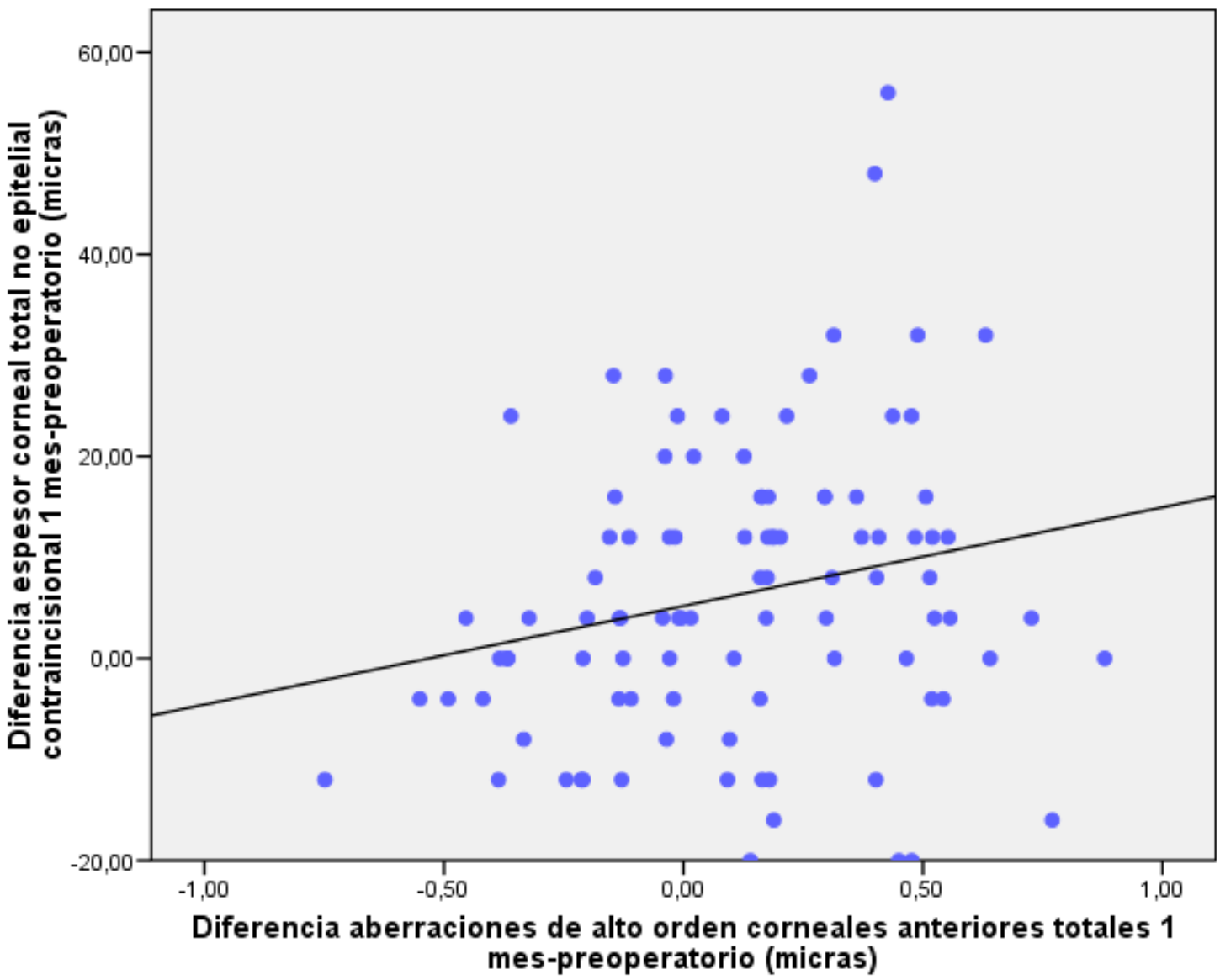

Figura 72: Asociación entre las variaciones encontradas en el espesor corneal total no epitelial en el hemi-meridiano de $0^{\circ}$ y las aberraciones de alto orden corneales anteriores totales en el periodo comprendido entre el preoperatorio y un mes postcirugía. Se representa la correlación mediante el gráfico de dispersión de puntos y la recta de regresión lineal de mejor ajuste.

Se observó también una correlación significativa entre las diferencias en el espesor corneal total no epitelial a nivel del ápex corneal entre el mes postcirugía y el preoperatorio, y las modificacións de las aberraciones de alto orden corneales anteriores totales en ese espacio de tiempo $(r=0.18, p=0.05)$ (Figura 73). 


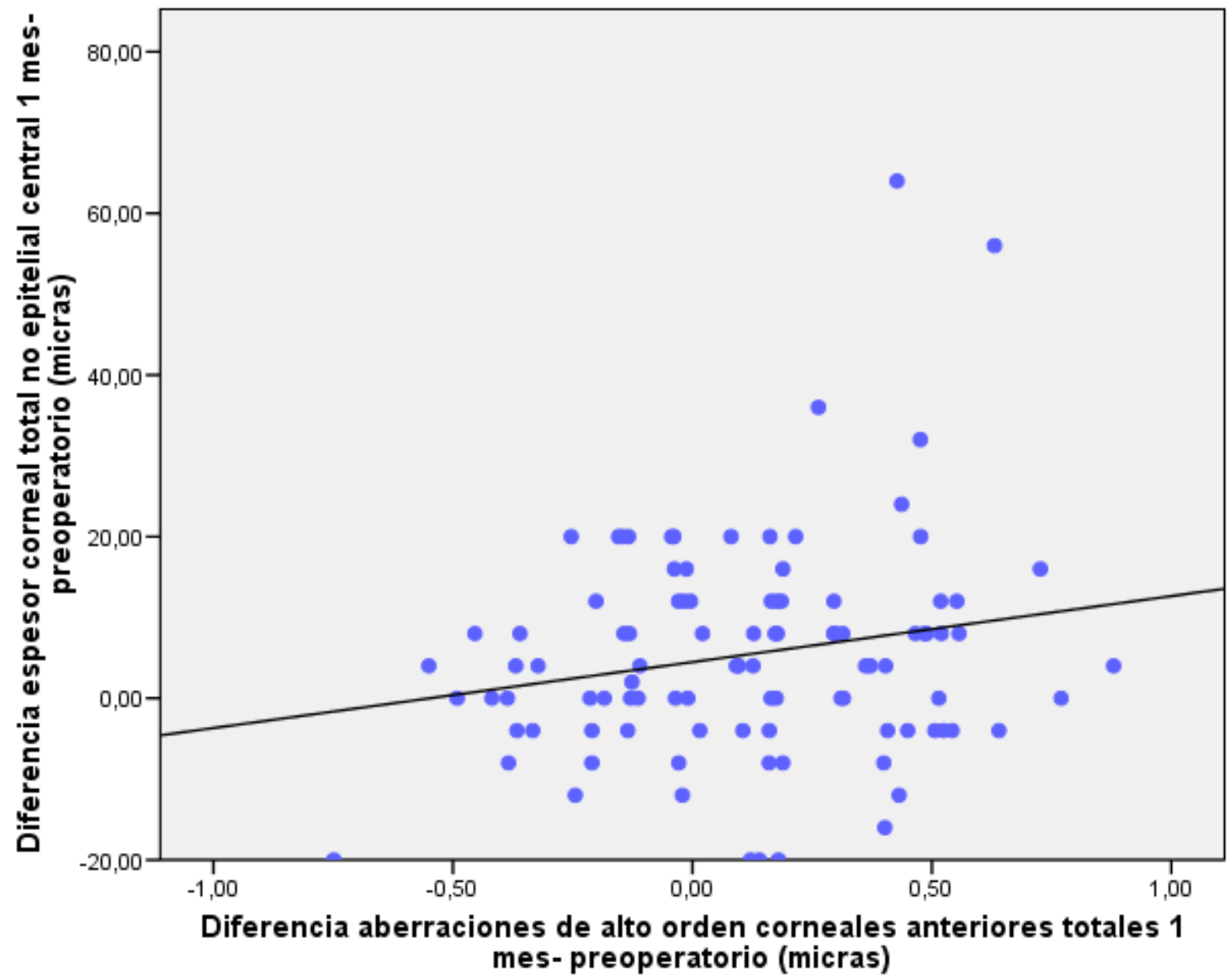

Figura 73: Asociación entre las variaciones encontradas en el espesor corneal total no epitelial en el ápex corneal y las aberraciones de alto orden corneales anteriores totales en el periodo comprendido entre el preoperatorio y un mes postcirugía. Se representa la correlación mediante el gráfico de dispersión de puntos y la recta de regresión lineal de mejor ajuste.

Finalmente, en el análisis de correlación realizado también encontramos asociaciones negativas significativas entre la excentricidad y las aberraciones de alto orden corneales anteriores totales en el periodo comprendido entre 1 semana y 1 mes tras la cirugía $(r=-0.37, p<0.001)$; entre 1 semana y 3 meses postoperatorios $(r=-0.3, p=0.02)$ y entre 1 mes y 3 meses tras la cirugía $(r=-0.4, p<0.001)$. Del mismo modo, entre la excentricidad y la aberración esférica primaria en el periodo comprendido entre 1 semana y 3 meses postoperatorios $(r=-0.7, p<0.001)$ y entre 1 
mes y 3 meses tras la cirugía $(r=-0.6, p<0.001)$; y por último, entre la excentricidad y el "spherical-like" durante el periodo comprendido entre 1 semana y 3 meses postoperatorios $(r=-0.7, p<0.001)$ y entre 1 mes y 3 meses $(r=-0.6, p<0.001)$. 
DISCUSIÓN 



\section{DISCUSIÓN}

La discusión de este trabajo se va a abordar en un apartado que discute la metodología y en otro que discute la plausibilidad biológica.

\subsection{DISCUSIÓN DE LA METODOLOGÍA EMPLEADA}

\subsubsection{SISTEMAS DE MEDIDA}

\section{Tomografía de Coherencia óptica (OCT)}

El instrumento utlizado como paquímetro en este estudio, el Cirrus HD-OCT, tiene una repetibilidad con una desviación estándar intrasujeto $\left(D E_{i}\right)$ de $2.29 \mu \mathrm{m}$ y un coeficiente de variación (CV) de 7.7\% (Prakash y cols., 2012) (3.8\% en nuestro estudio, Tabla 6), mientras que otros biómetros, como el que utiliza ultrasonidos de muy alta frecuencia (Artemis, Arcscan, Morrison, Colorado, EEUU), presentan mucha mejor repetibilidad $\left(D_{i}=0.58 \mu \mathrm{m}\right)$ (Reinstein y cols., 2010b); lo que probablemente nos hubiera proporcionado más precisión a la hora de analizar los cambios epiteliales, aunque a pesar de ello, la fiablidad de nuestro sistema fue suficientemente alta como para detectar un cambio de $8.5 \%$ en nuestros pacientes. Por otro lado, la resolución axial del sistema Cirrus HD-OCT es de $4 \mu \mathrm{m}$, y esto supone una limitación considerable a la hora de medir manualmente un espesor tan reducido como es el del epitelio. 


\section{Queratógrafo CTK-922}

En este estudio utilizamos un topógrafo de reflexión, que se ve muy influenciado por la calidad de la película lagrimal. Montés-Micó y cols. (2004) refieren que la contribución de la película lagrimal a las aberraciones corneales totales aumenta de manera sustancial si el periodo inter-parpadeo excede de los 10 segundos. En nuestro caso, realizamos las topografías después de que el paciente parpadease por lo que la distribución de la lágrima fue lo más homogénea posible favoreciendo así una buena proyección de los discos de Plácido. Por otro lado, el topógrafo utilizado sólo proporciona datos de la cara anterior de la córnea y no de la posterior, con lo cual no pudimos evaluar alteraciones secundarias a la pérdida de células endoteliales, que en principio deberían afectar especialmente a la cara posterior. Sin embargo Ye y cols. (2014) no encontraron cambios significativos en las aberraciones corneales totales, incluídas las de la superficie corneal posterior, a los 2 meses de la cirugía de cataratas con respecto a los datos preoperatorios.

\subsubsection{METODOLOGÍA ESTADÍSTICA}

\section{Análisis de la Varianza (ANOVA)}

El test estadístico denominado $\mathrm{t}$ de Student determina si hay diferencias significativas entre las medias de dos grupos, por lo tanto se utiliza cuando deseamos comparar dos grupos que poseen una distribución normalizada. Intentar determinar si existe concordancia (acuerdo) entre dos grupos de medidas realizando únicamente el test t de Student pareado es un error debido a que este solo aportará 
datos relativos a la significación estadística sobre la diferencia media entre las medias de ambos grupos, es decir, indicará únicamente si existen o no diferencias sistemáticas. Además, el hecho de que dichas diferencias sistemáticas sean estadísticamente significativas no implica que lo sean clínicamente; e igualmente, la ausencia de significación estadística entre grupos tampoco implica que exista concordancia clínica entre ambos grupos de medida (Bland \& Altman, 1999).

Sin embargo, cuando queremos comparar varias medidas realizadas de forma repetida y evaluar su grado de acuerdo, sería más acertado utilizar un test de comparaciones múltiples. El análisis de la varianza (ANOVA) de medidas repetidas, es la metodología más adecuada para evaluar a la vez varios grupos, ya que compara la variación entre grupos con la variación dentro del grupo (Bland, 2000). Del mismo modo, la utilización del análisis gráfico convencional de Bland y Altman, tampoco sería el ideal para analizar analizar el grado de acuerdo entre medidas repetidas de forma consecutiva, puesto que evalúa el grado de acuerdo entre dos grupos de datos obtenidos tras realizar las mediciones en una sola ocasión, y no en ocasiones repetidas (Myles, Cui, 2007). Por tanto, ANOVA es un método óptimo para ser aplicado en la comparación de muestras relacionadas, como ha sido nuestro caso.

\section{Coeficiente de Correlación Intraclase (CCI)}

El coeficiente de correlación de Pearson analiza la asociación lineal de dos variables pero no estima adecuadamente la concordancia entre dos grupos de datos, que por otro lado no es asumible en caso de una muy buena correlación entre 
los mismos. Igualmente, el coeficiente de correlación de Pearson tampoco detecta errores sistemáticos entre dos grupos de datos (McAlinden y cols., 2011), por lo tanto su aplicabilidad es reducida. Al contrario, el $\mathrm{CCl}$ evalúa el grado de concordancia entre variables cuantitativas y no tiene en cuenta el orden en el que las medidas fueron tomadas; por tanto puede ser empleado con más de dos observaciones por sujeto, ya que estima la correlación media entre todos los posibles pares de observaciones (Bland, Altman, 1996b). Es por ello por lo que resulta un método óptimo para ser aplicado en la evaluación de la fiabilidad de un dispositivo mediante el análisis de la repetibilidad de las medidas de un observador y la reproducibilidad de las medias entre observadores, como ha sido nuestro caso.

\section{Metodología de Bland \& Altman}

En nuestro trabajo hemos empleado la metodología estadística de Bland y Altman que tiene como objetivo la mejor descripción de la relación existente entre diferentes métodos de medida de un mismo elemento o diferentes observadores midiendo una misma variable o la medición de dicha variable utilizando el mismo sistema en días distintos, siempre y cuando comparemos un solo par de observaciones (Bland \& Altman, 1999). En nuestro caso comparamos las diferencias al medir un mismo elemento entre dos observadores, con las medias de las medidas de ambos, estableciendo los LC del 95\% tras realizar el test t de Student pareado. Dichos LC del 95\% se calculan sumando y restando 1.96 DE a la diferencia media (sistemática) entre grupos de medidas, de tal forma que obtenemos la anchura de los LC del 95\%. Estos valores extremos o límites determinan el rango dentro del cual estarán la mayoría de las diferencias esperables entre ambos grupos de medida 
para el 95\% de las observaciones (Bland \&Altman, 1999). La magnitud máxima de la diferencia entre dos sistemas de medida, llamada amplitud del LC, debe interpretarse desde un punto de vista clínico, ya que aunque no existan diferencias significativas entre grupos de medidas tras realizar el análisis t de Student pareado, puede que la anchura de los LC del 95\% sea clínicamente excesiva.

Las premisas para poder realizar un análisis de Bland y Altman son dos:

1) Ausencia de correlación significativa entre las medias y las diferencias de las medidas. Los valores deberían distribuirse en forma de nube dispersa dentro de los LC y en torno a la media de las diferencias. En caso de presentar una correlación lineal, se aplica otro método basado en los residuos absolutos a partir del análisis de regresión de Bland y Altman (Bland, Altman, 1999).

2) Distribución normal de los valores de las diferencias entre las medidas (Bland, Altman, 1999).

3) Homogeneidad de las varianzas o también denominado homocedasticidad (Bland, Altman, 1999).

En el análisis de las diferencias en la medida del espesor no epitelial corneal entre observadores se observó una correlación lineal de modo que se aplicó el análisis de regresión de Bland y Altman ya mencionado para evaluar el grado de acuerdo entre los examinadores (Figuras 38 y 39 ).

\subsection{DISCUSIÓN DE LOS RESULTADOS}


El edema corneal derivado de la cirugía de catarata mediante facoemulsificación del cristalino implica cambios en el grosor corneal que previsiblemente revierten en el periodo postoperatorio. Se ha realizado un análisis de los cambios mediante Cirrus HD-OCT no solo a nivel epitelial sino también a nivel corneal total no epitelial. Estos cambios reversibles en el espesor corneal podrían además provocar modificaciones definitivas en términos queratométricos y de aberraciones de alto orden corneales que deben ser tenidos en cuenta a la hora de planificar la cirugía.

\subsubsection{ESTUDIO PILOTO DEL ANÁLISIS DEL ESPESOR CORNEAL POR CAPAS EN PACIENTES OPERADOS DE CATARATA.}

Numerosos trabajos han estudiado el edema corneal central y la arquitectura incisional con el objeto de entender el comportamiento de la córnea tras una cirugía mediante facoemulsificación, aunque no hay muchos trabajos que analicen los cambios corneales postquirúrgicos capa a capa. Recientemente, se ha publicado un trabajo en el que se describen cambios en el espesor epitelial corneal tras facoemulsificación en los anillos centrales, paracentrales y periféricos (Kanellopoullos, Asimellis, 2014a). Sin embargo, estos autores no analizaron las variaciones del espesor epitelial en relación a la incisión principal, un aspecto relevante en la facoemulsificación coaxial. Por tanto, sí que podemos decir que somos los primeros en documentar las variaciones en el espesor epitelial y corneal total no epitelial en relación al área de la incisión principal en la cirugía de facoemulsificación. Para ello, utilizamos el sistema Cirrus HD-OCT puesto que desde 
hace más de una década se viene utilizando la tecnología de tomografía óptica de coherencia para obtener medidas corneales (Maldonado y cols., 2000), y además los nuevos dispositivos de dominio espectral proporcionan medidas fiables del epitelio corneal (Correa-Perez y cols., 2012; Prakash y cols., 2012).

Los resultados del estudio piloto mostraton que el espesor epitelial corneal variaba al mes de la cirugía, mientras que los valores encontrados a la semana resultaban similares a los valores preoperatorios, como se muestra en la tabla 3 . El espesor corneal total no epitelial aumentó a la semana de la facoemulsificación y volvió a recuperar valores similares a los preoperatorios tras un mes (Tabla 4). Es conocido que el epitelio aumenta o disminuye su espesor en función de los cambios producidos en el grosor estromal, como se ha documentado en pacientes tras cirugía corneal refractiva mediante láser (LASIK) tanto miopes (Reinstein y cols., 2012b) como hipermétropes (Reinstein y cols., 2010) o en pacientes miopes en tratamiento con ortoqueratología nocturna (Reinstein y cols., 2009). Durante las cirugías de cataratas, presumiblemente puedieron tener lugar estos fenómenos compensatorios, puesto que observamos un descenso de aproximadamente un $8.5 \%$ del espesor epitelial un mes después de la cirugía. Esta disminución del espesor epitelial podría haber estado desencadenado por el edema estromal observado en la primera semana post-cirugía (Tabla 3). Por otro lado, los valores del espesor epitelial a la semana de la cirugía eran muy similares a los valores preoperatorios, por lo que podemos decir que en el contexto de una cirugía de catarata mediante facoemulsificación sin incidencias, no se puede considerar que el epitelio corneal se edematice y por tanto, no contribuye al engrosamiento corneal total. Este tipo de variaciones en el espesor epitelial fueron también recientemente publicadas por Kanellopoullos y Asimellis (2014a). En su caso, estos autores detectaron la 
disminución del espesor epitelial central a la semana de la cirugía, antes que nosotros, que lo observamos en la visita del mes.

En nuestro grupo de pacientes, el espesor corneal total no epitelial se incrementó en la primera semana post-cirugía. Si durante la cirugía de catarata se produce daño en el endotelio, el cual regula la hidratación estromal, se producirá un aumento de la permeabilidad con el consiguiente edema estromal, siempre y cuando la bomba endotelial no sea capaz de compensarlo. En nuestros pacientes, los valores del espesor corneal total no epitelial al mes de la cirugía eran clínicamente similares a los valores previos (Tabla 4), lo que implica la recuperación de la bomba endotelial, de la permeabilidad endotelial y es congruente con la normalización del coeficiente de variación del tamaño celular al mes de la cirugía (Ravalico y cols., 1997). Además, el epitelio no pareció afectarse por el edema postquirúrgico tanto como el estroma a la semana de la cirugía, ya que los incrementos observados en el espesor epitelial fueron reducidos $(0.7 \%, 2 \%$ y $4.6 \%$ en las zonas central, paracentral a $180^{\circ}$ y paracentral a $0^{\circ}$, respectivamente), al contrario que los incrementos significativos observados en el espesor no epitelial $(6 \%, 7.2 \%$ y $4.7 \%$, en las zonas central, paracentral a $180^{\circ}$ y paracentral a $0^{\circ}$, respectivamente).

El edema estromal crónico no se instaura en la medida en que el endotelio se recupera tras una cirugía sin incidencias. Sabemos que el edema estromal crónico producirá edema epitelial; sin embargo, el aumento de la presión de imbibición estromal después de una cirugía de catarata sin incidencias, si no se mantiene durante un periodo de tiempo suficientemente largo, no producirá edema epitelial (Dohlman, 1971), como ocurre en nuestros pacientes en los que no se observó un aumento significativo del espesor epitelial. También la diferencia estructural entre el estroma, formado por colágeno y matriz extracelular principalmente, y el epitelio, 
formado por células con fuertes uniones intercelulares entre sí, podría explicar el mayor engrosamiento estromal en el postoperatorio precoz de la facoemulsificación.

En nuestro estudio piloto analizamos el espesor epitelial y corneal total no epitelial en el meridiano horizontal. Lundberg y cols. (2005) encontraron que en el postoperatorio precoz el edema corneal era significativamente mayor a nivel central que en nasal debido a una mayor pérdida de células endoteliales durante la realización de las incisiones temporales. Por otro lado, Bolz y cols. (2006) encontraron un aumento del espesor corneal después de la cirugía de catarata en el meridiano horizontal en la zona próxima a la incisión temporal, aunque sus hallazgos no fueron significativos. El daño endotelial por trauma directo o por la energía utilizada en forma de ultrasonidos va a derivar en un aumento del espesor corneal a nivel incisional que además es mayor que en la córnea central (Wang, 2012). En nuestros pacientes, encontramos un aumento significativo del espesor no epitelial en la zona central y en el hemimeridiano próximo al área incisional en comparación con el área más alejada de la incisión. También observamos que este engrosamiento postquirúrgico se resolvió de manera similar en ambas áreas paracentrales al mes de la cirugía. El hecho de haber realizado las cirugías de facoemulsificación del cristalino utilizando energía torsional en lugar de longitudinal, implica un menor tiempo de ultrasonido y menor energía disipada acumulada (Reuschel y cols., 2010), lo que puede favorecer una menor pérdida de células endoteliales y un menor engrosamiento paquimétrico (Liu y cols., 2007). Probablemente el uso de energía longitudinal podría haber incrementado las diferencias en los aumentos del espesor corneal total no epitelial entre las tres localizaciones analizadas a la semana de la cirugía. 
En lo que se refiere a la variación del espesor corneal total, en nuestro estudio piloto aumentó a la semana de la cirugía y se resolvió tras un mes, resultados que coinciden plenamente con lo reportado en la literatura científica (De Juan y cols., 2013; Li y cols., 2011; Lundberg y cols., 2005). Bolz y cols. (2006) no encontraron diferencias significativas en la paquimetría central entre las visitas preoperatorias y a la semana de la cirugía; mientras que en nuestro estudio, a diferencia de Lundberg y cols. (2005), no encontramos diferencias significativas en el espesor corneal total en las diferentes localizaciones analizadas como ocurría en el caso de los espesores epitelial y corneal total no epitelial, probablemente debido al efecto compensador del epitelio sobre el engrosamiento no epitelial que encontramos en nuestros tiempos de medida.

La importancia de conocer las variaciones del espesor epitelial y corneal total no epitelial se va a reflejar en el análisis de los errores refractivos postquirúrgicos; en primer lugar porque el epitelio tiene un índice de refracción distinto al estroma anterior y posterior (1.401, 1.380 y 1.373 respectivamente) (Patel y cols., 1995), y en segundo lugar, porque según la cantidad y localización del edema corneal, el poder refractivo corneal total variará, sobre todo a costa de cambios en el índice refractivo del estroma posterior (Meek y cols., 2003).

El estudio piloto tiene varias limitaciones. En primer lugar, el pequeño tamaño muestral $(n=20)$, a pesar del cual encontramos un descenso estadísticamente significativo del espesor epitelial en las zonas central y paracentrales al mes de la cirugía. En segundo lugar, no registramos los tiempos de facoemulsificación ni hicimos contaje endotelial tras la cirugía, aunque la relación entre estos factores y el edema corneal ya ha sido ampliamente descrita. En tercer lugar, el periodo de seguimiento fue corto (1 mes), sin embargo, dado que los cambios en el 
engrosamiento corneal son máximos a las 4 semanas (Bolz y cols., 2007), creímos que en caso de ocurrir modificaciones en el espesor epitelial éstos se darían en el postoperatorio inmediato. Por último, no tuvimos en cuenta ni evaluamos las alteraciones epiteliales que se producen en el contexto del síndrome de ojo seco. Se ha descrito recientemente un epitelio corneal más grueso (alrededor de $6 \mu \mathrm{m}$ ) en pacientes con síndrome de ojo seco en contraste con pacientes controles (Kanellopoullos, Asimellis, 2014b). También se ha descrito un empeoramiento máximo al mes de la cirugía de catarata de los signos y síntomas de ojo seco (Li y cols., 2012). En cualquier caso, lo que observamos en nuestros pacientes fue el descenso en el espesor epitelial y no un incremento del mismo por lo que no creemos que los cambios respondieran a un síndrome de ojo seco.

Los hallazgos iniciales en este estudio piloto con los primeros 20 pacientes fomentaron el continuar con un estudio clínico reclutando un mayor número de pacientes que confirmase o desmintiese los hallazgos observados relativos al posible rol compensatorio del epitelio derivado de los cambios en el grosor corneal no epitelial tras facoemulsificación, así como su ampliación al estudio de otras variables relacionadas con la morfología corneal.

7.2.2. ESTUDIO DE FIABILIDAD DE MEDIDA: REPETIBILIDAD INTRAOBSERVADOR $\quad Y \quad$ REPRODUCIBILIDAD INTEROBSERVADOR DE LAS MEDIDAS DE ESPESOR CORNEAL POR CAPAS CON CIRRUS HD-OCT 
La mejora en la resolución axial de los sistemas SD-OCT frente a los de TDOCT permite una mayor diferenciación de las capas de la córnea (Ge y cols., 2013), incluso en dispositivos diseñados para el análisis de polo posterior.

Las medias globales obtenidas en los grupos de pacientes operados y no operados para la paquimetría total (536 y $547 \mu \mathrm{m})$ y para el epitelio (53 y $51 \mu \mathrm{m})$ indican que se trataba de una muestra representativa de la población normal (Tabla 6). La repetibilidad intraobservador para el espesor epitelial central con el Cirrus HDOCT fue aceptable, con un $\mathrm{CCl} \geq 0.73$. Nuestro trabajo mostró que el $\mathrm{CV}_{\mathrm{i}}$ esperado al medir manualmente el espesor epitelial con el caliper era aproximadamente de $3.8 \%$ del espesor epitelial central total, tanto para el grupo de no operados como para el de operados. En el caso del espesor no epitelial y el espesor corneal central la repetibilidad fue excelente, con valores de $\mathrm{CV}_{\mathrm{i}} \leq 0.8 \%$ y $\mathrm{CCl} \geq 0.97$. Nuestros resultados fueron mejores a los obtenidos por Prakash y cols. (2012), que obtuvieron un $\mathrm{CV}_{\mathrm{i}}$ de $7.7 \%$ para el espesor epitelial central en una población de sujetos sanos con el mismo dispositivo SD-OCT. El examinador principal de este estudio (MCG) estaba familiarizado con la medida manual del espesor corneal y el uso del caliper proporcionado por el Cirrus HD-OCT, lo que probablemente haya influido positivamente en los mejores resultados obtenidos. En este estudio, para evitar errores subjetivos a la hora de obtener las medidas, no se realizó ninguna medida manual hasta que se reclutó el último paciente. Tampoco se midieron consecutivamente las cinco imágenes de cada paciente sino que primero se midieron las primeras imágenes de todos los pacientes, después las segundas imágenes y así sucesivamente.

Ma y cols. (2013) también estudiaron la fiabilidad de las medias del epitelio corneal central en sujetos sanos con un sistema SD-OCT, en su caso un RTVue 
OCT (Optovue, Inc., Fremont, California, EEUU), obteniendo un $\mathrm{CV}_{\mathrm{i}}$ de $0.98 \%$. Sus mejores resultados de repetibilidad pueden responder a que el RTVue OCT proporciona medias automáticas, al contrario que las nuestras las cuales fueron medidas manualmente. Este hecho favorece la obtención de resultados más consistentes siempre y cuando la segmentación automática proporcionada por el software sea correcta. Por otro lado, el RTVue OCT proporciona la media del espesor epitelial central en los $2 \mathrm{~mm}$ centrales en lugar del espesor en un único punto como ocurre en el caso de Cirrus HD-OCT. Esto se traduce en una menor variabilidad que cuando se mide únicamente el ápex corneal como hicimos nosotros, y explica la mayor repetibilidad intraobservador descrita para RTVue OCT en comparación con Cirrus HD-OCT, aun siendo los dos dispositivos de dominio espectral (SD-OCT). Los resultados de Ma y cols. (2013) son similares a los de Ge y cols. (2013), que midieron el espesor epitelial central con distintos dispositivos de OCT obteniendo un $\mathrm{CV}_{\mathrm{i}}$ de $0.89 \%$ con RTVue OCT. Otro dispositivo que proporciona medidas automáticas es el que se basa en la técnica de ultrasonidos de muy alta frecuencia descrita por Reinstein y cols. (2012b). La utilizaron para medir el espesor epitelial central de pacientes operados con LASIK, obteniendo un $\mathrm{CV}_{\mathrm{i}}$ de $1.0 \%$ y un $\mathrm{CCl}$ de 0.97. Sin embargo, esta técnica requiere contacto corneal y por tanto anestesia de la superficie corneal y alteración de las posteriores exploraciones, a diferencia del SD-OCT que además realiza la prueba en un menor tiempo, suponiendo mayor comodidad para el paciente. En cuanto al espesor corneal total no epitelial y el espesor corneal central, Prakash y cols. también obtuvieron peores resultados que los nuestros, con un $\mathrm{CV}_{\mathrm{i}}$ de $2.3 \%$ y $2.15 \%$ respectivamente, utilizando el mismo dispositivo de OCT. Estos resultados de nuevo pueden estar justificados por la mayor habilidad de nuestro observador principal a la hora de 
obtener las medidas manualmente. La repetibilidad que obtuvimos para el espesor corneal central en pacientes no operados $(0.7 \%)$, es similar a la descrita por CorreaPérez y cols. (2012) (0.9\%) en voluntarios sanos con el mismo dispositivo SD-OCT. Ma y cols. (2013) reportaron un increíble resultado de $\mathrm{CV}_{\mathrm{i}}$ para el espesor corneal central en sujetos sanos $(0.16 \%)$ probablemente gracias a las medidas automáticas proporcionadas por su dispositivo. A pesar de todo, Li y cols. (2008) demostraron una buena repetibilidad en la medida manual del espesor corneal con dispositivos como Visante OCT (Carl Zeiss Meditec, Inc., Dublin, California, EEUU) y Slit-Lamp OCT (Heidelberg Engineering, Dossenheim, Alemania) que también proporcionan medidas automáticas, obteniendo valores similares $\left(\mathrm{CV}_{\mathrm{i}}\right.$ de $0.9 \%$ para la media automática con Visante OCT y $1.2 \%$ para la medida manual y $\mathrm{CV}_{\mathrm{i}}$ de $1 \%$ para la medida automática con Slit-Lamp OCT y $1 \%$ para la medida manual con el mismo dispositivo).

La reproducibilidad interobservador para el espesor epitelial, corneal total no epitelial y corneal total central también fue evaluada, dado que en la práctica clínica diaria es complicado que sea la misma persona la que realiza las exploraciones. En este caso, los valores de $\mathrm{CV}_{\mathrm{i}}$ para el espesor epitelial central fueron algo mejores que para la repetibilidad intraobservador (Tabla 7), aunque esa diferencia (1.1-1.5\%) no presenta una relevancia clínicamente significativa. En el caso del espesor corneal total no epitelial y el espesor corneal central las diferencias entre la repetibilidad intraobservador y la reproducibilidad interobservador fueron todavía menores $(0.2 \%$ aproximadamente). Prakash y sus colaboradores también en este caso obtuvieron perores resultados de $\mathrm{CV}_{\mathrm{i}}$ que nosotros $(11.1 \%$ para el espesor epitelial, $3.5 \%$ para el espesor corneal total no epitelial y $2.7 \%$ para el espesor corneal central). La amplitud de los límites de concordancia para las medidas de cada estrato corneal fue 
clínicamente buena en nuestro estudio, por lo que podemos decir que ante unos examinadores bien entrenados, se pueden obtener resultados intercambiables en las medidas manualmente realizadas sobre las imágenes proporcionadas por el sistema Cirrus HD-OCT.

Este estudio de fiabilidad tiene varias limitaciones. En primer lugar, no calculamos la exactitud del Cirrus HD-OCT para las medidas del espesor epitelial central. Pero dado que el objetivo no era comparar Cirrus HD-OCT con el "goldstandard" (paquímetro ultrasónico) y otros autores ya habían descrito la leve infraestimación de las medidas del espesor corneal central del SD-OCT frente a la ultrasonografía (Northey y cols., 2012), no nos pareció oportuno calcular el error aleatorio de medida del sistema. En segundo lugar, en nuestro estudio sólo incluimos sujetos normales y pacientes operados de catarata mediante facoemulsificación sin incidencias con engrosamiento corneal transitorio en las distintas capas estudiadas (Kanellopoullos, Asimellis, 2014), por lo que no podemos asegurar plenamente que estos valores se puedan aplicar a pacientes con alteraciones epiteliales crónicas.

7.2.3. ESTUDIO CLÍNICO: DETERMINACIÓN DE LOS CAMBIOS ABERROMÉTRICOS Y EN EL GROSOR POR CAPAS DE LA CÓRNEA TRAS CIRUGÍA DE CATARATA CON FACOEMULSIFICACIÓN.

Con nuestro estudio clínico se intentó contrastar los resultados obtenidos en el estudio piloto. En este caso se incluyó en el estudio una muestra $(n=100)$ 
considerablemente mayor de pacientes operados de catarata mediante facoemulsificación con un periodo de seguimiento ampliado a los 3 meses. Igualmente, se seleccionó el ojo contralateral de los 30 primeros pacientes que cumplieron con los criterios de inclusión y exclusión para formar el grupo control. Los resultados obtenidos para el espesor epitelial en las tres localizaciones analizadas (hemimeridiano a $180^{\circ}$, hemimeridiano a $0^{\circ}$ y ápex corneal) no mostraron diferencias estadísticamente significativas entre las distintas visitas, es decir, la disminución del espesor epitelial observada al mes de la cirugía en el estudio piloto no se confirmó en una muestra mayor de pacientes. Sí que observamos valores mayores del epitelio en el caso de los controles, aunque probablemente la diferencia entre grupos se deba al tamaño muestral ( $n=30$ versus $n=100$ ). Kanellopoulos y Asimellis (2014a) encontraron en una muestra de 116 pacientes operados de catarata mediante facoemulsificación, una disminución estadísticamente significativa del espesor epitelial central $(<2 \mu \mathrm{m})$ tras una semana de la cirugía utilizando el RTVue OCT, volviendo a los valores iniciales al mes de la cirugía. La modificación en el grosor epitelial a la semana que ellos encontraron fue realmente mínima por lo que se podría considerar clínicamente irrelevante, confirmando de esta forma nuestros hallazgos relativos a la ausencia de modificación del grosor epitelial.

En el caso del espesor corneal total no epitelial, los resultados son similares a los encontrados en el estudio piloto: aumentaba en las tres zonas analizadas, disminuyendo al mes aunque siendo todavía algo superior al espesor preoperatorio y volviendo a los valores iniciales a los 3 meses de la cirugía. En el estudio piloto no había diferencias significativas entre los valores preoperatorios y al mes de la cirugía. Tras el daño endotelial producido en la cirugía de catarata, el tiempo de recuperación del endotelio se estima entre 1 y 6 meses (Hayashi y cols., 1996), por 
lo que se explica que a los 3 meses de la cirugía el espesor no epitelial sea menor que al mes de la cirugía. El espesor corneal total muestra el mismo comportamiento que el espesor corneal total no epitelial en las 3 zonas analizadas, aumentando a la semana de la cirugía, disminuyendo al mes y volviendo a los valores iniciales a los 3 meses postoperatorios, al igual que en el trabajo publicado por Aribaba y cols (2015), que detectaron valores similares a los preoperatorios en el espesor corneal central a las 8 semanas y a los 3 meses. Cabe destacar que en el grupo control se encontraron diferencias significativas entre la visita inicial y la final en el espesor corneal total no epitelial y corneal a nivel central siendo mayores los espesores preoperatorios. En primer lugar, estas variaciones, aún siendo estadísticamente significativas, clínicamente no lo son ya que las variaciones son cercanas a las $5 \mu \mathrm{m}$, es decir, variaciones del $\leq 1 \%$ de la magnitud paquimétrica evaluada, y en segundo lugar, son similares a los valores de reproducibilidad de medida del propio sistema, por lo que se puede considerar que estas variaciones están dentro de los errores aleatorios de medida esperables. Estas pequeñas variaciones de medida también han sido reportadas por otros autores como Aribaba y cols. (2015), que utilizaron como control el ojo no operado de sus pacientes. Ellos encontraron al día siguiente de la cirugía en los ojos no operados un aumento del espesor corneal central que disminuyó a las 2 semanas de la cirugía, el cual volvió a aumentar a los 2 meses y volvió a disminuir a los 3 meses. Hallazgos que en principio carecen de sentido y que deberían asignarse a los errores de medida sistemática propios del aparato utilizado.

No encontramos cambios queratométricos significativos en el postoperatorio inmediato y tardío de la facoemulsificación. Aykut y cols. (2014), analizaron las variaciones refractivas en la queratometría corneal en pacientes a los que se realizó 
o bien la técnica de preincisión o bien incisión en un solo paso y también diferenciaron entre incisión superonasal y superotemporal. A estos pacientes se les implantó LIO tras la facoemulsificación. Al igual que nuestro grupo, tras un seguimiento de 3 meses, no observaron diferencias significativas en el poder refractivo corneal, aunque en el grupo de pre-incisión del estudio de Aykut y cols. (2014) se encontraron cambios significativos a la semana y al mes que posteriormente se estabilizaron. Sin embargo, Barequet y cols. (2004) describieron un astigmatismo inducido a las 6 semanas de la cirugía y persistente tras 12 meses. En cualquier caso, las incisiones corneales sin sutura cuanto más pequeñas sean, inducirán menos astigmatismo postquirúrgico, siempre y cuando su localización no sea superior (Wang y cols., 2009).

La excentricidad media en el grupo de controles (0.50 \pm 0.03$)$ fue considerablemente mayor que en el grupo de casos $(0.28 \pm 0.02)$. En el grupo de casos, la excentricidad a los 3 meses era significativamente mayor (Media $=0.1$ ) que en el resto de visitas. Estos resultados se pueden considerar fiables ya que OrtizToquero y cols. (2014) encontraron una buena repetibilidad en la medida de la excentricidad mediante topografía de reflexión en sujetos sanos $(\mathrm{CCl}=0.96, \mathrm{CVi}=$ $5,79 \%)$ y en pacientes con queratocono $(\mathrm{CCl}=0.93, \mathrm{CVi}=14.53 \%)$, con un dispositivo similar al que utilizamos en nuestro estudio. Park y cols. (2011) describieron una correlación positiva entre el astigmatismo inducido quirúrgicamente y la excentricidad corneal: a menor astigmatismo inducido, menor excentricidad corneal. También encontraron una correlación negativa entre la excentricidad corneal y la edad de los pacientes, por lo que se podría decir que la córnea central se aplana con la edad, generando en los pacientes ancianos un aumento de las aberraciones esféricas positivas. Los valores preoperatorios medios de la 
excentricidad de Park y cols. (2011) $(0.28 \pm 0.28)$ coinciden con los de nuestro grupo de casos aunque no ocurre lo mismo en el grupo de controles, probablemente debido a la diferencia en el tamaño muestral $(n=30)$. Si bien los valores en el grupo de pacientes operados eran mayores tras 3 meses de la cirugía, siempre se aproximaban al valor medio de la excentricidad (0.55) (Hansen, 2003).

En el estudio de las aberraciones corneales, observamos que el único componente del tercer orden donde existió alguna diferencia significativa a lo largo del tiempo, en este caso entre el preoperatorio y los valores tras 3 meses de cirugía, fue en el $Z_{5}{ }^{1}$, aunque clínicamente se puede considerar inapreciable. El valor de "coma-like" tampoco varió a lo largo de las distintas visitas aunque se encontraron valores levemente mayores en el grupo de los casos.

En el caso de las aberraciones esféricas, observamos un descenso significativo de la aberración esférica primaria positiva a los 3 meses de la visita con respecto al valor preoperatorio (Diferencia $=0.037 \mu \mathrm{m}, \mathrm{p}=0.002$ ), siendo los valores mayores en el grupo de casos $($ Media $=0.33 \mu \mathrm{m})$ que en los controles $($ Media $=0.25$ $\mu \mathrm{m})$. El "spherical-like" presentaba el mismo comportamiento. Según Park y cols. (2011), el descenso en la excentricidad corneal asociado a la edad puede contribuir al aumento de las aberraciones esféricas a medida que el paciente envejece, a lo que se añade la positivización de las aberraciones esféricas producidas por el cristalino. Los valores de excentricidad en nuestro grupo de casos $(0.28 \pm 0.02)$ presentan valores por debajo de la media poblacional (0.55) (Hansen, 2003) y la aberración esférica de nuestros casos $(0.33 \pm 0.01 \mu \mathrm{m})$ valores superiores a la media poblacional $(0.103 \mu \mathrm{m})$ (Wang, Koch, 2003), aunque no contradicen esta teoría. En nuestra muestra de pacientes, en relación a las modificaciones producidas a lo largo del periodo postquirúrgico, encontramos una correlación negativa entre la 
excentricidad y la aberración esférica primaria y por consiguiente el "spherical-like", es decir, a mayor aplanamiento corneal inducido quirúrgicamente, menor aberración esférica primaria en la superficie corneal anterior.

Las aberraciones corneales anteriores totales, con valores mayores en el grupo de casos, aumentaron a la semana y descendieron al mes de la cirugía, volviendo a recuperar valores prácticamente similares a los preoperatorios pasados 3 meses de la cirugía. En este caso podríamos decir que el patrón de variación es similar al del espesor corneal total no epitelial, y en el momento de máximo grosor del mismo (máximo edema), el cambio en la curvatura estromal asociada al edema podría haber afectado de alguna forma a las aberraciones corneales totales anteriores. Los resultados de nuestro análisis de correlación apoyan este punto, puesto que la correlación positiva entre las variaciones en el espesor corneal total no epitelial y las aberraciones de alto orden corneales anteriores totales responde probablemente a la alteración de la homogeneidad corneal secundaria al edema estromal con el consiguiente aumento de las aberraciones corneales anteriores.

La superficie corneal anterior puede contribuir hasta en un $80 \%$ a la refracción total ocular, y pequeñas modificaciones en su forma son suficientes para generar cambios dióptricos significativos. Según Calossi (2007), en el área corneal paraxial, una modificación en la curvatura equivalente a a $0.4 \mu \mathrm{m}$ de radio equivaldrían a una variación de 0.25 D. Tras las cirugías realizadas en este estudio observamos un aumento final de la excentricidad de 0.1 , es decir, podríamos decir que es la variación esperable tras cirugía de catarata convencional para nuestro cirujano (MCG), que por otro lado supone una disminución de la aberración esférica positiva primaria y de las aberraciones de alto orden corneales anteriores totales de $0.04 \mu \mathrm{m}$, según el modelo estadístico creado. Este aumento del aplanamiento en los $30^{\circ}$ 
periféricos esperado puede influir en la calidad visual postoperatoria, especialmente en aquellos casos en los que se implante una LIO asférica. De este modo podríamos buscar no sólo mejorar la agudeza visual sino también la calidad visual en aquellos pacientes que se demuestre que poseen tamaños pupilares mesópicos por encima de los $3.5 \mathrm{~mm}$ (Yamaguchi y cols., 2009). Sin embargo, en base a nuestros resultados, a la hora de seleccionar la LIO asférica que reduzca a cero la aberración esférica (o la modifique de forma personalizada), hay que tener en cuenta las variaciones de la excentricidad corneal esperada responsables de modificar la aberración esférica postoperatoria, ya que es muy probable que haya desviaciones sobre las medidas preoperatorias iniciales como hemos demostrado en nuestro estudio. Dado que estas variaciones observadas pueden ser cirujano-dependientes, sería recomendable crear modelos personalizados que evalúen los cambios postoperatorios en la excentricidad corneal con el objetivo de ser lo más preciso posible en el resultado final de la cirugía en términos de calidad visual. En nuestro estudio encontramos una correlación negativa entre la excentricidad y la aberración esférica primaria y las aberraciones de alto orden corneales anteriores totales.

Este estudio presenta varias limitaciones. En primer lugar, las derivadas del dispositivo utilizado como topógrafo mencionadas en el apartado 7.1.1. En segundo lugar, el tamaño muestral del grupo de pacientes controles $(n=30)$ ha podido ser la causa de las diferencias significativas encontradas preoperatoriamente entre ambos grupos para algunas variables, lo cual no ha afectado al análisis comparativo ya que se desarrollo un modelo estadístico de inferencia anulando los posibles sesgos asociados. Por último, Calvo-Maroto y cols. (2015) observaron mayores aberraciones totales de alto orden en pacientes con diabetes insulinodependientes en comparación con los no insulinodependientes. En nuestro estudio no se 
diferenció entre pacientes diabéticos en tratamiento y no diabéticos, por lo tanto desconocemos si la evolución observada en las aberraciones puede haber sido diferente y por consiguiente, haber influido en los resultados finales. 
CONCLUSIONES 



\section{CONCLUSIONES}

\subsection{CONCLUSIÓN GENERAL}

Tras una cirugía de catarata senil mediante facoemulsificación sin incidencias intra o post-quirúrgicas, no se producen cambios relevantes en el espesor epitelial a lo largo de los 3 meses postoperatorios, al contrario de lo que sucede en el espesor corneal total no epitelial donde se observa un aumento reversible de mayor magnitud en las áreas paracentrales más próximas a la incisión principal. Dichos cambios transitorios se acompañan de un incremento definitivo de la excentricidad corneal que da lugar a una reducción de la aberración esférica positiva primaria preoperatoria, que podría tenerse en cuenta en el diseño asférico de lentes intraoculares en el contexto de una cirugía de la catarata cada vez más personalizada; teniendo en cuenta al paciente y al cirujano.

\subsection{CONCLUSIONES ESPECÍFICAS}

- Es de esperar que tras una cirugía de cataratas senil mediante facoemulsificación sin incidencias intra- o post-quirúrgicas, no haya cambios clínicos relevantes en el grosor epitelial, mientras que sí que se producirá un edema corneal sin afectación epitelial que se elimina desde el punto de vista clínico al mes, y estadísticamente a los tres meses de la cirugía.

- En el postoperatorio de la cirugía de cataratas mediante facoemulsificación no se observan diferencias en la variación del grosor 
epitelial corneal a lo largo del meridiano horizontal, mientras que las variaciones del grosor corneal total no epitelial son de igual magnitud tanto en las áreas paracentrales como en la córnea central.

- La tomografía de coherencia óptica de dominio espectral presenta una repetibilidad y reproducibilidad clínicamente aceptables en el análisis manual del espesor epitelial, mientras que resulta excelente en el análisis del espesor corneal total no epitelial, siempre que los examinadores estén familiarizados con la estrategia de medición manual.

- Tras la cirugía de cataratas senil mediante facoemulsificación no existe un incremento de las aberraciones de alto orden corneales anteriores totales, sin embargo, sí que puede existir una disminución de la aberración esférica primaria derivada de un aumento de la excentricidad corneal, que clínicamente podría ser relevante a la hora de la predicción y planificación de los resultados postoperatorios esperados en los casos en los que se desee mejorar la calidad visual del paciente seleccionando una lente intraocular asférica. 
BIBLIOGRAFÍA 



\section{BIBLIOGRAFÍA}

1. Alió JL, Soria F, Abdou AA, Peña-García P, Fernández-Buenaga R, Javaloy J, 2014. Comparative outcomes of bimanual MICS and 2.2-mm coaxial phacoemulsification assisted by femtosecond technology. J Refract Surg. 30, $34-40$.

2. Altman DG, Bland JM, 1983. Measurement in Medicine: the Analysis of Method Comparison Studies. Statistician. 32, 307-17.

3. Ambrósio R Jr, Alonso RS, Luz A, Coca Velarde LG, 2006. Corneal-thickness spatial profile and corneal-volume distribution: tomographic indices to detect keratoconus. J Cataract Refract Surg. 32, 1851-9.

4. Arffa R C, Grayson M, 1998. Enfermedades de la Córnea 4⿳亠丷a ed. Harcourt Brace. Madrid. Pp 5-18.

5. Aribaba OT, Adenekan OA, Onakoya AO et al, 2015. Central corneal thickness changes following manual small incision cataract surgery. Clin Ophthalmol. 9, $151-5$

6. Arkins A, Roper M, 1985. Control of postoperative astigmatism. Br. J. Ophthal. 69, 348.

7. Arshinoff SA, Jafari M, 2005. New classification of ophthalmic viscosurgical devices--2005. J Cataract Refract Surg. 31, 2167-71.

8. Artal P, Berrio E, Guirao A, Piers P, 2002. Contribution of the cornea and internal surfaces to the change of ocular aberrations with age. J Opt Soc Am A Opt Image Sci Vis. 19, 137-43.

9. Ashwin PT, Shah S, Wolffsohn JS, 2009. Advances in cataract surgery. Clin Exp Optom. 92, 333-42. 
10. Asuquo IM, Busuyi HM, Umar KO, 2014. The dangers of couching in southwest Nigeria. Malays J Med Sci. 21(5), 60-5.

11. Aykut V, Kirgiz A, Gül Ay B, Celik U, 2014. Comparison of pre-incision and single-stepped clear corneal incision in phacoemulsification surgery. Eur Rev Med Pharmacol Sci. 18(12), 1698-703.

12. Barequet IS, Yu E, Vitale S, Cassard S, Azar DT, Stark WJ, 2004. Astigmatism outcomes of horizontal temporal versus nasal clear corneal incision cataract surgery. J Cataract Refract Surg. 30, 418-42.

13. Barraquer J, 1958. Total extraction of the lens after disintegration of the zonula by alpha-chymotrypsin=enzymatic zonulysis. Klin Monbl Augenheilkd Augenarztl Fortbild. 133, 609-15.

14. Barrio M, Iglesias I, Vico-Ruiz E, Iradier MT, 2006. Eficacia y seguridad del hialuronato sódico con condroitín sulfato en facoemulsificación con alto riesgo de descompensación endotelial. Revista Sociedad Española Cirugía Ocular e Implanto Refractiva. 2

15. Bates D, Maechler M, Bolker B, Walker S, 2014. Ime4: Linear mixed-effects models using Eigen and S4. $\mathrm{R}$ package version 1.1-7. http://CRAN.Rproject.org/package=Ime4 .

16. Behndig A, Lundberg B, 2002. Transient corneal edema after phacoemulsification: comparison of 3 viscoelastic regimens. J Cataract Refract Surg. 28, 1551-6.

17. Benítez del Castillo JM, Durán de la Colina JA, Rodriguez Ares MT, 2004. Superficie Ocular. LXXX Ponencia Oficial dela Sociedad Española de Oftalmología. Mac Line. Cap 1. Pp 1-12. 
18. Belin MW, Ratliff CD, 1996. Evaluating data acquisition and smoothing functions of currently available videokeratoscopes. J Cataract Refract Surg. $22(4), 421-6$.

19. Belin MW, Khachikian S, 2009. An introduction to understanding elevationbased topography: how elevation data are displayed - a review. Clin Experiment Ophthalmol. 37(1), 14-29.

20. Bhan A, Bhargava J, Vernon SA, et al, 2003. Repeatability of ocular blood flow pneumotonometry. Ophthalmology. 110, 1551-4.

21. Bland JM, Altman DG, 1996(a). Measurement error. BMJ. 313(7059), 744.

22. Bland JM, Altman DG, 1996(b). Measurement error and correlation coefficients. BMJ. 313, 41-2.

23. Bland JM, Altman DG, 1998. Statistical methods for assessing agreement between two methods of clinical measurement. Lancet.1, 307-10.

24. Bland M, 2000. An Introduction to Medical Statistics, 3rd ed. Oxford, UK: Oxford University Press. Pp 268-75.

25. Blumenthal EZ, Williams JM, Weinreb RN, et al, 2000. Reproducibility of nerve fiber layer thickness measurements by use of optical coherence tomography. Ophthalmology .107, 2278-82.

26. Bolz M, Sacu S, Drexler W, Findl O, 2006. Local corneal thickness changes after small-incision cataract surgery. J Cataract Refract Surg. 32, 1667-71.

27. Bourne RR, Alsbirk $\mathrm{PH}, 2006$. Anterior chamber depth measurement by optical pachymetry: systematic difference using the Haag-Streit attachments. Br J Ophthalmol. 90(2), 142-5. 
28. Boxer-Watchler BS, Krueger RR, 2000. Agreement and repeatability of pupillometry using videokeratography and infrared devices. J Cataract Refract Surg 26, 35-40.

29. Breingan PJ, Esaki K, Ishikawa H, Liebmann JM, Greenfield DS, Ritch R, 1999. Iridolenticular contact decreases following laser iridotomy for pigment dispersion syndrome. Arch Ophthalmol. 117(3), 325-8.

30. Brunette I, Bueno JM, Parent M, Hamam H y Simonet P, 2003. Monochromatic aberrations as a function of age, from childhood to advanced age. Invest Ophthalmol Vis Sci. 44(12), 5438-46.

31. Cairns G, McGhee CN, 2005. Orbscan computerized topography: attributes, applications, and limitations. J Cataract Refract Surg.31(1), 205-20

32. Calabuig-Goena M, López-Miguel A, Marqués-Fernández V, Coco-Martín MB, Iglesias-Cortiñas D, Maldonado MJ, 2015. Early changes in corneal sublayer thickness after cataract surgery: a pilot study. Curr Eye Res. 24, 1-7.

33. Calossi A, 2007. Corneal asphericty and spherical aberration. J Refract Surg. $23,505-14$

34. Calvo-Maroto AM, Pérez-Cambrodí RJ, García-Lázaro S, Albarrán-Diego C, Cerviño, 2015. A pilot study on total, corneal, and internal aberrations in insulin-dependent and non-insulin-dependent diabetes mellitus patients. Graefes Arch Clin Exp Ophthalmol. 253(4), 645-53.

35. Can I, Takmaz T, Çakıcı F, and Özgül M, 2004. Comparison of Nagahara phaco-chop and stop-and-chop phacoemulsification nucleotomy techniques. $\mathrm{J}$ Cataract Refract Surg. 30, 663-6

36. Carl Zeiss Meditec: Cirrus HD-OCT User Manual. 2007. 11-1. Dublin, CA. 
37. Carvalho LA, 2005. Accuracy of Zernike polynomials in characterizing optical aberrations and the corneal surface of the eye. Invest Ophthalmol Vis Sci. 46, 1915-26.

38. Carvalho LA, 2005. Preliminary results of neural networks and Zernike polynomials for classification of videokeratography maps.Optom Vis Sci. 82(2), $151-8$

39. Celiker H, Karabas L, Sahin O, 2014. A comparison of topical or retrobulbar anesthesia for 23-gauge posterior vitrectomy. J Ophthalmol. Epub 2014 Nov 18

40. Chang DF, 1999. Converting to phaco-chop: why and how. Ophthalmic Practice. 17, 202-10.

41. Chen W, McAlinden C, Pesudovs K, Wang Q, Lu F, Feng Y, et al, 2012. Scheimpflug-Placido topographer and optical low-coherence reflectometry biometer: repeatability and agreement. J Cataract Refract Surg. 38(9), 162632.

42. Chylack LT Jr, Wolfe JK, Singer DM, Leske MC, Bullimore MA, Bailey IL et al, 1993. The Lens Opacities Classification System III. The Longitudinal Study of Cataract Study Group. Arch Ophthalmol. 111(6), 831-6.

43. Ciolino JB, Belin MW, 2006. Changes in the posterior cornea after laser in situ keratomileusis and photorefractive keratectomy. J Cataract Refract Surg. 32(9), 1426-31.

44. Civis GW, 2007a. Ocular development. En: Fundamentals and principles of Ophthalmology. Section 2. American Academy of Ophthalmology. Elsevier, Boston. Pp 150-2. 
45. Civis GW, 2007b. Tear film. En: Fundamentals and principles of Ophthalmology. Section 2. American Academy of Ophthalmology. Elsevier, Boston. Pp 287-302.

46. Clark A, Morlet N, Ng JQ, Preen DB, Semmens JB, 2011. Whole Population Trends in Complications of Cataract Surgery over 22 Years in Western Australia. Ophthalmology .118, 1055-61.

47. Correa-Perez ME, Lopez-Miguel A, Miranda-Anta S, et al, 2012. Precision of high definition spectral-domain optical coherence tomography for measuring central corneal thickness. Invest Ophtalmol Vis Sci. 53, 1752-7.

48. Correa-Pérez ME, Olmo N, López-Miguel A, Fernández I, Coco-Martín MB y Maldonado MJ, 2014. Dependability of posterior-segment spectral domain optical coherence tomography for measuring central corneal thickness. Cornea. 33(11), 1219-24.

49. Coster DJ, 2002. Fundamentals of clinical Ophthalmology. Cornea. BMJ Books. London. Pp 21-3.

50. Cruysberg LP, Doors M, Verbakel F, Berendschot TT, De Brabander J, Nuijts $\mathrm{RM}, 2010$. Evaluation of the Lenstar LS 900 non-contact biometer. $\mathrm{Br} \mathrm{J}$ Ophthalmol. 94(1), 106-10.

51. Davis WR, Raasch TW, Lynn Mitchel G, Mutti DO, Zadnik K, 2005. Corneal asphericity and apical curvature in children: A cross-sectional and longitudinal evaluation. Invest Ophthamol Vis Sci. 46, 1899-906.

52. De Juan V, Herreras JM, Pérez I et al, 2013. Refractive stabilization and corneal swelling after cataract surgery. Optom Vis Sci. 90, 31-6.

53. Dohlman $\mathrm{CH}, 1971$. The function of corneal epithelium in health and disease. The Jonas S. Friedenwald Memorial Lecture. Invest Ophthalmol. 10, 383-407. 
54. Dole K, Kulkarni S, Shisode KD, Deshpande R, Kakade N, Khandekar R, Deshpande M, 2014. Comparison of clinical outcomes, patient, and surgeon satisfaction following topical versus peribulbar anesthesia for phacoemulsification and intraocular lens implantation: a randomized, controlled trial. Indian J Ophthalmol. 62(9), 927-30.

55. Doors M, Budo CJ, Christiaans BJ, Luger M, Marinho AA, Dick HB, Güell JL, Nuijts RM, 2012. Artiflex Toric foldable phakic intraocular lens: short-term results of a prospective European multicenter study. Am J Ophthalmol. 154(4), 730-9.

56. Doughty MJ, Zaman ML, 2000. Human corneal thickness and its impact on intraocular pressure measures: a review and meta-analysis approach. Surv Ophthalmol. 44(5), 367-408.

57. Dua HS, Faraj LA, Said DG, Gray T, Lowe J, 2013. Human corneal anatomy redefined: a novel pre-Descemet's layer (Dua's layer). Ophthalmology. 120(9), 1778-85.

58. Dubbelman M, Sicam VA, Van der Heijde GL, 2006. The shape of the anterior and posterior surface of the aging human cornea.Vision Res. 46(6-7), 9931001.

59. Duke-Elder S, 1969. Diseases of the lens and vitreous; glaucoma and hypotony. System of Ophthalmology. Vol. XI. London, Kimpton. Pp 248-63.

60. Erie JC, Baratz KH, Hodge DO, et al, 2007. Incidence of cataract surgery from 1980 through 2004: 25-year population-based study. J Cataract Refract Surg. $33,1273-7$. 
61. Fakhry MA, El Shazly MI, 2011. Torsional ultrasound mode versus combined torsional and conventional ultrasound mode phacoemulsification for eyes with hard cataract. Clin Ophthalmol. 5, 973-8.

62. Faust KJ, 1984. Hidrodissection of soft nuclei. Am Intra-Oc. Implant Soc J. 10, 75-7.

63. Feng Y, Varikooty J, Simpson T, 2001. Diurnal variation of corneal and corneal epitelial thickness measured using optical coherence tomography. Cornea. 20, 480-3.

64. Fernandez-Vega $L$ et al, 2001. Facoemulsificación y emetropía. IV Monografía de la Sociedad Española de Cirugía Ocular e Implanto-Refractiva. Mac Line. Pp 13-27.

65. Fujimoto JG, Brezinski ME, Tearney GJ, Boppart SA, Bouma B, Hee MR, Southern JF, Swanson EA, 1995. Optical biopsy and imaging using optical coherence tomography. Nat Med. 1, 970-2.

66. Fujimoto, James G, 2001. Optical coherence tomography. Comptes Rendus de l'Académie des Sciences-Series IV-Physics 2.8, 1099-111.

67. Funderburgh JL, 2000. Keratan sulfate: structure, biosynthesis, and function. Glycobiology. 10, 951-8.

68. Garzón N, Poyales F, 2007. ORBSCAN: Mapas topográficos. Gaceta Optica. $420,24-8$

69. Gatinel D, Malet J, Hoang-Xuan T, Azar DT, 2011. Corneal elevation topography: best fit sphere, elevation distance, asphericity, toricity, and clinical implications. Cornea. 30(5), 508-15. 
70. Ge L, Shen M, Tao A, Wang J, Dou G, Lu F, 2012. Automatic segmentation of the central epithelium imaged with three optical coherence tomography devices. Eye \& Contact Lenses. 38, 150-7.

71. Ge L, Yuan Y, Shen M et al, 2013. The role of axial resolution of optical coherence tomography on the measurement of corneal and epitelial thicknesses. Invest Ophthalmol Vis Sci. 54, 746-55.

72. Germundsson J, Karanis G, Fagerholm P, Lagali N, 2013. Age-related thinning of Bowman's layer in the human cornea in vivo. Invest Ophthalmol Vis Sci. 54(9), 6143-9.

73. Gimbel HV, Neuhann T, 1990. Development, advantages, and methods of the continuous circular capsulorhexis technique. J Cataract Refract Surg. 16, 317.

74. Gimbel HV, 1991. Divide and conquer nucleofractis phacoemulsification: development and variations. J Cataract Refract Surg. 17: 281-91.

75. Hansen DW, 2003. Evaluating the eye with corneal topography. Contact Lens Spectrum. 18(8), 27-32.

76. Hamzah F, Shinojima A, Mori R, Yuzawa M, 2014. Choroidal thickness measurement by enhanced depth imaging and swept-source optical coherence tomography in central serous chorioretinopathy. BMC Ophthalmol.14, 145.

77. Hayashi K, Hayashi H, Nakao F, Hayashi F, 1996. Risk factors for corneal endothelial injury during phacoemulsification. J Cataract Refract Surg. 22, 1079-84 
78. Hermann B, Fernández EJ, Unterhuber A, Sattmann H, Fercher AF, Drexler W et al, 2004. Adaptive-optics ultrahigh-resolution optical coherence tomography. Opt Lett. 29(18), 2142-4.

79. Hong JP, Nam SM, Kim TI, Seo KY, Lee SY, Meduri A, Kim EK, 2012. Reliability of RTVue, Visante, and slit-lamp adapted ultrasonic pachymetry for central corneal thickness measurement. Yonsei Med J. 53(3), 634-41.

80. Huang AJ, Tseng SC, 1991. Corneal epithelial wound healing in the absence of limbal epithelium. Invest. Ophthalmol. Vis. Sci. 32(1), 96-105.

81. Huang D, Wang J, Lin CP, Puliafito CA, Fujimoto JG, 1991. Micron-resolution ranging of cornea anterior chamber by optical reflectometry. Lasers Surg Med. 11(5), 419-25.

82. Ishibazawa A, Igarashi S, Hanada K, Nagaoka T, Ishiko S, Ito H, Yoshida A, 2011. Central corneal thickness measurements with Fourier-domain optical coherence tomography versus ultrasonic pachymetry and rotating Scheimpflug camera. Cornea. 30(6), 615-9.

83. Javitt JC y Steinert RF, 2000. Cataract extraction with multifocal intraocular lens implantation: a multinational clinical trial evaluating clinical, functional, and quality-of-life outcomes. Ophthalmology. 107, 2040-8.

84. Jaycock P, Johnston RL, Taylor H, et al, UK EPR User Group, 2009. The Cataract National Dataset electronic multi-centre audit of 55,567 operations: updating benchmark standards of care in the United Kingdom and internationally. Eye. 23, 38-49.

85. Jonuscheit S, Doughty MJ, Martin R, Río-Cristóbal A, Cruikshank V, Lang S, 2015. Peripheral nasal-temporal corneal asymmetry in relation to corneal thickness: a Scheimpflug imaging study. Ophthalmic Physiol Opt. 35(1), 45-51. 
86. Kanellopoulos AJ, Asimellis G, 2014a. Corneal epithelial remodeling following cataract surgery: three-dimensional investigation with anterior-segment optical coherence tomography. J Refract Surg. 30(5), 348-53.

87. Kanellopoullos AJ, Asimellis G, 2014b. In vivo 3-dimensional corneal epitelial thickness mapping as an indicator of dry eye: preliminary clinical assesment. Am J Ophthalmol. 157, 63-8.

88. Kawana K, Tokunaga T, Miyata K, Okamoto F, Kiuchi T, Oshika T, 2004. Comparison of corneal thickness measurements using Orbscan II, non-contact specular microscopy, and ultrasonic pachymetry in eyes after laser in situ keratomileusis. Br J Ophthalmol. 88(4), 466-8.

89. Kiss B, Findl O, Mepanace R, Petternel V, Wirtitsch M, Lorang T, Gengler M, Wolfgang $M, 2003$. Corneal endothelial cell protection with a dispersive viscoelastic material and an irrigating solution during phacoemulsification. $\mathrm{J}$ Cataract Refract Surg. 29, 733-74.

90. Klein M, 1958. A new keratoscope; with self-luminous placido disc.Br J Ophthalmol. 42(6), 380-1.

91. Klyce SD, 1984. Computer-assisted corneal topography. High-resolution graphic presentation and analysis of keratoscopy. Invest Ophthalmol Vis Sci. 25(12), 1426-35.

92. Klyce SD, Karon MD, Smolek MK, 2004. Advantages and disadvantages of the Zernike expansion for representing wave aberration of the normal and aberrated eye.J Refract Surg. 20(5), 537-41.

93. Koch PS, Katzen LE, 1994. Stop and chop phacoemulsification. J Cat Refract Surg. 20, 566-70. 
94. Komai Y, Ushiki T, 1991. The three-dimensional organization of collagen fibrils in the human cornea and sclera. Invest Ophthalmol Vis Sci. 32, 224458.

95. Krachmer JH, Mannis MJ, Holland EJ, 1997. Cornea. Volume 1. Fundamentals of cornea and external diseases. Mosby. Pp 509-17.

96. Kuznetsova A, Brockhoff PB, Bojesen Christensen RH, 2014. ImerTest: Tests in Linear Mixed Effects Models. R package version 2.0-20. http://CRAN.Rproject.org/package=ImerTest

97. Lagali N, Germundsson J, Fagerholm P, 2009. The role of Bowman's layer in corneal regeneration after phototherapeutic keratectomy: a prospective study using in vivo confocal microscopy. Invest Ophthalmol Vis Sci. 50, 4192-8.

98. Lai MM, Lai JC, Lee WH, Huang JJ, Patel S, Ying HS et al, 2005. Comparison of retrobulbar and sub-Tenon's capsule injection of local anesthetic in vitreoretinal surgery. Ophthalmology. 112(4), 574-9.

99. Li H et al, 2008. Comparative study of central corneal thickness measurement with slit-lamp optical coherence tomography and visante optical coherence tomography. Ophthalmol. 115(5), 796-801.

100. Li XM, Hu L, Hu J, Lanier JD, 2007. Investigation of dry eye disease and analysis of the pathogenic factors in patients after cataract surgery. Cornea. $26,16-20$

101. Li YJ, Kim HJ y Joo CK, 2011. Early changes in corneal edema following torsional phacoemulsification using anterior segment optical coherence tomography and Scheimpflug photography. Jpn J Ophthalmol. 55, 196-204. 
102. Li Y, Tan O, Brass R, et al, 2012. Corneal epitelial thickness mapping by Fourier-domain optical coherence tomography in normal and keratoconic eyes. Ophthalmology. 119, 2425-33.

103. Liu Y, Zeng M, Liu X et al, 2007. Torsional mode versus conventional ultrasound mode phacoemulsification: randomized comparative clinical study. J Cataract Refract Surg. 33, 287-92.

104. López-Miguel A, Correa-Pérez ME, Miranda-Anta S, Iglesias-Cortiñas D, Coco-Martín MB, Maldonado MJ, 2012. Comparison of central corneal thickness using optical low-coherence reflectometry and spectral-domain optical coherence tomography. J Cataract Refract Surg. 38(5), 758-64.

105. López-Miguel A, Martínez-Almeída L, Coco-Martín MB, del Val M, Pichel M, Maldonado MJ, 2014. Clinical utility of combined Placido-scanning-slit midperipheral and thinnest point pachymetry after corneal ablation for myopia. Cornea. 33(3), 266-70.

106. Lorente R, Mendicute J, 2008. Capsulorrexis. En: Lorente R, Mendicute J (Eds.), Cirugía del cristalino. LXXXIV Ponencia Oficial de la Sociedad Española de Oftalmología. Mac Line. Pp 627-43.

107. Losada Bayo D, Ruiz Casas D, Almendral Gómez A, Muñoz Negrete FJ, 2011. OCT. Recuerdo histórico y bases teóricas de funcionamiento. En: Muñoz Negrete FJ, Rebolleda G, Díaz Llopis M (Eds.), Tomografía de Coherencia óptica. LXXXVII Ponencia Oficial de la Sociedad Española de Oftalmología. Mac Line. Pp 27-32.

108. Lozano J, 2001. La cirugía de catarata hasta 1748. Cir Ciruj. 69, 141-3. 
109. Lundberg B, Jonsson M, Bendhig A, 2005. Postoperative corneal swelling correlates strongly to corneal endothelial cell loss after phacoemulsification cataract surgery. Am J Ophthalmol. 139, 1035-41.

110. Ma XJ, Wang L, Koch DD, 2013. Repeatability of corneal epithelial thickness measurements using Fourier-domain optical coherence tomography in normal and post-LASIK eyes. Cornea. 32, 1544-8.

111. Maár N, Graebe A, Schil G, Stur M, Amon M, 2001. Influence of viscoelastic substances used en cataract surgery on corneal metabolism and endothelial morphology: Comparison of Healon and Viscoat. J Cataract Refract Surg. 27, $1756-61$

112. Maeda N, 2009. Clinical applications of wavefront aberrometry - a review. Clin Experiment Ophthalmol. 37(1), 118-29.

113. Maldonado MJ, Ruiz-Oblitas L, Munuera JM, Aliseda D, García-Layana A, Moreno-Montañés J, 2000. Optical coherence tomography evaluation of the corneal cap and stromal bed features after laser in situ keratomileusis for high myopia and astigmatism. Ophthalmology. 107, 81-7.

114. Maldonado MJ, Nieto JC, Díez-Cuenca M, Piñero DP, 2006. Posterior corneal curvature changes after undersurface ablation of the flap and in-thebed LASIK retreatment. Ophthalmology. 113(7), 1125-33.

115. Maldonado López MJ y Nieto Fernández JC, 2007. Topografía de la ectasia corneal. En: Peris Martínez C, Menezo Rozalén JL (Eds.), Tratamiento de la ectasia corneal. Mesa Redonda del LXXXIII Congreso de la Sociedad Española de Oftalmología. Mac Line. Pp 67-96. 
116. Marcon AS, Rapuano CJ, Jones MR, Laibson PR, Cohen EJ, 2002. Descemet's membrane detachment after cataract surgery: management and outcome. Ophthalmology. 109(12), 2325-30.

117. Martinez-Finkelshtein A, Delgado AM, Castro GM, Zarzo A, Alió JL, 2009. Comparative analysis of some modal reconstruction methods of the shape of the cornea from corneal elevation data. Invest Ophthalmol Vis Sci. 50(12), $5639-45$

118. Masmali AM1, Purslow C, Murphy PJ, 2014. The tear ferning test: a simple clinical technique to evaluate the ocular tear film. Clin Exp Optom. 97(5), 399406.

119. Mathur A, Atchison DA y Tabernero J, 2012. Effect of age on components of peripheral ocular aberrations. Optom Vis Sci. 89(7), 967-76.

120. McAlinden C, Khadka J, Pesudovs K, 2011. Statistical methods for conducting agreement (comparison of clinical tests) and precision (repeatability or reproducibility) studies in optometry and ophthalmology. Ophthalmic \& Physiological Optics. 31, 330-8.

121. McCarey BE, Edelhauser HF, Lynn MJ, 2008. Review of corneal endothelial specular microscopy for FDA clinical trials of refractive procedures, surgical devices, and new intraocular drugs and solutions. Cornea. 27(1), 1-16.

122. Meek KM, Denis S, Khan S, 2003. Changes in the refractive index of the stroma and its extrafibrillar matrix when the cornea swells. Biophys J. 85, 2205-12.

123. Mello GR, Rocha KM, Santhiago MR, Smadja D, Krueger RR, 2012. Applications of wavefront technology. J Cataract Refract Surg. 38(9), 1671-83. 
124. Mendicute J, Lorente R, 2008. Técnicas de fractura o craking. En: Lorente R, Mendicute J (Eds.), Cirugía del cristalino. LXXXIV Ponencia Oficial de la Sociedad Española de Oftalmología. Mac Line. Pp 652-74.

125. Meuleners LB, Hendrie D, Fraser ML, Ng JQ, Morlet N, 2013. The impact of first eye cataract surgery on mental health contacts for depression and/or anxiety: a population-based study using linked data. Acta Ophthalmol. 91(6): $445-9$.

126. Miglior S, Albe E, Guareschi M, et al, 2004. Intraobserver and interobserver reproducibility in the evaluation of ultrasonic pachymetry measurements of central corneal thickness. Br J Ophthalmol. 88,174-7.

127. Milla M, Piñero DP, Amparo F, Alió JL, 2011. Pachymetric measurements with a new Scheimpflug photography-based system: intraobserver repeatability and agreement with optical coherence tomography pachymetry. $\mathrm{J}$ Cataract Refract Surg. 37(2), 310-6.

128. Montés-Micó R, Alió JL, Muñoz G, Charman WN, 2004. Temporal changes in optical quality of air-tear film interface at anterior cornea after blink. Invest Ophthalmol Vis Sci. 45, 1752-7.

129. Moore DB, Harris A, Siesky B, 2010. The world through a lens: the vision of Sir Harold Ridley. Br J Ophthalmol. 94, 1277-80.

130. Morcillo R, Durán S, 2008. Lentes monofocales: características generales. LIOs para incisiones sub-2mm. En: Lorente R, Mendicute J (Eds.), Cirugía del cristalino. LXXXIV Ponencia Oficial de la Sociedad Española de Oftalmología. Mac Line. Pp 798-814.

131. Morcillo Laiz R, 2011. Uso intraoperatorio de la OCT. En: Muñoz Negrete FJ, Rebolleda G, Díaz Llopis M (Eds.), Tomografía de Coherencia óptica. 
LXXXVII Ponencia Oficial de la Sociedad Española de Oftalmología. Mac Line. Pp 37-8.

132. Morikubo S, Takamura Y, Kubo E, et al, 2004. Corneal changes after smallincision cataract surgery in patients with diabetes mellitus. Arch Ophthalmol. $122,966-9$

133. Müller LJ, Marfurt CF, Kruse F, Tervo TM, 2003. Corneal nerves: structure, contents and function. Exp Eye Res. 76(5), 521-42.

134. Muñoz Negrete FJ, Ruiz Casas D, Losada D, Almendral Gómez A, Rebolleda G, 2011. Características diferenciales de las tecnologías OCT disponibles. En: Muñoz Negrete FJ, Rebolleda G, Díaz Llopis M (Eds.), Tomografía de Coherencia óptica. LXXXVII Ponencia Oficial de la Sociedad Española de Oftalmología. Mac Line. P 62.

135. Muscat S, McKay N, Paks S, et al, 2002. Repeatability and reproducibility of corneal thickness measurements by optical coherence tomography. Invest Ophthalmol Vis Sci. 43, 1791-5.

136. Myles PS, Cui J, 2007. Using the Bland-Altman method to measure agreement with repeated measurements. Br J Anaesth. 99, 309-11.

137. Ni Y, Liu XL, Wu MX, Lin Y, Sun YY, He C, Liu YZ, 2011. Objective evaluation of the changes in the crystalline lens during accommodation in young and presbyopic populations using Pentacam HR system. Int $\mathrm{J}$ Ophthalmol. 4(6), 611-5.

138. Nieto Fernández JC, Maldonado López MJ, 2007. Aberrometría de la ectasia corneal. En: Peris Martínez C, Menezo Rozalén JL (Eds.), Tratamiento de la ectasia corneal. Mesa Redonda del LXXXIII Congreso de la Sociedad Española de Oftalmología. Mac Line. Pp 97-111. 
139. Nishi O, Nishi K, Osakabe Y, 2004. Effect of intraocular lenses on preventing posterior capsule opacification: design versus material. J Cataract Refract Surg. 30(10), 2170-6.

140. Nithyanandarajah G, Athanasiadis Y, Scollo P, Sharma B, Dorgham A, Sharma A, 2014. Hydration of the anterior stroma in phacoemulsification cataract surgery. J Cataract Refract Surg. 40(5), 702-4.

141. Northey LC, Gifford P, Boneham GC, 2012. Comparison of Topcon optical coherence tomography and ultrasound pachymetry. Optom Vis Sci. 89, 170814.

142. Oliveira CM, Ribeiro C, Franco S, 2011. Corneal imaging with slit-scanning and Scheimpflug imaging techniques. Clin Exp Optom. 94(1), 33-42.

143. Ollero A, Lorente R, Moreno C, Dominguez R, 2008. Plataformas de facoemulsificación. En: Lorente R, Mendicute J (Eds.), Cirugía del cristalino. LXXXIV Ponencia Oficial de la Sociedad Española de Oftalmología. Mac Line. . Pp 541-49

144. Oner FH, Gunenc U, Ferliel ST, 2000. Posterior capsule opacification after phacoemulsification: foldable acrylic versus poly(methyl methacrylate) intraocular lenses. J Cataract Refract Surg. 26(5), 722-6.

145. Ortiz-Toquero S, Rodriguez G, de Juan V, Martin R, 2014. Repeatability of placido-based corneal topography in keratoconus. Optom Vis Sci. 91(12), 1467-73.

146. Oshika T, Klyce SD, Applegate RA, Howland HC, 1999. Changes in corneal wavefront aberrations with aging. Invest Ophthalmol Vis Sci. 40(7), 1351-5. 
147. Pandey SK, Milverton EJ, Maloof AJ, 2004. A tribute to Charles David Kelman MD: ophthalmologist, inventor and pioneer of phacoemulsification surgery. Clin Experiment Ophthalmol. 32(5), 529-33.

148. Park CY, Chuck RS, Channa P, Lim CY, Ahn BJ, 2011. The effect of corneal anterior surface eccentricity on astigmatism after cataract surgery.Ophthalmic Surg Lasers Imaging. 42(5), 408-15.

149. Patel S, Marshall J, Fitzke FW, 1995. Refractive index of the human corneal ephithelium and stroma. J Refract Surg. 11, 100-5.

150. Piñero DP, Alió JL, Alesón A, Escaf M, Miranda M, 2009. Pentacam posterior and anterior corneal aberrations in normal and keratoconic eyes. Clinical and Experimental Optometry. 92(3), 297-303.

151. Podoleanu AG, Rosen RB, 2008. Combinations of techniques in imaging the retina with high resolution. Progress in Retinal and Eye Research. 27, 464-99.

152. Prakash G, Agarwal A, Mazhari Al, et al, 2012. Reliability and reproducibility of assessment of corneal epithelial thickness by Fourier domain optical coherence tomography. Invest Ophthalmol Vis Sci. 53, 2580-5.

153. Prakash G, Agarwal A, Mazhari Al, Kumar G, Desai P, Kumar DA et al, 2012. A new, pachymetry-based approach for diagnostic cutoffs for normal, suspect and keratoconic cornea. Eye (Lond). 26(5), 650-7.

154. Rainer G, Menapace R, Findl O, Georgopoulos M, Kiss B and Petternel V, 2000. Intraocular pressure after small incision cataract surgery with Healon 5 and Viscoat. J Cataract Refract Surg. 26, 271-6.

155. Ramos JLB, Li Y, Huang D, 2009. Clinical and research applications of anterior segment optical coherence tomography-a review. Clin Experiment Ophthalmol. 37, 81-9. 
156. Ravalico G, Tognetto D, Palomba DA et al, 1997. Corneal endotelial function after extracapsular cataract extraction and phacoemulsification. J Cataract Refract Surgery. 23, 1000-5.

157. Reinstein DZ, Gobbe M, Archer TJ, Couch D, Bloom B, 2009. Epithelial, stromal, and corneal pachymetry changes during orthokeratology. Optom Vis Sci. 86(8), 1006-14.

158. Reinstein DZ, Archer TJ, Gobbe M, Silverman RH, Coleman DJ, 2010(a). Epithelial thickness after hyperopic LASIK: three-dimensional display with Artemis very high-frequency digital ultrasound. J Refract Surg. 26(8), 555-64.

159. Reinstein DZ, Archer TJ, Gobbe M et al, 2010(b). Repeatability of layered corneal pachymetry with the Artemis very high-frequency digital ultrasound arc-scanner. J Refract Surg. 26, 646-59.

160. Reinstein DZ, Archer TJ, Gobbe M, 2012(b). Change in epithelial thickness profile 24 hours and longitudinally for 1 year after myopic LASIK: threedimensional display with Artemis very high-frequency digital ultrasound. J Refract Surg. 28(3), 195-201.

161. Reinstein DZ, Gobbe M y Archer TJ, 2012(a). Anterior segment biometry: a study and review of resolution and repeatability data. J Refract Surg. 28(7):509-20.

162. Reuschel A, Bogatsch H, Barth T, Wiedemann R, 2010. Comparison of endothelial changes and power settings between torsional and longitudinal phacoemulsification. J Cataract Refract Surg. 36, 1855-61.

163. Rio-Cristobal A, Martin R, 2014. Corneal assessment technologies: current status. Surv Ophthalmol. 59(6), 599-614. 
164. Roberts C, 1994. Characterization of the inherent error in a sphericallybiased corneal topography system in mapping a radially aspheric surface. $\mathrm{J}$ Refract Corneal Surg. 10(2), 103-11.

165. Rosenfeld SI, 2007. Patohology. En: Lens and cataract. Section 11. American Academy of Ophthalmology. Elsevier, Boston. Pp 45.

166. Ruiz Casas D, González López JJ, Muñoz Negrete FJ, Martín Justicia A, Cintrano M, Rebolleda G, 2011. OCT Stratus y OCT Cirrus. Protocolos de adquisición y análisis macular En: Muñoz Negrete FJ, Rebolleda G, Díaz Llopis M (Eds.), Tomografía de Coherencia óptica. LXXXVII Ponencia Oficial de la Sociedad Española de Oftalmología. Mac Line. Pp 63-71.

167. Rushood AA, Zahrani MH, Khamis A, Rushood AA, 2012. Central corneal thickness in full-term Saudi newborns. Acta Ophthalmol. 90(5), 355-8.

168. Sadler TW, Langman J, 2006. Langman's medical embriology. Lippincott Williamson \& Wilkins Inc, USA. Cap 19. Pp 337-46.

169. Sakata LM, Deleon-Ortega J, Sakata V, Girkin CA, 2009. Optical coherence tomography of the retina and optic nerve - a review. Clin Experiment Ophthalmol. 37(1), 90-9.

170. Savini G, Carbonelli M, Barboni P, Hoffer KJ, 2011. Repeatability of automatic measurements performed by a dual Scheimpflug analyzer in unoperated and post-refractive surgery eyes. J Cataract Refract Surg. 37(2), $302-9$.

171. Savini G, Carbonelli M, Sbreglia A, Barboni P, Deluigi G, Hoffer KJ, 2011. Comparison of anterior segment measurements by 3 Scheimpflug tomographers and 1 Placido corneal topographer. J Cataract Refract Surg. 37(9), 1679-85. 
172. Schultz RO, Glasser DB, Matsuda M, et al, 1986. Response of the corneal endothelium to cataract surgery. Arch Ophthalmol. 104, 1164-9.

173. Schwiegerling J, Greivenkamp JE, 1997. Using corneal height maps and polynomial decomposition to determine corneal aberrations. Optom Vis Sci. 74(11), 906-16.

174. Shepherd JR, 2003. The in situ (four quadrant) phaco-fracture technique. In: Burato L, Werner L, Zanini M, Apple D. Phacoemulsification: principles and techniques. 2nd ed. Thorofare: Slack. Pp 289-94.

175. Shiba T, Tsuneoka H, 2014. Prefilled syringes and usability of ophthalmic viscosurgical devices. Clin Ophthalmol. 8, 1697-702.

176. Simon JW, 2007. Growth and development of the eye. En: Paediatric Ophthalmology. Section 6. American Academy of Ophthalmology. Elsevier, Boston. P 199.

177. Singh M, See JLS, Aquino MC, Thean LSY, Chew PTK, 2009. Highdefinition imaging of trabeculectomy blebs using spectral domain optical coherence tomography adapted for the anterior segment. Clin Exp Ophthalmol. 37, 345-51.

178. Smolek MK, Klyce SD, Hovis JK, 2002. The universal standard scale. Proposed improvements to the American National Standards Institute (ANSI) for corneal topography. Ophthalmology. 105, 223-30.

179. Smolek MK, Klyce SD, 2003. Zernike polynomial fitting fails to represent all visually significant corneal aberrations. Invest Ophthalmol Vis Sci. 44(11), 4676-81. 
180. Spaide RF, Koizumi H, Pozzoni MC, 2008. Enhanced depth imaging spectral-domain optical coherence tomography. Am J Ophthalmol. 146(4), 496-500.

181. Sugar A, 2002. Ultrafast (femtosecond) laser refractive surgery. Curr Opin Ophthalmol. 13(4), 246-9.

182. Sutphin JE, 2007. Structure and function of the external eye and cornea. En: External disease and cornea. Section 8. American Academy of Ophthalmology. Elsevier, Boston. Pp 6-14.

183. Swartz T, Marten L, and Wang M, 2007. Measuring the cornea: the latest developments in corneal topography. Curr Opin Ophthalmol. 18(4), 325-33.

184. Tanabe T, Oshika T, Tomidokoro A, et al, 2002. Standarized color-coded scales for anterior and posterior elevation maps of scanning-slit corneal topography.Ophtalmology. 107, 1328-32.

185. Taylor HR, 2000. Cataract: how much surgery do we have to do? $\mathrm{Br} \mathrm{J}$ Ophthalmol. 84, 1-2.

186. Uva MG, Reibaldi M, Longo A, Avitabile T, Gagliano C, Scollo D, Lionetti E, Reibaldi A, 2011. Intraocular pressure and central corneal thickness in premature and full-term newborns. J AAPOS. 15(4), 367-9.

187. Waldstein SM, Faatz H, Szimacsek M, Glodan AM, Podkowinski D, Montuoro A et al, 2015. Comparison of penetration depth in choroidal imaging using swept source vs spectral domain optical coherence tomography. Eye (Lond). 29(3), 409-15.

188. Walkow T, Anders $\mathrm{N}$ y Klebe $\mathrm{S}, 2000$. Endothelial cell loss after phacoemulsification: relation to preoperative and intraoperative parameters. $\mathrm{J}$ Cataract Refract Surg. 26, 727-32. 
189. Wang J, Zhang EK, Fan WY, Ma JX, Zhao PF, 2009. The effect of microincision and small-incision coaxial phacoemulsification on corneal astigmatism. Clin Experiment Ophthalmol. 37, 664-9.

190. Wang L, Koch DD, 2003. Ocular higher-order aberrations in individuals screened for refractive surgery. J Cataract Refract Surg. 29(10), 1896-903.

191. Wang Y, Xia Y, Liu X et al, 2012. Comparison of bimanual and micro-coaxial phacoemulsification with torsional ultrasound. Acta Ophtahlmol. 90, 184-7.

192. Wilson SE, Klyce SD, Husseini ZM, 1993. Standarized color-coded maps for corneal topography.Ophthalmology. 100, 1723-7.

193. Wong IY, Koizumi H, Lai WW, 2011. Enhanced depth imaging optical coherence tomography. Ophthalmic Surg Lasers Imaging. 42 Suppl, 75-84.

194. Wong MY, 2003. Securing clear corneal incisions. The stromal hydration of a supraincisional pocket helps to prevent bacterial endophthalmitis. Cataract \& Refractive Surgery Today. Pp 5-27.

195. Yamaguchi T, Negishi K, Ono T, Torii H, Dogru M, Yamaguchi K, Ohnuma K, Tsubota K, 2009. Feasibility of spherical aberration correction with aspheric intraocular lenses in cataract surgery based on individual pupil diameter. $\mathrm{J}$ Cataract Refract Surg. 35(10), 1725-33.

196. Ye H, Zhang K, Yang J, Lu Y, 2014. Changes of corneal higher-order aberrations after cataract surgery. Optom Vis Sci. 91(10), 1244-50.

197. Zernike F, 1934. Beugungstheorie des Schneidenverfahrens und Seiner Verbesserten Form, der Phasenkontrastmethode. Physica. 1, 689-704. 
ANEXOS 



\section{ANEXOS}

10.1. INFORME DE APROBACIÓN DEL ESTUDIO POR PARTE DEL COMITÉ ÉTICO DE INVESTIGACIÓN CLÍNICA DEL HOSPITAL UNIVERSITARIO DEL RÍO HORTEGA DE VALLADOLID 


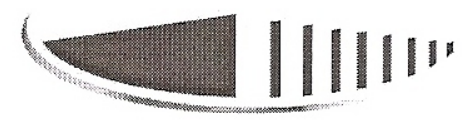

HOSPITAL UNIVERSITARIO

RÍO HORTEGA

\section{INFORME DEL COMITÉ ÉTICO DE INVESTIGACIÓN CLÍNICA}

D. FLORENTINO PINACHO PELAEZ, Secretario del Comité Ético de Investigación Clínica del Centro Hospitalario: Hospital Universitario del Río Hortega de Valladolid,

\section{CERTIFICA:}

Que este Comité ha evaluado, en su reunión del día 13 de Marzo de 2013, el Estudio titulado: "Estudio de la variación del grosor de la córnea por capas en la facoemulsificación de la catarata mediante tomografía de coherencia óptica de dominio espectral" $\mathrm{N}^{\circ}$ del Estudio: CT-EDEMA-01 y considera que:

Se cumplen los requisitos necesarios de idoneidad del protocolo en relación con los objetivos del estudio y están justificados los riesgos y molestias previsibles para el sujeto.

La capacidad del investigador y los medios disponibles son apropiados para llevar a cabo el estudio.

Y que este Comité acepta que dicho Estudio sea realizado en el Hospital Universitario del Río-Hortega de Valladolid por la Dra. M. Calabuig como Investigadora Principal.

Lo que firmo en Valladolid, a 14 de Marzo de 2013

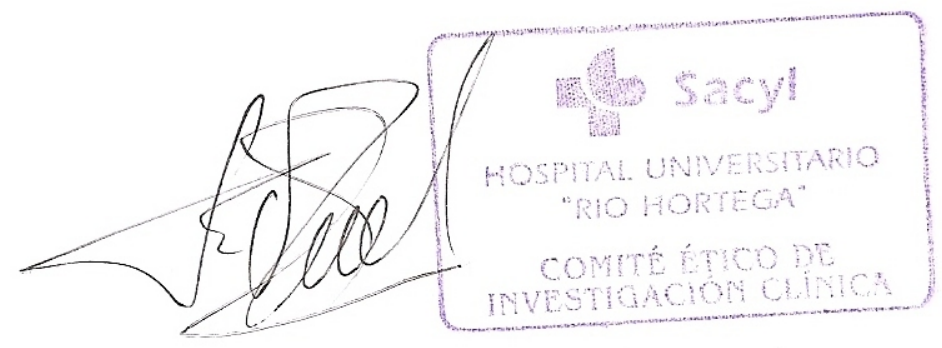

Fdo. D Florentino Pinacho Peláez Secretario CEIC 


\subsection{ARTÍCULOS CIENTÍFICOS}





\section{Current}

Eye Research

informa

healthcare

\section{Early Changes in Corneal Epithelial Thickness after Cataract Surgery}

\begin{tabular}{|r|l|}
\hline Journal: & Current Eye Research \\
\hline Manuscript ID: & Draft \\
\hline Danuscript Type: & Original Articles \\
\hline Complete List of Authors: & n/a \\
\hline & $\begin{array}{l}\text { Calabuig-Goena, María; Universidad de Valladolid, IOBA } \\
\text { López-Miguel, Alberto; Universidad de Valladolid, IOBA } \\
\text { Marqués-Fernández, Victoria; Hospital Rio Hortega, } \\
\text { Coco, Begoña; University of Valladolid, Institute of Applied } \\
\text { Ophthalmobiology IOBA } \\
\text { Iglesias-Cortiñas, Dario; Hospital Rio Hortega, } \\
\text { Maldonado, Miguel; Univesidad de Valladolid, IOBA }\end{array}$ \\
\hline Keywords: & $\begin{array}{l}\text { Epithelial thickness, Corneal edema, Phacoemulsification, Fourier-domain } \\
\text { optical coherence tomography, Senile cataract }\end{array}$ \\
\hline & \\
\hline
\end{tabular}

SCHOLARONE ${ }^{\text {m }}$

Manuscripts 


\section{Early Changes in Corneal Epithelial Thickness after Cataract Surgery}

María Calabuig-Goena, MD, ${ }^{1,2}$ Alberto López-Miguel, PhD, ${ }^{1}$

Victoria Marqués-Fernández, $M D,{ }^{2}$ María B. Coco-Martín, PhD, ${ }^{1}$

Darío Iglesias-Cortiñas, $M D, P h D,{ }^{2}$ Miguel J. Maldonado, $M D, P h D^{l}$

${ }^{1}$ IOBA, Universidad de Valladolid, Valladolid, Spain.

${ }^{2}$ Hospital Universitario Rio Hortega, Valladolid, Spain.

Corresponding author: Miguel J. Maldonado, MD, PhD, IOBA, Paseo Belén, 17, 47011

Valladolid, Spain. Phone: 983184750; E-mail: maldonado@ioba.med.uva.es.

35

36

37

38

39

40

41

42

43

44

45

46

47

48

49

50

51

52

53

54

55

56

57

58

59

60 
Calabuig-Goena et al.--2

\begin{abstract}
Purpose: To assess early variations in central and paracentral corneal epithelial and nonepithelial thicknesses after uneventful clear corneal incision phacoemulsification.

Materials and Methods: Twenty patients with a senile cataract underwent coaxial phacoemulsification through a $2.75-\mathrm{mm}$-wide corneal incision created at $180^{\circ}$ in a prospective cohort pilot study. Corneal sublayer thickness measurements were obtained with Fourier-domain optical coherence tomography (FD-OCT) before and 1 week and 1 month postoperatively. Central measurements were performed in the middle of the FDOCT scan and in the 3-mm corneal diameter (paracentral $180^{\circ}$ and $0^{\circ}$ locations). Epithelial, non-epithelial and total corneal pachymetry were measured at the central and paracentral locations.
\end{abstract}

Results: No significant changes in epithelial thickness were seen one week postoperatively. However, one month postoperatively, the central, $180^{\circ}$, and $0^{\circ}$ paracentral epithelial thicknesses $(52.7 \pm 3.8,53.1 \pm 5.4$, and $52.7 \pm 5.3 \mu \mathrm{m}$, respectively) decreased significantly $(\mathrm{P}<0.01)$ compared to preoperatively $(57.2 \pm 4.8,58.0 \pm 5.7,56.6 \pm 5.3 \mu \mathrm{m}$, respectively). The 1 -week central, $180^{\circ}$, and $0^{\circ}$ paracentral non-epithelial corneal thicknesses $(515.5 \pm 39.6,534.3 \pm 45.6$, and $521.3 \pm 36.9 \mu \mathrm{m})$ were significantly $(\mathrm{P}<0.01)$ higher than preoperatively $(486.2 \pm 34.7,498.2 \pm 33.8,497.5 \pm 32.3 \mu \mathrm{m}$, respectively). The non-epithelial corneal thickness increase was significantly $(\mathrm{P}=0.02)$ greater after 1 week in the central $(29.3 \pm 17.2 \mu \mathrm{m})$ and the $180^{\circ}$ paracentral $(36.1 \pm 28.7 \mu \mathrm{m})$ locations than at the $0^{\circ}$ paracentral location $(23.8 \pm 16.5 \mu \mathrm{m})$.

Conclusions: Immediate postoperative corneal edema following phacoemulsification irregularly affects the cornea at the sublayer level. The initial central and paracentral nonepithelial thickening is compensated by subsequent central and paracentral epithelial 


\section{Calabuig-Goena et al.--3}

1

2

3

4

5

6

7

8

9

10

11

12

13

14

15

16

17

18

19

20

21

22

23

24

25

26

27

28

29

30

31

32

33

34

35

36

37

38

39

40

41

42

43

44

45

46

47

48

49

50

51

52

53

54

55

56

57

58

59

60

thinning. These initial changes occurred more markedly closest to the main incision over the entrance pupil, which may have visual implications.

\section{KEYWORDS}

Epithelial thickness; phacoemulsification; Fourier-domain optical coherence tomography; corneal edema; senile cataract.

URL: http://mc.manuscriptcentral.com/ncer E-mail: g.geerling@med.uni-duesseldorf.de or r-linsenmeier@northwestern.edu 
Phacoemulsification is currently the cataract surgery that is performed most often. ${ }^{1}$ This small-incision technique is under constant refinement to reduce sight-threatening adverse events $^{2}$ and to achieve better functional postoperative outcomes as a result of improvements in multifocal, aspheric, and toric optical designs in foldable intraocular lenses (IOLs). ${ }^{3}$ Although visual rehabilitation is considered generally rapid, factors such as transient postoperative corneal edema affect the initial postoperative course. ${ }^{4-7}$ Corneal edema has been correlated positively with intraoperative endothelial loss, ${ }^{4}$ which occurs because of the toxicity of intracameral solutions and ultrasonic (phacoemulsification time), and/or direct mechanical (phacoemulsification probe) trauma. ${ }^{5}$ The endothelial cellular loss alters the pumping activity of this corneal layer resulting in increased stromal hydration that reduces the immediate postoperative corneal transparency; this temporal postoperative corneal change usually resolves in a few weeks in most cases. ${ }^{4,7}$ Corneal edema only rarely becomes a persistent major postoperative complication. ${ }^{8}$

Corneal edema after cataract surgery has been estimated using ultrasound, ${ }^{6}$ scanning-slit topography, ${ }^{9}$ specular microscopy, ${ }^{4}$ Scheimpflug photography ${ }^{10}$ and optical coherence tomography $(\mathrm{OCT})^{10}$ techniques that assess the changes in the full corneal thickness. Fourier-domain (FD)-OCT technology allows rapid and precise corneal evaluation $^{11}$ and can provide full-thickness pachymetry measurements and reliable epithelial measurements. ${ }^{12}$ Several authors ${ }^{13,14}$ have already reported the corneal changes that occur postoperatively in relation to the corneal incision (Descemet's membrane detachment, posterior wound gape, posterior wound retraction and corneal edema); however, no studies have reported thickness variations in the central epithelium after phacoemulsification or thickness evolution during the first postoperative weeks. The aim of the current pilot study was to assess variations in the central and paracentral 
epithelium thicknesses and the non-epithelial corneal thickness after conventional clear corneal incision coaxial phacoemulsification for senile cataracts.

\section{Materials and Methods}

All procedures were performed in accordance with the Declaration of Helsinki. All subjects received detailed information about the nature of the investigation and provided written informed consent. The institutional Ethics Committee prospectively approved this study. The authors certify that all applicable institutional and governmental regulations concerning the ethical use of human volunteers were followed during this research.

Patients were included who underwent uneventful standard coaxial phacoemulsification to treat senile cataracts. Patients were eligible for cataract extraction if they have a grade $\geq 2$ using the Lens Opacities Classification System III classification assessing nuclear, cortical, and posterior subcapsular opacities. Patients were excluded who had a history of ocular surgery, contact lens wear, suspected clinical and subclinical keratectasia, an active anterior and/or posterior segment anomaly other than cataract, an endothelial cellular count below 2,000 cells $/ \mathrm{mm},{ }^{4}$ IOL sulcus implantation, suturing of the main incision, intraoperative complications, postoperative treatment with hypotensive or anti-edema drugs, and a cognitive disability that prevents an understanding of the nature of the study and providing informed consent. All subjects had a complete preoperative ophthalmic examination that included measurement of the manifest refraction, slit-lamp biomicroscopy, applanation tonometry, and indirect ophthalmoscopy.

Surgical Technique 
One surgeon $(\mathrm{MCG})$ performed all cataract surgeries using topical $(0.1 \%$ tetracaine and 0.4\% oxybuprocaine, Alcon, Barcelona, Spain) and intracameral anesthesia (unpreserved $2 \%$ lidocaine diluted to $1 \%$, B. Braun, Barcelona, Spain). One side-port incision was created initially with a 15 -degree steel blade. An ophthalmic viscosurgical device $(1.0 \%$ sodium hyaluronate, Biolon, Bio-Technology General Ltd., Kiryat Malachi, Israel) then was injected into the anterior chamber before the main incision was created. A clear corneal uniplanar incision was performed at $180^{\circ}$ (temporal in right eyes and nasal in left eyes) with a $2.75-\mathrm{mm}$ steel blade. Phacoemulsification was performed using Ozil (Alcon, Fort Worth, TX) torsional technology on an Infiniti phacoemulsification platform (Alcon). An IOL (SN60WF, Alcon) was implanted in the bag using the AcrySert C preloaded injector (Alcon). After the ophthalmic viscosurgical device was washed out using an irrigation and aspiration system, the lateral walls and roof of the main incision were hydrated using balanced salt solution until the stroma visibly whitened. The main sutureless incision was checked for leakage using a cellulose sponge test. Patients were prescribed

TobraDex ophthalmic suspension (tobramycin $0.3 \%$, dexamethasone $0.1 \%$; Alcon Laboratories Inc, Fort Worth, Tex) four times a day for the first week, tapering the dose for a further 3 weeks.

\section{Patient Examination}

All patients were examined using Cirrus HD-OCT (Carl Zeiss Meditec, Inc., Dublin, CA) using the five-line raster scan protocol that produces five high-resolution (4,096 Ascans) horizontal scan lines $3 \mathrm{~mm}$ long. ${ }^{15} \mathrm{We}$ always tried to center the image capture on the corneal vertex; however, if the scan was tilted or decentered and/or image quality was poor, a second acquisition was performed. Only images with signal strength equal to or higher than seven were evaluated. ${ }^{11}$ Corneal thickness measurements were 
obtained manually after acquisition using a caliper tool included in the software. ${ }^{11}$ The epithelial thickness was determined as previously described. ${ }^{16}$ We measured corneal thickness, excluding the epithelium (referred to as the "non-epithelial thickness," i.e., the distance between the epithelium-Bowman's and endothelium-aqueous humor interfaces) and including Bowman's membrane, stroma, Descemet's membrane, and endothelium as Prakash et al. ${ }^{12}$ previously described. The total pachymetry also was calculated after adding the epithelial and non-epithelial thicknesses.

Corneal thickness measurements were obtained at three locations for each scan, one at the corneal apex and the other two at both edges of the scan, which represent the 3-mm corneal diameter at the $180^{\circ}$ and $0^{\circ}$ hemi-meridians. We analyzed the corneal center and the paracentral locations along the horizontal meridian to determine whether the postoperative corneal edema was greater in regions closer to the main incision. To monitor the corneal thickness, scans were acquired before operation, 1 week, and 1 month postoperatively. Corneal thickness measurements were obtained between 11:00 and 13:00 hours to avoid diurnal variations. ${ }^{17}$

\section{Statistical Analyses}

Data from the prospectively completed forms were entered into a database, and statistical calculations were performed (SPSS, version 19.0 for Windows, SPSS, Chicago, IL). The mean and standard deviation (SD) were calculated for all data; when data did not correspond to a normal distribution, the median and interquartile range (values between the $25^{\text {th }}$ and $75^{\text {th }}$ percentiles of the distribution) also were calculated. The thickness variations were tested for significance using analysis of variance and the Bonferroni post-hoc tests for normally distributed data, and using the Friedman and the Wilcoxon signed-rank tests for non-normally distributed data. For all statistical tests, a two-tailed $P<0.05$ was considered significant. 
Calabuig-Goena et al.--8

\section{Results}

Twenty eyes ( 9 right, 11 left) of 20 patients ( 9 women, 11 men) were studied. The mean patient age was $72.2 \pm 8.8$ years (range, 55-86). The mean IOL power was $21.0 \pm 2.81$ diopters (range, 13-25). The mean corrected distance visual acuity (CDVA) values before operation, 1 week, and 1 month postoperatively were $0.42 \pm 0.21,0.11 \pm 0.13$ $(P \leq 0.001)$, and $0.05 \pm 0.07$ logarithm of the minimum angle of resolution (LogMAR) $(P \leq 0.001)$, respectively; the 1 -month CDVA also was significantly $(P=0.01)$ higher than that at 1 week.

The corneal epithelial and non-epithelial thickness measurements obtained before, 1 week, and 1 month postoperatively are shown in Table 1 . Because the epithelial thickness data were not normally distributed, the median values and interquartile ranges are provided. The epithelial thickness values varied significantly $(P<0.01) 1$ month postoperatively compared with preoperatively at any location measured, but no significant changes were observed for the 1-week epithelial thickness values.

We found significant differences between the non-epithelial thickness measurements obtained preoperatively and 1 week postoperatively for the three locations measured; however, after 1 month, the increases were not significant (Table 1). In addition, the non-epithelial thickness increases were significantly $(P=0.02)$ higher at the 1 -week time point in the central and the $180^{\circ}$ paracentral locations compared with the $0^{\circ}$ paracentral location (Table 1 ).

The total pachymetry increased significantly 1 week postoperatively in the central and paracentral locations; however, we did not find significant differences among the increases obtained for each location (central, $180^{\circ}$, and $0^{\circ}$ paracentral) as we did for the non-epithelial thickness (Table 1). The total pachymetry measurements observed 1 
month after phacoemulsification were not significantly higher than the preoperative values (Figure 1).

\section{Discussion}

Phacoemulsification is the most frequently performed cataract surgery. ${ }^{1}$ It is usually a rapid and straightforward procedure; however, some degree of postoperative corneal edema occurs routinely and has been studied extensively. ${ }^{4,6,9,10}$ To increase the knowledge about the postoperative corneal behavior, some studies also have evaluated the wound architecture of the clear corneal incision; thus, postoperative epithelial and endothelial gaping, endothelial misalignment, Descemet's detachment, loss of coaptation along the tunnel, and corneal edema have been described. ${ }^{10,13,14}$ Nonetheless, the central and paracentral postoperative corneal epithelial thickness variations have not been analyzed previously. The current study addressed this issue for the first time. We used the OCT technique because for longer than a decade it has facilitated obtaining detailed corneal measurements in a clinical setting, ${ }^{18}$ and now new FD-OCT technology provides reliable epithelial measurements. ${ }^{11,12}$

The current study showed that the epithelial corneal thickness varied significantly 1 month after phacoemulsification; however, the 1-week thickness values were similar to those obtained preoperatively (Table 1); while the non-epithelial thickness increased after cataract surgery, recovering to values similar to the preoperative values after 1 month (Table 1). It has been widely reported that the epithelium becomes thinner or thicker to compensate for changes in stromal thickness, as reported after myopic ${ }^{19}$ or hyperopic ${ }^{20}$ corneal laser refractive surgery. Lenticular epithelial changes occur when myopic laser in situ keratomileusis (LASIK) is performed so that the central epithelium thickens. ${ }^{19}$ In contrast, when a hyperopic ablation is performed in the cornea, epithelial 
thickening is observed in the periphery and the central cornea becomes thinner. ${ }^{20}$ Therefore, an epithelial thickness change seems to compensate for the stromal tissue removed during an excimer laser procedure. This compensatory phenomenon also may have occurred during our cataract surgeries, because we observed a significant decrease of about $8 \%$ in the epithelial thickness 1 month after phacoemulsification that might have been triggered by the stromal edema that peaked earlier, as shown by our 1-week postoperative data (Table 1). In addition, the epithelial thickness values after 1 week were similar to preoperatively, which may indicate that in uneventful standard phacoemulsification the central corneal epithelium is not considerably edematous and does not contribute significantly to the total corneal thickening.

In the current patients, the 1-week non-epithelial thickness values increased markedly after uneventful phacoemulsification. It is well known that the corneal endothelium regulates stromal hydration by the endothelial mechanical barrier and active pump function. ${ }^{21}$ If the endothelium is damaged during cataract surgery, there will be increased permeability causing aqueous humor entrance resulting in corneal edema, unless the endothelial pumping activity can compensate rapidly for it. However, 1 month after phacoemulsification, the coefficient of variation in cellular size, endothelial permeability, and pump activity recover, which results in a functional endothelial monolayer that can recuperate to the preoperative pachymetry values. ${ }^{6}$ As a result, our 1-month non-epithelial thickness values at any location measured were clinically similar to those obtained preoperatively (Table 1). The progressive recovery of the endothelium after uneventful cataract surgery might play an important role in avoiding chronic stromal edema, which would lead to epithelial edema as in other anomalies (i.e., bullous keratopathy); however, the imbibition pressure of the stroma after uneventful phacoemulsification might not be high for sufficiently long to produce 
short-term epithelial edema, ${ }^{22}$ which corresponds to the current data that did not show significant increases in the epithelial thickness.

We evaluated the epithelial and non-epithelial paracentral thicknesses along the horizontal meridian, because Lundberg et al. ${ }^{4}$ found that during the early postoperative period the edema was significantly higher in the central cornea than nasally due to a higher endothelial cellular loss when performing temporal corneoscleral incisions. Similarly, Bolz et al. $^{23}$ reported greater thickening after cataract surgery in the horizontal meridian closer to the temporal incision; however, these differences in corneal thickening did not reach significance. In the current patients, we found significantly higher increases in the non-epithelial thickness in the center and the hemimeridian closer to the main incision than in the opposite horizontal hemi-meridian. The corneal thickness usually increases greatly at wound level after cataract surgery, because endothelial cellular damage close to the incision can be caused by direct injury (trauma or ultrasound energy); thus, the corneal thickening is notably greater next to the incision compared with centrally. ${ }^{24} \mathrm{We}$ also showed that the non-epithelial increase is also higher in the paracentral areas over the pupil entrance closer to the incision, although postoperative thickening resolved similarly in both paracentral locations 1 month postoperatively. Nonetheless, we performed the torsional phacoemulsification technique, which might use lower level of phacoemulsification time and energy, resulting in lower endothelial cellular loss and central pachymetry thickening. ${ }^{25}$ Hence, the longitudinal phacoemulsification technique could have enhanced the differences in the thickness increases among the three locations gauged that we found in the nonepithelial measurements 1 week postoperatively.

Total pachymetry thickening 1 week postoperatively was reversed during the onemonth visit (Table 1), which agrees with previous results that the corneal edema usually 
Calabuig-Goena et al.--12

resolved 1 month postoperatively. ${ }^{4,9,10,25}$ Bolz et al. ${ }^{23}$ reported no differences in central corneal thickness during the 1-week postoperative visit compared with the preoperative values. In contrast to Lundberg et al. ${ }^{4}$ we did not find significant variations in total corneal thickening along the horizontal meridian as we did for the epithelial and nonepithelial thicknesses when we analyzed the corneal behavior after phacoemulsification.

The variations in epithelial and non-epithelial thicknesses after cataract surgery should be of paramount importance when analyzing the resulting short-term postoperative refractive errors, because, first, the epithelium has a different refractive index compared with the anterior and posterior stroma (1.401, 1.380, 1.373, respectively), ${ }^{26}$ and, second, depending on the amount and location of the corneal swelling, the total corneal refractive power should vary. The average refractive index of the corneal stroma decreases with tissue swelling. ${ }^{27}$ Because the anterior stroma tends to be less hydrated and more resistant to water flow than the posterior stroma, ${ }^{28}$ the changes in corneal power should primarily result from changes in the refractive index of the posterior lamellae, ${ }^{27}$ which might prevent more rapid refractive stabilization postoperatively. Moreover, postoperative corneal edema could not only cause lower order aberrations (conventional optical refraction) but also higher order aberrations as Elkady et al. $^{29}$ reported. They found significantly higher aberrations and thicker peripheral edema 1 month postoperatively in patients who underwent standard phacoemulsification compared with those who underwent microincisional cataract surgery.

The current study had several limitations. First, the study size was relatively small. However, despite the sample size, this pilot study showed that the epithelial thickness can significantly decrease 1 month postoperatively in the central and paracentral areas to compensate for the stromal edema occurring immediately after 
uneventful phacoemulsification. Second, we did not record phacoemulsification times intraoperatively or endothelial cellular loss postoperatively; however, our goal was not to determine the correlation between both variables and corneal thickness variations because these associations have been reported. ${ }^{4,5}$ Our goal was to perform for the first time a pilot study to determine how corneal edema after phacoemulsification affects epithelial and non-epithelial corneal thickening separately. In addition, the follow-up time was short. However, because corneal thickness changes are maximal during the 4week period, ${ }^{23}$ we hypothesized that if any differential behavior of the corneal epithelium had to occur, it should happen during the early postoperative period. Third, the pachymetry technique that we used (FD-OCT) has a repeatability within-subject standard deviation $\left(\mathrm{S}_{\mathrm{w}}\right)$ of $2.29 \mu \mathrm{m},{ }^{12}$ while other anterior segment biometry techniques such as very high-frequency digital ultrasound technology (Artemis, ArcScan, Morrison, CO, USA) provide better repeatable $\mathrm{S}_{\mathrm{w}}(0.58 \mu \mathrm{m}),{ }^{30}$ which could have resulted in more precise epithelial thickness changes. Finally, we did not assess specifically the potential role of dry eye as a cofounding variable; it has been recently reported that dry eye patients might have a thicker epithelium (around $6 \mu \mathrm{m}$ ) than controls, ${ }^{31}$ and it is also known that there is a transient increase (peaking at one month) in dry eye signs and symptoms after cataract surgery. ${ }^{32}$ However, because dry eye tends to increase epithelial thickness and we detected the opposite, it is highly unlikely that the epithelial thinning we detected one month postoperatively is the result of dry eye syndrome.

In conclusion, the central and 3-mm paracentral corneal epithelium does not vary significantly soon after uneventful phacoemulsification; therefore, it does not seem to contribute considerably to the approximate $5 \%$ total corneal thickness increase occurring 1 week postoperatively. However, the epithelial thickness appears to decrease 
by about $8 \% 1$ month postoperatively to compensate for the transient stromal edema that thickens the non-epithelial cornea by about $6 \% 1$ week postoperatively. This increase in non-epithelial thickness 1 week postoperatively is not uniform along the horizontal meridian over the pupil entrance, because paracentral locations closer to the main incision tend to thicken more than those located farther away. Corneal measurement techniques with even higher imaging capabilities such as very highfrequency digital ultrasound should expand the findings of this pilot study, despite FDOCT is be able to detect regional differences in epithelial thickness in healthy and diseased corneas. ${ }^{33}$ Because the refraction index of the corneal epithelium and stroma differ, ${ }^{26}$ future studies also should determine the effect of these corneal sublayer and regional differences occurring early after standard phacoemulsification on lower and higher order aberrations, postoperative refractive shifts, and visual rehabilitation of patients undergoing routine cataract surgery. The current pilot study was the first to indicate the hypothesis that the corneal epithelium behaves differently than the remaining cornea during the postoperative period of standard phacoemulsification and provided data to appropriately design future studies. Finally, the tendency for the corneal epithelium to remain thinner than preoperatively or regain its usual thickness in the long term should be investigated and considered if a transepithelial approach is desired in surface ablation procedures after phacoemulsification. ${ }^{34}$ 


\section{FUNDING}

Supported in part by the Spanish Ministry of Economy and Competivity through Research Projects RETICS RD12/0034/0001 (Oftalmología) and SAF2012-40227-C0201.

\section{DECLARATION OF INTEREST}

The authors report no conflicts of interest. The authors alone are responsible for the content and writing of the paper. 


\section{REFERENCES} 1. Jaycock P, Johnston RL, Taylor H, Adams M, Tole DM, Galloway P, et al. The Cataract National Dataset electronic multi-centre audit of 55,567 operations: updating benchmark standards of care in the United Kingdom and internationally. Eye. 2009;23:38-49.

2. Stein JD, Grossman DS, Mundy KM, Sugar A, Sloan FA. Severe adverse events after cataract surgery among Medicare beneficiaries. Ophthalmology. 2011;118:1716-1723.

3. Javitt JC, Steinert RF. Cataract extraction with multifocal intraocular lens implantation: a multinational clinical trial evaluating clinical, functional, and quality-of-life outcomes. Ophthalmology. 2000;107:2040-2048.

4. Lundberg B, Jonsson M, Behndig A. Postoperative corneal swelling correlates strongly to corneal endothelial cell loss after phacoemulsification cataract surgery. Am J Ophthalmol. 2005;139:1035-1341.

5. Walkow T, Anders N, Klebe S. Endothelial cell loss after phacoemulsification: relation to preoperative and intraoperative parameters. J Cataract Refract Surg. 2000;26:727-732.

6. Ravalico G, Tognetto D, Palomba MA, Lovisato A, Baccara F. Corneal endothelial function after extracapsular cataract extraction and phacoemulsification. J Cataract Refract Surg. 1997;23:1000-1005.

7. Schultz RO, Glasser DB, Matsuda M, Yee RW, Edelhauser HF. Response of the corneal endothelium to cataract surgery. Arch Ophthalmol. 1986;104:11641169.

8. Polack FM, Sugar A. The phacoemulsification procedure. III. Corneal complications. Invest Ophthalmol Vis Sci. 1977;16:39-46. 
9. Morikubo S, Takamura Y, Kubo E, Tsuzuki S, Akagi Y. Corneal changes after small-incision cataract surgery in patients with diabetes mellitus. Arch Ophthalmol. 2004;122:966-969.

10. Li YJ, Kim HJ, Joo CK. Early changes in corneal edema following torsional phacoemulsification using anterior segment optical coherence tomography and Scheimpflug photography. Jpn J Ophthalmol. 2011;55:196-204.

11. Correa-Pérez ME, López-Miguel A, Miranda-Anta S, Iglesias-Cortiñas D, Alió JL, Maldonado MJ. Precision of high definition spectral-domain optical coherence tomography for measuring central corneal thickness. Invest Ophthalmol Vis Sci 2012;53:1752-1757.

12. Prakash G, Agarwal A, Mazhari AI, Chari M, Kumar DA, Kumar G, et al. Reliability and reproducibility of assessment of corneal epithelial thickness by Fourier domain optical coherence tomography. Invest Ophthalmol Vis Sci. 2012;53:2580-2585.

13. Wang L, Dixit L, Weikert MP, Jenkins RB, Koch DD. Healing changes in clear corneal cataract incisions evaluated using Fourier-domain optical coherence tomography. J Cataract Refract Surg. 2012;38:660-665.

14. Cavallini GM, Campi L, Torlai G, Forlini M, Fornasari E. Clear corneal incisions in bimanual microincision cataract surgery: long-term wound-healing architecture. J Cataract Refract Surg. 2012;38:1743-1748.

15. Zhang X, Li Q, Liu B, Zhou H, Wang H, Zhang Z, Xiang M, et al. In vivo crosssectional observation and thickness measurement of bulbar conjunctiva using optical coherence tomography. Invest Ophthalmol Vis Sci. 2011;52:7787-7791. 
16. Li Y, Tan O, Brass R, Weiss JL, Huang D. Corneal epithelial thickness mapping by Fourier-domain optical coherence tomography in normal and keratoconic eyes. Ophthalmology. 2012;119:2425-2433.

17. Feng Y, Varikooty J, Simpson T. Diurnal variation of corneal and corneal epithelial thickness measured using optical coherence tomography. Cornea. $2001 ; 20: 480-483$.

18. Maldonado MJ, Ruiz-Oblitas L, Munuera JM, Aliseda D, García-Layana A, Moreno-Montañés J. Optical coherence tomography evaluation of the corneal cap and stromal bed features after laser in situ keratomileusis for high myopia and astigmatism. Ophthalmology. 2000;107:81-87.

19. Reinstein DZ, Archer TJ, Gobbe M. Change in epithelial thickness profile 24 hours and longitudinally for 1 year after myopic LASIK: three-dimensional display with Artemis very high-frequency digital ultrasound. J Refract Surg. 2012;28:195-201.

20. Reinstein DZ, Archer TJ, Gobbe M, Silverman RH, Coleman DJ. Epithelial thickness after hyperopic LASIK: three-dimensional display with Artemis very high-frequency digital ultrasound. J Refract Surg. 2010;26:555-564.

21. Klyce SO, Beuerman RW. Structure and function of the cornea. In: Kaufman HE, McDonald MB, Barron BA, Waltman SR, eds, The Cornea. New York, Churchill Livingstone, 1988;3-54.

22. Dohlman $\mathrm{CH}$. The function of the corneal epithelium in health and disease. The Jonas S. Friedenwald Memorial Lecture. Invest Ophthalmol. 1971;10:383-407.

23. Bolz M, Sacu S, Drexler W, Findl O. Local corneal thickness changes after small-incision cataract surgery. J Cataract Refract Surg. 2006;32:1667-1671. 
24. Wang Y, Xia Y, Liu X, Zheng D, Luo L, Liu Y. Comparison of bimanual and micro-coaxial phacoemulsification with torsional ultrasound. Acta Ophthalmol. 2012;90:184-187.

25. Liu Y, Zeng M, Liu X, Luo L, Yuan Z, Xia Y, et al. Torsional mode versus conventional ultrasound mode phacoemulsification: randomized comparative clinical study. J Cataract Refract Surg. 2007;33:287-292.

26. Patel S, Marshall J, Fitzke FW $3^{\text {rd }}$. Refractive index of the human corneal epithelium and stroma. J Refract Surg. 1995;11:100-105.

27. Meek KM, Dennis S, Khan S. Changes in the refractive index of the stroma and its extrafibrillar matrix when the cornea swells. Biophys J. 2003;85:2205-2212.

28. Patel S, Alió JL, Pérez-Santonja JJ. Refractive index change in bovine and human corneal stroma before and after LASIK: a study of untreated and retreated corneas implicating stromal hydration. Invest Ophthalmol Vis Sci. 2004; $45: 3523-3530$.

29. Elkady B, Piñero D, Alió JL. Corneal incision quality: microincision cataract surgery versus microcoaxial phacoemulsification. J Cataract Refract Surg. 2009;35:466-474.

30. Reinstein DZ, Archer TJ, Gobbe M, Silverman RH, Coleman DJ. Repeatability of layered corneal pachymetry with the Artemis very high-frequency digital ultrasound arc-scanner. J Refract Surg. 2010;26:646-659.

31. Kanellopoulos AJ, Asimellis G. In vivo 3-dimensional corneal epithelial thickness mapping as an indicator of dry eye: preliminary clinical assessment. Am J Ophthalmol. 2014;157:63-68.

32. Li XM, Hu L, Hu J, Lanier JD. Investigation of dry eye disease and analysis of the phatogenic factors in patients after cataract surgery. Cornea. 2007;26:16-20. 
33. Rocha KM, Perez-Straziota E, Stulting RD, Randleman JB. SD-OCT analysis of regional epithelial thickness profiles in keratoconus, postoperative corneal ectasia, and normal eyes. J Refract Surg. 2013;29:173-179.

34. Arba Mosquera S, Awwad ST. Theoretical analyses of the refractive implications of transepithelial PRK ablations. Br J Ophthalmol. 2013;97:905911. 


\section{FIGURE LEGENDS}

Fig. 1. Epithelial and non-epithelial thickness measurements in the central and paracentral locations preoperatively and 1 week and 1 month postoperatively. * Statistically significant changes from the preoperative values. 

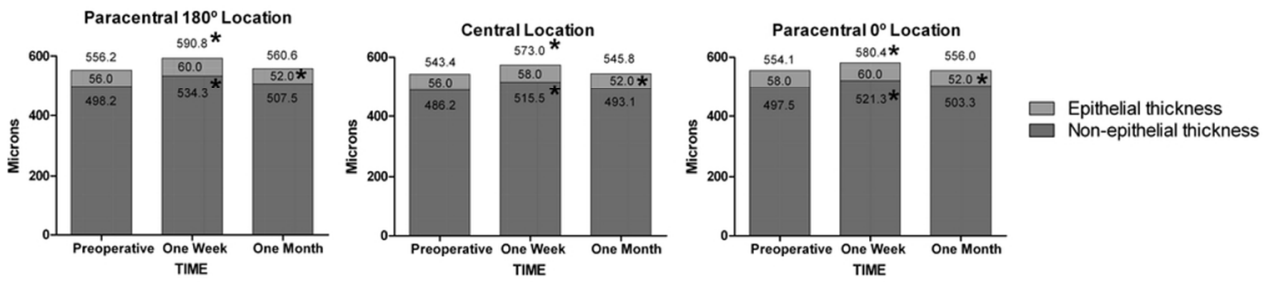

Figure 1. Epithelial and non-epithelial thickness measurements in the central and paracentral locations preoperatively and 1 week and 1 month postoperatively. *Statistically significant changes from the preoperative values. $44 \times 11 \mathrm{~mm}(600 \times 600 \mathrm{DPI})$ 
Table 1. Central and Paracentral Corneal Thickness Measurements Preoperatively and 1 Week and 1 Month after Cataract Surgery.

\begin{tabular}{|c|c|c|c|c|c|}
\hline & \multicolumn{5}{|c|}{ Acquisition Time } \\
\hline Location & Preoperatively & & Week & $1 \mathrm{~N}$ & \\
\hline $\begin{array}{l}\text { Epithelial } \\
\text { thickness }\end{array}$ & $\begin{array}{l}\text { Mean } \pm \text { SD } \\
\text { Median }(I Q R) \\
(\text { Range })(\mu \mathrm{m})\end{array}$ & $\begin{array}{l}\text { Mean } \pm \text { SD } \\
\text { Median }(I Q R) \\
(\text { Range })(\mu \mathrm{m})\end{array}$ & $\begin{array}{l}\text { Change from } \\
\text { Baseline } \\
\text { Mean } \pm \text { SD } \\
\text { Median (IQR) } \\
(\mu \mathrm{m})\end{array}$ & $\begin{array}{l}\text { Mean } \pm \text { SD } \\
\text { Median }(I Q R) \\
(\text { Range })(\mu \mathrm{m})\end{array}$ & $\begin{array}{l}\text { Change from } \\
\text { Baseline } \\
\text { Mean } \pm \text { SD } \\
\text { Median (IQR) } \\
(\mu \mathrm{m})\end{array}$ \\
\hline Central & $\begin{array}{l}57.2 \pm 4.8 \\
56.0(52.0 / 56.0) \\
(48 / 64)\end{array}$ & $\begin{array}{l}57.6 \pm 4.7 \\
58.0(53.0 / 58.0) \\
(48 / 64)\end{array}$ & $\begin{array}{l}0.4 \pm 7.4 \\
0.0(-4.0 / 0.0)\end{array}$ & $\begin{array}{l}\mathbf{5 2 . 7} \pm \mathbf{3 . 8} \dagger \\
52.0(48.0 / 52.0) \\
(48 / 60)\end{array}$ & $\begin{array}{l}-4.5 \pm 5.5 \\
-4.0(-8.0 /-4.0)\end{array}$ \\
\hline $\begin{array}{l}\text { Paracentral } \\
\left(180^{\circ}\right)\end{array}$ & $\begin{array}{l}58.0 \pm 5.7 \\
56.0(48.0 / 72.0) \\
(48 / 72)\end{array}$ & $\begin{array}{l}59.2 \pm 6.8 \\
60.0(56.0 / 60.0) \\
(44 / 72)\end{array}$ & $\begin{array}{l}1.2 \pm 9.3 \\
0.0(-4.0 / 0.0)\end{array}$ & $\begin{array}{l}\mathbf{5 3 . 1} \pm \mathbf{5 . 4} \dagger \\
52.0(48.0 / 52.0) \\
(44 / 64)\end{array}$ & $\begin{array}{l}-4.9 \pm 6.4 \\
-4.0(-9.0 /-4.0)\end{array}$ \\
\hline Paracentral $\left(0^{\circ}\right)$ & $\begin{array}{l}56.6 \pm 5.3 \\
58.0(52.0 / 58.0) \\
(48 / 68)\end{array}$ & $\begin{array}{l}59.2 \pm 6.3 \\
60.0(56.0 / 60.0) \\
(48 / 68)\end{array}$ & $\begin{array}{l}2.6 \pm 7.4 \\
4.0(0.0 / 4.0)\end{array}$ & $\begin{array}{l}\mathbf{5 2 . 7} \pm \mathbf{5 . 3} \dagger \\
52.0(48.0 / 52.0) \\
(44 / 68)\end{array}$ & $\begin{array}{l}-3.9 \pm 5.5 \\
-4.0(-8.0 /-4.0)\end{array}$ \\
\hline $\begin{array}{l}\text { Non-epithelial } \\
\text { thickness }\end{array}$ & $\begin{array}{l}\text { Mean } \pm \text { SD } \\
\text { (Range) }(\mu \mathrm{m})\end{array}$ & $\begin{array}{l}\text { Mean } \pm \text { SD } \\
(\text { Range })(\mu \mathrm{m})\end{array}$ & $\begin{array}{l}\text { Change from } \\
\text { Baseline }(\mu \mathrm{m})\end{array}$ & $\begin{array}{l}\text { Mean } \pm \text { SD } \\
\text { (Range) }(\mu \mathrm{m})\end{array}$ & $\begin{array}{l}\text { Change from } \\
\text { Baseline }(\mu \mathrm{m})\end{array}$ \\
\hline Central & $\begin{array}{l}486.2 \pm 34.7 \\
(424 / 548)\end{array}$ & $\begin{array}{l}\mathbf{5 1 5 . 5} \pm \mathbf{3 9 . 6} \\
(435 / 584)\end{array}$ & $29.3 \pm 17.2 ¥$ & $\begin{array}{l}493.1 \pm 37.3 \\
(428 / 576)\end{array}$ & $6.9 \pm 12.2$ \\
\hline $\begin{array}{l}\text { Paracentral } \\
\left(180^{\circ}\right)\end{array}$ & $\begin{array}{l}498.2 \pm 33.8 \\
(416 / 548)\end{array}$ & $\begin{array}{l}\mathbf{5 3 4 . 3} \pm \mathbf{4 5 . 6} \\
(452 / 618)\end{array}$ & $36.1 \pm 28.79$ & $\begin{array}{l}507.5 \pm 36.8 \\
(440 / 568)\end{array}$ & $9.3 \pm 30.1$ \\
\hline Paracentral $\left(0^{\circ}\right)$ & $\begin{array}{l}497.5 \pm 32.3 \\
(436 / 548)\end{array}$ & $\begin{array}{l}\mathbf{5 2 1 . 3} \pm \mathbf{3 6 . 9} \\
(456 / 592)\end{array}$ & $23.8 \pm 16.5$ & $\begin{array}{l}503.3 \pm 38.7 \\
(440 / 588)\end{array}$ & $5.8 \pm 19.5$ \\
\hline $\begin{array}{l}\text { Total } \\
\text { thickness }\end{array}$ & $\begin{array}{l}\text { Mean } \pm \text { SD } \\
(\text { Range })(\mu \mathrm{m})\end{array}$ & $\begin{array}{l}\text { Mean } \pm \text { SD } \\
(\text { Range })(\mu \mathrm{m})\end{array}$ & $\begin{array}{l}\text { Change from } \\
\text { Baseline }(\mu \mathrm{m})\end{array}$ & $\begin{array}{l}\text { Mean } \pm \text { SD } \\
(\text { Range })(\mu \mathrm{m})\end{array}$ & $\begin{array}{l}\text { Change from } \\
\text { Baseline }(\mu \mathrm{m})\end{array}$ \\
\hline Central & $\begin{array}{l}543.4 \pm 35.4 \\
(476 / 600)\end{array}$ & $\begin{array}{l}\mathbf{5 7 3 . 0} \pm 39.2 \\
(496 / 644)\end{array}$ & $29.6 \pm 17.1$ & $\begin{array}{l}545.8 \pm 38.9 \\
(476 / 636)\end{array}$ & $2.4 \pm 14.2$ \\
\hline $\begin{array}{l}\text { Paracentral } \\
\left(180^{\circ}\right)\end{array}$ & $\begin{array}{l}556.2 \pm 35.5 \\
(476 / 604)\end{array}$ & $\begin{array}{l}\mathbf{5 9 0 . 8} \pm \mathbf{4 1 . 9} \\
(520 / 664)\end{array}$ & $34.6 \pm 26.2$ & $\begin{array}{l}560.6 \pm 37.7 \\
(492 / 624)\end{array}$ & $4.4 \pm 31.5$ \\
\hline
\end{tabular}





\section{Eye \& Contact Lens \\ Consistency of Corneal Sublayer Thickness Measurements Using Fourier-Domain Optical Coherence Tomography after Phacoemulsification \\ --Manuscript Draft--}

\begin{tabular}{|c|c|}
\hline \multicolumn{2}{|l|}{ Manuscript Number: } \\
\hline Full Title: & $\begin{array}{l}\text { Consistency of Corneal Sublayer Thickness Measurements Using Fourier-Domain } \\
\text { Optical Coherence Tomography after Phacoemulsification }\end{array}$ \\
\hline Article Type: & Original Study \\
\hline Keywords: & Corneal epithelial thickness, phacoemulsification, repeatability, reproducibility \\
\hline Corresponding Author: & $\begin{array}{l}\text { M. Maldonado } \\
\text { Universidad de Valladolid } \\
\text { Valladolid, SPAIN }\end{array}$ \\
\hline \multicolumn{2}{|l|}{$\begin{array}{l}\text { Corresponding Author Secondary } \\
\text { Information: }\end{array}$} \\
\hline Corresponding Author's Institution: & Universidad de Valladolid \\
\hline \multicolumn{2}{|l|}{$\begin{array}{l}\text { Corresponding Author's Secondary } \\
\text { Institution: }\end{array}$} \\
\hline First Author: & Alberto López-Miguel \\
\hline \multicolumn{2}{|l|}{ First Author Secondary Information: } \\
\hline \multirow[t]{6}{*}{ Order of Authors: } & Alberto López-Miguel \\
\hline & María Calabuig-Goena \\
\hline & Victoria Marqués-Fernández \\
\hline & Itziar Fernández \\
\hline & Jorge L Alió \\
\hline & M. Maldonado \\
\hline \multicolumn{2}{|c|}{ Order of Authors Secondary Information: } \\
\hline Abstract: & $\begin{array}{l}\text { Objectives: To assess the reliability of the corneal epithelial thickness (CET), non- } \\
\text { epithelial central corneal thickness (CCT), and CCT measurements using Cirrus high- } \\
\text { definition optical coherence tomography (HD-OCT) in patients who did and did not } \\
\text { undergo cataract surgery. } \\
\text { Methods: Forty patients who underwent uneventful phacoemulsification and } 40 \text { normal } \\
\text { subjects were recruited to evaluate the intraobserver repeatability and interobserver } \\
\text { reproducibility of CET, non-epithelial CCT, and CCT measurements using Cirrus HD- } \\
\text { OCT. To analyze repeatability, one examiner obtained five consecutive scans in each } \\
\text { participant; for interobserver reproducibility, another examiner randomly obtained } \\
\text { another scan. The within-subject (Sw) standard deviation, coefficient of variation (CV), } \\
\text { limits of agreement, and intraclass correlation coefficient (ICC) data were obtained. } \\
\text { Results: For intraobserver repeatability, the intrasession coefficient of variation (CVw) } \\
\text { and ICC values of the CET in the operated and non-operated groups were } 3.7 \% \text { and } \\
0.80 \text { and } 3.8 \% \text { and } 0.73 \text {, respectively; for non-epithelial CCT, } 0.7 \% \text { and } 0.98 \text { and } 0.8 \% \\
\text { and } 0.97 \text {; and for CCT } 0.6 \% \text { and } 0.99 \text { and } 0.7 \% \text { and } 0.98 \text {. For interobserver } \\
\text { reproducibility, the CVw and ICC values for the CET in the operated and non-operated } \\
\text { groups were } 2.6 \% \text { and } 0.82 \text { and } 2.3 \% \text { and } 0.62 \text {, respectively; for non-epithelial CCT, } \\
0.7 \% \text { and } 0.98 \text { and } 0.5 \% \text { and } 0.98 \text {; and for CCT, } 0.5 \% \text { and } 0.99 \text { and } 0.4 \% \text { and } 0.99 \text {. } \\
\text { Conclusions: The corneal sublayer thickness can be measured reliably using Cirrus } \\
\text { HD-OCT in patients who underwent cataract surgery and elderly subjects; however, } \\
\text { the CET consistency is poorer than the non-epithelial CCT. CET modifications } \\
\text { exceeding } 4 \% \text { reflect true thickness changes instead of random-error variations using } \\
\text { HD-OCT. }\end{array}$ \\
\hline Suggested Reviewers: & José M González-Méijome, PhD \\
\hline
\end{tabular}


Professor, Universidade do Minho

jgmeijome@fisica.uminho.pt

Researcher who is expert in anterior segment imaging and has published numerous reports in Eye \& Contact Lens journal.

Michael J Doughty, PhD

Professor, Glasgow Caledonian University

m.doughty@gcal.ac.uk

World leading expert in anterior segment imaging who has published numerous papers

in Eye \& Contact Lens journal.

Colm McAlinden , PhD

Researcher, Flinders Medical Centre and Flinders University

colm.mcalinden@gmail.com

Researcher specialized in the evaluation of diagnostic technology applied to anterior segment devices.

David P Piñero, PhD

Assistant Professor, Universitat dl'Alacant

dpinero@oftalmar.es

Worldwide expert in anterior segment imaging devices who has published above 100 papers in the field.

Eric Papas, PhD

Researcher, Brien Holden Vision Institute, Sydney, New South Wales, Australia e.papas@brienholdenvision.org

Worldwide expert in ocular surface and cornea imaging. 
Universidad deValladolid

June $15^{\text {th }}, 2015$

Penny Asbell, MD, FACS, MBA

Editors-in-Chief

Eye \& Contact Lens

Dear Dr. Asbell:

I am submitting a manuscript entitled "Consistency of Corneal Sublayer Thickness Measurements using Fourier-domain Optical Coherence Tomography after Phacoemulsification." for consideration for publication as an original manuscript in the Eye $\&$ Contact Lens journal. This manuscript has been written according to the authors guidelines.

Each author has reviewed and agrees with the final version of the manuscript, and none of the authors has a financial, commercial, or proprietary interest in any device mentioned. The manuscript has not been published or submitted for publication elsewhere.

We hope the revised manuscript is suitable for publication in the Eye \& Contact Lens Journal.

Thank you for your consideration.

Sincerely,

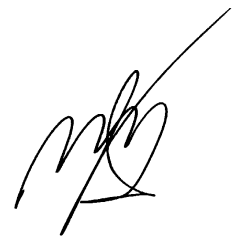

Corresponding Author:

Miguel J. Maldonado, MD, PhD

IOBA, University of Valladolid

Paseo de Belén, 17, 47011, Valladolid, Spain

Tel. +34-938183534. Fax: +34 983184762. E-mail: maldonado@ioba.med.uva.es 


\section{Original Article - Clinical Science}

\section{Consistency of Corneal Sublayer Thickness Measurements Using Fourier-Domain Optical Coherence Tomography after Phacoemulsification} Alberto López-Miguel, PhD, ${ }^{*}$ María Calabuig-Goena, MD,${ }^{* \dagger}$ Victoria MarquésFernández, MD,$^{\dagger}$ Itziar Fernández, PhD,$^{\dagger}+$ Jorge L Alió, MD, PhD, $\S$ Miguel J. Maldonado, MD, $P h D^{*}$

*IOBA, Universidad de Valladolid, Valladolid, Spain.

${ }^{\dagger}$ Hospital Universitario Rio Hortega, Valladolid, Spain.

†Centro de Investigación Biomédica en Red en Bioingeniería, Biomateriales y Nanomedicina (CIBER-BBN), Valladolid, Spain.

${ }^{\S}$ Vissum Instituto Oftalmologico de Alicante, Alicante, Spain.

The authors have no financial interest in any product, method, or material named or used throughout the whole manuscript.

Tables: 3. Figures: 0

Date the paper was submitted: June $16^{\text {th }}, 2015$.

Supported in part by the Spanish Ministerio de Economía y Competitividad through Research Projects RETICS RD12/0034/0001 (Oftalmología) and SAF2012-40227C02-01. No funding organizations had a role in the design or conduct of this research.

Corresponding author: Miguel J. Maldonado, MD, PhD, IOBA, Paseo Belén, 17, 47011 Valladolid, Spain. Phone: 983184750; E-mail: maldonado@ioba.med.uva.es. 


\begin{abstract}
Objectives: To assess the reliability of the corneal epithelial thickness (CET), nonepithelial central corneal thickness (CCT), and CCT measurements using Cirrus highdefinition optical coherence tomography (HD-OCT) in patients who did and did not undergo cataract surgery.
\end{abstract}

Methods: Forty patients who underwent uneventful phacoemulsification and 40 normal subjects were recruited to evaluate the intraobserver repeatability and interobserver reproducibility of CET, non-epithelial CCT, and CCT measurements using Cirrus HDOCT. To analyze repeatability, one examiner obtained five consecutive scans in each participant; for interobserver reproducibility, another examiner randomly obtained another scan. The within-subject (Sw) standard deviation, coefficient of variation (CV), limits of agreement, and intraclass correlation coefficient (ICC) data were obtained.

Results: For intraobserver repeatability, the intrasession coefficient of variation $(\mathrm{CVw})$ and ICC values of the CET in the operated and non-operated groups were $3.7 \%$ and 0.80 and $3.8 \%$ and 0.73 , respectively; for non-epithelial CCT, $0.7 \%$ and 0.98 and $0.8 \%$ and 0.97; and for CCT $0.6 \%$ and 0.99 and $0.7 \%$ and 0.98 . For interobserver reproducibility, the $\mathrm{CVw}$ and ICC values for the CET in the operated and non-operated groups were $2.6 \%$ and 0.82 and $2.3 \%$ and 0.62 , respectively; for non-epithelial CCT, $0.7 \%$ and 0.98 and $0.5 \%$ and 0.98; and for CCT, $0.5 \%$ and 0.99 and $0.4 \%$ and 0.99 .

Conclusions: The corneal sublayer thickness can be measured reliably using Cirrus HDOCT in patients who underwent cataract surgery and elderly subjects; however, the CET consistency is poorer than the non-epithelial CCT. CET modifications exceeding 4\% reflect true thickness changes instead of random-error variations using HD-OCT. 
López Miguel et al. -3

Key Words: Corneal epithelial thickness, phacoemulsification, repeatability, reproducibility 
The epithelium is a stratified non-keratinizing squamous layer that plays a major role in the eye as the first tissue barrier against environmental hazards and a critical interface between the tear film and cornea for refractive power purposes. ${ }^{1}$ Variations in the corneal epithelium have been reported previously in primary and secondary ectatic disorders because the apical thickness tends to be thinner, ${ }^{2}$ in corneas that underwent myopic refractive surgery because central epithelium thickening occurs, ${ }^{3}$ in long-term soft contact lens wearers in whom central and paracentral epithelial thinning can develop, ${ }^{4}$ and in myopic orthokeratology contact lens wearers. ${ }^{5}$ These changes in the corneal morphology may be important to understand patient symptoms and clinical test findings, and currently, new commercial diagnostic ophthalmic technology can provide clinicians with highresolution imaging of the individual corneal layers. ${ }^{6}$ Thus, it is worthwhile to assess the clinical usefulness of this technology in routine patients in a conventional outpatient clinic.

The use of Fourier-domain optical coherence tomography (FD-OCT) for assessing the ocular anterior segment in daily clinic has increased recently because it is a rapidly performed non-contact method with high axial resolution. ${ }^{6}$ In addition, the measurement reliability of any commercially available diagnostic ophthalmic instrument should be determined clinically to avoid misdiagnosis or erroneous treatment based on the readings provided. Consequently, our research group reported previously that FD-OCT is a reliable technique for measuring the central corneal thickness (CCT) regardless of the commercial instrument used. ${ }^{7,8}$ Prakash et al. ${ }^{9}$ also reported that this technology provides reliable corneal epithelial thickness (CET) measurements at the vertex. Ma et al. ${ }^{10}$ and Li et al. ${ }^{11}$ also have reported that FD-OCT instruments provide repeatable automatic CET readings; however, those authors also have found that CET readings are slightly less repeatable in 
eyes that underwent myopic LASIK and those with keratoconus, respectively. The repeatability of the CET measurements may be worse in cases in which the CET can increase as after myopic LASIK or decrease as in keratoconus. Recent studies have reported transient corneal epithelium remodeling after phacoemulsification. ${ }^{12,13}$ Therefore, it is worthwhile to assess if the repeatability of CET measurements also decreases in cases in which there has been a transient morphology variation as in patients undergoing senile cataract surgery. ${ }^{12,13}$ In the current study, we also evaluated for the first time the interobserver reproducibility of the FD-OCT CET measures because in everyday practice several clinicians often perform the same clinical diagnostic tests. Thus, the random errors associated with interobserver FD-OCT use also should be estimated for CET measurements.

\section{METHODS}

\section{Materials and Methods}

All procedures were performed in accordance with the Declaration of Helsinki. All participants received detailed information about the nature of the investigation and provided written informed consent. The institutional ethics committee prospectively approved this study.

The study had two groups: 40 patients who underwent uncomplicated standard coaxial phacoemulsification to treat senile cataracts, understood the nature of the study, and provided informed consent and 40 normal subjects. Patients were eligible for surgery if they had a grade 2 or worse cataract using the Lens Opacities Classification System III. ${ }^{14}$ Patients were excluded who had a history of contact lens wear, corneal diseases, ocular surgery, an active anterior and/or posterior segment anomaly other than cataract, an endothelial cellular count below 2,000 cells $/ \mathrm{mm}^{2}$ suturing of the main incision, intraocular 
lens sulcus implantation, intraoperative complications, and postoperative treatment with hypotensive or anti-edema drugs. For the non-operated group, similarly aged volunteers who understood the nature of the study and provided informed consent were included. Subjects were excluded if they had history of contact lens wear, ocular surgery, corneal anomalies, or an active anterior and/or posterior segment anomaly. Subjects with a mild senile cataract were included. Subjects in the non-operated group were recruited from the outpatient clinic and the eye for inclusion was selected following a computer-generated random table.

\section{Patient Examination}

All participants underwent a complete preoperative ophthalmic examination that included measurement of the manifest refraction, slit-lamp biomicroscopy, applanation tonometry, and indirect ophthalmoscopy. The Cirrus HD-OCT (Carl Zeiss Meditec, Inc., Dublin, CA) using the five-line raster scan protocol that produces five high-resolution (4,096 A-scans) horizontal scan lines $3 \mathrm{~mm}$ long was used for the examinations. ${ }^{7}$ The image capture was always centered on the corneal vertex. A second acquisition was performed if the scan was tilted or decentered and/or the image quality was poor (signal strength $<7) .{ }^{7}$ The corneal sublayer thickness measurements were obtained manually after acquisition using a caliper included in the software. ${ }^{9}$ For each corneal scan image validated, we measured the CET and the non-epithelial CCT as Prakash et al. ${ }^{9}$ previously described. The non-epithelial CCT was defined as the distance between the epitheliumBowman's and endothelium-aqueous humor interfaces and included Bowman's membrane, stroma, Descemet's membrane, and endothelium. The total CCT also was calculated after adding the CET and non-epithelial CCT values. The corneal sublayer 
thickness measurements were obtained between 11:00 and 13:00 hours to avoid diurnal variations. ${ }^{15}$ Patients underwent FD-OCT analysis 1 month after phacoemulsification.

To avoid subjective bias when measuring the corneal sublayer thicknesses, the FDOCT images were not evaluated until all participants were included in the study. For the intraobserver repeatability analysis, the examiner (MC-G) measured all first FD-OCT images of each patient and then all second FD-OCT images, so that the examiner could not memorize the sublayer thickness values obtained from the previous corneal FD-OCT image for each patient, as we described previously. ${ }^{7}$ For the interobserver reproducibility analysis, both examiners (MC-G, VM-F) were masked to the sublayer thickness values obtained by each other.

\section{Statistical Analyses}

To investigate the intraobserver repeatability, the first examiner obtained independent test results using the same method on the same patient with the shortest time possible between successive sets of readings. The first examiner performed five consecutive examinations. To calculate the intraobserver repeatability, the within-subject $(\mathrm{Sw})^{16}$ standard deviation (SD) of five consecutive measurements was calculated by obtaining the square root of the value, referred to as the residual mean square, using oneway analysis of variance. ${ }^{16}$ The repeatability, or the value below which the difference between two measurements will lie with a probability of 0.95 , also was analyzed and defined as $2.77 \mathrm{x} \mathrm{Sw} .{ }^{16} \mathrm{We}$ also calculated the intrasession coefficient of variation $(\mathrm{CVw})$, which is defined as the ratio of the Sw over the mean. ${ }^{16}$ The intrasession reliability of the measurement method also was calculated with the intraclass correlation coefficient (ICC). ${ }^{17}$ 
To estimate the interobserver reproducibility, a second examiner obtained only one FD-OCT image. The first of the five CET and non-epithelial CCT and CCT measurements performed by the first examiner was computed to establish agreement between observers for each variable. The order of the measurements performed by each examiner was random and within the shortest time to prevent fatigue bias. The agreement between the two observers was analyzed by calculating the interobserver Sw. ${ }^{16}$ The reproducibility of the measurements $(2.77 \mathrm{x}$ interobserver $\mathrm{Sw})$, and the interobserver $\mathrm{CVw}$ (expressed as a percentage) also was calculated. ${ }^{16}$ Graphs of the differences from the means also were plotted to ascertain that there was no relation between the differences and the range of measurement and that the differences between measurements were approximately normally distributed. ${ }^{16,18}$ The $95 \%$ limits of agreement (LoA) were defined as the mean difference in measurements performed by two different examiners $\pm 1.96 \mathrm{SD}$, with lower values indicating higher interobserver reproducibility. ${ }^{16}$ The paired t-test was used to establish whether there was a significant systematic bias between examiners.

Data from the prospectively completed forms were entered into a database, and statistical calculations were performed using SPSS version 19.0 for Windows (SPSS, Cary, NC). Data distribution was evaluated using the Shapiro-Wilk test. The mean and the SD were calculated for normally distributed data. Spearman's rank correlation coefficient was used to measure the association between the mean corneal thickness readings and the SD of the five readings (repeatability) or two readings (interobserver reproducibility) to confirm the assumption that the amplitude of variation was unrelated to the magnitude before proceeding with reliability analyses. A two-tailed $P \leq 0.05$ was considered significant for all statistical tests.

\section{RESULTS}


Forty eyes (20 right, 20 left) of 40 patients who had undergone cataract surgery (19 women, 21 men), and 40 eyes (23 right, 17 left) of 40 non-operated volunteers (23 women, 17 men) were studied. The mean age of the operated and non-operated groups was $72.8 \pm 8.9$ years (range, $48-87$ ) and $67.3 \pm 11.8$ years (range, 42-76), respectively.

Table 1 shows the global mean, Sw, intraobserver repeatability, CVw, and ICC for the CET, non-epithelial CCT, and CCT in the operated and non-operated groups. The intraobserver $\mathrm{CVw}(\leq 0.8 \%)$ and ICC $(\geq 0.97)$ for the non-epithelial CCT and CCT were excellent; the values for the CET were acceptable ( $\leq 3.8 \%$ and $\geq 0.73$, respectively). There were no statistical differences $(P>0.05)$ in repeatability values between the operated and non-operated groups.

Table 2 shows the global mean, $\mathrm{Sw}$, interobserver reproducibility, CVw, and ICC for the CET, non-epithelial CCT, and CCT in the operated and non-operated groups. The mean differences between observers for the CET in the non-operated and operated groups were 0.08 micron $(95 \%$ confidence interval $[\mathrm{CI}],-0.59-0.75)$ and 0.45 micron $(\mathrm{CI},-0.28-$ 1.18); for the non-epithelial CCT 1.81 microns (CI, 0.17-3.44) and -0.9 micron (95\% CI, 2.69-0.89); and for the CCT 1.7 microns (CI, 0.43-2.97) and -0.56 microns (CI, -2.131.01), respectively. No significant $(P>0.05)$ differences were observed between the operated and non-operated groups for the interobserver analysis when all thickness measurements were compared.

Bland-Altman plots were created to assess the differences in individual measurements as a function of the mean of two measurements. The widths of the $95 \%$ LoA for the CET, non-epithelial CCT, and CCT in the non-operated and operated groups were 10.4 and 10.9 microns; 24.6 and 24.2 microns; and 19.2 and 21.9 microns, 
respectively. Table 3 shows the upper and lower limits of the LoA for the CET, nonepithelial CCT, and CCT in the non-operated and operated group.

\section{DISCUSSION}

New developments in ophthalmic diagnostic technology allow clinicians to obtain higher quality ocular imaging. These instruments provide more information to better characterize ocular structures for screening, diagnosing, providing preoperative counseling, and evaluating patients during follow-up. Incorporation of OCT technology, specifically FD-OCT, into daily practice has provided numerous advantages for both posterior segment ${ }^{19}$ and anterior segment specialists. ${ }^{7}$ The increased axial resolution of the FD-OCT devices provides better differentiation of the corneal layers; ${ }^{20}$ consequently, the current study aimed to determine the reliability of a commercial FD-OCT device primarily designed for posterior-segment purposes when measuring the corneal sublayer thickness in patients undergoing uneventful senile cataract surgery. Thus, considering the current outcomes, true changes can be differentiated from random errors when evaluating CET and non-epithelial CCT changes after uneventful phacoemulsification using Cirrus HDOCT. ${ }^{12,13}$

The global mean thicknesses obtained in the operated and non-operated groups for total pachymetry $(536$ and $547 \mu \mathrm{m})$ and epithelium $(53$ and $51 \mu \mathrm{m})$ indicated that the current participants represent the normal population attending any ophthalmology outpatient clinic (Table 1). The intraobserver repeatability when using Cirrus HD-OCT was sufficient. The current study showed that the expected variation $(\mathrm{CVw})$ when assessing the CET using the manual caliper should be about $3.8 \%$ of the total CET, regardless of whether the patient underwent or did not undergo cataract surgery (Table 1). For the non-epithelial CCT and CCT measurements, the repeatability results were 
excellent, with $\mathrm{CVw}$ values of $0.8 \%$ and lower and ICC values of 0.97 and higher for all cases; the differences between the operated and normal patients were not clinically

relevant. We obtained even better repeatability outcomes that those of Prakash et al., ${ }^{9}$ who reported a $\mathrm{CVw}$ for CET of $7.7 \%$ in a healthy population using the same FD-OCT device. In the current study, the examiner (MC-G) who performed the CET measurement for the repeatability analysis was experienced with use of the caliper in the Cirrus HD-OCT software for both anterior and posterior segment purposes. Thus, the skills of the examiner may have played an important role in obtaining better results. Additionally, to avoid subjective bias when obtaining thickness measurements from the scan image, no measurement was obtained until all participants were included in the study. Moreover, the five scan images corresponding to each participant were not analyzed consecutively.

Ma et al. ${ }^{10}$ also studied the reliability of the CET measurements in healthy volunteers using another commercial FD-OCT instrument (RTVue OCT, Optovue, Inc., Fremont, CA) and reported a clinically excellent $\mathrm{CVw}$ value $(0.89 \%)$. It is likely that they obtained better repeatability outcomes because of the methodology they followed to measure the CET. First, the RTVue OCT has automatic segmentation software that also can be used to measure the corneal sublayer thickness in contrast to the FD-OCT device used in the current study. Consequently, despite the fact that our examiner was skilled in performing thickness measurements using the caliper (manual task), automatic measurements should provide more consistent results if the segmentation software clearly differentiates the corneal layers. Second, the RTVue provides the average CET in the central zone (2-mm diameter) instead of a single-point thickness; thus, the RTVue OCT variability should be lower than when measuring only one point (corneal apex) as in the current study. Ge et al. ${ }^{20}$ also studied the reliability of the CET measurements in healthy 
volunteers using different OCT devices and obtained a better ICC value (0.89) than ours for CET when using the RTVue OCT, which agrees with the results of Ma et al. ${ }^{10}$ Reinstein et al. ${ }^{21}$ also estimated the repeatability of a very-high-frequency digital ultrasound technique for measuring CET in patients who underwent LASIK. The investigators reported excellent $\mathrm{CVw}(1.0 \%)$ and ICC (0.97) values using this technique because the instrument also provided automatic measurements. However, this technique has several shortcomings compared to FD-OCT technology, the most important being that it is a contact method requiring topical anesthesia. As a result, most subsequent ocular examinations usually performed during a conventional ophthalmology visit are altered unavoidably, and the technique is not as comfortable for patients as the non-contact FDOCT is. In addition, the acquisition time is longer than that of FD-OCT devices (only seconds). ${ }^{21}$

Regarding non-epithelial CCT and CCT outcomes, Prakash et al. ${ }^{9}$ reported poorer CVw results $(2.3 \%$ and $2.15 \%$, respectively) than the current results (Table 1$)$. The variations in the outcomes between the studies, despite using the same FD-OCT device, may result from differences in the skill level of each examiner in obtaining manual measurements. Moreover, our repeatability outcome for CCT measurements in participants $(0.7 \%)$ who did not undergo surgery was similar to that reported $(0.9 \%)$ previously when we evaluated volunteers without corneal diseases using the same FDOCT device. ${ }^{7}$ Besides, Ma et al. ${ }^{10}$ reported an excellent $\mathrm{CVw}$ value $(0.16 \%)$ for the CCT in healthy subjects; nonetheless, this value was obtained automatically in the central 2-mm diameter zone, instead of a single-point as in the current study.

In the current study, we also estimated the interobserver reproducibility of the CET, non-epithelial CCT, and CCT because at any given ophthalmic clinic the same examiner 
usually does not always perform the same ophthalmic tests in the same patient. The interobserver reproducibility $\mathrm{CVw}$ values for $\mathrm{CET}$ were slightly better than the intraobserver repeatability values (Tables 1,2 ); however, a $1 \%$ difference should not be clinically meaningful. Likewise, regarding the non-epithelial CCT and CCT measurements, the differences between intraobserver and interobserver values were even lower (around $0.2 \%$ ). The width of the LoAs for each corneal sublayer thickness measured was clinically good, and we assume that skilled examiners can interchangeably obtain FDOCT measures using the caliper in the Cirrus HD-OCT instrument. As with repeatability outcomes, Prakash et al. ${ }^{9}$ reported a poorer $\mathrm{CVw}$ value for the CET (11.1\%), nonepithelial CCT (3.5\%), and CCT (2.7\%). We might have obtained better outcomes because similar to our first examiner, the second examiner (VM-F) was experienced with the caliper in the Cirrus HD-OCT device.

A limitation of the current study was that we did not assess the accuracy of the Cirrus HD-OCT for the CET measurements. Nonetheless, our aim was to determine the random error of this FD-OCT instrument when measuring the corneal sublayer thickness after phacoemulsification instead of performing an agreement analysis with ultrasonography, which still can be considered the reference method. Moreover, previous authors $^{22}$ addressed the tendency of FD-OCT to slightly underestimate the CCT compared with ultrasonography. A second limitation was that we included only patients who underwent an uneventful cataract surgery with transient changes in the corneal sublayer thickness, ${ }^{12,13}$ and we did not include patients who underwent a cataract surgery and had persistent pachymetry thickening, or other conditions associated with corneal epithelial oedema. ${ }^{23}$ In these cases, the reliability of the FD-OCT sublayer thickness may have been slightly worse as in other conditions such as after myopic $\operatorname{LASIK}^{10}$ and in ectasias ${ }^{11}$ in 
which the CET differs from that in normal subjects. Finally, we used a FD-OCT device that requires manual measurement of corneal thickness in contrast to other FD-OCT devices that provides automated segmentation analysis ${ }^{24}$ nonetheless the measuring procedure is quite rapid and accurate.

In conclusion, the current study showed for the first time that FD-OCT technology provides reliable intraobserver and interobserver CET, non-epithelial CCT, and CCT measurements in patients with underwent uneventful cataract surgery and untreated elderly subjects. Additionally, determining the intraobserver and interobserver reproducibility of the Cirrus HD-OCT system should be useful clinically not only to discern true changes from random errors but also to provide clinicians with scientific evidence of its appropriateness for corneal purposes. Based on the current findings, the criteria for a significant change indicated that variations in the CET of $4 \%$ and $1 \%$ for non-epithelial CCT and CCT may reflect true thickness variations when skilled observers use the caliper in the Cirrus HD-OCT. 


\section{REFERENCES}

1. Del Monte DW, Kim T. Anatomy and physiology of the cornea. J Cataract Refract Surg. 2011;37:588-598.

2. Rocha KM, Perez-Straziota CE, Stulting RD, et al. SD-OCT analysis of regional epithelial thickness profiles in keratoconus, postoperative corneal ectasia, and normal eyes. J Refract Surg. 2013;29:173-179.

3. Reinstein DZ, Srivannaboon S, Gobbe M, et al. Epithelial thickness profile changes induced by myopic LASIK as measured by Artemis very high-frequency digital ultrasound. J Refract Sur.g 2009;25:444-450.

4. Hong J, Qian T, Yang Y, et al. Corneal Epithelial Thickness Map in Long-Term Soft Contact Lenses Wearers. Optom Vis Sci. 2014;91:1455-1461.

5. Nieto-Bona A, González-Mesa A, Nieto-Bona MP, et al. Long-term changes in corneal morphology induced by overnight orthokeratology. Curr Eye Res. 2011;36:895-904.

6. Reinstein DZ, Gobbe M, Archer TJ. Anterior segment biometry: a study and review of resolution and repeatability data. J Refract Surg. 2012;28:509-520.

7. Correa-Pérez ME, López-Miguel A, Miranda-Anta S, et al. Precision of high definition spectral-domain optical coherence tomography for measuring central corneal thickness. Invest Ophthalmol Vis Sci. 2012;53:1752-1757.

8. Correa-Pérez ME, Olmo N, López-Miguel A, et al. Dependability of posteriorsegment spectral domain optical coherence tomography for measuring central corneal thickness. Cornea. 2014;33:1219-24. 
9. Prakash G, Agarwal A, Mazhari AI, et al. Reliability and reproducibility of assessment of corneal epithelial thickness by Fourier domain optical coherence tomography. Invest Ophthalmol Vis Sci. 2012;53:2580-2585.

10. Ma XJ, Wang L, Koch DD. Repeatability of corneal epithelial thickness measurements using Fourier-domain optical coherence tomography in normal and post-LASIK eyes. Cornea. 2013;32:1544-1548.

11. Li Y, Tan O, Brass R, Weiss JL, et al. Corneal epithelial thickness mapping by Fourier-domain optical coherence tomography in normal and keratoconic eyes. Ophthalmology. 2012;119:2425-2433.

12. Kanellopoulos AJ, Asimellis G. Corneal epithelial remodeling following cataract surgery: three-dimensional investigation with anterior-segment optical coherence tomography. J Refract Surg. 2014;30:348-353.

13. Calabuig-Goena M, López-Miguel A, Marqués-Fernández V, et al. Early changes in corneal epithelial thickness after cataract surgery. Pilot study. Curr Eye Res. 2015 (in press).

14. Chylack LT Jr, Wolfe JK, Singer DM, et al. The Lens Opacities Classification System III. The Longitudinal Study of Cataract Study Group. Arch Ophthalmol. $1993 ; 111: 831-836$.

15. Feng Y, Varikooty J, Simpson T. Diurnal variation of corneal and corneal epithelial thickness measured using optical coherence tomography. Cornea. $2001 ; 20: 480-483$.

16. Bland M. Clinical measurement. In: Bland M, ed. An introduction to medical statistics. 3rd ed. Oxford, UK: Oxford University Press, 2000:269-294. 
17. Bland JM, Altman DG. Measurement error and correlation coefficients. BMJ. 1996;313:41-42.

18. Bland JM, Altman DG. Measuring agreement in method comparison studies. Stat Methods Med Res. 1999;8:135-160.

19. de-Lázaro-Yagüe JA, López-Miguel A, Sanabria MR, et al. A new manual retinal thickness measurement protocol to evaluate high myopia patients. Ophthalmologica. 2013;230:121-125.

20. Ge L, Yuan Y, Shen M, et al. The role of axial resolution of optical coherence tomography on the measurement of corneal and epithelial thicknesses. Invest Ophthalmol Vis Sci. 2013;54:746-755.

21. Reinstein DZ, Archer TJ, Gobbe M, et al. Repeatability of layered corneal pachymetry with the Artemis very high-frequency digital ultrasound arc-scanner. $J$ Refract Surg. 2010;26:646-659.

22. Northey LC, Gifford P, Boneham GC. Comparison of Topcon optical coherence tomography and ultrasound pachymetry. Optom Vis Sci. 2012;89:1708-1714.

23. Ghosheh FR, Cremona F, Ayres BD, et al. Indications for penetrating keratoplasty and associated procedures, 2001-2005. Eye Contact Lens. 2008;34:211-214.

24. Shen M, Xu Z, Yang C, et al. Agreement of corneal epithelial profiles produced by automated segmentation of SD-OCT images having different optical resolutions. Eye Contact Lens. 2014;40:99-105. 
TABLE 1. Intraobserver Repeatability of Corneal Sublayer Thickness Measurements

\begin{tabular}{|c|c|c|c|c|c|}
\hline $\begin{array}{l}\text { Central } \\
\text { Thickness }\end{array}$ & $\begin{array}{l}\text { Global Mean } \\
\text { (Range) } \\
(\mu \mathrm{m})\end{array}$ & $\begin{array}{l}\text { Sw }(\mu \mathrm{m}) \\
(95 \% \mathrm{CI})\end{array}$ & $\begin{array}{l}\text { Repeatability } \\
(\mu \mathrm{m}) \\
2.77 \mathrm{Sw} \\
(\mathbf{9 5 \%} \mathrm{CI})\end{array}$ & $\begin{array}{l}\text { CVw (\%) } \\
(95 \% \text { CI) }\end{array}$ & $\begin{array}{l}\text { ICC } \\
(95 \% \mathrm{CI})\end{array}$ \\
\hline \multicolumn{6}{|l|}{ Epithelium } \\
\hline Non-operated & $51.4(45-57)$ & $1.9(1.6-2.3)$ & $5.2(4.4-6.4)$ & $3.8(3.1-4.4)$ & $0.73(0.61-0.80)$ \\
\hline Operated & $53.6(44-64)$ & $2.0(1.6-2.4)$ & $5.5(4.4-7.5)$ & $3.7(2.9-4.4)$ & $0.80(0.71-0.87)$ \\
\hline \multicolumn{6}{|c|}{ Non-epithelial CCT } \\
\hline Non-operated & $496.4(486-506)$ & $4.2(3.4-5.1)$ & $11.6(9.4-14.1)$ & $0.8(0.7-1.0)$ & $0.97(0.96-0.98)$ \\
\hline Operated & $482.5(471-493)$ & $3.6(2.8-4.5)$ & $9.9(7.7-12.4)$ & $0.7(0.6-0.9)$ & $0.98(0.97-0.99)$ \\
\hline \multicolumn{6}{|l|}{$\mathrm{CCT}$} \\
\hline Non-operated & $547.6(478-618)$ & $3.6(2.7-4.5)$ & $9.9(7.5-12.4)$ & $0.7(0.5-0.8)$ & $0.98(0.97-0.98)$ \\
\hline Operated & $536.0(473-611)$ & $3.0(2.1-3.8)$ & $8.3(5.8-10.5)$ & $0.6(0.4-0.7)$ & $0.99(0.98-0.99)$ \\
\hline
\end{tabular}

$\mathrm{Sw}=$ within-subject standard deviation; $\mathrm{CI}=$ confidence interval $; \mathrm{CVW}=$ within-subject coefficient of variation; ICC $=$ intraclass correlation coefficient. 
TABLE 2. Interobserver Reproducibility of Corneal Sublayer Thickness Measurements

\begin{tabular}{|c|c|c|c|c|c|}
\hline $\begin{array}{l}\text { Central } \\
\text { Thickness }\end{array}$ & $\begin{array}{l}\text { Global mean } \\
(\text { Range })(\mu \mathrm{m})\end{array}$ & $\begin{array}{l}\text { Sw }(\mu \mathrm{m}) \\
(95 \% \mathrm{CI})\end{array}$ & $\begin{array}{l}\text { Reproducibility } \\
(\mu \mathrm{m}) \\
2.77 \mathrm{Sw} \\
(95 \% \mathrm{CI})\end{array}$ & $\begin{array}{l}\text { CVw (\%) } \\
(95 \% \mathrm{CI})\end{array}$ & $\begin{array}{l}\text { ICC } \\
(95 \% \mathrm{CI})\end{array}$ \\
\hline \multicolumn{6}{|l|}{ Epithelium } \\
\hline Non-operated & $51.4(44-58)$ & $1.2(0.9-1.5)$ & $3.3(2.5-4.1)$ & $2.3(1.7-2.8)$ & $0.62(0.54-0.75)$ \\
\hline Operated & $53.4(42-64)$ & $1.3(1.0-1.6)$ & $3.6(2.8-4.4)$ & $2.6(2.0-3.2)$ & $0.82(0.70-0.88)$ \\
\hline \multicolumn{6}{|l|}{ Non-epithelial CCT } \\
\hline Non-operated & $494.6(484-504)$ & $2.7(1.9-3.6)$ & $7.5(5.2-9.9)$ & $0.5(0.4-0.7)$ & $0.98(0.97-0.98)$ \\
\hline Operated & $483.4(473-493)$ & $3.2(2.4-3.9)$ & $8.8(7.5-10.8)$ & $0.7(0.5-0.8)$ & $0.98(0.97-0.99)$ \\
\hline \multicolumn{6}{|l|}{$\mathrm{CCT}$} \\
\hline Non-operated & $546.7(476-624)$ & $2.2(1.5-2.8)$ & $6.1(4.1-7.7)$ & $0.4(0.3-0.5)$ & $0.99(0.98-0.99)$ \\
\hline Operated & $536.2(473-612)$ & $2.6(1.8-3.3)$ & $7.2(4.9-9.1)$ & $0.5(0.3-0.6)$ & $0.99(0.98-0.99)$ \\
\hline
\end{tabular}

$\mathrm{Sw}=$ within-subject standard deviation; $\mathrm{CI}=$ confidence interval $; \mathrm{CVw}=$ within-subject coefficient of variation; $\mathrm{ICC}=$ intraclass correlation coefficient. 
TABLE 3. Interobserver Upper and Lower Limits of Agreement for Epithelial, NonEpithelial, and Corneal Thickness Measurements

\begin{tabular}{|c|c|c|c|c|c|c|}
\hline & \multicolumn{2}{|c|}{$\begin{array}{l}\text { Corneal Epithelial } \\
\text { Thickness }(95 \% \text { CI })(\mu \mathrm{m})\end{array}$} & \multicolumn{2}{|c|}{$\begin{array}{l}\text { Non-epithelial CCT }(95 \% \mathrm{CI} \\
(\mu \mathrm{m})\end{array}$} & \multicolumn{2}{|c|}{ CCT $(95 \%$ CI $)(\mu \mathrm{m})$} \\
\hline Group & Upper Limit & Lower Limit & Upper Limit & Lower Limit & Upper Limit & Lower Limit \\
\hline Non-operated & $\begin{array}{l}5.3 \\
(4.1 / 6.5)\end{array}$ & $\begin{array}{l}-5.1 \\
(-6.3 /-3.9)\end{array}$ & $\begin{array}{l}14.1 \\
(11.2 / 16.9)\end{array}$ & $\begin{array}{l}-10.5 \\
(-13.3 /-7.6)\end{array}$ & $\begin{array}{l}11.3 \\
(9.1 / 13.5)\end{array}$ & $\begin{array}{l}-7.9 \\
(-10.1 /-5.7)\end{array}$ \\
\hline Operated & $\begin{array}{l}5.9 \\
(4.6 / 7.2)\end{array}$ & $\begin{array}{l}-5.0 \\
(-6.2 /-3.7)\end{array}$ & $\begin{array}{l}11.7 \\
(8.8 / 14.6)\end{array}$ & $\begin{array}{l}-13.5 \\
(-16.5 /-10.6)\end{array}$ & $\begin{array}{l}10.4 \\
(7.8 / 12.9)\end{array}$ & $\begin{array}{l}-11.5 \\
(-14.0 /-8.9)\end{array}$ \\
\hline
\end{tabular}

$\mathrm{CCT}=$ central corneal thickness $; \mathrm{CI}=$ confidence interval . 